KLEYTON DE CARVALHO MESQUITA

DERMATITE ATÓPICA EM CRIANÇAS E ADOLESCENTES: AVALIAÇÃO DA RELEVÂNCIA DA VITAMINA D, HORMÔNIO PARATIREOIDEO E ÍNDICE ULTRAVIOLETA

BRASÍLIA, 2015 


$$
\begin{gathered}
\text { UNIVERSIDADE DE BRASÍLIA } \\
\text { FACULDADE DE CIÊNCIAS DA SAÚDE } \\
\text { PROGRAMA DE PÓS-GRADUAÇÃO EM CIÊNCIAS DA SAÚDE }
\end{gathered}
$$

KLEYTON DE CARVALHO MESQUITA

\section{DERMATITE ATÓPICA EM CRIANÇAS E ADOLESCENTES: AVALIAÇÃO DA RELEVÂNCIA DA VITAMINA D, HORMÔNIO PARATIREOIDEO E ÍNDICE ULTRAVIOLETA}

Tese apresentada como requisito parcial para obtenção do título de Doutor em Ciências da Saúde pelo Programa de Pós-Graduação em Ciências da Saúde da Universidade de Brasília.

Orientadora:

Prof. Dra. Izelda Maria Carvalho Costa.

BRASÍLIA 


\title{
DERMATITE ATÓPICA EM CRIANÇAS E ADOLESCENTES: AVALIAÇÃO DA RELEVÂNCIA DA VITAMINA D, HORMÔNIO PARATIREOIDEO E ÍNDICE ULTRAVIOLETA
}

\begin{abstract}
Tese apresentada como requisito parcial para obtenção do título de Doutor em Ciências da Saúde pelo Programa de Pós-Graduação em Ciências da Saúde da Universidade de Brasília.
\end{abstract}

Aprovado em 30 de junho de 2015

\section{BANCA EXAMINADORA}

Prof. Dra. Izelda Maria Carvalho Costa - Presidente Universidade de Brasília (UnB)

Prof. Dra. Angélica Amorim Amato - Membro Universidade de Brasília (UnB)

Prof. Dra. Carmen Déa Ribeiro de Paula - Membro Universidade de Brasília (UnB), Centro Universitário de Brasília (UniCEUB)

Prof. Dr. Augusto Cézar Florêncio Costa - Membro Universidade de Brasília (UnB)

Prof. Dra. Simone Karst Passos - Membro Escola Superior de Ciências da Saúde (ESCS)

Prof. Dra. Cristina Medeiros Ribeiro de Magalhães - Suplente Centro Universitário de Brasília (UniCEUB) 


\section{AGRADECIMENTOS}

À Ana Carolina Igreja, companheira inseparável de todas as horas e motivadora maior desse projeto, por me ensinar a olhar além de onde alcançam os limites da visão, por sua imensurável ajuda e por seu estímulo em cada momento dessa pesquisa.

À Profa Dra Izelda, exemplo de dedicação à Universidade de Brasília, à pesquisa científica e à Dermatologia, por seus ensinamentos, por acreditar nesse trabalho, por me guiar e me encorajar nessa trajetória, por suas soluções formidáveis a cada obstáculo do percurso.

À minha família, em especial minha mãe Erenice, pelo apoio incondicional e pela confiança plena em meu potencial.

Aos pacientes e seus responsáveis, por acreditarem na seriedade do trabalho.

Ao Dr Luiz Cláudio Gonçalves de Castro, pelos astuciosos palpites na elaboração do desenho do estudo.

À Edigrês, pela cordialidade e pela ajuda em todos os assuntos na secretaria da pós-graduação.

À Dra Carmen e aos colegas residentes da Dermatologia, em especial Aneline, pelo auxílio no ambulatório de dermatologia pediátrica durante a coleta de dados.

Ao Núcleo de Apoio à Pesquisa do laboratório Sabin pela realização gratuita da dosagem sérica de 25-hidróxi-vitamina $D$ em todos os pacientes.

Ao Prof Dr Eduardo Freitas da Silva, professor do Departamento de Estatística da Universidade de Brasília, pelo auxílio nas análises estatísticas.

A Deus, fonte de força de vontade e determinação, que permitiu que essa trajetória chegasse ao dia de hoje. 
"A dúvida é o princípio da sabedoria"

(Aristóteles) 


\section{RESUMO}

Introdução: O papel desempenhado pela vitamina $D$ na dermatite atópica (DA) é controverso e tem sido o foco de diversos estudos. O hormônio paratireoideo (PTH) e o índice ultravioleta (IUV), embora possivelmente envolvidos nessa associação, não têm sido considerados nessas pesquisas. Objetivos: Avaliar a concentração sérica da 25-hidroxivitamina $D[25(\mathrm{OH}) \mathrm{D}]$ em pacientes com DA e em grupo controle; avaliar a adequabilidade dos valores de referência da 25(OH)D por meio de sua relação com - PTH molécula intacta (PTHi); identificar preditores independentes da gravidade clínica da DA e da concentração sérica de 25(OH)D. Métodos: Em estudo transversal com 106 pacientes de 0 a 18 anos de idade portadores de DA, um grupo controle foi pareado (1:1) com uma subamostra de 54 sujeitos com DA. Foram avaliados dados epidemiológicos, índice SCORing Atopic Dermatitis (SCORAD), testes laboratoriais e IUV. Resultados: O subgrupo DA apresentou maior concentração sérica de $25(\mathrm{OH}) \mathrm{D}$ e maior IUV - em média $3,39 \mathrm{ng} / \mathrm{ml}$ e 2,54 acima, respectivamente - que o grupo controle $(p<0,05)$. Não houve associação significativa entre $25(\mathrm{OH}) \mathrm{D}$ e PTHi. Imunoglobulina E e IUV foram fatores independentes associados ao índice SCORAD. Por sua vez, fototipo, idade e IUV foram fatores independentes associados a 25(OH)D. Conclusões: A diferença da concentração de 25(OH)D entre casos e controles, embora significativa, pode não ter significância clínica e pode estar relacionada ao maior IUV médio encontrado nos casos com DA. A 25(OH)D e o PTHi não influenciaram o índice SCORAD. Estudos prospectivos com múltiplas dosagens de 25(OH)D são necessários para elucidar o papel da vitamina $D$ na prevalência e gravidade da DA. Os pontos de corte adotados para a $25(\mathrm{OH}) \mathrm{D}$ parecem inadequados à amostra testada no tocante à supressão do PTHi. Uma vez que o IUV se mostrou significativamente associado com o SCORAD e com a $25(\mathrm{OH}) \mathrm{D}$, esse índice pode atuar como fator de confusão e deve ser considerado em estudos envolvendo DA e vitamina $\mathrm{D}$.

Palavras-chave: dermatite atópica; vitamina D; hormônio paratireoideo; imunoglobulina E; índice ultravioleta. 


\begin{abstract}
Introduction: The role played by vitamin $D$ in atopic dermatitis (AD) is controversial and has been the focus of many studies. Although possibly involved in this association, parathyroid hormone (PTH) and ultraviolet index (UVI) have not been considered in such research. Objectives: To assess 25-hydroxy vitamin D [25(OH)D] serum levels in $A D$ patients and a control group; to assess the adequacy of the cutoff point used for 25(OH)D investigating its relationship with intact PTH (iPTH); to identify the independent predictors of the AD clinical severity and 25(OH)D serum level. Methods: We conducted a cross-sectional study of 106 AD patients from 0 to 18 years old. A control group was matched (1:1) with a subsample of 54 participants with AD. Epidemiological data, SCORing Atopic Dermatitis (SCORAD) index, laboratory tests and UVI were assessed. Results: The AD subgroup had higher serum 25(OH)D level and higher UVI than control group - difference between the means of $3.39 \mathrm{ng} / \mathrm{ml}$ and 2.54 , respectively $(p<0.05)$. There was no significant correlation of $\mathrm{iPTH}$ with $25(\mathrm{OH}) \mathrm{D}$. Immunoglobulin E and UVI were independent predictors associated with the SCORAD index. Skin type, age and UVI were independent predictors of 25(OH)D. Conclusions: The different levels of 25(OH)D between AD patients and controls may not have clinical consequences and may be related to the higher UVI found in AD subjects. The 25(OH)D and iPTH levels did not have an influence in SCORAD index. Prospective studies with multiple measurements of serum $25(\mathrm{OH}) \mathrm{D}$ levels are necessary to elucidate the role of vitamin $D$ in prevalence and severity of AD. The cutoff point of $25(\mathrm{OH}) \mathrm{D}$ seems to be inappropriate to the sample at least with regard to the suppression of iPTH. Once UVI was significantly associated with SCORAD and with $25(\mathrm{OH}) \mathrm{D}$, this index can work as a confounding factor and should be considered in studies involving $A D$ and vitamin $D$.
\end{abstract}

Keywords: atopic dermatitis; vitamin D; parathyroid hormone; immunoglobulin E; ultraviolet index. 


\section{LISTA DE FIGURAS}

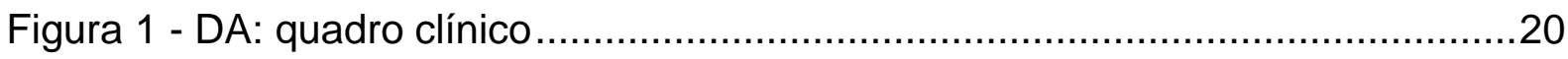

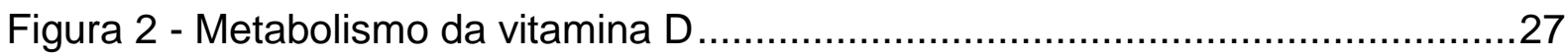

Figura 3 - Exemplo de Certificado de Proficiência emitido pela DEQAS ...................30

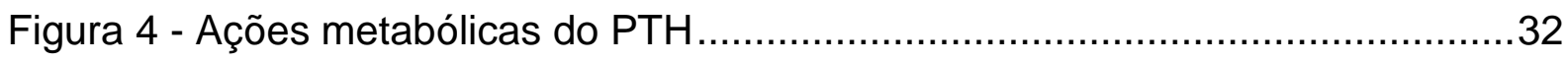

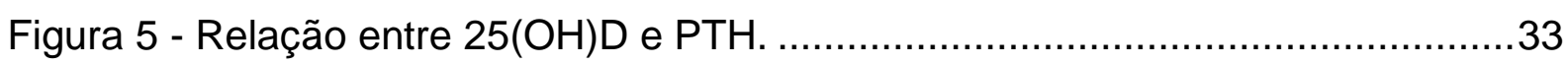

Figura 6 - Ações da vitamina D no sistema imunológico ........................................45

Figura 7 - Exemplo de curva representando os níveis de IUV no decorrer de um dia

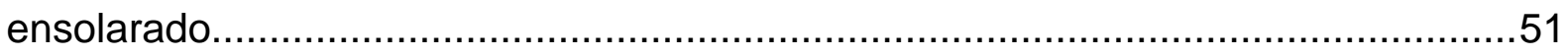

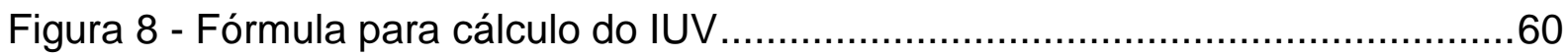

Figura 9 - Categorias de exposição à radiação UV ...................................................61

Figura 10 - Fluxograma de inclusão dos casos e controles ...................................63

Figura 11 - Distribuição das categorias de 25(OH)D no subgrupo DA e no grupo

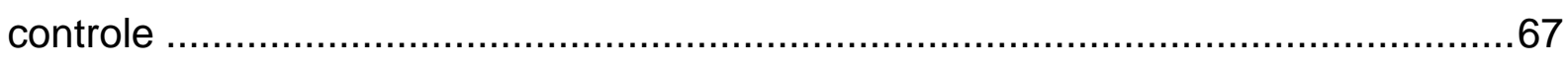

Figura 12 - IUV máximo diário no período do estudo ............................................68

Figura 13 - Comparação entre concentrações séricas de $25(\mathrm{OH}) \mathrm{D}$ em subgrupo DA e

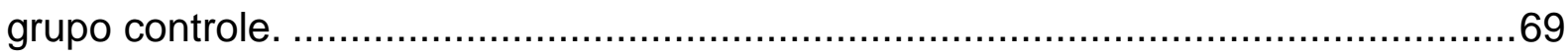

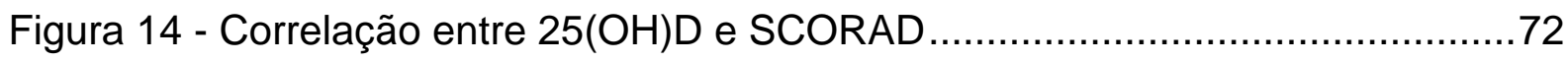

Figura 15 - Correlação entre 25(OH)D e SCORAD objetivo ………......................73

Figura 16 - Correlação entre 25(OH)D e SCORAD em pacientes com IgE elevada.75 Figura 17 - Correlação entre 25(OH)D e SCORAD objetivo em pacientes com IgE

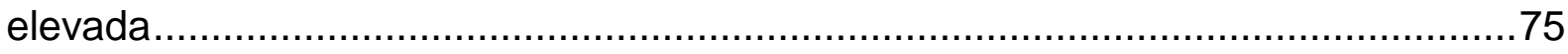

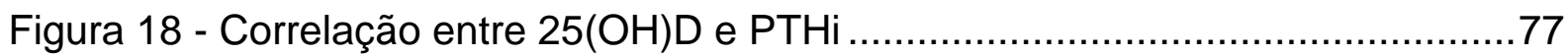

Figura 19 - Concentrações séricas de PTHi encontradas nas diferentes categorias de

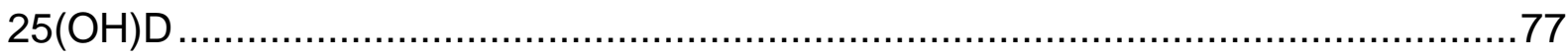

Figura 20 - Correlação entre SCORAD e concentração sérica de PTHi ...................79

Figura 21 - Distribuição das concentrações séricas de PTHi nas categorias SCORAD

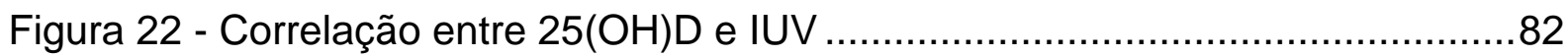

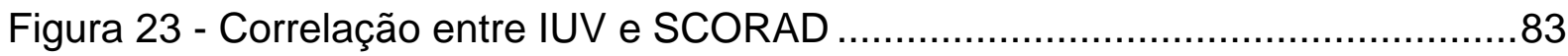

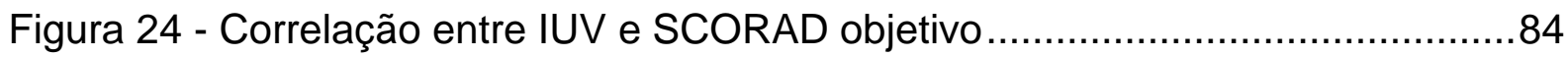

Figura 25 - Distribuição da idade nas diferentes categorias SCORAD .....................86 
Figura 26 - Distribuição da renda nas diferentes categorias SCORAD .87

Figura 27 - Distribuição do IMC nas diferentes categorias SCORAD.......................87

Figura 28 - Distribuição da idade de início dos sintomas nas diferentes categorias

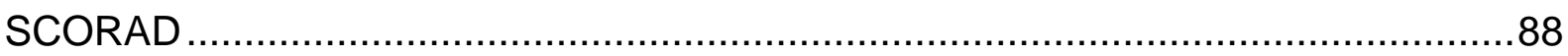

Figura 29 - Distribuição do IUV nas diferentes categorias SCORAD .......................88

Figura 30 - Distribuição de IgE nas diferentes categorias SCORAD ........................89

Figura 31 - Distribuição da eosinofilia relativa nas diferentes categorias SCORAD..89

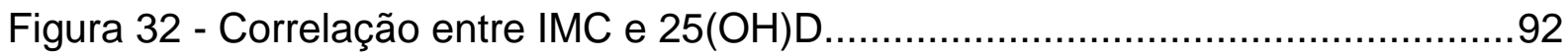

Figura 33 - Correlação entre idade e concentrações séricas de 25(OH)D ................93

Figura 34 - Distribuição das concentrações séricas de 25(OH)D nas diferentes

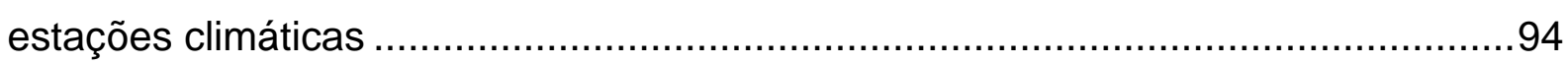

Figura 35 - Distribuição da idade nas diferentes categorias de 25(OH)D ................97

Figura 36 - Distribuição da renda nas diferentes categorias de 25(OH)D .................97

Figura 37 - Distribuição do IMC nas diferentes categorias de 25(OH)D....................98

Figura 38 - Distribuição do SCORAD nas diferentes categorias de 25(OH)D ...........98

Figura 39 - Distribuição do IUV nas diferentes categorias de 25(OH)D ...................99

Figura 40 - Distribuição da IgE total nas diferentes categorias de 25(OH)D .............99

Figura 41 - Distribuição da eosinofilia relativa nas diferentes categorias de 25(OH)D 


\section{LISTA DE QUADROS}

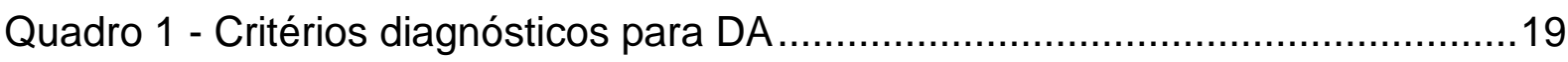

Quadro 2 - Aspectos da DA extrínseca e intrínseca..............................................21

Quadro 3 - Valores de referência para a 25(OH)D sérica .......................................33

Quadro 4 - Fatores de risco para deficiência / insuficiência de vitamina D ................35

Quadro 5 - Categorização do IMC para definição do status nutricional ....................58

Quadro 6 - Categorização da gravidade clínica da DA .......................................59

Quadro 7 - Sumário dos exames laboratoriais incluídos no estudo ..........................61

Quadro 8 - Causas de aumento de lgE.......................................................126 


\section{LISTA DE TABELAS}

Tabela 1 - Tamanho da amostra (n) para vários níveis de confiança. .57

Tabela 2 - Análise descritiva das variáveis encontradas no grupo de portadores de DA

Tabela 3 - Resultados do exame EPF no grupo de pacientes com DA .66

Tabela 4 - Características epidemiológicas e concentração de 25(OH)D em subgrupo com DA e em grupo controle pareado.

Tabela 5 - Concentrações séricas de 25(OH)D em subgrupo de pacientes com DA e em grupo controle 69

Tabela 6 - Categorias de 25(OH)D em subgrupo portador de DA e em grupo controle .70

Tabela 7 - IUV médio em subgrupo de pacientes com DA e em grupo controle .......71

Tabela 8 - Correlação entre variáveis contínuas 25(OH)D e SCORAD .....................72

Tabela 9 - Correlação entre 25(OH)D e SCORAD objetivo..................................... 72

Tabela 10 - Associação entre 25(OH)D e SCORAD categóricos ..............................73

Tabela 11 - Associação entre categorias de 25(OH)D e de SCORAD objetivo..........73

Tabela 12 - Correlação entre variáveis $25(\mathrm{OH}) \mathrm{D}$ e SCORAD em grupo de pacientes portadores de DA com IgE elevada...............................................................

Tabela 13 - Correlação entre 25(OH)D e SCORAD objetivo em grupo de pacientes

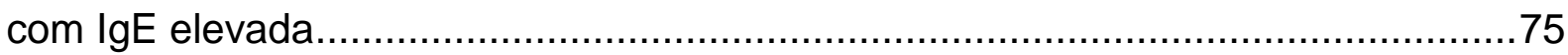

Tabela 14 - Correlação entre concentrações séricas de 25(OH)D e PTHi.................76 Tabela 15 - Associação entre categorias de 25(OH)D e concentrações séricas de PTHi

Tabela 16 - Associação entre SCORAD e concentração sérica de PTHi...................78

Tabela 17 - Associação entre concentrações séricas de PTHi e categorias do SCORAD .79

Tabela 18 - Comparação clínica e laboratorial entre pacientes com DA extrínseca e intrínseca.

Tabela 19 - Correlação entre concentrações séricas de 25(OH)D e IUV. 82

Tabela 20 - Correlação entre IUV e SCORAD ………......................................... 83

Tabela 21 - Correlação entre IUV e SCORAD objetivo 83

Tabela 22 - Associação das categorias de SCORAD com variáveis independentes 85 
Tabela 23 - Análise de regressão linear múltipla (modelos para predizer SCORAD)91 Tabela 24 - Correlação entre IMC e concentrações séricas de 25(OH)D .................91

Tabela 25 - Correlação entre idade e concentrações séricas de 25(OH)D ................93

Tabela 26 - Associação entre estações climáticas e concentrações séricas de

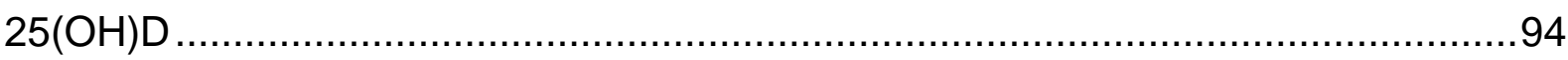

Tabela 27 - Associação entre categorias de 25(OH)D e variáveis independentes....95 Tabela 28 - Análise de regressão linear múltipla [modelos para predizer 25(OH)D] 101

Tabela 29 - Associação entre concomitância de DA com asma ou RA (sim versus não) e as variáveis genêro, idade de início, SCORAD, 25(OH)D, PTH, IgE e eosinófilos.

Tabela 30 - Comparação entre análise quantitativa e qualitativa da 25(OH)D entre os grupos 108

Tabela 31 - Diferença entre médias de 25(OH)D e IUV em casos com DA e em controles

Tabela 32 - Associação entre 25(OH)D e gravidade clínica da DA 


\section{LISTA DE ABREVIATURAS E SIGLAS}

1,25(OH) $2 \mathrm{D}$ : $1 \alpha, 25$-diidroxi-vitamina $\mathrm{D}$ ou calcitriol

25(OH)D: 25-hidroxivitamina D ou calcidiol

7-DHC: 7-deidrocolesterol

Bcl-3: Gene linfoma de células B 3

CLDN-1: Claudina-1

CPTEC: Centro de Previsão de Tempo e Estudos Climáticos

CYP27B1: Enzima 1 $\alpha$-hidroxilase

DA: Dermatite Atópica

DEM: Dose Eritematosa Mínima

DEQAS: Vitamin D External Quality Assessment Scheme

DF: Distrito Federal

DH $\beta-2$ : Defensina Humana $\beta 2$

DH $\beta-3$ : Defensina Humana $\beta 3$

DMO: Densidade Mineral Óssea

DNA: Ácido Desoxirribonucleico

DSA: Divisão de Satélites e Sistemas Ambientais

EASI: Eczema Area and Severity Index - escore de gravidade clínica da dermatite atópica

EPF: Exame Parasitológico de Fezes

EUA: Estados Unidos da América

HPS: Hiperparatireoidismo Secundário

HUB: Hospital Universitátio de Brasília

IC: Intervalo de Confiança

IgE: Imunoglobulina E

IL: Interleucina(s)

IMC: Índice de Massa Corporal

IFN- $\gamma$ : Interferon-gama

INPE: Instituto Nacional de Pesquisas Espaciais

IUV: Índice Ultravioleta

IOM: The Institute of Medicine

LPET: Linfopoetina Estromal Tímica 
MS: Ministério da Saúde

MRSA: Staphylococcus aureus Meticilina-Resistente

NESS: Nottingham Eczema Severity Score - escore de gravidade clínica da dermatite atópica

OMS: Organização Mundial da Saúde

PAM: Peptídeos Antimicrobianos

PASI: Psoriasis Area and Severity Index - escore de gravidade clínica da psoríase PTH: Hormônio Paratireoideo

PTHi: Hormônio Paratireoideo Molécula Intacta

PTHrp: Proteína Relacionada ao Hormônio Paratireoideo

RA: Rinite Alérgica

RVD: Receptor Nuclear da Vitamina D

RXR: Receptor X do Ácido Retinoico

SBD: Sociedade Brasileira de Dermatologia

SBEM: Sociedade Brasileira de Endocrinologia e Metabologia

SCORAD: SCOring Atopic Dermatitis - escore de gravidade clínica da dermatite atópica

SIDA: Síndrome da Imunodeficiência Adquirida

SISAM: Sistema de Informações Ambientais

TCLE: Termo de Consentimento Livre e Esclarecido

TGI: Trato Gastrointestinal

Th: Linfócito T auxiliar (T helper)

TNF-a: Fator de Necrose Tumoral $\alpha$

UCR: Unidades de Cópia Relativa

UV: Ultravioleta

UVA: Ultravioleta A

UVB: Ultravioleta B

UVC: Ultravioleta $C$ 
1 INTRODUÇÃO

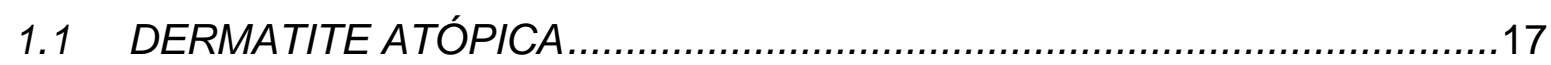

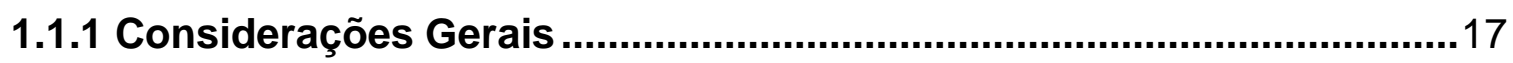

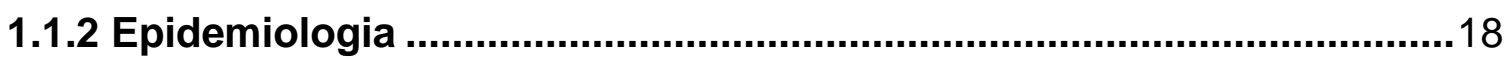

1.1.3 Diagnóstico e Quadro Clínico.............................................................18

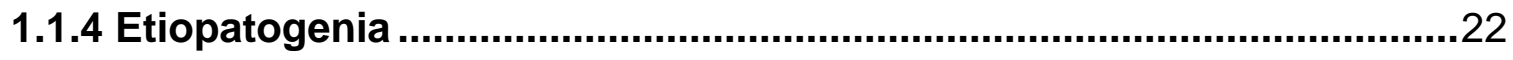

1.2 VITAMINA D: UM CONHECIMENTO EM CONSTRUÇÃO .......................25

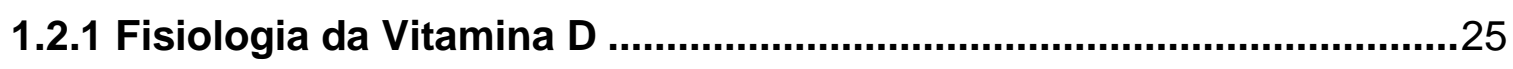

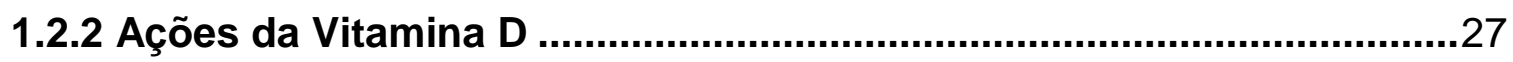

1.2.3 Vitamina D: Métodos de Mensuração, Relação com o Hormônio Paratireoideo e Valores de Referência.......................................................29

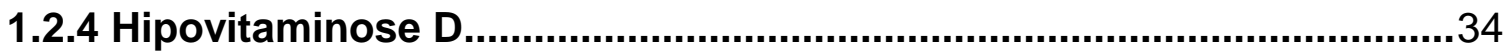

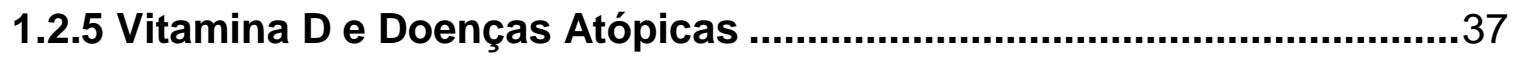

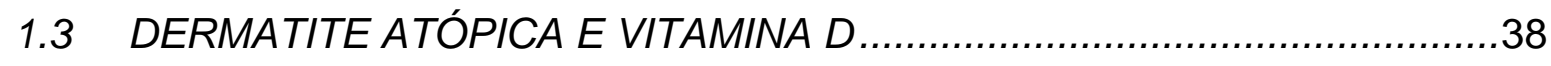

1.3.1 Relação entre a Concentração Sérica de 25(OH)D e a Prevalência /

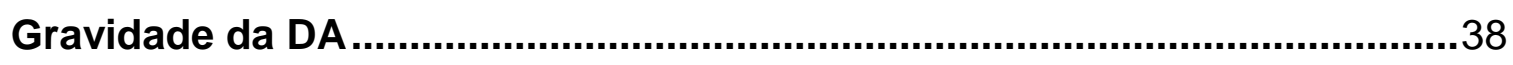

1.3.2 Plausibilidade Biológica: Associação entre Vitamina D e Dermatite

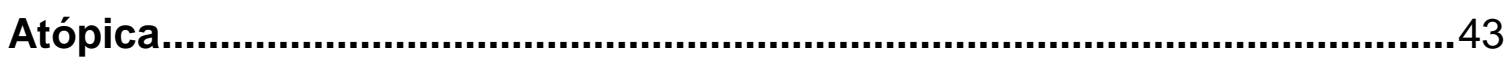

1.3.3 Papel Terapêutico da Suplementação de Vitamina D na DA ................48

1.4 RADIAÇÃO ULTRAVIOLETA: CONSIDERAÇÕES GERAIS ......................49

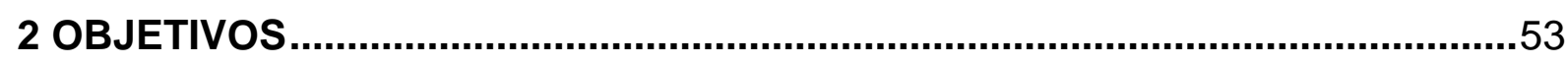

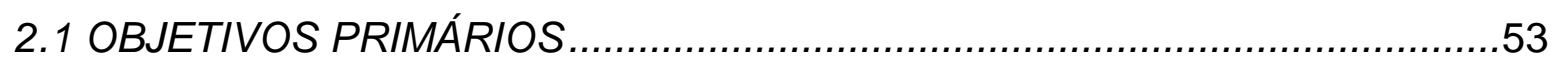

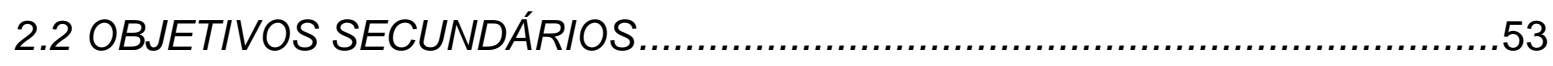

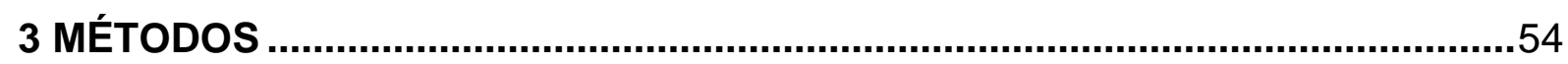

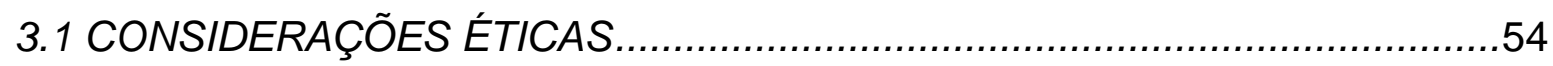

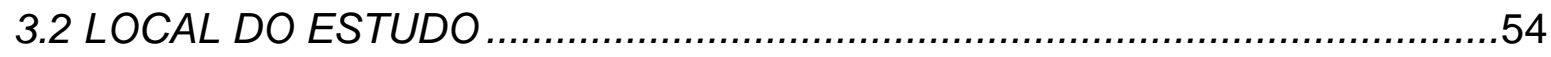

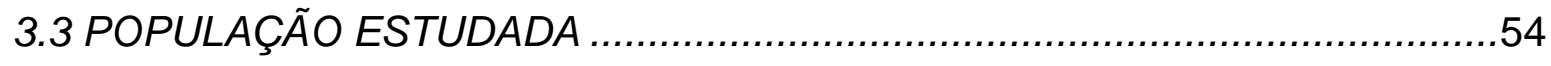

3.3.1 Grupo de Casos (Indivíduos com DA) ……....................................55

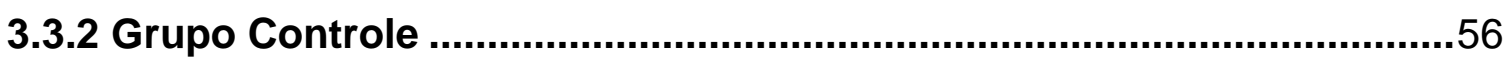

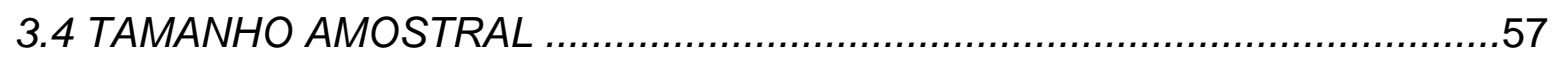

3.5 DELINEAMENTO DO ESTUDO E AFERIÇÃO DAS VARIÁVEIS....................57 
4 RESULTADOS

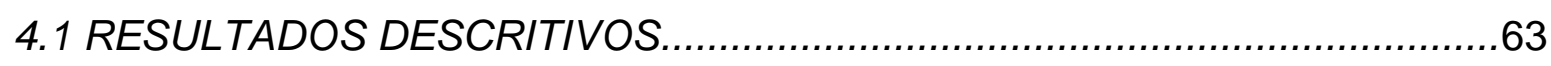

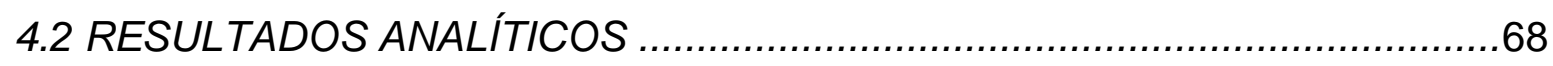

4.2.1 Concentrações Séricas e Categorias de 25(OH)D em Subgrupo de Pacientes Portadores de DA e em Grupo Controle .68

4.2.2 IUV Médio em Subgrupo de Pacientes Portadores de DA e em Grupo Controle .70

4.2.3 Associação entre 25(OH)D e Gravidade Clínica da DA (SCORAD e SCORAD Objetivo). 71

4.2.4 Correlação entre Concentrações Séricas de 25(OH)D e Gravidade Clínica da DA em Grupo de Pacientes com IgE Elevada..............................74

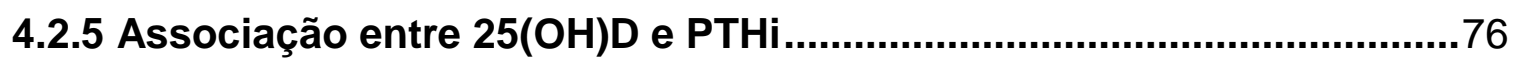

4.2.6 Correlação entre Concentrações Séricas de PTHi e Gravidade Clínica da DA .78

4.2.7 Análise Comparativa entre DA Intrínseca e DA Extrínseca ..................80

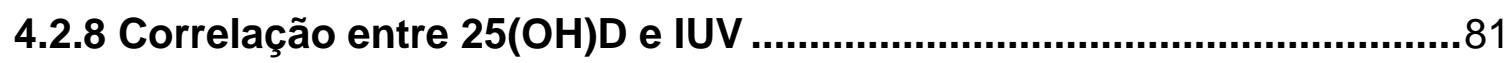

4.2.9 Correlação entre IUV e Gravidade Clínica da DA ................................82

4.2.10 Associação entre Categorias SCORAD e Variáveis Independentes .84 4.2.11 Análise Multivariada para Identificação de Variáveis Determinantes do SCORAD .90

4.2.12 Correlação entre IMC e Concentrações Séricas de 25(OH)D ...............91

4.2.13 Correlação entre Idade e Concentrações Séricas de 25(OH)D ..........92

4.2.14 Associação entre Estação do Ano e Concentrações Séricas de 25(OH)D .93

4.2.15 Associação entre Categorias de 25(OH)D e Variáveis Independentes

4.2.16 Análise Multivariada para Identificação de Variáveis Determinantes da 25(OH)D 100

4.2.17 Associação entre Concomitância de DA com Asma ou RA e Variáveis Independentes 101

5 DISCUSSÃO 103

5.1 DELINEAMENTO E RESULTADOS DESCRITIVOS. 103 
5.3 ANÁLISE COMPARATIVA ENTRE SUBGRUPO DA E GRUPO CONTROLE PAREADO

5.4 VITAMINA D E GRAVIDADE CLÍNICA DA DA

5.5 ASSOCIAÇÕES COM O PTH... 112

5.6 DA E INFLUÊNCIAS AMBIENTAIS . 117

5.7 PREDITORES DO SCORAD 120

5.8 PREDITORES DA 25(OH)D. 121

5.9 DA INTRÍNSECA E EXTRÍNSECA 124

5.10 ATOPIA PESSOAL CONCOMITANTE.. 128

5.11 FORÇAS E LIMITAÇÕES 128

6 CONCLUSÃO 131

7 REFERÊNCIAS. 133

APÊNDICE A - TCLE 156

APÊNDICE B - FICHA DE COLETA DE DADOS CLÍNICOS E LABORATORIAIS

ANEXO A - APROVAÇÃO DO COMITÊ DE ÉTICA. 158

ANEXO B - BULA DO EXAME 25(OH)D. 160

ANEXO C - BULA DO EXAME PTHI 170

ANEXO D - BULA DO EXAME IgE 173

ANEXO E - SCORAD. 175 ANEXO F - CONTRATO DE PRESTAÇÃO DE SERVIÇOS DO LABORATÓRIO SABIN .176 


\section{INTRODUÇÃO}

\subsection{DERMATITE ATÓPICA}

\subsubsection{Considerações Gerais}

A dermatite atópica (DA) é uma doença inflamatória crônica altamente pruriginosa, a qual geralmente se manifesta durante a fase de lactente ou infância. Considerada a manifestação mais precoce de atopia, sua prevalência predomina em crianças. Não obstante, a doença pode persistir em mais de 10\% dos pacientes até a adolescência ou a idade adulta. Dados globais evidenciam acentuado aumento em sua prevalência, que triplicou desde 1960 (1-5). Uma "marcha atópica" ocorre precocemente nas crianças com DA: mais de $50 \%$ desenvolverão asma e/ou alergias, normalmente por volta dos 3 anos de vida (6). Em virtude de seu caráter crônico e pruriginoso, a DA pode impactar sobremaneira no bem estar de seus portadores, superando o prejuízo da qualidade de vida causado pela asma brônquica, pelo diabetes, pela enurese e pela fibrose cística (7-10). Pode acarretar sintomas depressivos, isolamento social e distúrbio da autopercepção (11).

A DA foi, por muito tempo, entendida como uma anormalidade estrutural da epiderme causada por disfunção dos ceratinócitos. Conquanto, avanços no entendimento da fisiopatologia da doença ao longo das últimas duas décadas ressaltam o papel da desregulação imune dentro dos complexos e intrincados fatores etiopatogênicos da dermatose. Novos conceitos surgiram e vêm surgindo, demonstrando disfunções imunológicas e inflamatórias $(4,12)$.

Os pacientes com DA possuem uma predisposição única de colonização ou infecção por micro-organismos, notadamente o Staphylococcus aureus e o vírus herpes simples. Fatores ambientais e outros não identificados também podem influenciar a expressão da doença. A etiopatogenia da DA é complexa e ainda não totalmente elucidada (5), fato que impulsiona pesquisas acerca da etiologia e tratamento dessa dermatose. 


\subsubsection{Epidemiologia}

Dados globais evidenciam acentuado aumento na prevalência de doenças atópicas - incluindo a DA - em todo o mundo. Nos Estados Unidos da América (EUA), a prevalência de DA na infância era de 2 a 3\% antes de 1960, de 9 a 12\% após 1970 e, atualmente, varia entre $10 \%$ a $20 \%$ das crianças e 1 a $3 \%$ dos adultos $(8,13,14)$. As razões para esse aumento não são bem compreendidas (15). Há poucos dados sobre a prevalência da doença no Brasil. Estudo transversal realizado no Distrito Federal (DF) demonstrou aumento significativo da prevalência de DA em pacientes de 13-14 anos no período de 1996 a 2002: a prevalência aumentou de $9,8 \%$ para $13,6 \%$ nesse intervalo de tempo (16).

A prevalência da DA é variável entre países e mesmo dentro de regiões de um mesmo país. A grande variação de prevalência sugere que fatores ambientais e outros não identificados podem influenciar a expressão da doença $(5,17)$. Estudos indicam maior incidência e prevalência em países ocidentalizados e desenvolvidos.

Mais de 60 a $80 \%$ dos casos de DA apresentam-se antes do primeiro ano de vida, e 95\% dos casos ocorre antes dos 5 anos. Cerca de 70\% dos pacientes portadores de DA possuem antecedentes familiares de atopia, tais como asma e rinite alérgica (RA) (18).

\subsubsection{Diagnóstico e Quadro Clínico}

O diagnóstico de DA é clínico, estabelecido por meio de critérios definidos por Hanifin \& Rajka (1980) (19). Tais critérios são hierarquizados em maiores e menores. Para o diagnóstico de DA, são necessários 3 critérios de cada categoria (Quadro 1). 
Quadro 1 - Critérios diagnósticos para DA

\begin{tabular}{|c|c|}
\hline & Critérios Maiores \\
\hline & Prurido \\
\hline & $\begin{array}{l}\text { Morfologia e distribuição típica: adultos - lesões flexurais; crianças e lactentes - lesões } \\
\text { ha face e superfícies extensoras }\end{array}$ \\
\hline & Dermatite crônica recidivante \\
\hline & História familiar ou pessoal de atopia \\
\hline & Critérios Menores \\
\hline & Xerose \\
\hline & Ictiose / Ceratose pilar / Hiperlinearidade palmar \\
\hline & Reatividade cutânea positiva \\
\hline & IgE sérica elevada \\
\hline & Surgimento em idade precoce \\
\hline & Tendência a infecções de pele \\
\hline & Dermatite de mãos e pés \\
\hline & Eczema de mamilos \\
\hline & Queilite \\
\hline & Conjuntivite \\
\hline & Prega ocular de Dennie-Morgan \\
\hline & Ceratocone \\
\hline & Catarata subcapsular anterior \\
\hline & Escurecimento orbital \\
\hline & Eritema / Palidez facial \\
\hline & Pitiríase alba \\
\hline & Dobras no pescoço anterior \\
\hline & Prurido ao suor \\
\hline & Intolerância a lã e solventes lipídicos \\
\hline & Acentuação perifolicular \\
\hline & Intolerância alimentar \\
\hline & Fatores ambientais / emocionais alterando o curso da doença \\
\hline & Dermografismo branco \\
\hline
\end{tabular}

Fonte: Hanifin \& Rajka, 1980 (19)

A DA infantil é caracterizada por xerose generalizada e placas eritêmatoescamativas exsudativas afetando as bochechas, fronte, couro cabeludo e extremidades extensoras. Muitas vezes a área da fralda é poupada. Conforme a doença progride na infância, as lesões tendem a migrar para as áreas de flexuras, particularmente as fossas antecubital e poplítea. Escoriações e liquenificacões surgem secundárias à coçadura crônica (Figura 1). Entre os bebês e crianças que têm 
DA moderada a grave, 40\% desenvolverão alergias alimentares, sendo as mais comuns à leite de vaca, ovos, amendoim e soja (18).

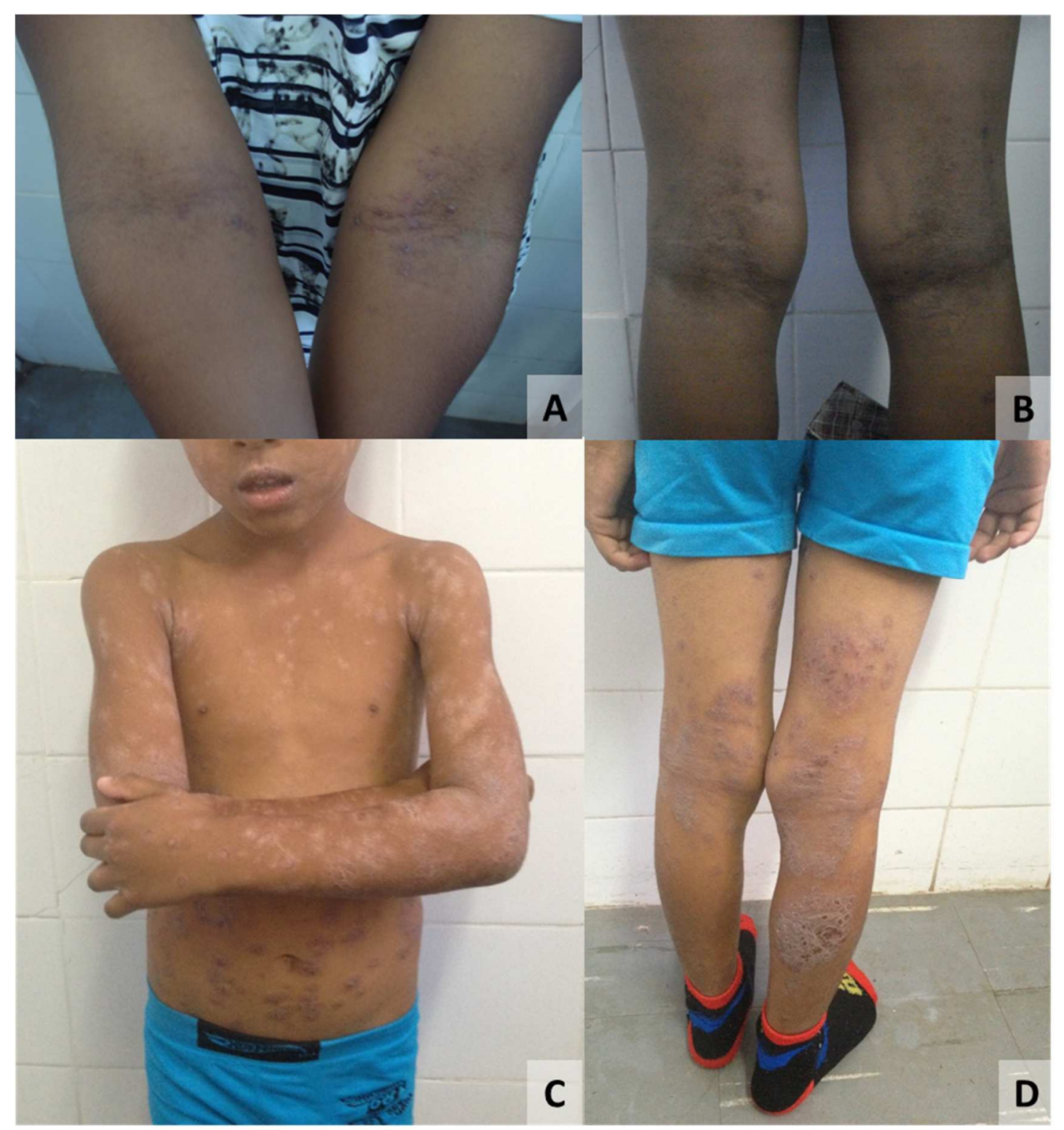

Figura 1 - DA: quadro clínico. A e B: lesões eczematosas em flexuras (fossas antecubitais e poplíteas); C e D: placas eczematosas disseminadas

A avaliação acurada da extensão e da gravidade do quadro clínico da doença é fundamental na condução de investigações clínicas, tanto para quantificar um estado basal quanto para avaliar a efetividade de qualquer regime terapêutico. Nas últimas duas décadas, houve consideráveis esforços para padronizar a avaliação da 
DA. O índice SCOring Atopic Dermatitis (SCORAD) foi validado em 1993 pela European Task Force on Atopic Dermatitis (20), mesclando observações de sinais e sintomas, direcionado à população pediátrica. O Eczema Area and Severity Index (EASI) - uma modificação do Psoriasis Area and Severity Index (PASI) - foi criado com objetivo de simplificar e abranger tanto a população pediátrica quanto a adulta (21). Outra ferramenta disponível, menos comumente utilizada, é o Nottingham Eczema Severity Score (NESS) (22).

A DA é classificada em dois subtipos: intrínseca (ou não-alérgica) e extrínseca (ou alérgica), com diferentes mecanismos fisiopatológicos subjacentes nessa aparente heterogênea doença. Essa dicotomia foi primeiramente utilizada para a asma e passou a ser considerada no fim dos anos 1980 no campo da DA. A DA extrínseca - o tipo clássico, de maior prevalência - mostra níveis aumentados de imunoglobulina $\mathrm{E}(\mathrm{IgE})$ total e presença de $\lg \mathrm{E}$ específica para alérgenos ambientais ou alimentares, presumidamente como consequência do dano da barreira e da permeabilidade aumentada a alérgenos. Por sua vez, a DA intrínseca mostra IgE normal e não é mediada por lgE específica a alérgenos $(23,24)$. As principais características da DA extrínseca e intrínseca estão sumarizadas no Quadro 2. As manifestações clínicas, porém, costumam ser indistinguíveis e alguns especialistas são céticos quanto à significância dessa distinção. Ademais, alguns consideram a DA intrínseca uma forma transicional para a forma extrínseca $(25,26)$. As causas e mecanismos diferenciais desses subtipos de DA permanecem não totalmente compreendidos.

Quadro 2 - Aspectos da DA extrínseca e intrínseca

\begin{tabular}{|l|l|l|}
\hline \multicolumn{1}{|c|}{ Característica } & \multicolumn{1}{|c|}{ DA intrínseca } & \multicolumn{1}{c|}{ DA extrínseca } \\
\hline $\begin{array}{l}\text { Parâmetros clínicos } \\
\text { Manifestações cutâneas }\end{array}$ & $\begin{array}{l}\text { Linha de Dennie-Morgan } \\
\text { mais frequente } \\
\text { Mais precoce }\end{array}$ & $\begin{array}{l}\text { Liquenificação em flexuras } \\
\text { mais comum } \\
\text { Mais tardio }\end{array}$ \\
Gênero de início & Predominância feminina & Ausência de predominância \\
Frequência & $16-45 \%$ dos casos de DA & $55-84 \%$ dos casos de DA \\
Atopia pessoal / familiar & Menor frequência & Maior frequência \\
Prick test & Negativo & Positivo \\
Barreira cutânea & Preservada & Prejudicada \\
Mutações no gene da & Ausente & Presente \\
filagrina & & \\
continua & \multicolumn{2}{|l}{}
\end{tabular}


continuação

Quadro 2 - Aspectos da DA extrínseca e intrínseca

\begin{tabular}{|l|l|l|}
\hline Característica & DA intrínseca & DA extrínseca \\
\hline Sangue Periférico & & \\
IgE total & Normal & Elevada \\
IgE específica & Negativo & Positivo \\
Eosinofilia & $\uparrow$ & $\uparrow$ \\
Citocinas & $\uparrow \mathrm{IL}-5, \uparrow \mathrm{IL}-4, \uparrow \uparrow$ IL-13 & $\uparrow$ IL-5, $\uparrow$ IL-4, $\uparrow$ IL-13 \\
Ativação de células B & $\uparrow$ Células B CD23 & $\uparrow \uparrow ~ C e ́ l u l a s ~ B ~ C D 23^{+}$ \\
\hline
\end{tabular}

Adapatado de Toruka, 2010 (23); Novak \& Bieber, 2003 (25); Brenninkmeijer e colaboradores, 2008 (26)

\subsubsection{Etiopatogenia}

Pacientes com DA têm fatores de risco geneticamente determinados que afetam a função de barreira da pele e a resposta imune, as quais interagem com fatores ambientais. Clinicamente, isso resulta em uma pele intensamente pruriginosa, inflamada, que permite a penetração de irritantes e alérgenos e que predispõe os pacientes à colonização e infecção por micro-organismos.

Fatores ambientais, incluindo os hábitos de exposição ao sol e higienodietéticos, exercem papel determinante na expressão de manifestações atópicas. É possível que a exposição precoce a micro-organismos, comum nos países em desenvolvimento, concorra para a maturação do sistema imune e reduza a incidência de DA. Acredita-se, ainda, que o contato com micro-organismos por via fecal-oral tenha maior efeito protetor do que o contato com os mesmos por via respiratória.

A desregulação imune local e sistêmica caracteriza a DA. A inflamação cutânea exibe um padrão bifásico de ativação das células T. É característico o predomínio de citocinas padrão T helper (Th) 2 na fase aguda de desenvolvimento das lesões sobretudo interleucinas (IL) 4 e 13 -, que influenciam a síntese de lgE e a expressão de moléculas de adesão. A maioria dos pacientes com DA tem níveis elevados de lgE, que se correlacionam com medidas clínicas da gravidade da doença. Na fase crônica da DA, ocorre uma mudança para o padrão Th1, com produção de interferon-gama (IFN-y) $(4,5,27,28)$. 
O papel de agentes infecciosos, sobretudo o Staphylococcus aureus, tem sido amplamente considerado na etiopagenia da DA. O S. aureus pode ser cultivado em 90\% das lesões cutâneas e pode colonizar a pele de aspecto aparentemente são na DA. Essa bactéria potencialmente exacerba ou contribui para a inflamação persistente da pele por meio da secreção de toxinas com propriedades superantigênicas, resultando na ativação de células T e outras células do sistema imunológico $(5,29)$.

Estudos genômicos sugerem provável herança poligênica. Há, porém, concordância relativamente baixa da incidência de DA entre gêmeos monozigóticos, evidenciando a multicausalidade etiopatogênica que influencia o risco de adoecer e as manifestações clínicas. Estudos identificaram diversos genes associados com a DA, nenhum conclusivamente apontado como locus ou gene específico. Os genes identificados codificam proteínas envolvidas predominantemente na função de barreira da pele - sobretudo a filagrina -, bem como a resposta imune inata e adaptativa (5).

Acredita-se que pacientes com DA sejam portadores de genes específicos desempenhando um papel importante junto com genes "genéricos" de atopia (5). Dold e colaboradores (1992) (30) observaram que o risco de uma criança ter DA era maior quando um ou ambos os pais tinham DA (OR: 3,4; IC95\% 2,6-4,4) em comparação com o risco quando os pais tinham asma (OR: 1,5; IC95\% 1,0-2,2) ou RA (OR: 1,4; IC95\% 1,1-1,8).

Há muito se suspeita da participação de condições climáticas na etiologia das doenças atópicas (31). A prevalência de sintomas de eczema correlaciona-se positivamente com a latitude e negativamente com a temperatura média anual. É possível, entretanto, que essas variáveis afetem a prevalência do eczema apenas indiretamente, devido a mudanças no comportamento e diferenças na exposição solar (32). O modo como fatores climáticos influenciam a DA não é completamente entendido, porém tem sido atribuída à luz solar - radiação ultravioleta $A$ (UVA) e ultravioleta $B$ (UVB) - um efeito positivo no eczema atópico em razão da imunossupressão local nas células da pele (33). Existem, porém, dados conflitantes e escassos com relação ao impacto de fatores climáticos específicos como umidade, índice pluviométrico e índice ultravioleta (IUV) (15).

As interações genéticas, ambientais, imunitárias e infecciosas que levam à expressão do fenótipo atópico ainda não são completamente entendidas (8). Anormalidades nas tight junctions também têm sido consideradas. O epitélio são de 
pacientes com DA tem anormalidades bioelétricas que podem ser consequência de níveis diminuídos de claudina-1 (CLDN1), uma proteína de adesão (34).

Dentre os diversos fatores etiológicos responsáveis pelo aumento da prevalência de doenças atópicas nas últimas décadas, o papel da vitamina $D$ tem recebido destaque. Uma vez que a patogênese da DA envolve uma interação complexa da disfunção da barreira epidérmica e da desregulação da resposta imune - e a vitamina D está envolvida em ambos os processos-, é razoável esperar que a vitamina $D$ esteja associada com o risco ou gravidade da DA. Tal associação vem sendo sugerida por dados epidemiológicos e experimentais (35).

Descobertas atuais destacam, de modo crescente, o papel da vitamina $D$ na imunomodulação de pacientes atópicos, portadores de doenças crônicas como asma brônquica e DA. Além do papel clássico na homeostase do cálcio, a vitamina D influencia a imunomodulação e a diferenciação celular, altera o balanço local de cálcio e liga-se aos receptores nucleares, regulando a transcrição gênica. Nesse contexto, a vitamina $D$ e seus análogos parecem desempenhar um papel cada vez mais importante no manejo de doenças dermatológicas, tais como DA, psoríase, vitiligo, acne e rosácea (12,36-38). 


\subsection{VITAMINA D: UM CONHECIMENTO EM CONSTRUÇÃO}

\subsubsection{Fisiologia da Vitamina D}

A vitamina $D$ foi descoberta há menos de um século, em 1920. A elucidação da estrutura química da vitamina D em 1932 revelou que essa vitamina era, na verdade, um esteróide. No final dos anos 1960, foi revelado que o esteróide vitamina $D$ era um precursor de um novo hormônio esteróide, a 1a,25-diidroxi-vitamina $D\left[1,25(\mathrm{OH})_{2} \mathrm{D}\right]$.

A descoberta, em 1969, do receptor nuclear da vitamina D (RVD) impulsionou duas décadas de estudos que coletivamente descreveram o vasto campo de influência do sistema endócrino da vitamina D. Classicamente envolvida no metabolismo osteomineral e homeostase do cálcio, diversos estudos passaram a ressaltar sua ação não-calcêmica na homeostase e metabolismo extra-ósseo (39). O RVD está expresso quase ubiquamente e a maioria das células respondem quando expostas à $1,25(\mathrm{OH})_{2} \mathrm{D}$. Cerca de $3 \%$ do genoma humano é regulado, direta ou indiretamente, pelo sistema endócrino da vitamina $D$, o que demonstra sua ampla gama de ações $(40,41)$.

Houve mais artigos científicos publicados sobre a vitamina $D$ no século $X X I$ do que sobre qualquer outra vitamina, refletindo a expansão maciça do seu campo de pesquisa. Concentrações adequadas de vitamina $D$ têm sido associadas à redução do risco de desenvolvimento de diversos tipos de câncer, infecções bacterianas, artrite reumatoide, doença de Crohn, doenças periodontais, esclerose múltipla, asma, DA, diabetes mellitus tipo 1 e 2, síndrome metabólica, doenças cardiovasculares, acidente vascular cerebral, doença arterial periférica, hipertensão, doença renal crônica, fraqueza muscular, comprometimento cognitivo, doença de Alzheimer, depressão e morte prematura (42).

As duas formas mais importantes de vitamina D são o colecalciferol (vitamina $D_{3}$ ) e o ergocalciferol (vitamina $D_{2}$ ), biologicamente inertes. A vitamina $D$ é lipossolúvel, sintetizada principalmente na pele. Quando há exposição à radiação UVB, o 7-deidrocolesterol (7-DHC) é convertido em pré-vitamina $\mathrm{D}_{3}$. A pré-vitamina $D_{3}$ é termolábil e, ao longo de um período de $48 \mathrm{~h}$, sofre isomerização térmica que resulta na produção de vitamina $D_{3}$. Alternativamente, esse produto termolábil pode 
isomerizar em dois produtos biologicamente inativos: o luminosterol e o taquisterol. Essa fotoisomerização alternativa impede a produção de quantidades excessivas de vitamina $\mathrm{D}_{3}$ com a exposição solar prolongada. A maior fonte de vitamina $\mathrm{D}$ (cerca de 80 a 90\%) para os humanos vem da exposição ao sol, tipicamente entre $10 \mathrm{~h}$ e $15 \mathrm{~h}$ nas estações ensolaradas. A pele sintetiza apenas vitamina $D_{3}$, não é capaz de sintetizar a vitamina $\mathrm{D}_{2}(43-45)$.

A vitamina $D$ pode ser obtida, também, por meio de alimentos e suplementos alimentares. As principais fontes dietéticas de vitamina D são os produtos lácteos, cereais fortificados, fungos, gema de ovo e óleo de peixes gordurosos de água fria, como salmão e atum. A vitamina $D$ fornecida por fontes vegetais está na forma de vitamina $D_{2}$, enquanto aquela fornecida por fontes animais está na forma de vitamina $D_{3}$. Essas duas formas possuem potências biológicas equivalentes e são ativadas de modo igualmente eficiente pelas hidroxilases em seres humanos $(41,46)$. A ingestão de vitamina $D$ é consuetudinariamente baixa, uma vez que sua ocorrência natural nos alimentos é pequena e a suplementação de alimentos com essa vitamina não é feita de modo universal (47). Entretanto, os idosos, os internados e aqueles que vivem em climas setentrionais obtêm grande parte da sua vitamina $D$ a partir de fontes dietéticas (46).

$A$ vitamina $D_{3}$ sintetizada na pele é transportada no sangue para o fígado firmemente presa à proteína de ligação da vitamina $D$. Já quando ingeridas, a vitamina $D_{2}$ e $D_{3}$ são incorporadas em quilomicrons, os quais são absorvidos pelo sistema linfático e ganham a circulação venosa $(44,48)$.

As vitaminas $D_{2}$ e $D_{3}$ são hidroxiladas no fígado pela enzima 25-hidroxilase, formando a 25-hidroxivitamina D ou calcidiol [25(OH)D]. Nos túbulos renais, a 25(OH)D é novamente hidroxilada pela enzima 1a-hidroxilase (CYP27B1) em $1,25(\mathrm{OH})_{2} \mathrm{D}$, forma biologicamente ativa que se liga ao RVD nos tecidos-alvo (49). A ligação da $1,25(\mathrm{OH})_{2} \mathrm{D}$ com o RVD leva à dimerização do RVD com o receptor $\mathrm{X}$ do ácido retinoico $(\mathrm{RXR})$. O complexo $1,25(\mathrm{OH})_{2} \mathrm{D}-\mathrm{RXR}$-RVD liga-se então aos elementos de resposta da vitamina D no ácido desoxirribonucleico (DNA) (50). O RVD é amplamente expresso em mais de 30 tecidos e órgãos. A enzima 1a-hidroxilase também é expressa em órgãos extrarrenais, incluindo o trato gastrointestinal (TGI), pele, vasos, células epiteliais mamárias, osteoblastos e osteoclastos. $A \quad 1,25(\mathrm{OH})_{2} \mathrm{D}$ estimula a expressão da enzima 24-hidroxilase, que a metaboliza em formas inativas hidrossolúveis (Figura 2) $(44,49,51)$. 


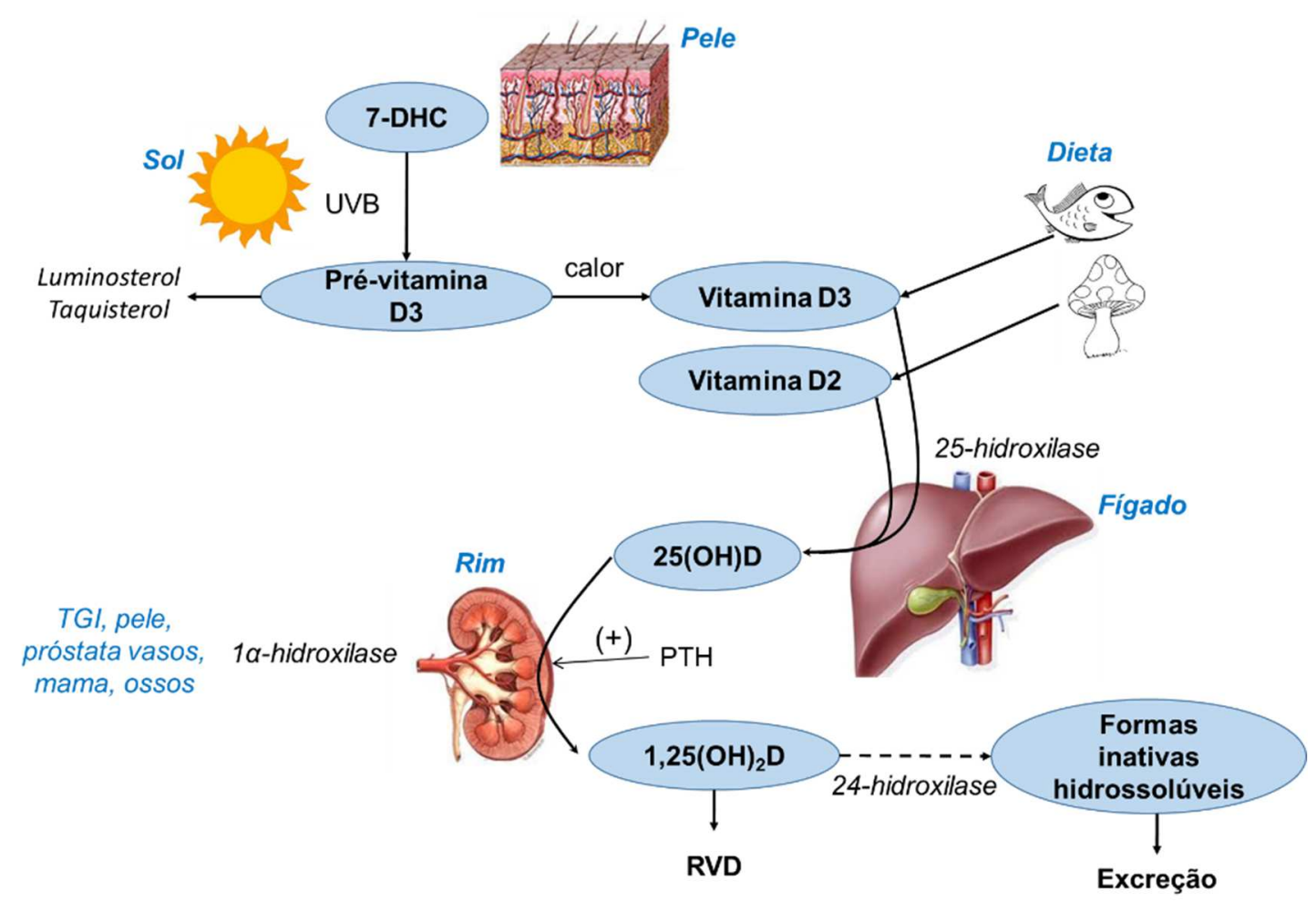

Figura 2 - Metabolismo da vitamina D. Adaptado de Tang e colaboradores, 2012 (51)

\subsubsection{Ações da Vitamina D}

A vitamina $D$ atua no metabolismo osteomineral. Sua deficiência causa o raquitismo em crianças e a osteomalácia em adultos. A $1,25(\mathrm{OH})_{2} \mathrm{D}$ aumenta a absorção renal de cálcio e a absorção intestinal de cálcio e fósforo. No tocante às ações extraesqueléticas, inibe a síntese de renina, aumenta a produção de insulina pelas células $\beta$ pancreáticas e aumenta a contratilidade miocárdica, dentre outras $(44,45)$. Adicionalmente, está envolvida em importantes mecanismos de regulação do sistema imune inato e adaptativo $(43,52)$.

Existem vários tecidos e células que possuem atividade 1a-hidroxilase. A produção local de 1,25(OH) $2 \mathrm{D}$ pode ser responsável pela regulação de até 200 genes que podem promover muitos dos pleiotrópicos benefícios que têm sido atribuídos à vitamina D (44). A $1,25(\mathrm{OH})_{2} \mathrm{D}$ controla genes responsáveis pela regulação da proliferação e diferenciação celular, da apoptose e da angiogênese. Isso explica a recente associação da hipovitaminose $\mathrm{D}$ com aumento do risco de neoplasias 
malignas de mama, cólon e próstata (49). Aplicação prática desse conceito é a utilização da $1,25(\mathrm{OH})_{2} \mathrm{D}$ e seus análogos ativos no tratamento da psoríase.

Modelos animais colaboraram no entendimento das inúmeras funções do sistema endócrino vitamina $\mathrm{D}\left[1,25(\mathrm{OH})_{2} \mathrm{D}\right.$ e seu receptor] na pele (53). Camundongos que não expressam o RVD desenvolvem alopecia total, o que não ocorre naqueles com deficiência de vitamina $D$ ou $1 \alpha$-hidroxilase, o que indica que as funções do RVD não se sobrepõem às do seu ligante. Além da alopecia total, camundongos desprovidos de RVD apresentam cistos dérmicos (54) e anormalidades na diferenciação dos ceratinócitos, com redução na expressão de múltiplas proteínas necessárias para a formação do estrato córneo (involucrina, pró-filagrina e loricrina) após a segunda semana de vida $(55,56)$. Após ruptura da barreira da pele, camundongos que não expressam a $1 \alpha$-hidroxilase têm uma recuperação da barreira significativamente mais lenta em comparação com camundongos tipo selvagem (57). A manutenção do cálcio em concentrações normais previne o defeito de barreira epidérmica, porém não a alopecia. Com relação a outras ações extraesqueléticas, camundongos deficientes em RVD ou vitamina D mostram maior propensão a doenças autoimunes como doença intestinal inflamatória ou diabetes tipo 1 após exposição a fatores predisponentes. Camundongos deficientes em RVD são mais propensos a tumores induzidos por oncogenes ou quimiocarcinógenos. Eles também desenvolvem hipertensão hiperreninêmica, hipertrofia cardíaca e aumento da trombogenicidade (40).

Grande debate cerca os relatados benefícios extraesqueléticos da vitamina D. O Institute of Medicine (IOM), uma organização norte-americana não-governamental sem fins lucrativos, concluiu que as evidências de que a vitamina $D$ reduz o risco de doenças crônicas não-esqueléticas são inconsistentes, inconclusivas e não preenchem critérios para estabelecer uma relação de causa-efeito. Além do mais, existem evidências recentes de curvas em forma de $U$ para diversos desfechos relacionados à vitamina $\mathrm{D}$, com menores riscos em concentrações moderadas $\mathrm{e}$ aumento do risco tanto em concentrações baixas e altas de 25(OH)D. Embora pesquisas futuras possam elucidar benefícios claros e, possivelmente, até mesmo diferentes necessidades de vitamina $D$ em relação a esses desfechos extraesqueléticos, os dados existentes não podem apoiar tais conclusões (58). 


\subsubsection{Vitamina D: Métodos de Mensuração, Relação com o Hormônio Paratireoideo e Valores de Referência}

A produção de vitamina $D$ na pele depende de vários fatores, merecendo destaque a latitude, estação do ano e cor da pele. Há calorosa controvérsia entre as concentrações séricas adequadas de vitamina $D$ para a saúde óssea e dos demais sistemas e órgãos humanos. O limite mínimo pode variar dependendo da localização geográfica e da exposição à luz solar da população de referência (59).

\subsubsection{Métodos de Mensuração da 25(OH)D}

A 25(OH)D é o metabólito cujo valor deve ser determinado no sangue para determinar o estado global da vitamina $D$, uma vez que representa a principal forma de armazenamento e tem maior meia-vida. A 25-hidroxilação não é rigidamente regulada; consequentemente as concentrações séricas de $25(\mathrm{OH}) \mathrm{D}$ refletem a quantidade de vitamina $D$ que adentra a circulação (46). Essa forma circulante primária de vitamina $D$ é biologicamente inativa, possui meia-vida de 2 a 3 semanas e concentrações cerca de 1.000 vezes superiores às da $1,25(\mathrm{OH})_{2} \mathrm{D}$ circulante.

Apesar de se tratar da forma ativa, as concentrações séricas de $1,25(\mathrm{OH})_{2} \mathrm{D}$ não refletem o status de vitamina $D$. Sua meia-vida é de aproximadamente 6 a 8 horas e sua concentração sérica é fortemente regulada pelos níveis séricos do hormônio paratideoideo $(\mathrm{PTH})$, cálcio e fosfato. $A 1_{1} 25(\mathrm{OH})_{2} \mathrm{D}$ sérica é frequentemente normal ou mesmo elevada em pacientes com deficiência de vitamina $D$, em razão do hiperparatiroidismo secundário (44).

Vários métodos laboratoriais podem ser utilizados para a mensuração da $25(\mathrm{OH}) \mathrm{D}$, sendo a cromatografia líquida associada à espectrofotometria de massa e a cromatografia líquida de alta pressão os mais acurados, porém de elevado custo. $O$ método de quimioluminescência, um ensaio competitivo automatizado, tem sido amplamente utilizado na prática clínica em razão do menor custo e da facilidade de uso, porém apresenta menor confiabilidade e acurácia $(41,48)$. 
Todos os ensaios clínicos utilizados para a aferição da 25(OH)D estão sujeitos à variabilidade, o que confunde tentativas de definir um único ponto de corte como indicador de baixa concentração de vitamina D (44). A medição precisa da $25(\mathrm{OH}) \mathrm{D}$ é prejudicada pela natureza lipofílica da molécula, o que torna os ensaios propensos à interferência não específica de outros lipídeos, incluindo lipoproteínas. Estudos clínicos envolvendo medições de 25(OH)D devem detalhar os métodos utilizados para que os leitores possam julgar a confiabilidade dos resultados e como eles se comparam com os de estudos semelhantes (48).

Tamanha a importância da variabilidade interlaboratorial, foi criado em 1989 o Vitamin D External Quality Assessment Scheme (DEQAS), um programa de garantia de qualidade externa sediado em Londres com objetivo de garantir a confiabilidade analítica de ensaios de 25(OH)D e 1,25(OH) $2 \mathrm{D}$ (http://www.deqas.org/). Os laboratórios participantes recebem anualmente um certificado de proficiência (Figura 3) quando $75 \%$ ou mais dos resultados de $25(\mathrm{OH}) \mathrm{D}$ enquadram-se dentro do valoralvo $\pm 25 \%$.

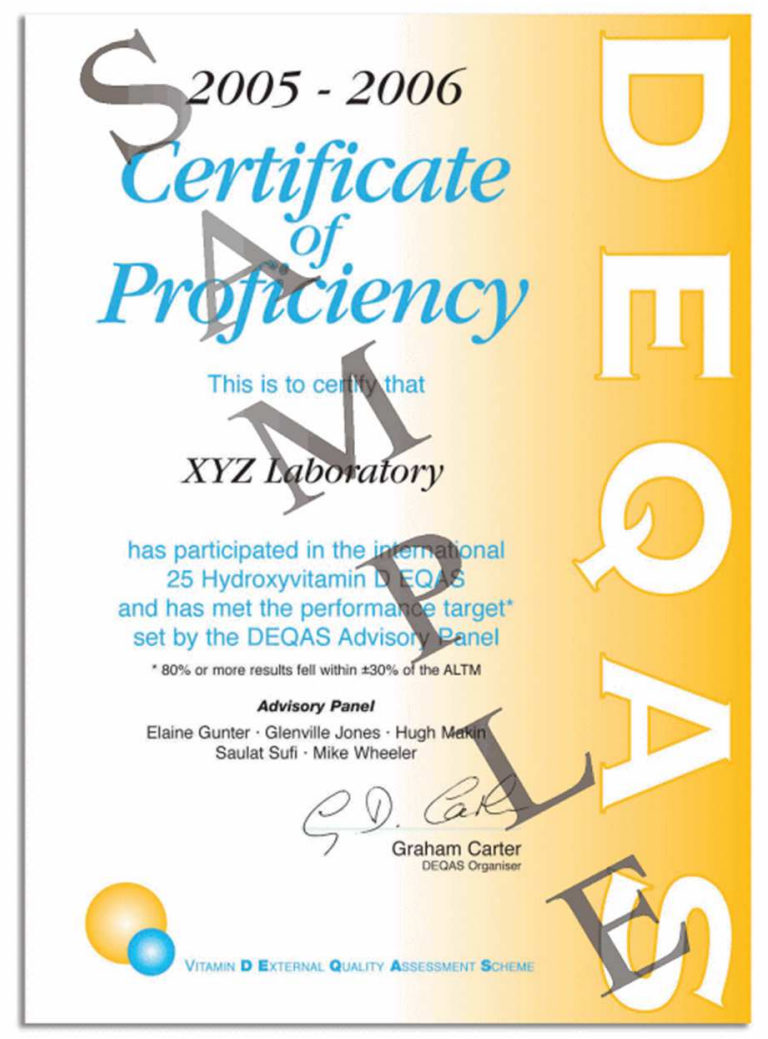

Figura 3 - Exemplo de Certificado de Proficiência emitido pela DEQAS 
Para a prática clínica, parece que todas as metodologias atuais são adequadas caso seja alcançado um valor de $25(\mathrm{OH}) \mathrm{D}$ maior que os valores de referência preconizados. A abordagem de obter uma concentração mais elevada de $25(\mathrm{OH}) \mathrm{D}$ parece salutar, uma vez que melhorando o status da vitamina $\mathrm{D}$, poder-se-ia reduzir múltiplas conseqüências adversas da deficiência dessa vitamina, com baixo custo e um mínimo risco de toxicidade (44).

\subsubsection{Relação com o PTH}

A vitamina D está inversamente relacionada com o PTH. A interação entre ambos é peça-chave na homeostase osteomineral. O PTH é o hormônio peptídico que controla a cada minuto o nível de cálcio ionizado no sangue e nos líquidos extracelulares. Ele se liga a receptores de superfície celular no osso e no rim, desencadeando respostas que elevam o cálcio sérico (46). A deficiência de vitamina $D$ resulta em diminuição na eficiência da absorção intestinal de cálcio e fósforo, que resulta em um aumento nos níveis de PTH. Mesmo a insuficiência leve de vitamina D é compensada por um aumento do PTH sérico (Figura 4). O PTH promove aumento da reabsorção tubular de cálcio e da excreção de fosfato, aumenta a síntese renal de $1,25(\mathrm{OH})_{2} \mathrm{D}$ e estimula a transformação de pré-osteoclastos em osteoclastos maduros. O aumento da atividade osteoclástica cria focos de fraqueza óssea e redução generalizada na densidade mineral óssea (DMO), resultando em osteopenia e osteoporose e aumentando o risco de fraturas $(45,60)$. 


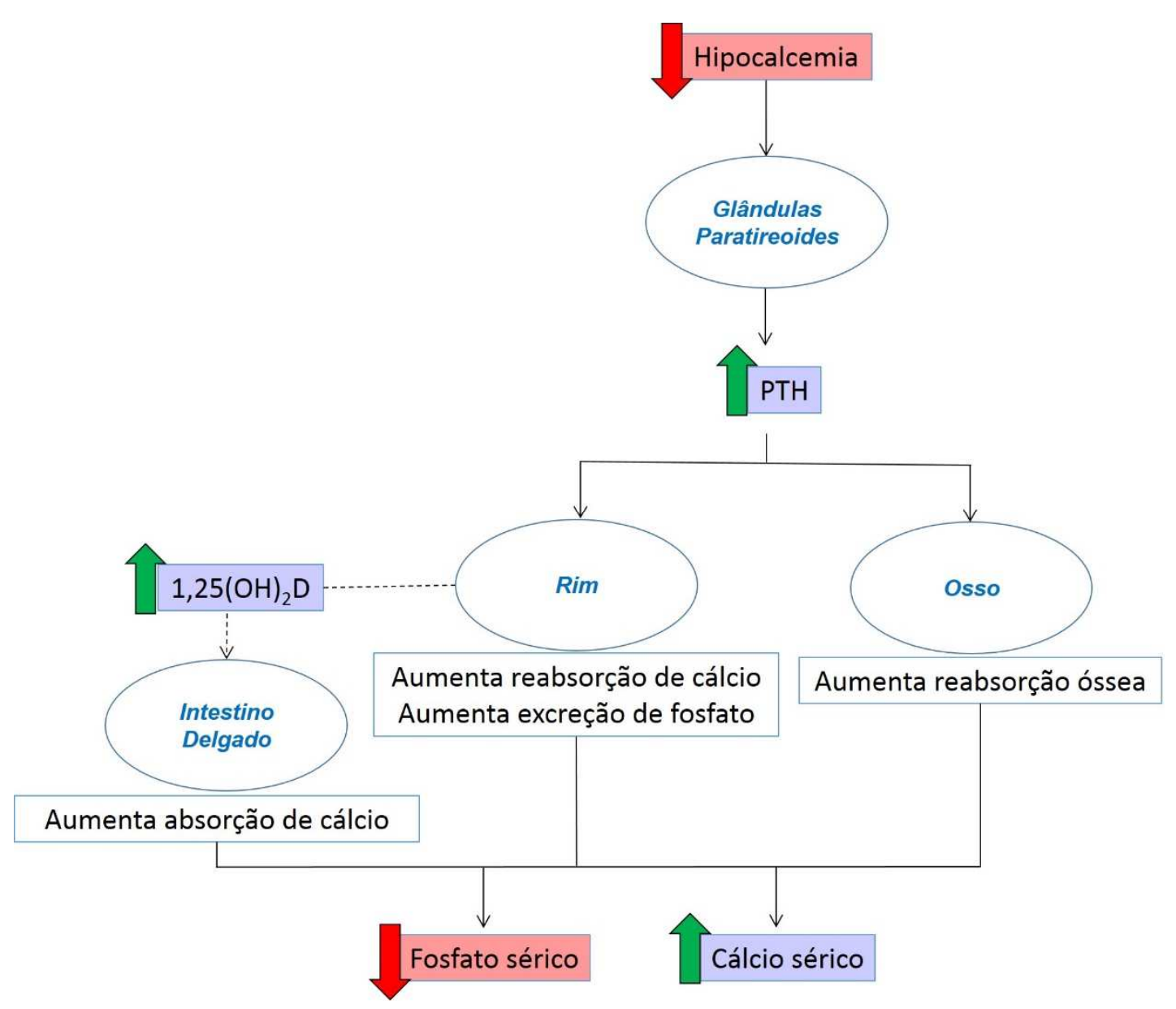

Figura 4 - Ações metabólicas do PTH. Fonte: elaborada pelo autor.

\subsubsection{Vitamina D: Valores de Referência}

A despeito de numerosos estudos prévios e em andamento, não existe consenso acerca das concentrações séricas ideais de vitamina $D$. A 25(OH)D sérica desejada para a saúde óssea é geralmente estabelecida por meio da avaliação da concentração a partir da qual a elevação compensatória do PTH sérico se inicia. Esse ponto varia - de acordo com a população estudada - aproximadamente entre 12 e 40 ng/ml (Figura 5). A elevação do PTH (hiperparatireoidismo secundário) é, portanto, sinal laboratorial precocemente identificável de hipovitaminose $D$ e um marcador secundário útil, podendo a avaliação conjunta dessas variáveis ser mais apropriada para definir a hipovitaminose do que as concentrações isoladas de 25(OH)D $(44,61,62)$. 


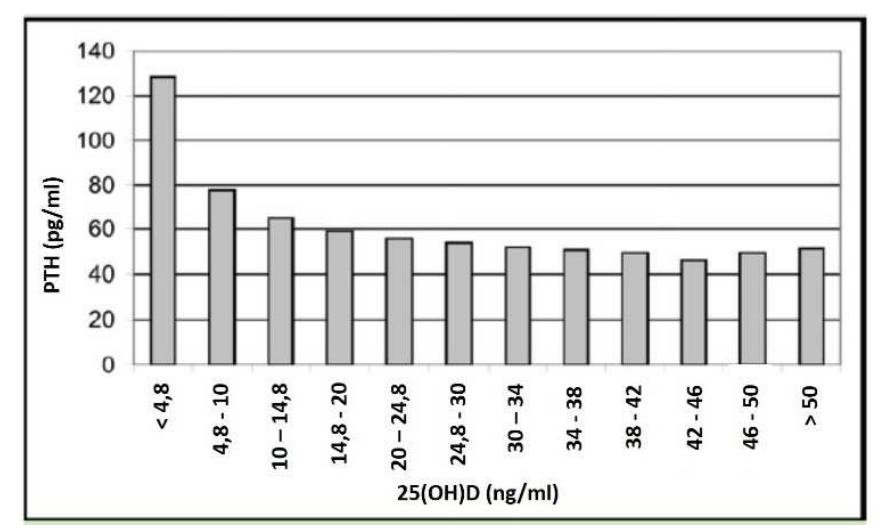

Figura 5 - Relação entre 25(OH)D e PTH. No exemplo, a supressão máxima do PTH ocorreu com concentrações de 25(OH)D acima de $21,5 \mathrm{ng} / \mathrm{ml}$. Adaptado de Saliba e colaboradores, 2011 (60).

Foram sugeridas concentrações de 25(OH)D $<12 \mathrm{ng} / \mathrm{ml},<15 \mathrm{ng} / \mathrm{mL},<25$ $\mathrm{ng} / \mathrm{mL},<30 \mathrm{ng} / \mathrm{mL}$ ou mesmo $<48 \mathrm{ng} / \mathrm{mL}$ como sendo prejudiciais aos ossos $(44,60,63)$. A discussão parece estar longe de ser resolvida. É possível que a ampla gama de limites sugeridos seja reflexo das diferentes características clínicas e demográficas das populações estudadas, bem como dos modelos estatísticos e métodos utilizados para medir as concentrações de 25(OH)D.

Não há diretrizes baseadas na população brasileira acerca das concentrações séricas adequadas de vitamina D. Por conseguinte, são utilizados os valores de referência preconizados por entidades internacionais. Os valores de referência adotados pela The Endocrine Society - amplamente utilizados - estão apresentados no Quadro $3(44,61,62)$. Os valores são os mesmos para todas as faixas etárias, incluindo recém-natos, crianças e adolescentes. Contudo, poucos estudos foram conduzidos na população pediátrica para determinar se esses limites são válidos (64).

Quadro 3 - Valores de referência para a 25(OH)D sérica

\begin{tabular}{|c|c|}
\hline Status de vitamina D & Concentração sérica de 25(OH)D \\
\hline Deficiência & $<20 \mathrm{ng} / \mathrm{ml}(<50 \mathrm{nmol} / \mathrm{l})$ \\
Insuficiência & $20-29,9 \mathrm{ng} / \mathrm{ml}(50-74,9 \mathrm{nmol} / /)$ \\
Adequado & $30-100 \mathrm{ng} / \mathrm{ml}(75-250 \mathrm{nmol} / \mathrm{l})$ \\
\hline
\end{tabular}

Fonte: The Endocrine Society (44) 
O IOM propôs em 2011 um valor de corte para a suficiência em 20 ng/ml, com argumentos de que essa concentração supriria a necessidade de vitamina D de 97,5\% da população, ao passo que a concentração de $16 \mathrm{ng} / \mathrm{ml}$ cobriria as necessidades de metade da população (65). A Academia Americana de Pediatria, em agosto de 2012, apoiou a publicação do IOM.

\subsubsection{Hipovitaminose D}

A insuficiência e a deficiência de vitamina $D$ representam um problema de saúde global reemergente. Estima-se que 1 bilhão de pessoas no mundo têm hipovitaminose D (45) A prevalência, porém, depende dos valores de referência utilizados. Pesquisas americanas demonstraram que 41,6\% dos adultos apresentavam concentração de 25(OH)D abaixo de $20 \mathrm{ng} / \mathrm{mL}$ e mais de $70 \%$ possuíam concentração <32 ng/ml (62).

Presumir-se-ia, pela fisiologia da vitamina $D$, que a prevalência de sua deficiência fosse baixa em países ensolarados como o Brasil. Entretanto, encontra-se alta prevalência mesmo em zonas tropicais (66). A hipovitaminose D é um problema generalizado, presente em todas as faixas etárias dos países em desenvolvimento. Configura um dos problemas de saúde mais prevalentes da infância, ao lado de doenças infecciosas e má-nutrição. A hipovitaminose é altamente prevalente na China, Mongólia, África Sub-Saariana, Oriente Médio e América Latina, sobretudo em crianças, idosos e mulheres. Na China e Mongólia, a hipovitaminose atinge mais de $50 \%$ das crianças (49).

No Brasil, um estudo com 136 adolescentes - habitantes da zona rural de São Paulo (latitude 23오 S) - encontrou insuficiência em vitamina D em 60\% dos indivíduos. O autor do estudo sugere que isso ocorreu predominantemente em razão da baixa ingestão de vitamina $D$ nesse grupo. Tal achado é preocupante, uma vez que a adolescência representa fase crítica para formação da massa óssea. O mesmo trabalho encontrou que apenas $14 \%$ dos adolescentes consomem a necessidade diária de vitamina $D$ e propõe ações futuras para implementar políticas de fortificação de alimentos (66). 
Ainda no Brasil, a avaliação de 73 jovens médicos residentes em um Hospital Geral de Porto Alegre mostrou que 57\% apresentavam concentrações séricas de 25(OH)D abaixo de 20ng/ml (67). Em uma coorte de 102 idosos saudáveis com idade média de 77 anos no sul do Brasil, 86\% apresentaram a 25(OH)D abaixo desse valor (68).

Explicam essa carência vitamínica, em grande parte, as mudanças de estilo de vida ocorridas nas últimas décadas. Os principais fatores de risco estão listados no Quadro 4. Considera-se que a principal causa da deficiência de vitamina D é a exposição inadequada à luz solar. A exposição reduzida ao sol deve-se ao trabalho em ambientes fechados, à utilização de roupas protetoras e à popularidade crescente dos protetores solares (69). O uso de um protetor solar com fator de proteção solar 30 reduz a síntese de vitamina $D$ na pele em mais de 95\%. A melanina atua como um protetor solar natural e reduz a produção de vitamina $D$ na pele humana. Por isso, indivíduos de pele mais pigmentada necessitam de um tempo de exposição três a cinco vezes maior para produzir a mesma quantidade de vitamina $D$ em comparação a uma pessoa com pele branca $(44,49)$. O consumo insuficiente de alimentos ricos em vitamina $D$ e seus precursores é um fator agravante (42). Há grupos que apresentam maior risco de não-suficiência em vitamina $D$, incluindo as mulheres, neonatos, afroamericanos e indivíduos com índice de massa corporal (IMC) aumentado (43,70). As crianças dependem da exposição à luz solar ou da ingesta de vitamina $\mathrm{D}$ para atender suas necessidades a partir do nascimento. Porém, tanto o leite materno quanto o leite de vaca não fortificado têm muito pouca vitamina D (cerca de 8 a $20 \mathrm{UI} / \mathrm{L}$ ) e as reservas do nascituro recebidas intra-útero esgotam-se rapidamente $(44,71)$.

Quadro 4 - Fatores de risco para deficiência / insuficiência de vitamina D

\footnotetext{
Ausência de exposição solar

Pigmentação da pele

Tipos de vestimentas (véus, lenços, etc.)

Uso de protetor solar

Obesidade

Neonatos, pré-escolares, idosos

Indivíduos institucionalizados

Gestações múltiplas com pequeno intervalo

continua
} 
continuação

Quadro 4 - Fatores de risco para deficiência / insuficiência de vitamina D

Doenças hepáticas

Má-absorção, intestino curto

Drogas (por exemplo, rifampicina, glicocorticoides, anticonvulsivantes)

Baixo nível socioeconômico

Má nutrição e deficiência proteica

Poluição atmosférica

Insuficiência hepática

Insuficiência renal crônica

Síndrome nefrótica

Adaptado de: Holick, 2007 (45); Gupta e colaboradores, 2012 (70)

Nas zonas intertropicais (entre as latitudes $23,5^{\circ} \mathrm{N}$ e $23,5^{\circ} \mathrm{S}$ ), os raios UVB são mais intensos e a síntese de vitamina $D$ é possível por todo o ano. Em zonas temperadas $\left(23,5^{\circ}-66,5^{\circ}\right)$, as pessoas carecem de UVB suficiente para síntese da vitamina $D$ por 1 mês durante $o$ ano, enquanto aquelas mais próximas aos polos não recebem radiação UVB suficiente durante a maior parte do ano (49,72,73). A síntese de vitamina $D$ sofre influência da estação do ano, ocorrendo redução sazonal no inverno (66).

Pacientes em uso de uma ampla gama de medicações, incluindo glicocorticoides, anticonvulsivantes e medicamentos para tratamento da síndrome da imunodeficiência adquirida (SIDA) são de alto risco para a hipovitaminose em decorrência do aumento do catabolismo da 25(OH)D e da 1,25(OH $)_{2} \mathrm{D}$. Pacientes com doenças granulomatosas, alguns linfomas e hiperparatireoidismo primário também são fatores de alto risco para deficiência de vitamina $D(44)$.

Campanhas de saúde pública e fortificação de alimentos com vitamina $D$ são meios eficazes e acessíveis para prevenir a deficiência dessa vitamina. Entretanto, o IOM considera que a prevalência da inadequação em vitamina $D$ tem sido superestimada e defende que são necessárias pesquisas que avaliem o efeito da suplementação da vitamina $D$ em desfechos clássicos e não-clássicos a fim de evitar problemas tanto de sub quanto de supertratamento (58). 


\subsubsection{Vitamina D e Doenças Atópicas}

A literatura vem, de modo paulatino, associando as concentrações de vitamina D a doenças neoplásicas, inflamatórias, auto-imunes, degenerativas, metabólicas e alérgicas. Nesse contexto, ensaios clínicos ainda não conseguiram demonstrar relação causal (50). À luz de dados conflitantes, um conjunto considerável de evidências sugere que a vitamina $D$ tenha uma influência importante na progressão de doenças alérgicas. Estudos epidemiológicos, realizados sobretudo na América do Norte e em países europeus, indicam que doenças atópicas são mais comuns em indivíduos com deficiência de vitamina D (74). Entretanto, as concentrações de vitamina $D$ também têm sido associados de forma positiva com a prevalência de doenças atópicas (75). Mecanismos relacionados à imunidade inata e adaptativa podem explicar o crescente corpo de evidências ligando a vitamina $D$ à asma, à DA, às alergias alimentares e à RA.

Existem argumentos epidemiológicos tanto para uma relação positiva quanto negativa entre atopias e deficiência de vitamina $D$, assim como há estudos que não encontram associação.

Brehm e colaboradores (2009) (76) encontraram associação de concentrações séricas baixas de vitamina $\mathrm{D}$ com marcadores aumentados de alergia e de gravidade da asma em 616 crianças asmáticas analisadas na Costa Rica. Bener e colaboradores (2012) (77), em um estudo com 483 crianças asmáticas e 483 não asmáticas, demonstraram que a deficiência de vitamina $D$ foi preditor de asma em crianças do Catar. Hollams e colaboradores (2011) (78) mostraram que a vitamina D está negativamente associada com fenótipos alérgicos em crianças de 6 ou 14 anos de idade no Reino Unido. Baixa concentração de vitamina $D$ aos 6 anos foi preditor de atopia e asma aos 14 anos. Por sua vez, Ito e colaboradores (2013) (79), consoante com Devereux e colaboradores (2010) (80), mostraram não haver diferença entre as concentrações séricas de vitamina $D$ entre pacientes asmáticos adultos e controles pareados por idade e gênero no Reino Unido. Defendendo ponto de vista diverso, Wjst \& Dold (1999) (75) propuseram que o aumento da prevalência da asma pode ser consequência do aumento do consumo de alimentos fortificados com vitamina $D$. Estudo de Gale e colaboradores (2008) (81) encontrou maior prevalência de eczema 
e asma na infância em crianças cujas mães possuíam maior concentração de 25(OH)D no fim da gestação.

As hipóteses sugeridas para explicar o efeito da vitamina D na gravidade de doenças atópicas incluem o efeito da vitamina $D$ no sistema imune, na redução da inflamação, na prevenção de infecções e na eliminação da resistência a esteroides. A vitamina $D$ inibe a proliferação de células $T$ e contribui para a conversão de células $T$ CD4+ para células T reguladoras, que suprimem mecanismos pró-alérgicos (74).

\subsection{DERMATITE ATÓPICA E VITAMINA D}

Dentre os fatores implicados na etiopatogênese da DA, destaca-se a importância crescente atribuída à deficiência de vitamina $D$ em pacientes atópicos. Além de seu papel clássico na homeostase do cálcio, estudos atuais destacam a influência da vitamina $D$ na imunomodulação e diferenciação celular. Está, ademais, associada com a produção de peptídeos antimicrobianos (PAM) pelos ceratinócitos, macrófagos e neutrófilos (12,36-38). A deficiência de vitamina D poderia, portanto, exacerbar a DA por meio do prejuízo na função de barreira epidérmica e da desregulação imunológica, com subsequente deficiência da defesa contra infecções. $(32,82)$. Estudos com número limitado de participantes têm demonstrado o papel da suplementação vitamínica no manejo da DA.

\subsubsection{Relação entre a Concentração Sérica de 25(OH)D e a Prevalência / Gravidade da DA}

Poucos estudos avaliaram a prevalência e a gravidade da DA em indivíduos deficientes em vitamina D. Oren e colaboradores (2008) (83), em um estudo casocontrole com 290 pacientes obesos, observaram aumento de 5 vezes na probabilidade de DA em sujeitos deficientes quando comparado com o grupo suficiente em vitamina $D(p<0,05)$. Não foi observada associação significativa com asma ou rinite alérgica. 
Peroni e colaboradores (2011) (12) avaliaram a relação entre vitamina D e gravidade da DA. Foram incluídas no estudo 37 crianças portadoras de DA (de 8 meses a 12 anos de idade). A concentração de 25(OH)D mostrou-se mais elevada em pacientes com DA leve quando comparada com pacientes com DA moderada ou grave $(p<0,05)$. Os autores não realizaram, porém, análise comparativa das concentrações séricas de 25(OH)D com grupo controle. El Taieb e colaboradores (2013) (84), em outro estudo caso-controle com 29 pacientes com DA (de 2 a 12 anos) e 30 controles, demonstraram que os atópicos tiveram menor concentração de 25(OH)D. As concentrações séricas de vitamina D correlacionaram-se negativamente com a gravidade clínica. Anuentemente, Wang e colaboradores (2014) (85) encontraram associação inversa entre $25(\mathrm{OH}) \mathrm{D}$ e a gravidade clínica da DA em um estudo caso-controle com 498 crianças portadoras de DA e 328 controles nãoalérgicos em Hong Kong. Pacientes com DA tiveram concentrações de 25(OH)D menores que os controles, porém os grupos não foram pareados. O grupo deficiente em vitamina $D$ teve níveis mais elevados de $\mathrm{lg} E$. Esses dados sugerem que a deficiência de vitamina $\mathrm{D}$ pode estar relacionada à gravidade da DA.

Levantamento nutricional comparando ingestão dietética de pacientes com DA ( $n=138$ ) e pacientes saudáveis de grupo controle pareados por idade e gênero demonstrou que os pacientes com DA tinham ingestão dietética de vitamina $\mathrm{D}$ inferior aos controles (2,3 versus 2,7 $\mu \mathrm{g}$ em mulheres e 4,7 versus 5,4 $\mathrm{\mu g}$ em homens). Não foi observada relação dose-resposta entre a gravidade da DA e a ingesta alimentar de vitamina D. Entretanto, as concentrações séricas de vitamina $D$ não foram mensuradas (86).

Corroboram com essa associação dietética estudos que demonstraram que crianças nascidas de mães com baixo consumo de peixe ou vitamina $D$ durante a gestação apresentam uma prevalência aumentada de DA $(87,88)$. Além disso, estudo transversal de Kuzume \& Kusu (2007) (89) mostrou uma maior prevalência de DA em crianças nascidas no outono e inverno comparado com aquelas nascidas na primavera e verão. Nestas estações há maior insolação e, por presunção, maiores concentrações maternas de vitamina $\mathrm{D}$.

O clima e a luz solar - notadamente a radiação ultravioleta (UV) - parecem influenciar a atividade da DA. Byremo e colaboradores (2006) (33) selecionaram aleatoriamente 30 crianças com DA grave de 4 a 13 anos na Noruega (clima subártico/temperado) para se instalarem por 4 semanas em uma zona tropical e 26 
crianças para permanecerem na Noruega. Observou-se redução significativa da gravidade clínica e melhora do índice de qualidade de vida no grupo índice ( $\mathrm{p}<$ 0,0005), os quais se mantiveram durante os 3 meses de seguimento. A colonização bacteriana por $S$ aureus foi reduzida nesse grupo no primeiro e terceiro mês $(p=0,001$ e $p=0,005$, respectivamente). O grupo índice reduziu o uso de corticoesteroides tópicos, mas não o grupo controle. A dosagem da 25(OH)D não foi, porém, considerada no estudo. Embora a vitamina $D$ seja potencialmente responsável por tais efeitos benéficos, deve-se ponderar que a radiação UV per se possui efeito imunossupressor, reduzindo em poucas horas a quantidade de células apresentadoras de antígenos na epiderme e, consequentemente, o processo inflamatório. Desta forma, não se pode inferir que os efeitos estejam diretamente associados ao aumento das concentrações séricas de vitamina D nos indivíduos pesquisados.

Apesar da associação positiva entre hipovitaminose $D$ e aumento da prevalência ou gravidade da DA encontrada nos estudos supracitados, há controvérsias. Diversos autores não foram capazes de reproduzir essa associação.

Ito e colaboradores (2013) (79) aplicaram o questionário ISAAC [International Study of Asthma and Allergies in Childhood (90)] em 1.115 crianças japonesas de 9 a 10 anos e realizaram a dosagem de vitamina D. A prevalência de DA na amostra foi de $14,7 \%$. Na amostra total, mais de $60 \%$ das crianças tinham deficiência ou insuficiência de vitamina $D$. Análise multivariada não mostrou associação entre status de vitamina $D$ e a prevalência de doenças alérgicas (asma, RA e DA), mesmo após ajuste para fatores de confundimento.

Samochocki e colaboradores (2013) (82) avaliaram 95 pacientes de 18 a 50 anos com DA e 58 controles pareados por idade e gênero na Polônia. Os autores não encontraram diferença estatística significativa com relação à concentração sérica de 25(OH)D entre pacientes com DA e controles $(p>0,05)$. A frequência de infecções cutâneas foi maior em pacientes com DA com menores concentrações de 25(OH)D. Não foi encontrada, também, associação significativa entre concentrações séricas de vitamina D e gravidade da doença - determinada pelo índice SCORAD e SCORAD objetivo -, duração da doença, coexistência de doenças atópicas, exacerbações sazonais, dieta, IMC e IgE.

Bäck e colaboradores (2009) (71) demonstraram que a ingesta de vitamina D aumentada durante a infância correlaciona-se com maior risco de DA aos 6 anos de 
idade. Dados pré-existentes sobre a ingesta diária de vitamina D no primeiro ano de vida foram resgatados e, por meio de um questionário via postal, foi investigada a incidência cumulativa de DA, RA ou asma aos 6 anos de vida em 123 crianças. A DA foi mais prevalente no grupo com maior ingesta de vitamina $D$, independente da história familiar de atopia. A amostra do estudo, entretanto, como destaca o próprio autor, foi pequena e mais investigações são necessárias para apoiar essa associação.

A amamentação nos primeiros 4 meses mostrou reduzir o risco de eczema da infância aos 4 anos de idade (91). A amamentação geralmente implica em baixa ingesta de vitamina $D$, enquanto a reposição com fórmulas infantis e bebidas lácteas de cereal, fortificadas com vitamina $D$, fornece uma ingesta consideravelmente maior (71). Corroborando essa associação, Milner e colaboradores (2004) (92) avaliaram mais de 8.000 pacientes e demonstraram que a suplementação multivitamínica infantil precoce (nos primeiros 6 meses de vida) era associada com maior risco de asma e de alergias alimentares. Uma grande coorte na Finlândia mostrou que a suplementação de vitamina $D$ durante o primeiro ano de vida foi associado com maior prevalência de atopia aos 31 anos de idade (93).

Entretanto, dados sobre aporte dietético de vitamina $D$ e aumento da prevalência de DA devem ser avaliados com cautela, especialmente no que tange 0 primeiro ano de vida, época em que há maior permeabilidade intestinal. A essa maior permeabilidade atribui-se o aumento da sensibilização alimentar e maior incidência de atopias em crianças expostas a alimentos que não o leite materno. Haveria, então, relação significativa entre elevação da prevalência de DA em crianças que recebem maior aporte dietético de vitamina $D$ na tenra idade e as concentrações séricas de tal secosteroide? Ou seria isso uma consequência da exposição precoce a diversos antígenos associada a maior permeabilidade intestinal, sabidamente predisponente a atopias?

O perfil materno de vitamina $D$ durante a gestação também se mostrou importante. Crianças cujas mães possuíam maiores concentrações séricas de 25(OH)D apresentaram maior risco de eczema aos 9 meses e asma aos 9 anos de idade (81).

Chiu e colaboradores (2013) (94) avaliaram 94 crianças de 1 a 16 anos residentes na área urbana de Milwaukee, EUA. Não foi encontrada correlação estatística significante entre o status de vitamina $D$ e a gravidade da DA. Curiosamente, as crianças com DA leve tiveram concentrações de 25(OH)D menores 
que os grupos com DA moderada e grave, embora essa diferença não tenha sido estatisticamente significativa.

Hata e colaboradores (2013) (95) realizaram estudo multicêntrico controlado duplo-cego em 30 sujeitos com DA, 30 sujeitos não atópicos e 16 sujeitos com psoríase. Não houve diferença significante na 25(OH)D sérica entre indivíduos com DA, psoríase e controles não atópicos. Baixa concentração sérica de $25(\mathrm{OH}) \mathrm{D}$ correlacionou-se apenas com fototipo de Fitzpatrick e IMC elevado. Porém, não houve uniformidade na distribuição do local de residência dos participantes, que foram recrutados em 3 cidades diferentes, o que acarreta diferentes condições ambientais.

Pelas considerações acima, podemos observar que o assunto é controverso. Por vezes a vitamina $D$ é considerada fator de proteção, por vezes fator de risco para a DA. Estudos recentes demonstraram que a $25(\mathrm{OH}) \mathrm{D}$ pode estar associada à gravidade clínica DA apenas em um grupo específico de pacientes.

Akan e colaboradores (2013) (74) avaliaram a associação entre 25(OH)D e gravidade clínica da DA em 73 crianças. Todos os indivíduos realizaram prick test e dosagem de lgE específica (contra alérgenos alimentares ou aeroalérgenos). Apresentaram positividade em pelo menos um desses exames 33 indivíduos (45,2\%). Apenas nesse grupo houve correlação negativa significativa entre a gravidade clínica e 25(OH)D ( $p=0,047)$, o que não se repetiu no grupo sem sensibilização $(p=0,30)$. $O$ autor postula que a vitamina $D$ pode ter efeito imunomodulador diverso nos diferentes perfis inflamatórios da DA - com ou sem sensibilização alérgica.

Lee e colaboradores (2013) (96) avaliaram 157 pacientes com DA. Não se encontrou correlação significativa entre concentrações séricas de 25(OH)D e gravidade da DA. Entretanto, entre os 36 pacientes com sensibilização alimentar definida por meio de lgE sérica específica -, as concentrações séricas de 25(OH)D foram significativamente maiores no grupo com DA leve comparado com DA moderado ou grave. Os dados indicam, portanto, um potencial papel para a vitamina D nesse grupo específico de pacientes.

Mullins e colaboradores (2011) (97) levantaram a hipótese de que a exposição à luz UV e o status de vitamina $D$ podem ser parte dos múltiplos fatores contribuintes para alergias alimentares na infância. Vários relatos sugerem que a falta de vitamina D prejudica a integridade da barreira epitelial levando ao aumento e inadequada exposição da mucosa aos antígenos alimentares. Assim, a deficiência de vitamina D promoveria um desequilíbrio imunológico pró-sensibilização que comprometeria a 
tolerância imunológica. A correção precoce da deficiência de vitamina $D$, segundo os autores, poderia promover a defesa da mucosa, manter uma barreira microbiana saudável e a tolerância a alérgenos alimentares em crianças.

Embora estudos apontem para o papel primordial do PTH como sinalizador precoce da deficiência de vitamina $D$, bem como evidências recentes sugiram papel importante da vitamina $D$ para o desenvolvimento ou agravamento da DA, não foram encontrados, até o momento, estudos que correlacionem as concentrações séricas de 25(OH)D e de PTH nas populações atópicas avaliadas.

\subsubsection{Plausibilidade Biológica: Associação entre Vitamina D e Dermatite Atópica}

Dado o fato de que a patogênese da DA envolve tanto disfunção de barreira epidérmica quanto disfunção imunológica, é possível que a vitamina $D$ possa ter um papel protetor contra a DA e o desenvolvimento de uma variedade de doenças cutâneas.

A expressão do RVD na pele foi confirmada após injeção de $1,25(\mathrm{OH})_{2} \mathrm{D}$ radiomarcada em ratos. Demonstrou-se concentração de radioatividade nos núcleos das células epidérmicas e em uma variedade de tecidos (98). A 1,25(OH) $2 \mathrm{D}$ induz a diferenciação dos ceratinócitos, além de outros efeitos concentração-dependentes, estimulatórios ou supressivos, no crescimento dessas células (99).

Não apenas a 25(OH)D tem sido investigada, como também o polimorfismo do RVD. Heine e colaboradores (2013) (100) mostraram que, em pacientes com DA grave, polimorfismos no gene do RVD são significativamente super-representados. Os autores investigaram a frequência de 4 polimorfismos comuns desse gene em pacientes com DA e encontraram haplótipos do RVD mais frequentemente em pacientes com DA grave, o que sugere que o RVD contribui para o controle da DA e pode exercer efeitos na regulação da função da barreira epidérmica e/ou da resposta imune local. O RVD pode reduzir a expressão de citocinas pró-inflamatórias, como a IL-6 e o fator de necrose tumoral a (TNF- $\alpha$ ) em células imunes e ceratinócitos, bem como inibir a maturação de células dendríticas. Variações no gene do RVD podem resultar na responsividade alterada à vitamina $D$ em condições inflamatórias. $O$ haplótipo identificado foi previamente associado com asma em coortes 
independentes. Uma vez que o haplótipo também ocorre com alta frequência em indivíduos saudáveis não-atópicos, o seu significado para suportar um fenótipo de DA grave deve ser considerado mais como um cofator, que requer um ou mais fatores ambientais e/ou genéticos adicionais.

Há várias explicações biologicamente plausíveis para a relação inversa entre as concentrações séricas de vitamina $D$ e a presença da DA, em particular com a gravidade da doença. Contudo, as evidências nessa área são, de modo geral, escassas e de baixa qualidade.

\subsubsection{Vitamina D: Regulação Imune e Atividade Antibacteriana}

A vitamina $D$ está envolvida em importantes mecanismos de regulação do sistema imune inato e adaptativo (12), atuando como um modulador do sistema imunológico. Várias linhas de evidência demonstram seus efeitos sobre citocinas próinflamatórias, células T reguladoras e respostas imunes (101). Quase todas as células exibem o RVD, incluindo os linfócitos $B$ e $T$, monócitos e células dendríticas. A vitamina $D$ favorece o fenótipo de células mononucleares - aumentando a expressão de RVD em monócitos e macrófagos -, promove aumento no potencial de "explosão oxidativa" dos macrófagos e impede a expressão excessiva de citocinas inflamatórias. Facilita a motilidade dos neutrófilos e a função fagocitária. Pode, também, reduzir respostas inflamatórias locais e sistêmicas, como resultado de modulação de citocinas e redução da ativação dos receptores Toll-símile. Além disso, inibe a proliferação de células Th1 (prejudicando a produção de IL-2, TNF- $\alpha$ e interferon) e de células Th17, desviando a produção de citocinas para um padrão Th2 (8,102-104). As complexas ações da vitamina $D$ no sistema imunológico estão simplificadamente esquematizadas na Figura 6. 


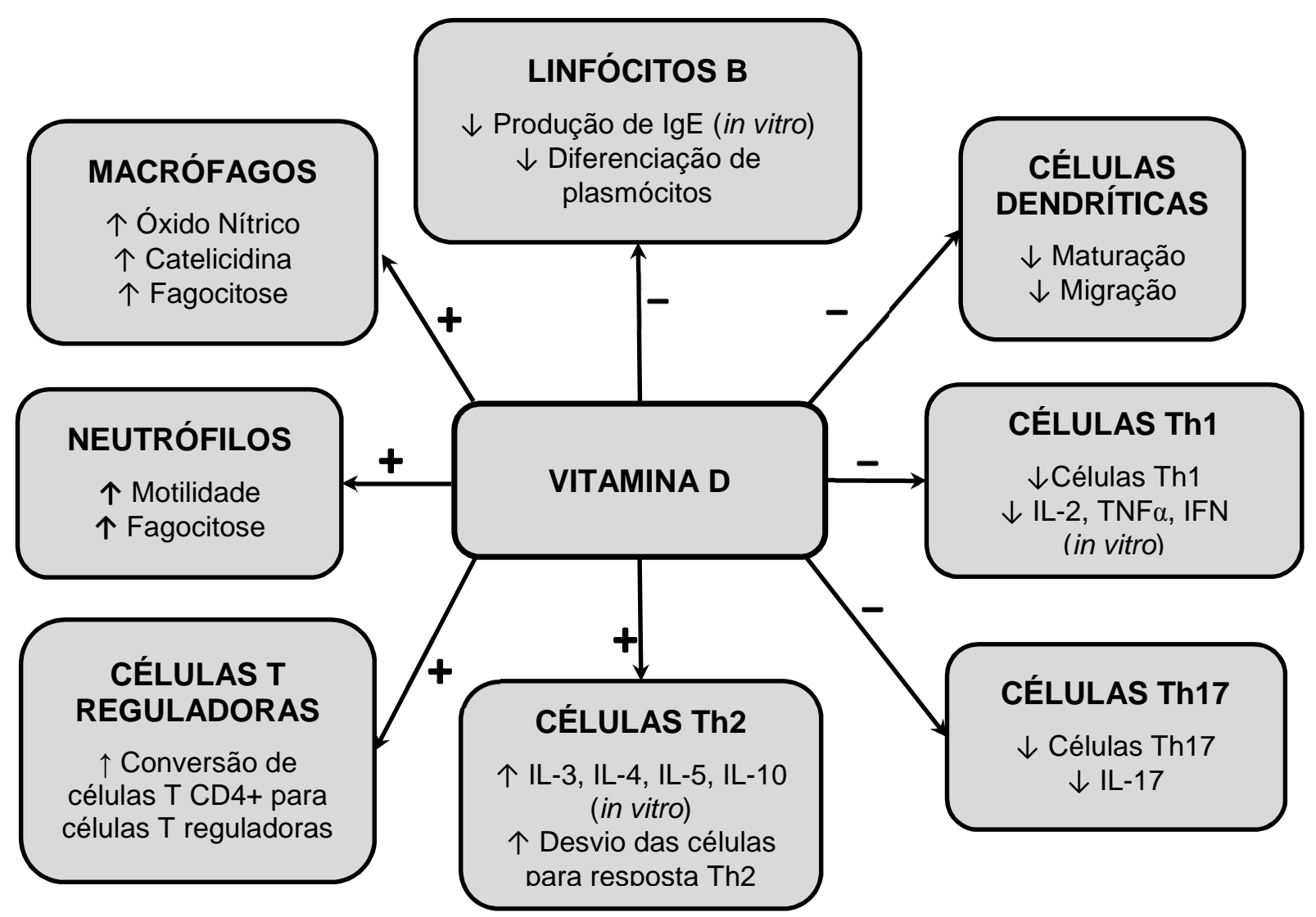

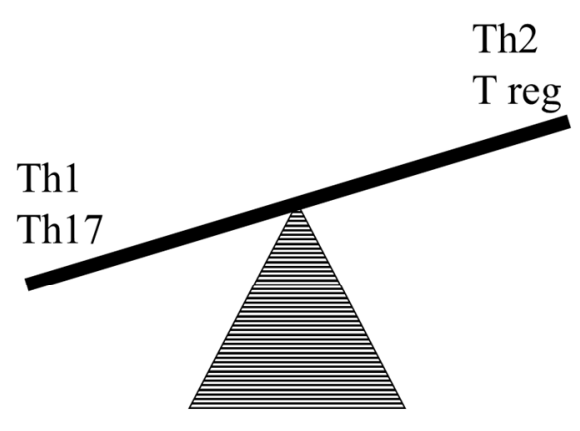

Suficiência em vitamina $D$
Th1

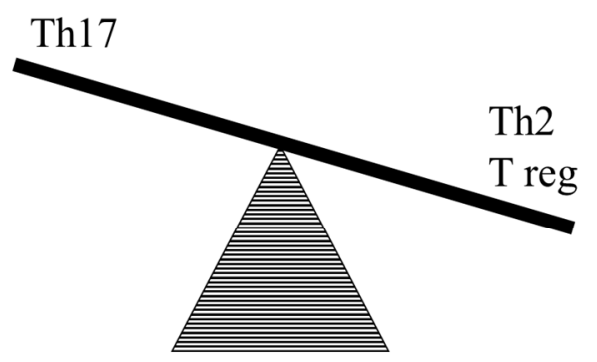

Deficiência em vitamina D

Figura 6- Ações da vitamina D no sistema imunológico. Adaptado de Benson e colaboradores, 2012 (50); Hewison, 2012 (103) e Norval, 2011 (104)

Evidências sugerem que a vitamina $D$ reduz a resposta inflamatória nos ceratinócitos. O efeito sobre as citocinas, juntamente com os efeitos inibidores sobre a maturação das células dendríticas, promovem propriedades tolerogênicas e aumentam o número de células $T$ reguladoras e supressoras, cruciais no controle de respostas alérgicas (101). 
Na contramão, Chi e colaboradores (2011) (105) avaliaram a influência do status de vitamina D pré-natal na função imune ao nascimento. Eles encontraram uma maior concentração plasmática de $25(\mathrm{OH}) \mathrm{D}$ no cordão umbilical associada com menor número de células $T$ reguladoras, sugerindo que a vitamina $\mathrm{D}$ in utero pode influenciar a regulação imunológica no início da vida.

A vitamina $D$ afeta a produção dos PAM, os quais têm amplo espectro de ação contra bactérias, fungos e vírus, exercendo função de regulação imune da pele e outras superfícies epiteliais $(50,52,96)$. Eles são diretamente bactericidas, capazes de neutralizar componentes bacterianos e de ativar o sistema imune adaptativo (106). Em estudos in vitro, a 1,25(OH $)_{2} \mathrm{D}$ induz a expressão de catelicidina - um PAM de amplo espectro - nos ceratinócitos, resultando no aumento da atividade antimicrobiana contra $S$. aureus e na redução seletiva da expressão de antígenos associados a linfócitos cutâneos (107). Quando monócitos e macrófagos são estimulados por um agente infeccioso, há aumento da expressão do RVD e da 1 $\alpha$-hidroxilase, aumentando a conversão de $25(\mathrm{OH}) \mathrm{D}$ em 1,25(OH) $2 \mathrm{D}$ e, por conseguinte, elevando a expressão de catelicidina (49). Matheson e colaboradores (2010) (108) demonstraram que indivíduos com deficiência de vitamina $D$ tinham um aumento significativo do risco de carrear $S$. aureus meticilina-resistente (MRSA). Ainda não se sabe, porém, se a suplementação de vitamina D pode reduzir a colonização por MRSA. Muehleisen e colaboradores (2012) (109) demonstraram que a $1,25(\mathrm{OH})_{2} \mathrm{D}$ age juntamente com 0 PTH ou com a proteína relacionada ao PTH (PTHrP) para sinergicamente aumentarem a expressão de catelicidina e a defesa imune.

Indivíduos com DA têm um defeito relativo na imunidade inata. Expressam alguns PAM [catelicidina, defensinas humanas $\beta 2(\mathrm{DH} \beta-2)$ e $\beta 3(\mathrm{DH} \beta-3)$ em menor quantidade que o esperado. A ausência de aumento dos PAM em resposta à inflamação cutânea na DA pode ser parcialmente devida aos efeitos supressivos das citocinas Th2 na capacidade de os ceratinócitos expressarem $\mathrm{DH} \beta-2, \mathrm{DH} \beta-3$ e filagrina (95).

Büchau e colaboradores (2009) (110) mostraram que a baixa expressão de PAM observada em amostras de pele lesionadas de DA está relacionada com a superexpressão do gene linfoma de células $B(B c l)-3$. Biópsias de pele lesionadas apresentaram mais RNA mensageiro Bcl-3 do que biópsias de pele não lesionadas. Após suplementação de vitamina $D$, houve menor expressão de Bcl-3 ( $p=0,077)$. 
Fototerapia com UVB tem sido utilizada por vários anos com sucesso no tratamento da DA (38). Estudos recentes sugerem que a vitamina $D$ induzida pelo UVB seja um possível mediador da melhora dos sintomas e da gravidade da doença. Pacientes com DA submetidos à fototerapia com UVB banda estreita possuem maiores níveis de PAM em biópsias cutâneas que grupo controle (111).

\subsubsection{Vitamina D e a Função de Barreira da Pele}

A $1,25(\mathrm{OH})_{2} \mathrm{D}$ é conhecida por modular - estimular ou inibir - a proliferação e diferenciação de ceratinócitos, dependendo da sua concentração $(5,99)$. Estudos relacionados à psoríase indicam que o tratamento tópico com calcipotriol, análogo da $1,25(\mathrm{OH})_{2} \mathrm{D}$, aumenta a expressão do RVD nos ceratinócitos. Reichrath e colaboradores (1997) (112) demonstraram que efeitos do calcipotriol na proliferação e diferenciação epidérmica dos ceratinócitos foram mais pronunciados que os efeitos na inflamação dérmica.

Em experimentos com ratos, Hong e colaboradores (2008) (113) observaram recuperação mais rápida da barreira cutânea no grupo submetido à fototerapia UVB banda larga, observando maiores níveis histológicos de filagrina e involucrina nesse grupo. A vitamina D induzida pela fototerapia foi considerada responsável pela aceleração na recuperação da barreira epidérmica. No grupo de ratos tratados com cetoconazol, um potente inibidor da síntese da vitamina $D$, foi observada menor expressão do receptor da vitamina $D$ e da 1 $\alpha$-hidroxilase, assim como um tempo de recuperação da barreira epidérmica mais prolongado e aumento da perda transepidérmica de água quando comparado com o grupo controle.

Os ceratinócitos expressam altos níveis de 1a-hidroxilase. Nos ratos que não possuem essa enzima e, por conseguinte, a $1,25(\mathrm{OH})_{2} \mathrm{D}$, há redução da involucrina, filagrina e loricrina - marcadores da diferenciação dos ceratinócitos -, essenciais para a formação do envelope córneo. Ratos que são defeituosos no RVD têm um aumento da perda transepidérmica de água mediante ruptura da barreira epidérmica. A $1,25(\mathrm{OH})_{2} \mathrm{D}$ mostra-se essencial para a diferenciação epidérmica normal, provavelmente pela indução de proteínas e mediação da sinalização do cálcio na epiderme necessárias para gerar e manter a barreira cutânea (114). 
Russell (2012) (43) avaliou a associação entre concentrações séricas de 25(OH)D e a condutância do estrato córneo em 83 pacientes femininas de 18 a 45 anos, assim como o efeito da aplicação tópica da vitamina D na pele seca. Encontrou concentrações mais baixas de vitamina $\mathrm{D}$ nos pacientes com menor teor de hidratação da pele $(p=0,02)$. Nos pacientes com vitamina $D$ insuficiente ou deficiente, suplementação de colecalciferol tópico $\left(10 \mu \mathrm{g} / \mathrm{g}\right.$ de vitamina $D_{3}$ em emulsão O/A aplicada 2 vezes ao dia, contendo glicerina, petrolatum e dimeticona) aumentou significantemente as medidas de hidratação cutânea e resultou em melhoria na classificação clínica subjetiva da xerose cutânea quando comparados ao grupo controle em que veículo idêntico, porém sem adição de vitamina $D$, foi utilizado na mesma posologia.

Observações de que os inibidores tópicos da calcineurina podem corrigir parcialmente o defeito de barreira na DA e que a gentamicina pode restaurar a produção de cadeias de filagrina fornecem evidências de uma complexa relação entre a barreira epidérmica e o sistema imune (115).

\subsubsection{Papel Terapêutico da Suplementação de Vitamina D na DA}

Confirmando dados de estudos observacionais, estudos clínicos recentes sugerem um papel terapêutico para a suplementação de vitamina $D$ no tratamento da DA. Sidbury e colaboradores (2008) (116) realizaram um estudo duplo-cego no qual 11 crianças com idade de 2 a 13 anos foram randomizadas a utilizar vitamina D (1.000 UI/dia) ou placebo durante um mês. Quatro das cinco crianças que tomaram vitamina D apresentaram melhora, enquanto apenas uma das seis crianças do grupo controle apresentou melhora $(p=0,04)$. O número muito pequeno de participantes enfraquece a representatividade do estudo.

Amestejani e colaboradores (2012) (8) publicaram estudo clínico randomizado, duplo-cego, placebo-controlado, em que 30 pacientes receberam $1.600 \mathrm{UI} / \mathrm{dia}$ de vitamina $D$ e 30 pacientes receberam placebo. Após 60 dias, o grupo que recebeu vitamina $D$ mostrou melhora significativa da doença, independentemente da gravidade inicial da DA $(p<0,05)$. No grupo placebo, a melhora não foi significativa $(p>0,05)$. 
Os resultados do estudo sugerem que a suplementação de vitamina $D$ tem efeito terapêutico na DA.

Outro estudo avaliou os efeitos da suplementação da vitamina D e E nas manifestações clínicas da DA. Quarenta e cinco pacientes com DA foram incluídos em um estudo randomizado, duplo-cego, placebo-controlado. A melhora clínica foi avaliada por meio do SCORAD, que apresentou redução significativa após 60 dias nos grupos que utilizaram apenas vitamina D, apenas vitamina $E$, e ambas as vitaminas $(p=0,004)(117)$.

Outros estudos examinaram o efeito da vitamina D na gravidade da DA utilizando helioterapia. Vähävihu e colaboradores (2008) (118) avaliaram 23 pacientes com DA de países nórdicos antes e depois de 2 semanas de banhos de sol ao ar livre. Houve redução do número de pacientes com deficiência de vitamina $D$ e redução do SCORAD. Um estudo posterior realizado pelos mesmos autores demonstrou resultado semelhante após 15 sessões de UVB banda estreita (111).

Observou-se aumento significativo dos níveis da catelicidina em lesões de pele de 14 pacientes com DA moderada a grave após tratamento com $4.000 \mathrm{UI}$ de vitamina D oral por 21 dias. A média passou de 3,53 unidades de cópia relativa (UCR) para 23,91 UCR após a suplementação $(p<0,01)$. A pele dos pacientes sem DA e a pele sã dos pacientes com DA também mostraram aumento da catelicidina, porém não significativos. Esses resultados sugerem que a suplementação oral de vitamina D induz significantemente a produção de catelicidina na pele lesionada do paciente com DA (119)

De modo geral, estudos que tentaram avaliar o efeito do tratamento com vitamina $D$ nas doenças alérgicas da pele avaliaram amostras pequenas e as evidências ainda são pouco consistentes.

\subsection{RADIAÇÃO ULTRAVIOLETA: CONSIDERAÇÕES GERAIS}

Quando a luz solar passa pela atmosfera, todo a radiação ultravioleta C (UVC) (100-280nm) e aproximadamente 90\% da radiação UVB (280-315nm) são absorvidos pelo ozônio, vapor de água, oxigênio e dióxido de carbono. A radiação UVA (315- 
400nm) é menos afetada pela atmosfera (120). Reconhece-se que a exposição à radiação UV tem efeitos tanto benéficos quanto maléficos à saúde humana.

A radiação UV é utilizada para tratar diversas doenças cutâneas, como psoríase, vitiligo, DA e esclerodermia localizada, as quais podem ser abordadas com radiação solar (helioterapia) ou radiação UV artificial (fototerapia) (121). Apesar de sua longa história na medicina, a capacidade de raios UV aturarem como agentes imunossupressores e anti-inflamatórios tem sido reconhecida há relativamente pouco tempo. Os efeitos UV no sistema imune são tão complexos e múltiplos que um modo de ação preciso não pode ainda ser definido com exatidão (122).

$A$ radiação solar UV pode suprimir a imunidade para antígenos apresentados dentro de um curto período após a exposição. Há diferenças entre UVA (que requer administração de psoralenos como fotossensibilizantes) e UVB, o qual provoca efeitos fototóxicos diretamente no DNA $(122,123)$.

A radiação UV interfere em uma ampla gama de mediadores imunes e acarreta redução na produção de citocinas Th1, inibição das células dendríticas acarretando apresentação de antígenos menos efetiva, indução de células $\mathrm{T}$ reguladoras, produção de IL-4 pelas células natural killer, apoptose de linfócitos T, ação inibitória sobre a resposta de células $\mathrm{T}$ primárias e de memória, migração das células de Langerhans para linfonodos ou sua apoptose, dentre outros. O resultado final é a imunossupressão local e sistêmica dentro de poucos dias após a exposição UV $(104,121,122)$.

Entrementes, diversos efeitos nocivos à saúde podem ser causados pelo excesso de exposição à radiação UV, tais como queimaduras, fotodermatoses, fotoenvelhecimento, depressão imunológica, redução da eficácia de vacinas [poliovirus, bacilo de Calmette-Guérin, sarampo e hepatite B], catarata e câncer de pele $(104,124)$. Quantidades pequenas de radiação UV, entretanto, são benéficas e essenciais para a produção de vitamina $\mathrm{D}$. Os riscos e benefícios devem ser avaliados individualmente (120) e a indicação terapêutica nas diversas doenças passíveis de aplicação fica limitada pelos efeitos adversos oriundos da exposição aguda ou crônica à radiação UV.

Devido à crescente incidência dos casos de câncer de pele, campanhas públicas objetivando alertar a população dos riscos da exposição solar desprotegida estão cada vez mais presentes, com objetivo de mudar atitudes e comportamentos e reduzir os casos de malignidades dermatológicas. Em dezembro de 2003, a Divisão 
de Satélites e Sistemas Ambientais (DSA) do Centro de Previsão de Tempo e Estudos Climáticos / Instituto Nacional de Pesquisas Espaciais (CPTEC / INPE) lançou o portal http://satelite.cptec.inpe.br/uv contendo informações relevantes sobre o tema, acompanhadas das previsões diárias do IUV (Figura 7) (125). De acordo com o nível do IUV, há recomendações específicas padronizadas pela Organização Mundial da Saúde (OMS) direcionadas à proteção da luz solar (120). O IUV máximo expressa a quantidade de radiação UV que incide sobre a superfície e que tem impacto na saúde humana. Este índice é referente ao meio dia solar, aproximadamente meio dia local, sem as condições de nebulosidade.

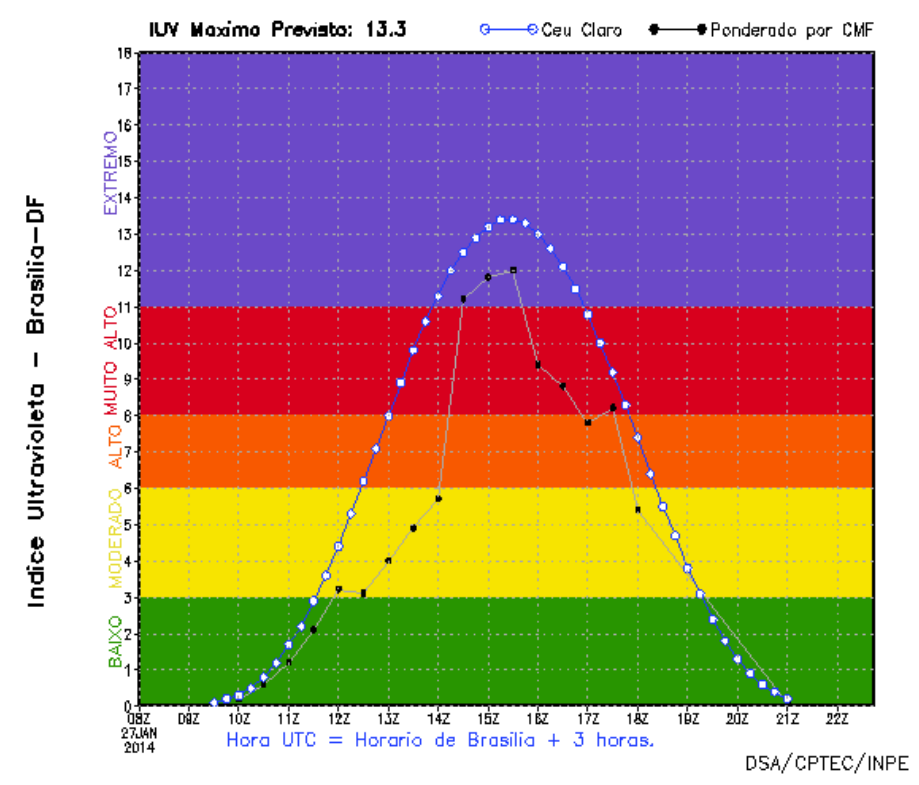

Figura 7 - Exemplo de curva representando os níveis de IUV no decorrer de um dia ensolarado

A DA é frequentemente associada com fatores climáticos e diversos trabalhos demonstram melhora clínica após exposição solar. A fototerapia - sobretudo a UVB banda estreita (310-315nm) - representa opção valiosa para o tratamento da DA moderada a grave (121). Alguns trabalhos atribuem parte do benefício terapêutico ao aumento das concentrações séricas de vitamina $\mathrm{D}$ em virtude da exposição cutânea ao UVB. 
Os benefícios terapêuticos da exposição ao UV, seja natural ou artificial, no manejo da DA são amplamente relatados e é um tema pacificado entre os especialistas. Já a associação entre prevalência/gravidade clínica da DA com IUV é um tema recente - o IUV foi desenvolvido apenas em 1992 - e há poucos estudos publicados. A maioria dos estudos correlacionam a exposição à luz solar às doenças atópicas sem considerar o IUV. Kemp e colaboradores (2013) (126), por exemplo, observaram que maior exposição solar associa-se com a redução do risco de eczema e rinite, independente das concentrações de vitamina D. Silverberg e colaboradores (2013) (15), por sua vez, consideraram o IUV e demonstraram menor prevalência de DA em estados americanos com maior índice, porém as concentrações séricas de 25(OH)D e o SCORAD não foram mensurados. Dentre os estudos publicados que investigaram a associação entre DA e vitamina $D$, não foram encontradas investigações que tenham apreciado o IUV como variável independente. 


\section{OBJETIVOS}

\subsection{OBJETIVOS PRIMÁRIOS}

Comparar a concentração sérica e o status de $25(\mathrm{OH}) \mathrm{D}$ em pacientes de 0 a 18 anos com DA e em grupo controle pareado.

Avaliar a adequabilidade dos valores de referência de $25(\mathrm{OH}) \mathrm{D}$ por meio de sua correlação com a concentração sérica de PTH.

Avaliar a associação das variáveis $25(\mathrm{OH}) \mathrm{D}$, PTH e IUV com a gravidade clínica da DA.

Identificar, por meio de análise multivariada, preditores independentes das concentrações séricas de $25(\mathrm{OH}) \mathrm{D}$ e da gravidade clínica da DA.

\subsection{OBJETIVOS SECUNDÁRIOS}

Avaliar a associação das variáveis $25(\mathrm{OH})$ D e SCORAD em grupo de pacientes com DA e IgE total elevada.

Avaliar a influência das variáveis idade, gênero, fototipo, renda familiar, estado nutricional, atopia pessoal concomitante (asma ou RA), atopia familiar, idade de início dos sintomas da DA, IUV, IgE total e eosinofilia relativa sobre as categorias de gravidade clínica da DA mensuradas pelo SCORAD.

Avaliar a influência das variáveis idade, gênero, fototipo, renda familiar, estado nutricional, asma ou RA concomitante, atopia familiar, SCORAD, IUV, estação climática, IgE e eosinófilos sobre as concentrações séricas de 25(OH)D.

Avaliar a prevalência de DA extrínseca e DA intrínseca, assim como diferenças clínicas e epidemiológicas dessas variantes de DA.

Avaliar a influência da concomitância de doenças atópicas na gravidade clínica e no perfil laboratorial dos pacientes com DA. 


\section{MÉTODOS}

\subsection{CONSIDERAÇÕES ÉTICAS}

O estudo está de acordo com a resolução CNS/MS № 196/96 sobre pesquisa em seres humanos, assim como com a declaração de Helsinki de 1975, revisada em 2008. Foi aprovado pelo Comitê de Ética em Pesquisa da Faculdade de Medicina da Universidade de Brasília (número do parecer: 293.564) (ANEXO A). Foi garantida a confidencialidade dos participantes e toda a obtenção de dados foi realizada por profissional médico cujas atividades são regidas pelo Código de Ética Médica, o qual garante sigilo profissional regulamentado pelo Conselho Federal de Medicina.

\subsection{LOCAL DO ESTUDO}

O estudo foi realizado no ambulatório de dermatologia pediátrica do Hospital Universitário de Brasília (HUB) - Brasília (DF). O ambulatório de dermatologia pediátrica do HUB é destinado ao atendimento de pacientes situados na faixa etária de 0 a 19 anos. $O$ acesso majoritário a esse serviço ocorre via encaminhamento pelas unidades básicas de saúde ou por outros hospitais da rede pública do DF. Em virtude de se tratar de serviço terciário de atenção à saúde, casos complexos ou de difícil manejo são igualmente encaminhados a esse ambulatório.

\subsection{POPULAÇÃO ESTUDADA}

A população-alvo deste estudo foi constituída por pacientes situados na faixa etária de 0 aos 18 anos portadores de DA (grupo de casos) ou outras dermatoses (grupo controle) que procuraram o serviço de dermatologia pediátrica do HUB ou 
foram encaminhados para tal serviço no período de novembro de 2012 a outubro de 2013.

\subsubsection{Grupo de Casos (Indivíduos com DA)}

\subsubsection{Critérios de Inclusão}

Apenas foram incluídos na pesquisa pacientes de 0 a 18 anos cujo diagnóstico de DA pôde ser confirmado pelos critérios de Hanifin \& Rajka (1980) (19) (Quadro 1). O uso de medicamentos utilizados rotineiramente no tratamento da DA foi permitido (emolientes, corticoesteroides tópicos e anti-histamínicos orais), salvo os citados nos critérios de exclusão. Somente pacientes cujos pais ou responsáveis foram concordantes com a participação dos mesmos foram incluídos no estudo, após o devido preenchimento do termo de consentimento livre e esclarecido (TCLE) (APÊNDICE A).

\subsubsection{Critérios de Exclusão}

Foram excluídos do estudo pacientes que se encontraram em quaisquer das seguintes condições:

- SCORAD zero;

- Hepatopatias;

- Suplementação vitamínica regular nos últimos 6 meses;

- Uso de inibidores tópicos da calcineurina ou corticoesteroides orais nas 4 semanas prévias;

- Tratamento com fototerapia;

- Inflamação sistêmica concomitante;

- Doenças sistêmicas;

- Uso de anticonvulsivantes, anticoagulantes ou antifúngicos; 
- Dermatoses ou terapêuticas que levassem à reduzida exposição solar;

- Síndrome de Hiper lgE;

- Gestação;

\subsubsection{Grupo Controle}

\subsubsection{Critérios de Inclusão}

Foram incluídos no grupo controle pacientes de 0 a 18 anos atendidos no ambulatório de dermatologia pediátrica do HUB sob livre demanda. Os pacientes foram selecionados de acordo com características de gênero, idade, estado nutricional e fototipo, com vistas a pareamento com pelo menos 50 pacientes do grupo de portadores de DA. Foram obrigatórios a concordância na participação da pesquisa e o preenchimento do TCLE pelos pais ou responsáveis.

Para que um participante fosse selecionado para o grupo controle, o mesmo deveria se enquadrar nos seguintes critérios: gênero similar ao do caso, idade do caso \pm 2 anos, IMC do caso $\pm 2 \mathrm{~kg} / \mathrm{m}^{2}$ e fototipo do caso \pm 1 . Realizado o pareamento, o caso com DA não era mais utilizado para seleção dos controles.

\subsubsection{Critérios de Exclusão}

Foram excluídos do grupo controle pacientes que se enquadravam nas mesmas condições dos critérios de exclusão no grupo dos casos. Adicionalmente, foram excluídos participantes com qualquer tipo de atopia pessoal, incluindo asma e RA. Indivíduos cujas queixas eram compatíveis com DA, porém sem preencher os critérios para o diagnóstico da doença, foram recusados. Portadores de psoríase e rosácea também foram excluídos, em razão de evidências recentes da associação dessas doenças com concentrações reduzidas de vitamina $D(127,128)$. 


\subsection{TAMANHO AMOSTRAL}

Para calcular o tamanho da amostra a ser estudada, consideramos a prevalência de hipovitaminose D estimada em 60\% (66). O tamanho da população considerada - número de pacientes portadores DA atendidos no ambulatório de dermatologia pediátrica no período de 12 meses - foi estimada em 145 indivíduos, baseado em registros internos de agendamento. Para calcular o tamanho da amostra, foi utilizado o ambiente OpenEpi ${ }^{\circledR}$ Version 3. Para um nível de confiança de $95 \%$, a amostra pretendida foi de 105 pacientes com DA (Tabela 1).

Tabela 1 - Tamanho da amostra (n) para vários níveis de confiança

\begin{tabular}{cc}
\hline Intervalo de confiança (\%) & Tamanho da amostra \\
\hline $80 \%$ & 76 \\
$90 \%$ & 94 \\
$95 \%$ & 105 \\
$97 \%$ & 110 \\
$99 \%$ & 119 \\
$99,9 \%$ & 128 \\
$99,99 \%$ & 132 \\
\hline Tamanho da população: 145 & \\
Frequência \% hipotética do fator do resultado na população $(p): 60 \% \pm 5$ \\
Limites de confiança como \% de 100 (absoluto $\pm \%)(d): 5 \%$ \\
Efeito de desenho (para inquéritos em grupo-EDFF): 1 \\
Equação Tamanho da amostra $n=\left[\right.$ EDFF*Np(1-p)]/ [(d²/ $\left.{ }^{2}{ }_{1-\alpha / 2}{ }^{*}(\mathrm{~N}-1)+p^{*}(1-p)\right]$
\end{tabular}

\subsection{DELINEAMENTO DO ESTUDO E AFERIÇÃO DAS VARIÁVEIS}

O trabalho consistiu em estudo observacional transversal. Objetivou-se um número de participantes de 105 sujeitos, além de uma amostra de pelo menos 50 controles. Todos os participantes com DA foram submetidos à anamnese, avaliação clínica da gravidade da DA por meio dos índices SCORAD e SCORAD objetivo, prescrição médica individualizada e solicitação da dosagem da concentração sérica de $25(\mathrm{OH}) \mathrm{D}$, hormônio paratireoideo molécula intacta (PTHi), IgE, hemograma e 
exame parasitológico de fezes (EPF). Calculou-se, também, a média aritmética do IUV máximo nos 30 dias precedentes à avaliação clínica de cada paciente.

A estatura foi mensurada com uso de fita métrica com precisão de $1 \mathrm{~mm}$, ao passo que para aferição da massa corporal foi utilizada balança portátil com precisão de $0,1 \mathrm{~kg}$. O IMC foi plotado nas curvas preconizadas pelo Ministério da Saúde (MS) / OMS $(129,130)$ e categorizado conforme definido no Quadro 5. Tais curvas fazem parte da Caderneta de Saúde da Criança, instrumento de grande utilidade para acompanhar a saúde, o crescimento e o desenvolvimento da criança.

Quadro 5 - Categorização do IMC para definição do status nutricional

\begin{tabular}{|c|c|}
\hline Localização na curva IMC versus Idade & Status Nutricional \\
\hline$>+3$ escores $z$ & Obesidade \\
$\leq+3$ e $>+2$ escores $z$ & Sobrepeso \\
$\leq+2$ e $>+1$ escores $z$ & Risco de sobrepeso \\
$\leq+1$ e $\geq-2$ escores $z$ & IMC adequado \\
$<-2$ e $\geq-3$ escores $z$ & Magreza \\
$<-3$ escores $z$ & Magreza acentuada \\
\hline
\end{tabular}

A dosagem sérica de 25(OH)D foi realizada em laboratório privado pelo método de imunoquimioluminescência - plataforma LIAISON XL (Diasorin, Sallugia, Itália) (ANEXO B). O status de 25(OH)D foi determinado de acordo com os valores de referência adotados pela The Endocrine Society: suficiente (>30 ng/ml), insuficiente (20 a $30 \mathrm{ng} / \mathrm{ml}$ ) e deficiente $(<20 \mathrm{ng} / \mathrm{ml})$.

A dosagem sérica de $\mathrm{PTHi}$ foi realizada pelo método da eletroquimioluminescência STAT Elecsys (Roche, Basileia, Suíça) (ANEXO C), sendo considerados normais valores situados na faixa entre 15 e 65 pg/ml.

A mensuração da $\lg E$ sérica total foi realizada por imunonefelometria pelo sistema BN II e BN ProSpec (Siemens, Marburgo, Alemanha) (ANEXO D). Os valores de referência considerados normais foram como se segue: neonatos: até 1,5 Ul/ml; 0 a 1 ano: até $15 \mathrm{UI} / \mathrm{ml} ; 1$ a 5 anos: até $60 \mathrm{Ul} / \mathrm{ml} ; 6$ a 9 anos: até $90 \mathrm{Ul} / \mathrm{ml} ; 10$ a 15 anos: até $480 \mathrm{UI} / \mathrm{ml}$; adultos: até $100 \mathrm{UI} / \mathrm{ml}$ (131).

O hemograma foi realizado pelo equipamento Cell-Dyn Ruby (Abbott, Illinois, EUA). Quando houve eosinofilia acima de 5\%, foi realizada confirmação com 
contagem microscópica manual, cujo resultado prevalecia sobre o automático. O EPF foi realizado pelo método da sedimentação espontânea, também denominado método de Hoffmann.

A mensuração da 25(OH)D foi realizada gratuitamente pelo laboratório privado Sabin, o qual possui inúmeros postos de atendimento no Distrito Federal e Goiás, além de outros Estados. O laboratório reúne certificações segundo o Programa de Acreditação para Laboratórios Clínicos da Sociedade Brasileira de Patologia Clínica e as normas técnicas de gestão de qualidade ISO 9001 e ISO 14001. Os demais exames laboratoriais foram realizados no laboratório de análises clínicas do HUB. O intervalo máximo permitido entre a avaliação clínica e a coleta dos exames foi de 7 dias.

A gravidade da DA foi avaliada em todas as crianças portadoras de DA por meio da ferramenta SCORAD (ANEXO E) (20). Este índice mostrou, em estudos prévios, ter alto grau de validade para mensurar a gravidade da DA $(132,133)$ e é considerado um indicador adequado para medir ou representar sinteticamente o fenômeno considerado. Não acarreta malefícios ou prejuízos às pessoas investigadas e, sob o ângulo técnico-administrativo, é simples, de fácil obtenção e baixo custo operacional.

A fórmula utilizada para cálculo do SCORAD é: A/5 + 7B/2 + C. Nessa fórmula A corresponde à extensão da doença (0-100), B corresponde à intensidade (0-18) e C corresponde aos sintomas subjetivos (0-20). O SCORAD máximo é 103. Uma variação comumente utilizada é o SCORAD objetivo, no qual se excluem os sintomas subjetivos. O SCORAD objetivo utiliza apenas os itens A (extensão) e B (intensidade), sendo a fórmula para o seu cálculo $A / 5+7 B / 2$. O SCORAD objetivo máximo é 83 (134). A classificação da gravidade clínica da DA de acordo com o escore obtido pelo instrumento de coleta utilizado está representada no Quadro 6.

Quadro 6 - Categorização da gravidade clínica da DA

\begin{tabular}{|c|c|c|}
\hline Gravidade da DA & SCORAD & SCORAD objetivo \\
\hline Leve & $<25$ & $<15$ \\
Moderada & $25-50$ & $15-40$ \\
Grave & $>50$ & $>40$ \\
\hline
\end{tabular}


A aferição do SCORAD foi feita por profissional médico único, reduzindo viés na coleta dos dados. O treinamento para a utilização da ferramenta SCORAD foi feito via internet pelo sítio http://adserver.sante.univ-nantes.fr.

O IUV no período do estudo foi obtido por meio do CPTEC / INPE, que disponibiliza diariamente o IUV nas capitais dos Estados brasileiros ao longo do dia no endereço eletrônico http://satelite.cptec.inpe.br/uv/. Foi utilizado o IUV máximo diário para os cálculos que envolveram essa variável.

O método de cálculo do IUV foi um modelo matemático-físico que descreve a interação da radiação solar com os gases da atmosfera e a sua incidência na superfície (Figura 8). Nesse modelo, $E_{\lambda}$ corresponde à irradiância espectral em superfície, $\varepsilon_{\lambda}$ é o espectro de ação eritêmica e $C$ é a constante de conversão. Desse modo, o IUV nada mais é do que um formato simplificado para a apresentação da irradiância eritêmica. Cada unidade de IUV corresponde a $25 \mathrm{~mW} / \mathrm{m}^{2}$ de energia. $\mathrm{O}$ método considera as variações diárias de concentrações de ozônio estimadas via satélite, posição geográfica, altitude da superfície e estações do ano. O IUV máximo representa o nível máximo de radiação UV esperado para determinado dia e local em condições de céu sem presença de nuvens e ao meio dia solar. De acordo com o seu valor, o IUV é categorizado em baixo, moderado, alto, muito alto e extremo, segundo recomendações da OMS (120) (Figura 9). No Brasil o IUV é considerado, na maior parte do ano e na maior parte de seu território, muito alto ou extremo (125).

$$
\mathrm{IUV}=\mathrm{C} \int_{j=\mathrm{m}}^{\operatorname{mat}} \mathrm{E}_{\lambda} \varepsilon_{\lambda} \mathrm{d} \lambda
$$

Figura 8 - Fórmula para cálculo do IUV 


\begin{tabular}{|c|c|}
\hline Categoria de exposição & Valores IUV \\
\hline Baixo & $<2$ \\
\hline Moderado & 3 a 5 \\
Alto & 6 a 7 \\
Muito Alto & 8 a 10 \\
\hline Extremo & $11+$ \\
\hline
\end{tabular}

Figura 9 - Categorias de exposição à radiação UV. Adaptado de World Health Organization, 2002 (120)

Os valores de referência, métodos laboratoriais utilizados e local de aferição dos exames laboratoriais incluídos como variáveis no estudo encontram-se sumarizados no Quadro 7. Não houve ônus aos pacientes concernentes à realização dos exames laboratoriais. Os exames realizados no laboratório Sabin foram gratuitos, em virtude de apoio fornecido aos pesquisadores por intermédio do Núcleo de Apoio à Pesquisa desse laboratório (ANEXO F). Aos participantes detectados insuficientes e deficientes em vitamina $D$, suplementação oral de vitamina $D_{3}$ foi prescrita.

Quadro 7 - Sumário dos exames laboratoriais incluídos no estudo

\begin{tabular}{|c|c|c|c|}
\hline Exame & Laboratório & Método & Valor de Referência \\
\hline $25(\mathrm{OH}) \mathrm{D}$ & Sabin & Quimioluminescência & $\begin{array}{l}\text { Suficiente: } \geq 30 \mathrm{ng} / \mathrm{ml} \\
\text { Insuficiente: } 20-30 \mathrm{ng} / \mathrm{ml} \\
\text { Deficiente: }<20 \mathrm{ng} / \mathrm{ml}\end{array}$ \\
\hline PTHi & HUB & Quimioluminescência & 15 a $65 \mathrm{pg} / \mathrm{ml}$ \\
\hline $\lg E$ total & HUB & Nefelometria & $\begin{array}{l}\text { Neonatos: até } 1,5 \mathrm{Ul} / \mathrm{ml} \\
0 \text { a } 1 \text { ano: até } 15 \mathrm{Ul} / \mathrm{ml} \\
1 \text { a } 5 \text { anos: até } 60 \mathrm{Ul} / \mathrm{ml} \\
6 \text { a } 9 \text { anos: até } 90 \mathrm{Ul} / \mathrm{ml} \\
10 \text { a } 15 \text { anos: até } 480 \mathrm{Ul} / \mathrm{ml} \\
\text { > } 15 \text { anos: até } 100 \mathrm{Ul} / \mathrm{ml}\end{array}$ \\
\hline Hemograma & HUB & Cell-Dyn 3500 Abbott $^{\circledR}$ & Eosinófilos: 1 a $5 \%$ \\
\hline EPF & HUB & $\begin{array}{l}\text { Método de Hoffmann } \\
\text { (sedimentação } \\
\text { espontânea) }\end{array}$ & Negativo \\
\hline
\end{tabular}




\subsection{ANÁLISES ESTATÍSTICAS}

Os dados foram submetidos à análise estatística pelo software SAS ${ }^{\circledR} 9.3$ (SAS Institute, Cary, NC). Em razão de associações envolvendo variáveis quantitativas e qualitativas, ora com ora sem distribuição gaussiana, estratificadas em até 3 categorias, foram utilizados testes estatísticos diversos (ANOVA; Kruskal-Wallis; quiquadrado; teste t de Student; coeficiente de correlação linear de Pearson; teste exato de Fisher; teste de comparações múltiplas de Dwass, Steel, Critchlow-Fligner), de acordo com as variáveis a serem testadas. Foram consideradas estatisticamente significativas associações quando o $p$-valor foi $p<0,05$ e o intervalo de confiança (IC) $95 \%$.

Foram realizadas, ainda, análises multivariadas por meio de regressão linear múltipla com o intuito de identificar variáveis independentes significativamente associadas com o SCORAD ou com as concentrações séricas de 25(OH)D. 


\section{RESULTADOS}

\subsection{RESULTADOS DESCRITIVOS}

O número total de participantes portadores de DA recrutados para o estudo foi de 112 indivíduos. Foram excluídos do estudo 06 indivíduos que não realizaram os exames laboratoriais solicitados, resultando numa perda de 5,36\% da amostra inicial. Foram incluídos nas análises, portanto, 106 pacientes portadores de DA. Os pacientes do grupo controle foram selecionados por critério cronológico quando, obedecidos critérios de inclusão e exclusão, eram compatíveis para pareamento com um caso do grupo DA, de acordo com as variáveis idade, gênero, IMC e fototipo. Foram selecionados 54 pacientes para o grupo controle (Figura 10), os quais foram pareados com subamostra de 54 pacientes do grupo DA (pareamento 1:1).

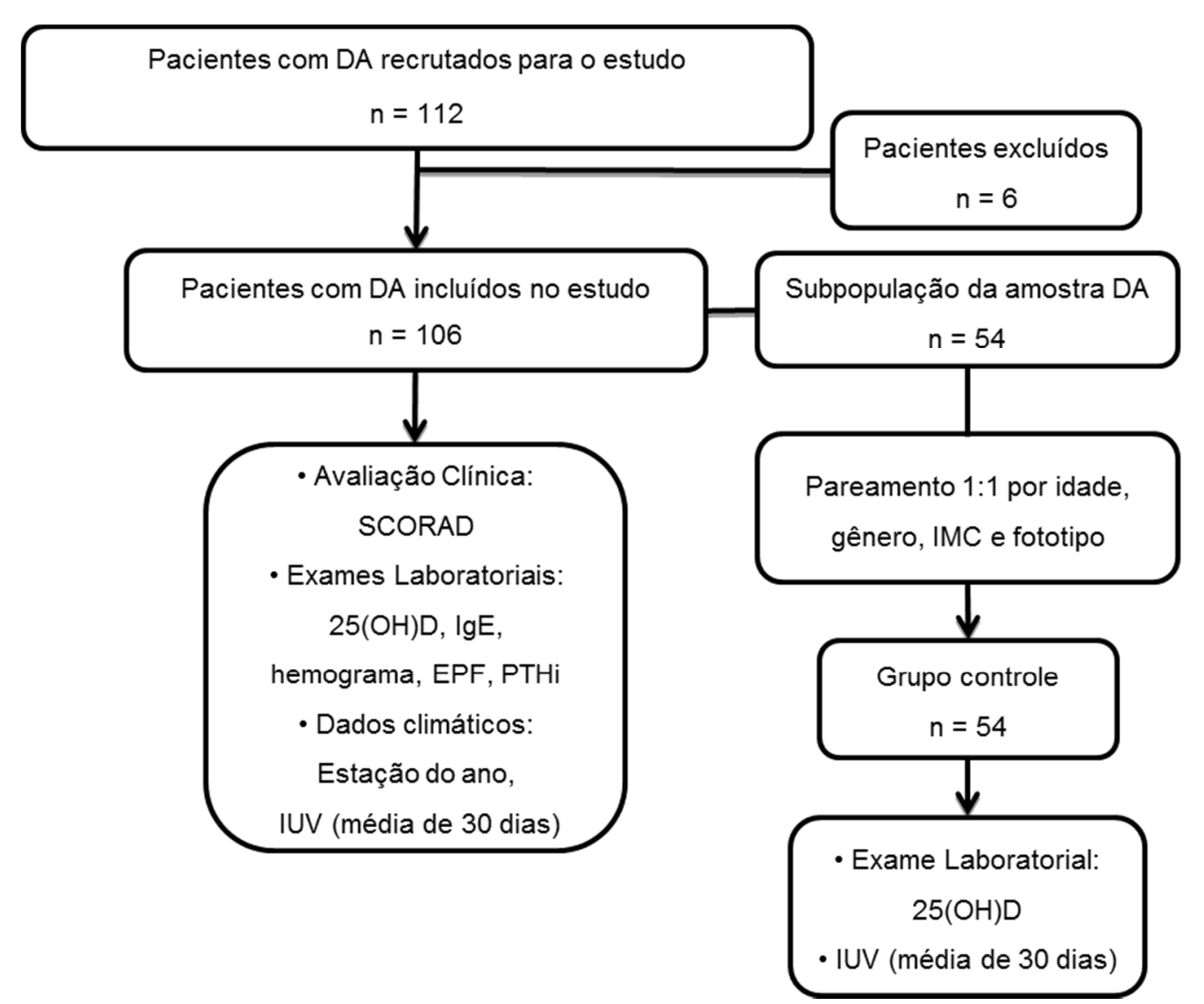

Figura 10 - Fluxograma de inclusão dos casos e controles 
Características clínicas, epidemiológicas, sociológicas, laboratoriais e ambientais relacionadas ao grupo de pacientes com DA encontram-se sumarizadas na Tabela 2.

Tabela 2 - Análise descritiva das variáveis encontradas no grupo de portadores de DA

\begin{tabular}{|c|c|c|c|}
\hline & Portadores de DA $(n=106)$ & Valor mínimo & Valor máximo \\
\hline Idade (anos) & $8,18 \pm, 4,02$ & 0,75 & 17,9 \\
\hline $\begin{array}{l}\text { Gênero } \\
\text { Masculino } \\
\text { Feminino }\end{array}$ & $\begin{array}{l}38(35,85 \%) \\
68(64,15 \%)\end{array}$ & & \\
\hline $\begin{array}{l}\text { Fototipo Fitzpatrick } \\
\text { II } \\
\text { III } \\
\text { IV } \\
\text { V }\end{array}$ & $\begin{array}{c}7(6,60 \%) \\
30(28,30 \%) \\
65(61,32 \%) \\
4(37,78 \%)\end{array}$ & & \\
\hline $\begin{array}{l}\text { Renda } \\
\text { (salários-mínimos) }\end{array}$ & $3,31 \pm 2,68$ & 1 & 10 \\
\hline IMC $\left(\mathbf{k g} / \mathrm{m}^{2}\right)$ & $17,75 \pm 3,17$ & 13,15 & 32,3 \\
\hline $\begin{array}{l}\text { IMC score } Z \\
\text { Magreza } \\
\text { Adequado } \\
\text { Risco de sobrepeso } \\
\text { Sobrepeso } \\
\text { Obesidade }\end{array}$ & $\begin{array}{c}2(1,89 \%) \\
70(66,03 \%) \\
24(22,64 \%) \\
8(7,55 \%) \\
2(1,89 \%)\end{array}$ & & \\
\hline $\begin{array}{l}\text { Asma ou RA } \\
\text { Sim } \\
\text { Não }\end{array}$ & $\begin{array}{l}60(56,60 \%) \\
46(43,40 \%)\end{array}$ & & \\
\hline $\begin{array}{l}\text { Atopia familiar } \\
\text { Sim } \\
\text { Não }\end{array}$ & $\begin{array}{l}72(67,92 \%) \\
34(32,08 \%)\end{array}$ & & \\
\hline Idade de início (anos) & $2,06 \pm 2,83$ & 0 & 15 \\
\hline $\begin{array}{l}\text { SCORAD } \\
\text { DA Leve } \\
\text { DA Moderada } \\
\text { DA Grave }\end{array}$ & $\begin{array}{c}28,29 \pm 15,33 \\
49(46,23 \%) \\
48(45,28 \%) \\
9(8,49 \%)\end{array}$ & 3,5 & 76,1 \\
\hline $\begin{array}{l}\text { SCORAD objetivo } \\
\text { DA Leve } \\
\text { DA Moderada } \\
\text { DA Grave }\end{array}$ & $\begin{array}{c}19,03 \pm 11,40 \\
45(42,45 \%) \\
55(51,89 \%) \\
6(5,66 \%)\end{array}$ & 3,5 & 58,1 \\
\hline
\end{tabular}

continua 
continuação

Tabela 2 - Análise descritiva das variáveis encontradas no grupo de portadores de DA

\begin{tabular}{lccc}
\hline & Portadores de DA (n = 106) & Valor mínimo & Valor máximo \\
\hline 25(OH)D (ng/ml) & $28,97 \pm 9,68$ & 12,1 & 76,9 \\
Suficiência & $45(42,45 \%)$ & & \\
Insuficiência & $44(41,51 \%)$ & & \\
Deficiência & $17(16,04 \%)$ & & \\
PTHi (pg/ml) & $33,85 \pm 15,7$ & 7 & 15.39 \\
IgE (Ul/ml) & $1.242,83 \pm 2.297,69$ & 3,3 & 22 \\
Eosinófilos (\%) & $7,68 \pm 5,02$ & 0 & \\
Estação do ano & $28(26,41 \%)$ & & \\
Primavera & $38(35,85 \%)$ & & \\
Verão & $22(20,76 \%)$ & & \\
Outono & $18(16,98 \%)$ & & \\
Inverno & $11,8 \pm 2,6$ & & \\
IUV* & & & \\
\hline
\end{tabular}

Valores expressos em média \pm desvio padrão ou $n(\%)$

a PTHi realizado em 69 pacientes

b IgE realizado em 102 pacientes

* IUV representa o IUV máximo nos 30 dias anteriores à avaliação clínica

A razão entre o gênero feminino e $\circ$ masculino foi de 1,8 . $A$ idade média relatada para início dos sintomas de DA foi de 2,06 anos. Houve predomínio de fototipos mais elevados (III e V) na amostra. Constatou-se grande prevalência de associação de asma ou RA nos casos de portadores de DA (56,6\%), assim como de atopia familiar positiva $(67,92 \%)$. A média do SCORAD foi de 28,29 , sendo que $91,51 \%$ dos sujeitos foram portadores de DA leve ou moderada.

A média de 25(OH)D encontrada no grupo de portadores de DA foi de 28,97 \pm $9,68 \mathrm{ng} / \mathrm{ml}$. Após alocação nas categorias definidas pela The Endocrine Society (44), $42,45 \%$ dos pacientes foram considerados suficientes e $57,55 \%$ foram considerados hipossuficientes (insuficientes ou deficientes) em vitamina $D$.

A média de IgE total foi de $1.242,83 \pm 2.297,69$. Da amostra de 106 pacientes com DA, 4 sujeitos não realizaram a dosagem de lgE. Dos 102 pacientes que realizaram o exame, $27(26,47 \%)$ possuíam concentração sérica normal de lgE, ao passo que 75 (73,53\%) apresentaram concentração sérica de IgE acima dos valores de referência. 
O EPF foi positivo em 12 pacientes, sendo identificados os protozoários listados na Tabela 3. Não foram encontrados geohelmintos.

Tabela 3- Resultados do exame EPF no grupo de pacientes com DA

\begin{tabular}{lcc}
\hline \multicolumn{1}{c}{ Parasitas } & Frequência (n) & Porcentagem \\
\hline Negativo & 81 & $76,42 \%$ \\
Giardia intestinalis & 7 & $6,61 \%$ \\
Entamoeba coli & 3 & $2,83 \%$ \\
Giardia intestinalis e Entamoeba coli & 1 & $0,94 \%$ \\
Endolimax nana & 1 & $0,94 \%$ \\
Pacientes que não realizaram o exame & 13 & $12,26 \%$ \\
\hline
\end{tabular}

Da amostra de 106 participantes do grupo DA, foi obtida uma subpopulação de 54 sujeitos para realização de pareamento com grupo controle. O modo de obtenção da amostra obedeceu à ordem cronológica de inclusão dos sujeitos atópicos na pesquisa e os critérios estabelecidos para o pareamento, detalhados em 'Métodos'. Os 52 pacientes portadores de DA que não foram pareados foram excluídos da análise comparativa com o grupo controle.

O pareamento foi realizado na proporção de 1 sujeito-controle (não portador de DA) para 1 sujeito-índice (portador de DA), resultando em um grupo controle composto por 54 participantes. A distribuição das variáveis utilizadas para o pareamento nos dois grupos, assim como o resultado da concentração sérica de 25(OH)D nesses, estão detalhados na Tabela 4.

Tabela 4- Características epidemiológicas e concentração de 25(OH)D em subgrupo com DA e em grupo controle pareado

\begin{tabular}{lcc}
\hline & Subgrupo DA $(\mathbf{n}=\mathbf{5 4})$ & Controle $(\mathbf{n}=\mathbf{5 4})$ \\
\hline Idade (anos) & $9,09 \pm 4,11$ & $9,04 \pm 4,32$ \\
Gênero & & \\
$\quad$ Masculino & $22(40,74 \%)$ & $22(40,74 \%)$ \\
$\quad$ Feminino & $32(59,26 \%)$ & $32(59,26 \%)$ \\
continua & &
\end{tabular}


continuação

Tabela 4 - Características epidemiológicas, concentrações de 25(OH)D e IUV médio em subgrupo com DA e em grupo controle pareado

\begin{tabular}{lcc}
\hline & Subgrupo DA (n = 54) & Controle (n = 54) \\
\hline Fototipo & $1(1,85 \%)$ & \\
II & $17(31,48 \%)$ & $5(9,26 \%)$ \\
III & $35(64,82 \%)$ & $9(16,67 \%)$ \\
IV & $1(1,85 \%)$ & $39(72,22 \%)$ \\
V & $17,73 \pm 2,65$ & $1(1,85 \%)$ \\
IMC (kg/m $\mathbf{2})$ & $28,95 \pm 8,78$ & $17,83 \pm 2,48$ \\
25(OH)D (ng/mI) & $23(42,59 \%)$ & $25,55 \pm 7,02$ \\
Suficiência & $21(38,89 \%)$ & $12(22,22 \%)$ \\
Insuficiência & $10(18,52 \%)$ & $33(61,11 \%)$ \\
Deficiência & $12,85 \pm 2,09$ & $9(16,67 \%)$ \\
IUV médio (30 dias) & $10,31 \pm 2,54$ \\
\hline
\end{tabular}

Valores expressos em média \pm desvio padrão ou $\mathrm{n}(\%)$

A representação gráfica comparativa da frequência das categorias de 25(OH)D no subgrupo DA e no grupo controle está representada na Figura 11.

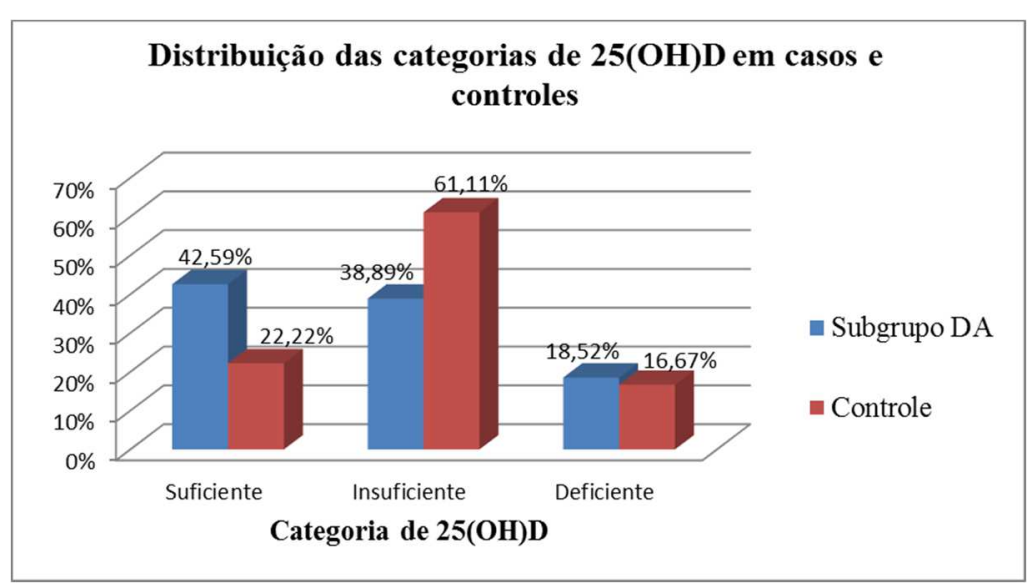

Figura 11 - Distribuição das categorias de 25(OH)D no subgrupo DA e no grupo controle

Os valores do IUV máximo encontrados no período do estudo em Brasília-DF encontram-se representados na Figura 12. Para construção do gráfico, foram 
utilizados os valores diários de IUV máximo mensurados pelo CPTEC / INPE. A média do IUV no período do estudo foi de $11,8 \pm 2,61$.

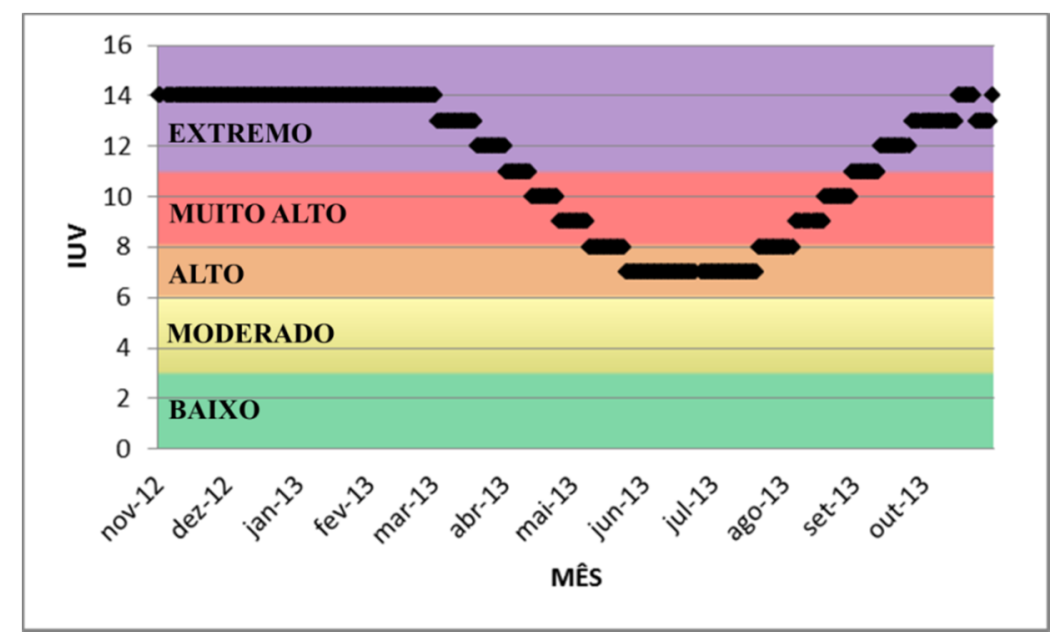

Figura 12 - IUV máximo diário no período do estudo

\subsection{RESULTADOS ANALÍTICOS}

\subsubsection{Concentrações Séricas e Categorias de 25(OH)D em Subgrupo de Pacientes Portadores de DA e em Grupo Controle}

\subsubsection{Metodologia}

Inicialmente, verificou-se pelo teste de Kolmogorov-Smirnov que a diferença de 25(OH)D entre os dois grupos apresentava distribuição gaussiana. Empregou-se o teste $t$ de Student emparelhado com o intuito de verificar se a diferença média da concentração de 25(OH)D entre os grupos foi significativamente diferente de zero.

Em seguida, empregou-se o teste de homogeneidade marginal com objetivo de comparar se as proporções marginais de deficiência, insuficiência e suficiência em vitamina $\mathrm{D}$ diferiram entre os grupos. 


\subsubsection{Resultado}

Pacientes com DA apresentaram valores médios de 25(OH)D significativamente maiores do que aqueles do grupo controle $(p=0,0176)$. A diferença entre as médias foi de 3,39 ng/ml (Tabela 5 e Figura 13).

Tabela 5 - Concentrações séricas de 25(OH)D em subgrupo de pacientes com DA e em grupo controle

\begin{tabular}{|c|c|c|c|c|}
\hline \multicolumn{2}{|c|}{ 25(OH)D } & \multirow{2}{*}{ Diferença entre Médias } & \multirow{2}{*}{$\mathbf{t}\left(\left.\mathbf{g}\right|^{\star}\right)$} & \multirow{2}{*}{$\mathbf{p}$} \\
\hline DA Subgrupo & Controle & & & \\
\hline $28,95 \pm 8,78$ & $25,55 \pm 7,02$ & $3,39 \pm 1,38$ & $2,45(53)$ & 0,0176 \\
\hline
\end{tabular}

Valores expressos em média \pm desvio padrão

${ }^{*} \mathrm{gl}=$ grau de liberdade

$\mathrm{p}$-valor calculado pelo teste t de Student emparelhado

Distribuição da Diferença: 25(OH)D em pacientes com DA - 25(OH)D em controles Com intervalo de confiança de $95 \%$ para a média

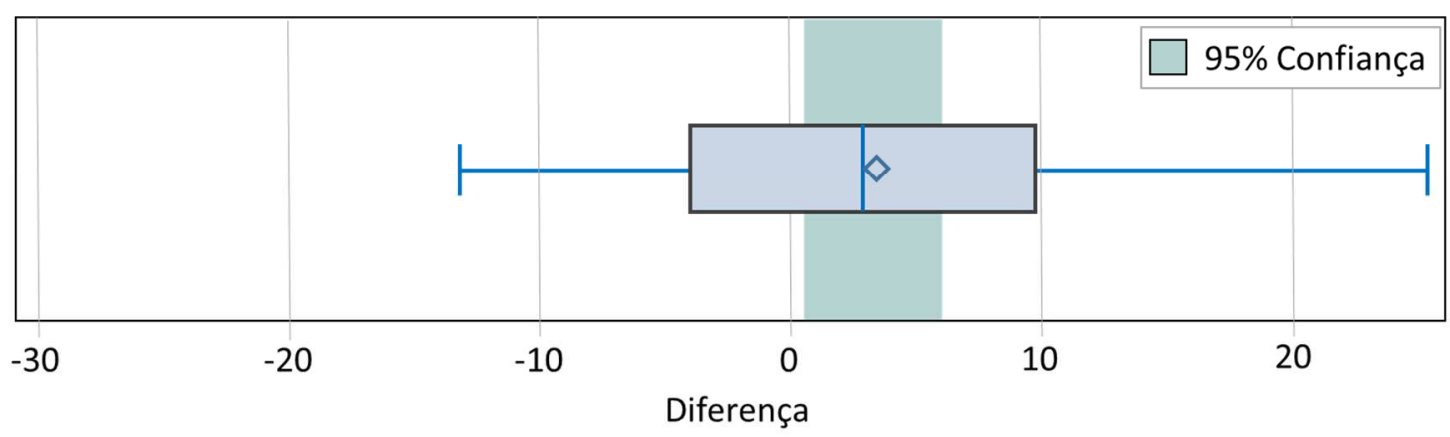

Figura 13 - Comparação entre concentrações séricas de 25(OH)D em subgrupo DA e grupo controle.

Por meio da avaliação do resultado do teste de homogeneidade marginal, a hipótese de igualdade marginal não pôde ser rejeitada e, portanto as proporções de pacientes deficientes, insuficientes e suficientes no grupo de pacientes com DA não diferiram significativamente das respectivas proporções no grupo controle (Tabela 6). 
Tabela 6 - Categorias de 25(OH)D em subgrupo portador de DA e em grupo controle

\begin{tabular}{lccccc}
\hline \multicolumn{1}{c}{$\begin{array}{c}\text { 25(OH)D } \\
\text { Subgrupo } \\
\text { DA }\end{array}$} & \multicolumn{2}{c}{ 25(OH)D - Grupo Controle } & \multirow{2}{*}{ Total } & p \\
\cline { 2 - 4 } & Deficiência & Insuficiência & Suficiência & & \\
\hline Deficiência & $2(3,70)$ & $8(14,81)$ & $0(0,00)$ & $10(18,52)$ & \\
Insuficiência & $5(9,26)$ & $8(14,81)$ & $8(14,81)$ & $21(38,89)$ & 0,0885 \\
Suficiência & $2(3,70)$ & $17(31,48)$ & $4(7,41)$ & $23(42,59)$ & \\
Total & $9(16,67)$ & $33(61,11)$ & $12(22,22)$ & $54(100,00)$ & \\
\hline
\end{tabular}

Teste de homogeneidade marginal $\left(x^{2}=4,85 ; g l=2 ; p=0,0885\right)$

\subsubsection{IUV Médio em Subgrupo de Pacientes Portadores de DA e em Grupo Controle}

\subsubsection{Metodologia}

As médias do IUV máximo nos 30 dias anteriores à avaliação clínica no subgrupo de pacientes com DA e no grupo controle pareado foram comparadas por meio do teste $\mathrm{t}$ de Student emparelhado.

\subsubsection{Resultado}

O IUV dos casos foi significativamente maior que o IUV dos controles ( $p<$ 0,0001). Os pacientes do subgrupo DA apresentaram o IUV em média 2,54 acima dos pacientes do grupo controle (Tabela 7). 
Tabela 7 - IUV médio em subgrupo de pacientes com DA e em grupo controle

\begin{tabular}{|c|c|c|c|c|}
\hline \multicolumn{2}{|c|}{ IUV } & \multirow{2}{*}{ Diferença entre Médias } & \multirow{2}{*}{$t\left(g l^{\star}\right)$} & \multirow{2}{*}{$\mathbf{p}$} \\
\hline DA Subgrupo & Controle & & & \\
\hline $12,85 \pm 2,09$ & $10,31 \pm 2,54$ & $2,54 \pm 3,06$ & $6,10(53)$ & $<0,0001$ \\
\hline
\end{tabular}

\subsubsection{Associação entre 25(OH)D e Gravidade Clínica da DA (SCORAD e SCORAD Objetivo)}

\subsubsection{Metodologia}

As correlações entre as variáveis quantitativas 25(OH)D e SCORAD, assim como entre 25(OH)D e SCORAD objetivo, foram feitas por meio do coeficiente de correlação linear de Pearson. Quando as variáveis foram analisadas categoricamente, utilizou-se o teste exato de Fisher em virtude da frequência menor que 5 em mais de $20 \%$ das caselas.

\subsubsection{Resultado}

Não existiu correlação significativamente diferente de zero entre as variáveis contínuas 25(OH)D e SCORAD ( $r=0,03424 ; p=0,7269)$ (Tabela 8 e Figura 14). 
Tabela 8 - Correlação entre variáveis contínuas 25(OH)D e SCORAD

\begin{tabular}{cccccc}
\hline $\begin{array}{c}\text { Variável } \\
\text { dependente }\end{array}$ & $\begin{array}{c}\text { Variável } \\
\text { independente }\end{array}$ & $\mathbf{N}$ & $\begin{array}{c}\text { Correlação } \\
\text { estimada }\end{array}$ & IC 95\% & $\mathbf{p}$ \\
\hline $25(\mathrm{OH}) \mathrm{D}$ & SCORAD & 106 & 0,03424 & $\begin{array}{c}-0,157543 \\
0,223536\end{array}$ & $\mathbf{0 , 7 2 6 9}$ \\
\hline
\end{tabular}

p-valor calculado pelo coeficiente de correlação linear de Pearson

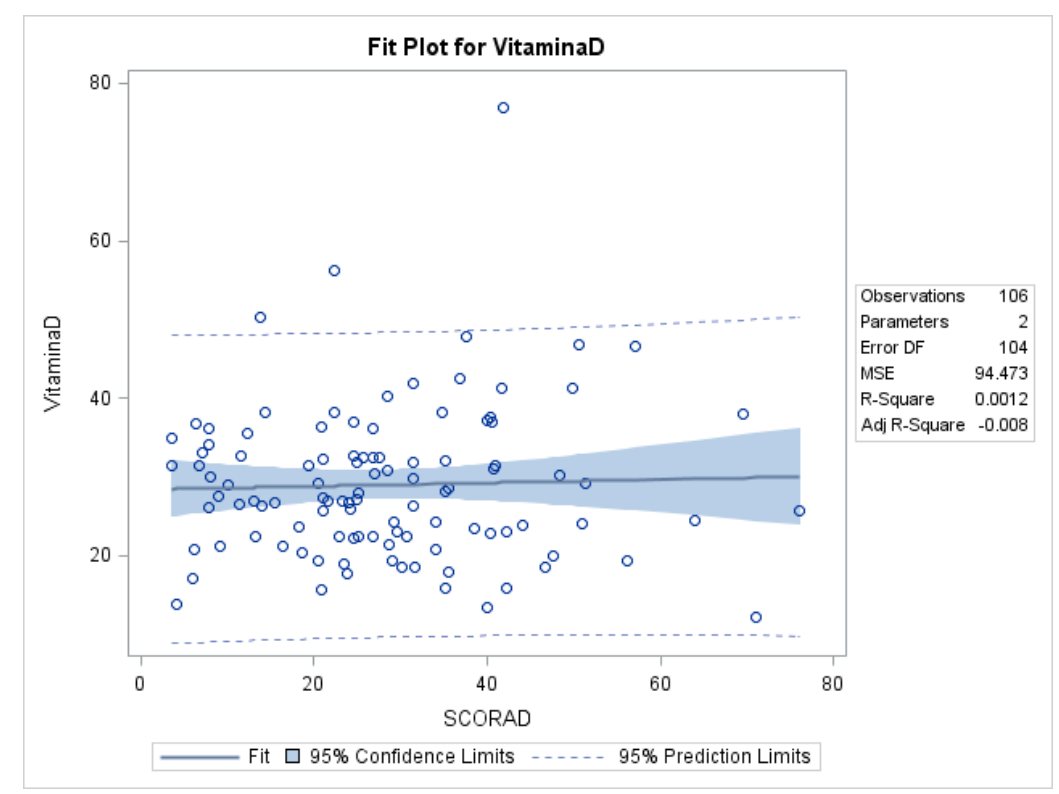

Figura 14 - Correlação entre 25(OH)D e SCORAD

Não existiu correlação significativamente diferente de zero entre as variáveis quantitativas 25(OH)D e SCORAD objetivo ( $r=0,00451 ; p=0,9633$ ) (Tabela 9, Figura 15).

Tabela 9 - Correlação entre 25(OH)D e SCORAD objetivo

\begin{tabular}{cccccc}
\hline $\begin{array}{c}\text { Variável } \\
\text { dependente }\end{array}$ & $\begin{array}{c}\text { Variável } \\
\text { independente }\end{array}$ & $\mathbf{N}$ & $\begin{array}{c}\text { Correlação } \\
\text { estimada }\end{array}$ & IC 95\% & $\mathbf{p}$ \\
\hline $25(\mathrm{OH}) \mathrm{D}$ & $\begin{array}{c}\text { SCORAD } \\
\text { objetivo }\end{array}$ & 106 & 0,00451 & $\begin{array}{c}-0,186407 \\
0,195096\end{array}$ & $\mathbf{0 , 9 6 3 3}$ \\
\hline
\end{tabular}

p-valor calculado pelo coeficiente de correlação linear de Pearson 


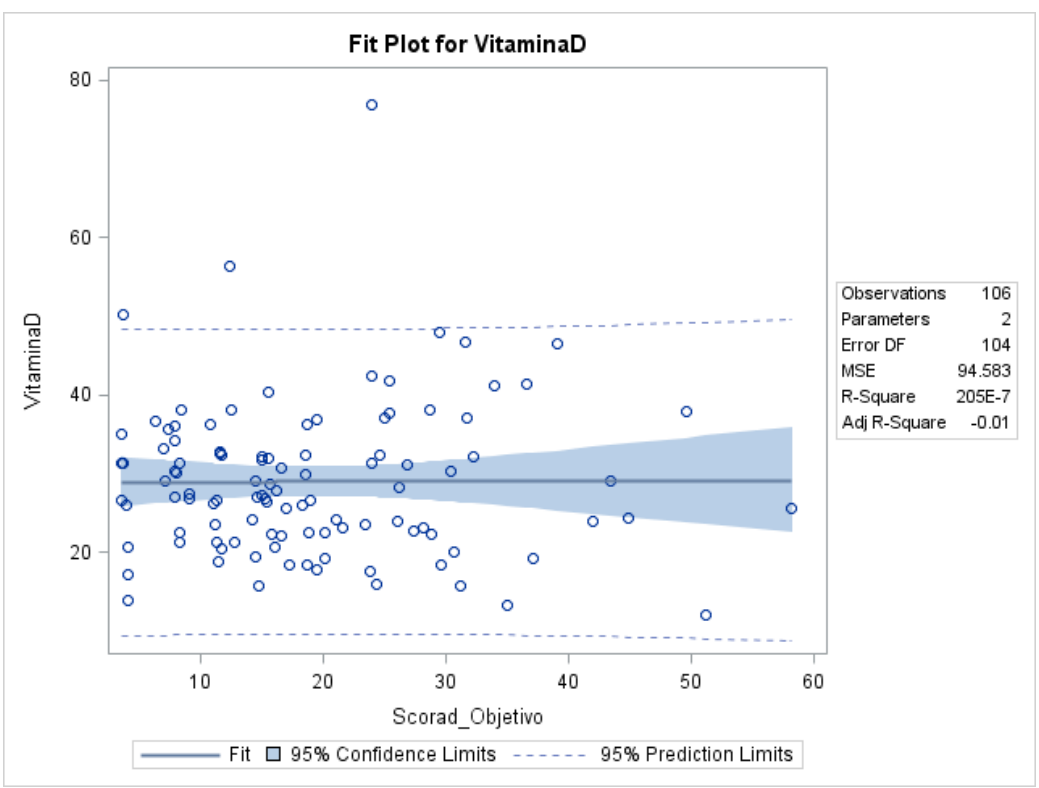

Figura 15 - Correlação entre 25(OH)D e SCORAD objetivo

Não existiu associação significativa entre as categorias de 25(OH)D e SCORAD $(p=0,7629)$ (Tabela 10), tampouco entre as categorias de $25(\mathrm{OH}) \mathrm{D}$ com as categorias de DA determinadas pelo SCORAD objetivo $(p=0,4812)$ (Tabela 11).

Tabela 10 - Associação entre 25(OH)D e SCORAD categóricos

\begin{tabular}{|c|c|c|c|c|}
\hline \multirow{2}{*}{$\begin{array}{c}\text { 25(OH)D } \\
\text { (ng/ml) }\end{array}$} & \multicolumn{3}{|c|}{ Dermatite atópica (SCORAD) } & \multirow[b]{2}{*}{$\mathbf{p}$} \\
\hline & $\begin{array}{c}\text { DA leve } \\
(n=49)\end{array}$ & $\begin{array}{l}\text { DA moderada } \\
\quad(n=48)\end{array}$ & $\begin{array}{c}\text { DA grave } \\
(n=9)\end{array}$ & \\
\hline Suficiência & $20(40,82 \%)$ & $22(45,83 \%)$ & $3(33,33 \%)$ & \\
\hline Insuficiência & $23(46,94 \%)$ & $17(35,42 \%)$ & $4(44,44 \%)$ & 0,7629 \\
\hline Deficiência & $6(12,24 \%)$ & $9(18,75 \%)$ & $2(22,22 \%)$ & \\
\hline
\end{tabular}

p-valor calculado pelo teste exato de Fisher

Tabela 11 - Associação entre categorias de 25(OH)D e de SCORAD objetivo

\begin{tabular}{lccccc}
\hline \multirow{2}{*}{$\begin{array}{c}\text { Categoria } \\
\text { 25(OH)D }\end{array}$} & \multicolumn{2}{c}{ Categoria SCORAD Objetivo } & \multirow{2}{*}{ Total } & p \\
\cline { 2 - 5 } & & $\begin{array}{c}\text { DA } \\
\text { moderada }\end{array}$ & DA grave & & \\
\hline Deficiência & $5(11,11 \%)$ & $11(20 \%)$ & $1(16,67 \%)$ & 17 & \\
Insuficiência & $19(42,22 \%)$ & $21(38,18 \%)$ & $4(66,67 \%)$ & 44 & $\mathbf{0 , 4 8 1 2}$ \\
Suficiência & $21(46,67 \%)$ & $23(41,82 \%)$ & $1(16,67 \%)$ & 45 & \\
Total & 45 & 55 & 6 & 106 & \\
\hline
\end{tabular}

$p$ - valor calculado pelo teste exato de Fisher 


\subsubsection{Correlação entre Concentrações Séricas de 25(OH)D e Gravidade Clínica da DA em Grupo de Pacientes com IgE Elevada}

\subsubsection{Metodologia}

As correlações entre as variáveis quantitativas 25(OH)D e SCORAD, assim como entre 25(OH)D e SCORAD objetivo no grupo de pacientes com lgE elevada, foram feitas por meio do coeficiente de correlação linear de Pearson.

\subsubsection{Resultado}

Não existiu correlação significativamente diferente de zero entre 25(OH)D e SCORAD $(r=0,04977 ; p=0,6704)$ (Tabela 12 e Figura 16), tampouco entre 25(OH)D e SCORAD objetivo ( $r=0,02194 ; p=0,8513$ ) (Tabela 13 e Figura 17) no grupo de pacientes com IgE elevada.

Tabela 12 - Correlação entre variáveis 25(OH)D e SCORAD em grupo de pacientes portadores de DA com IgE elevada

\begin{tabular}{cccccc}
\hline $\begin{array}{c}\text { Variável } \\
\text { dependente }\end{array}$ & $\begin{array}{c}\text { Variável } \\
\text { independente }\end{array}$ & $\mathbf{N}$ & $\begin{array}{c}\text { Correlação } \\
\text { estimada }\end{array}$ & IC 95\% & $\mathbf{p}$ \\
\hline SCORAD & $25(\mathrm{OH}) \mathrm{D}$ & 75 & 0,04977 & $\begin{array}{c}-0,179215 \\
0,273642\end{array}$ & $\mathbf{0 , 6 7 0 4}$ \\
\hline
\end{tabular}

p-valor calculado pelo coeficiente de correlação linear de Pearson 


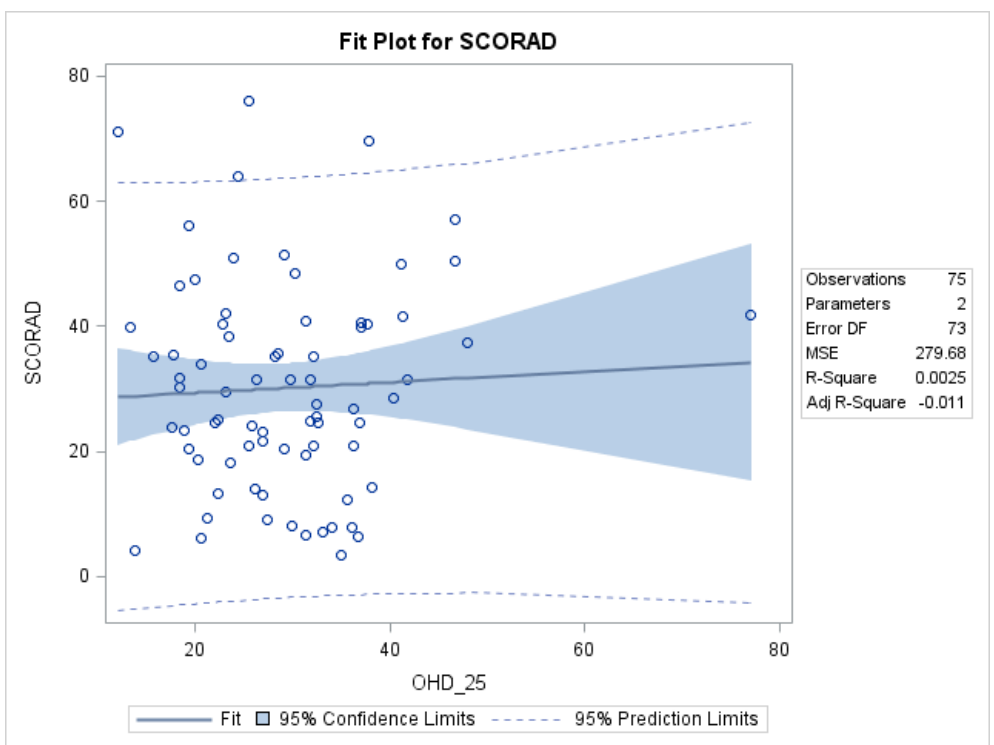

Figura 16 - Correlação entre 25(OH)D e SCORAD em pacientes com IgE elevada

Tabela 13 - Correlação entre 25(OH)D e SCORAD objetivo em grupo de pacientes com lgE elevada

\begin{tabular}{cccccc}
\hline $\begin{array}{c}\text { Variável } \\
\text { dependente }\end{array}$ & $\begin{array}{c}\text { Variável } \\
\text { independente }\end{array}$ & $\mathbf{N}$ & $\begin{array}{c}\text { Correlação } \\
\text { estimada }\end{array}$ & IC $95 \%$ & $\mathbf{p}$ \\
\hline $\begin{array}{c}\text { SCORAD } \\
\text { objetivo }\end{array}$ & $25(\mathrm{OH}) \mathrm{D}$ & 75 & 0,02194 & $\begin{array}{c}-0,206050 \\
0,247666\end{array}$ & $\mathbf{0 , 8 5 1 3}$ \\
\hline
\end{tabular}

p-valor calculado pelo coeficiente de correlação linear de Pearson

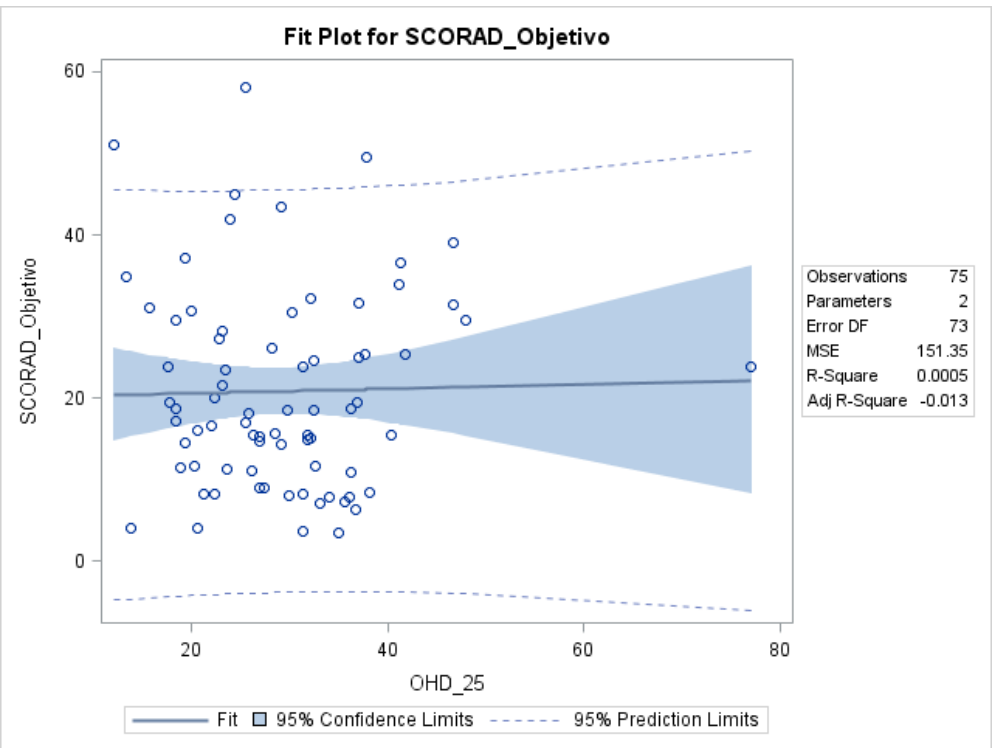

Figura 17 - Correlação entre 25(OH)D e SCORAD objetivo em pacientes com IgE elevada 


\subsubsection{Associação entre 25(OH)D e PTHi}

\subsubsection{Metodologia}

As correlações entre as variáveis contínuas 25(OH)D e PTHi foram feitas empregando-se o coeficiente de correlação linear de Pearson. Para a comparação entre as categorias de vitamina D e as concentrações séricas de PTHi, utilizou-se o teste de Kruskal-Wallis.

\subsubsection{Resultado}

Não existiu correlação significativamente diferente de zero entre as variáveis quantitativas PTHi e 25(OH)D ( $r=-0,01319 ; p=0,9140)$ (Tabela 14 e Figura 18). Da mesma forma, as concentrações séricas de PTHi não tiveram correlação significativa com as categorias de 25(OH)D (Tabela 15, Figura 19).

Tabela 14 - Correlação entre concentrações séricas de 25(OH)D e PTHi

\begin{tabular}{cccccc}
\hline $\begin{array}{c}\text { Variável } \\
\text { dependente }\end{array}$ & $\begin{array}{c}\text { Variável } \\
\text { independente }\end{array}$ & $\mathbf{N}$ & $\begin{array}{c}\text { Correlação } \\
\text { estimada }\end{array}$ & IC 95\% & $\mathbf{p}$ \\
\hline PTHi & $25(\mathrm{OH}) \mathrm{D}$ & 69 & $-0,01319$ & $\begin{array}{c}-0,249097 \\
0,224187\end{array}$ & $\mathbf{0 , 9 1 4 0}$ \\
\hline
\end{tabular}

p-valor calculado pelo coeficiente de correlação linear de Pearson 


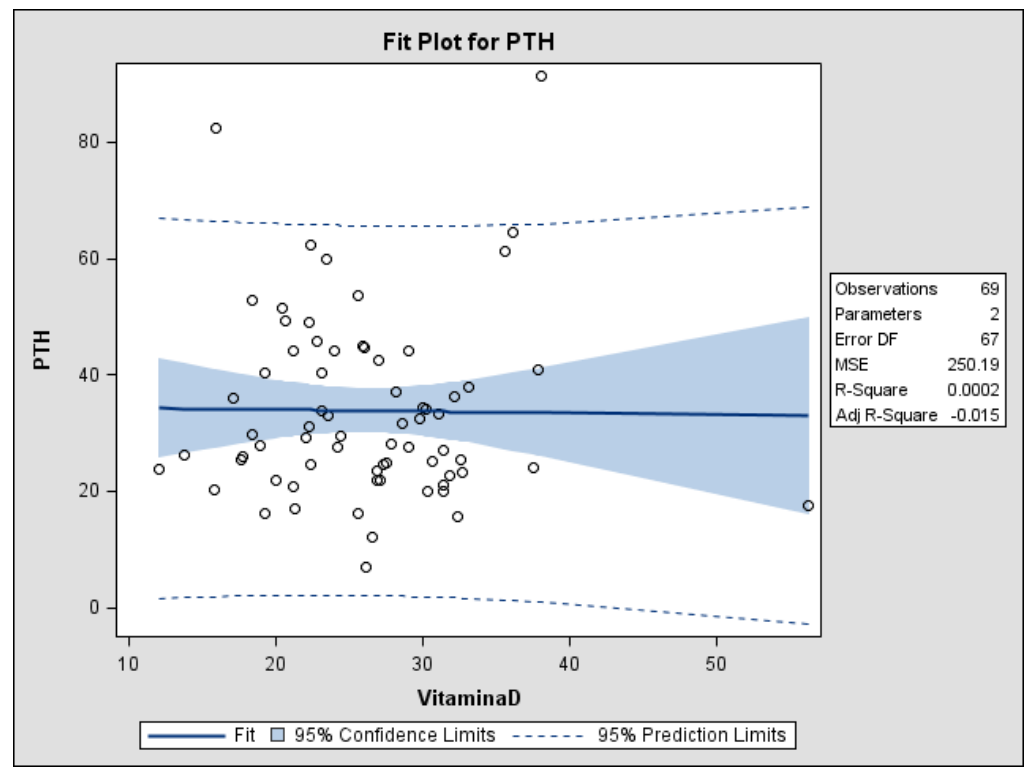

Figura 18 - Correlação entre 25(OH)D e PTHi

Tabela 15 - Associação entre categorias de 25(OH)D e concentrações séricas de PTHi

\begin{tabular}{|c|c|c|c|c|}
\hline & \multicolumn{3}{|c|}{ 25(OH)D } & \multirow[b]{2}{*}{$\mathbf{p}$} \\
\hline & $\begin{array}{l}\text { Deficiência } \\
\quad(n=13)\end{array}$ & $\begin{array}{c}\text { Insuficiência } \\
(n=36)\end{array}$ & $\begin{array}{l}\text { Suficiência } \\
(n=20)\end{array}$ & \\
\hline PTHi (pg/ml) & $32,95 \pm 17,65$ & $34,22 \pm 13,37$ & $33,79 \pm 18,86$ & 0,5429 \\
\hline
\end{tabular}

Valores expressos em média \pm desvio padrão p-valor calculado pelo teste de Kruskal-Wallis

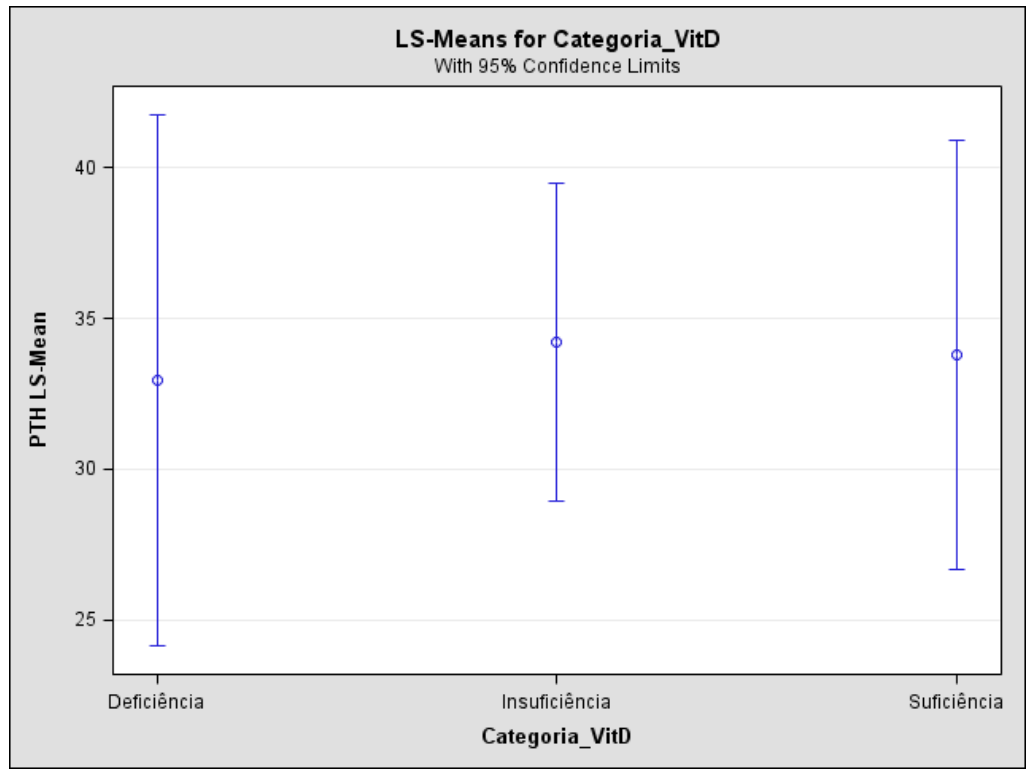

Figura 19 - Concentrações séricas de PTHi encontradas nas diferentes categorias de 25(OH)D 


\subsubsection{Correlação entre Concentrações Séricas de PTHi e Gravidade Clínica da DA}

4.2.6.1 Metodologia

A correlação entre as variáveis contínuas foram feitas empregando-se o coeficiente de correlação linear de Pearson. Para a comparação entre as variáveis PTHi (expressa em média \pm desvio padrão) e as categorias SCORAD, utilizou-se o teste de Kruskal-Wallis.

\subsubsection{Resultado}

Não houve correlação significativamente diferente de zero entre o PTHi e o SCORAD contínuos $(r=0,0691 ; p=0,5710)$ (Tabela 16, Figura 20).

Tabela 16 - Associação entre SCORAD e concentração sérica de PTHi

\begin{tabular}{cccccc}
\hline $\begin{array}{c}\text { Variável } \\
\text { dependente }\end{array}$ & $\begin{array}{c}\text { Variável } \\
\text { independente }\end{array}$ & $\mathbf{N}$ & $\begin{array}{c}\text { Correlação } \\
\text { estimada }\end{array}$ & IC 95\% & p-valor \\
\hline SCORAD & PTHi & 69 & $\mathbf{0 , 0 6 9 1}$ & $\begin{array}{c}-0,170353 \\
0,300874\end{array}$ & $\mathbf{0 , 5 7 1 0}$ \\
\hline
\end{tabular}

p-valor calculado pelo coeficiente de correlação linear de Pearson 


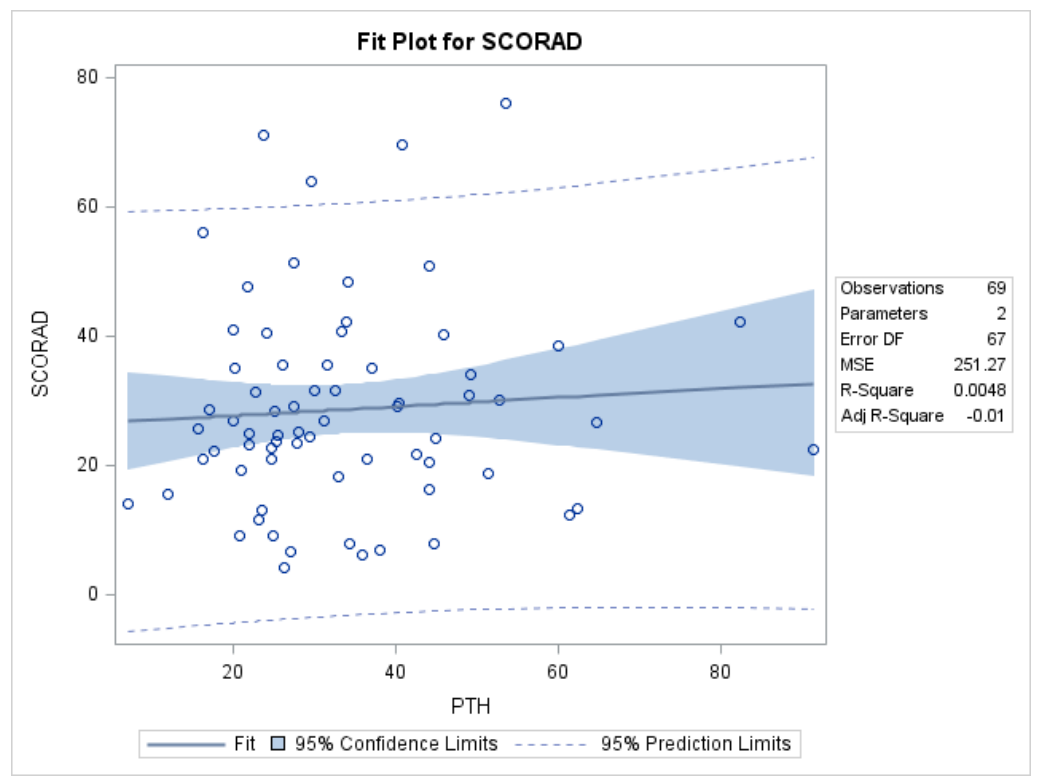

Figura 20 - Correlação entre SCORAD e concentração sérica de PTHi

Não houve correlação significativa entre concentrações séricas de PTHi e categorias clínicas de gravidade da DA (Tabela 17, Figura 21).

Tabela 17 - Associação entre concentrações séricas de PTHi e categorias do SCORAD

\begin{tabular}{lcccc}
\hline & \multicolumn{3}{c}{ SCORAD } & P \\
\cline { 2 - 4 } & $\begin{array}{c}\text { Leve } \\
(\mathbf{n}=\mathbf{3 3})\end{array}$ & $\begin{array}{c}\text { Moderado } \\
(\mathbf{n}=\mathbf{2 9})\end{array}$ & $\begin{array}{c}\text { Grave } \\
(\mathbf{n}=\mathbf{7})\end{array}$ & $\mathbf{p}$ \\
\hline PTHi $(\mathbf{p g} / \mathbf{m l})$ & $32,87 \pm 16,66$ & $35,02 \pm 15,58$ & $33,61 \pm 13,00$ & $\mathbf{0 , 8 0 3 9}$ \\
\hline $\begin{array}{l}\text { Valores expressos em média } \pm \text { desvio padrão ou n }(\%) \\
\text { p-valor calculado pelo teste de Kruskal-Wallis }\end{array}$ & &
\end{tabular}




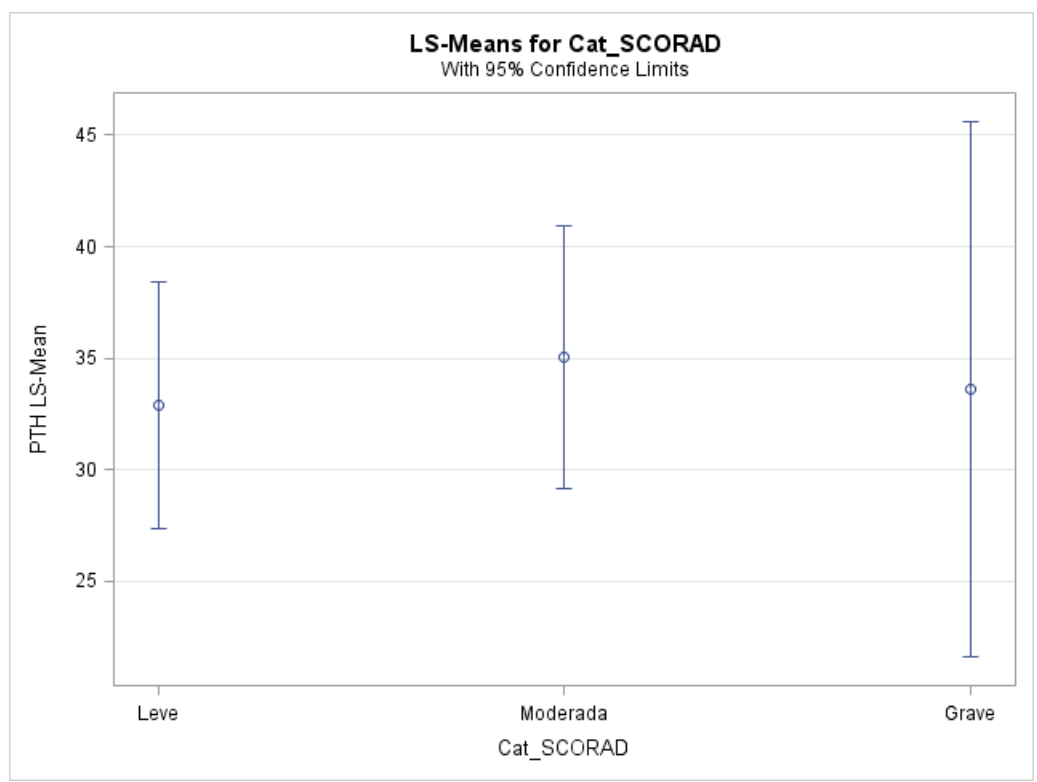

Figura 21 - Distribuição das concentrações séricas de PTHi (média \pm desvio-padrão) nas categorias SCORAD

\subsubsection{Análise Comparativa entre DA Intrínseca e DA Extrínseca}

\subsubsection{Metodologia}

Para as variáveis expressas em frequência, a comparação entre os subtipos de DA se deu por meio do teste de qui-quadrado. Para as variáveis expressas em média \pm desvio padrão sem distribuição gaussiana, a comparação se deu pelo teste de Mann-Whitney.

\subsubsection{Resultado}

O SCORAD objetivo médio dos pacientes com DA extrínseca (sujeitos com IgE elevada) foi significativamente maior que o SCORAD objetivo médio de pacientes com DA intrínseca (sujeitos com $\lg E$ normal) ( $p=0,0233$ ). As demais variáveis pesquisadas não apresentaram diferença significativa entre os grupos (Tabela 18). 
Tabela 18 - Comparação clínica e laboratorial entre pacientes com DA extrínseca e intrínseca

\begin{tabular}{|c|c|c|c|}
\hline & $\begin{array}{c}\text { DA extrínseca } \\
n=75\end{array}$ & $\begin{array}{c}\text { DA intrínseca } \\
n=27\end{array}$ & p-valor \\
\hline \multicolumn{4}{|l|}{ Gênero } \\
\hline Masculino & $28(37,33 \%)$ & $9(33,33 \%)$ & $0,7109^{a}$ \\
\hline Feminino & $47(62,67 \%)$ & $18(66,67 \%)$ & \\
\hline SCORAD & $30,14 \pm 16,63$ & $23,96 \pm 10,69$ & $0,1361^{b}$ \\
\hline SCORAD objetivo & $20,83 \pm 12,22$ & $14,44 \pm 7,85$ & $0,0233^{b}$ \\
\hline 25(OH)D & $29,21 \pm 9,94$ & $28,41 \pm 9,10$ & $0,6086^{b}$ \\
\hline Idade de início & $2,12 \pm 3,10$ & $1,72 \pm 1,91$ & $0,3854^{b}$ \\
\hline \multicolumn{4}{|l|}{ Asma ou RA } \\
\hline Sim & 47 (62,67\%) & $12(44,44 \%)$ & $0,1001^{a}$ \\
\hline Não & $28(37,33 \%)$ & $15(55,56 \%)$ & \\
\hline \multicolumn{4}{|l|}{ Atopia familiar } \\
\hline Sim & $51(68 \%)$ & $19(70,37 \%)$ & $0,8199^{a}$ \\
\hline Não & $24(32 \%)$ & $8(29,63 \%)$ & \\
\hline
\end{tabular}

Valores expressos em média \pm desvio padrão ou $\mathrm{n}(\%)$
a) $p$-valor calculado pelo teste de qui-quadrado
b) p-valor calculado pelo teste de Mann-Whitney

\subsubsection{Correlação entre 25(OH)D e IUV}

\subsubsection{Metodologia}

A correlação entre as variáveis $25(\mathrm{OH}) \mathrm{D}$ e IUV foi realizada empregando-se 0 coeficiente de correlação linear de Pearson.

\subsubsection{Resultado}

Não existiu correlação significativamente diferente de zero entre 25(OH)D e IUV $(r=0,11350 ; p=0,2451)$ (Tabela 19 e Figura 22). 
Tabela 19 - Correlação entre concentrações séricas de 25(OH)D e IUV

\begin{tabular}{cccccc}
\hline $\begin{array}{c}\text { Variável } \\
\text { dependente }\end{array}$ & $\begin{array}{c}\text { Variável } \\
\text { independente }\end{array}$ & $\mathbf{N}$ & $\begin{array}{c}\text { Correlação } \\
\text { estimada }\end{array}$ & IC 95\% & $\mathbf{p}$ \\
\hline $25(\mathrm{OH}) \mathrm{D}$ & IUV & 106 & 0,11350 & $\begin{array}{c}-0,078969 \\
0,297804\end{array}$ & $\mathbf{0 , 2 4 5 1}$ \\
\hline
\end{tabular}

p-valor calculado pelo coeficiente de correlação linear de Pearson

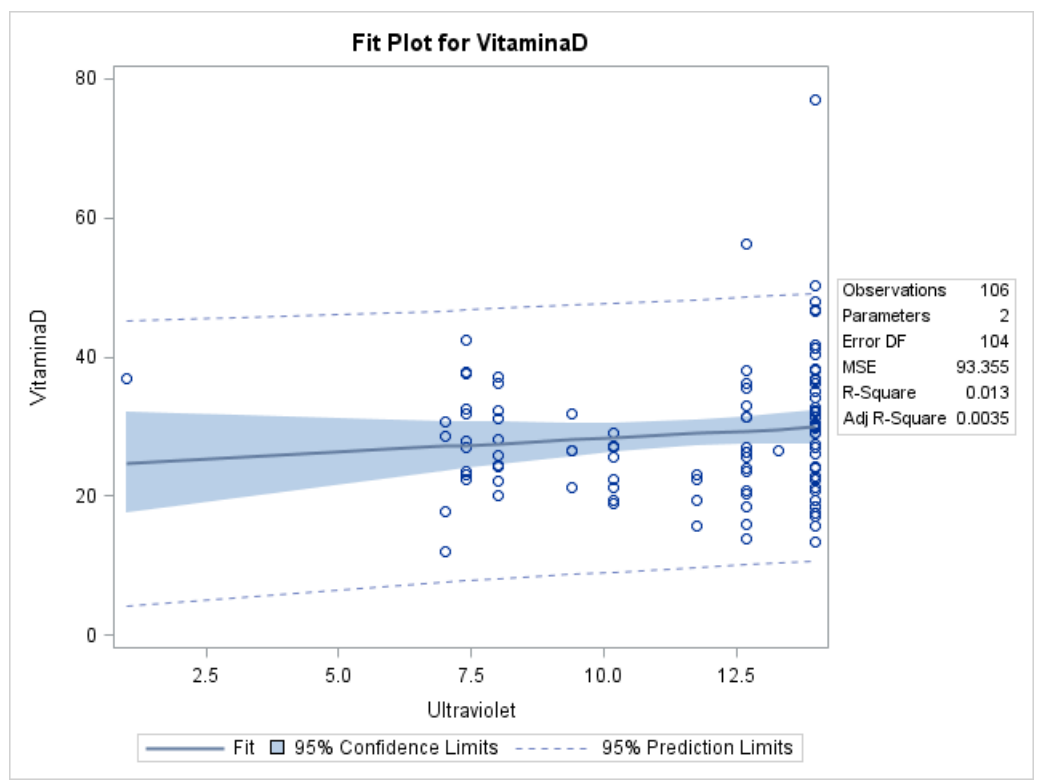

Figura 22 - Correlação entre 25(OH)D e IUV

\subsubsection{Correlação entre IUV e Gravidade Clínica da DA}

\subsubsection{Metodologia}

As correlações entre as variáveis IUV e SCORAD, assim como entre IUV e SCORAD objetivo, foram feitas empregando-se o coeficiente de correlação linear de Pearson. 


\subsubsection{Resultado}

Houve uma correlação significativamente diferente de zero $(r=-0,25306, p=$ 0,0083) entre IUV e SCORAD. Quanto maior foi o IUV, menor foi o SCORAD (Tabela 20, Figura 23). Houve tendência semelhante, porém estatisticamente não significante, entre IUV e SCORAD objetivo ( $r=-0,16750, p=0,0847)$ (Tabela 21 e Figura 24).

Tabela 20 - Correlação entre IUV e SCORAD

\begin{tabular}{cccccc}
\hline $\begin{array}{c}\text { Variável } \\
\text { dependente }\end{array}$ & $\begin{array}{c}\text { Variável } \\
\text { independente }\end{array}$ & $\mathbf{N}$ & $\begin{array}{c}\text { Correlação } \\
\text { estimada }\end{array}$ & IC 95\% & $\mathbf{p}$ \\
\hline SCORAD & IUV & 106 & $-0,25306$ & $\begin{array}{c}-0,423378 \\
0,065465\end{array}$ & $\mathbf{0 , 0 0 8 3}$ \\
\hline
\end{tabular}

p-valor calculado pelo coeficiente de correlação linear de Pearson

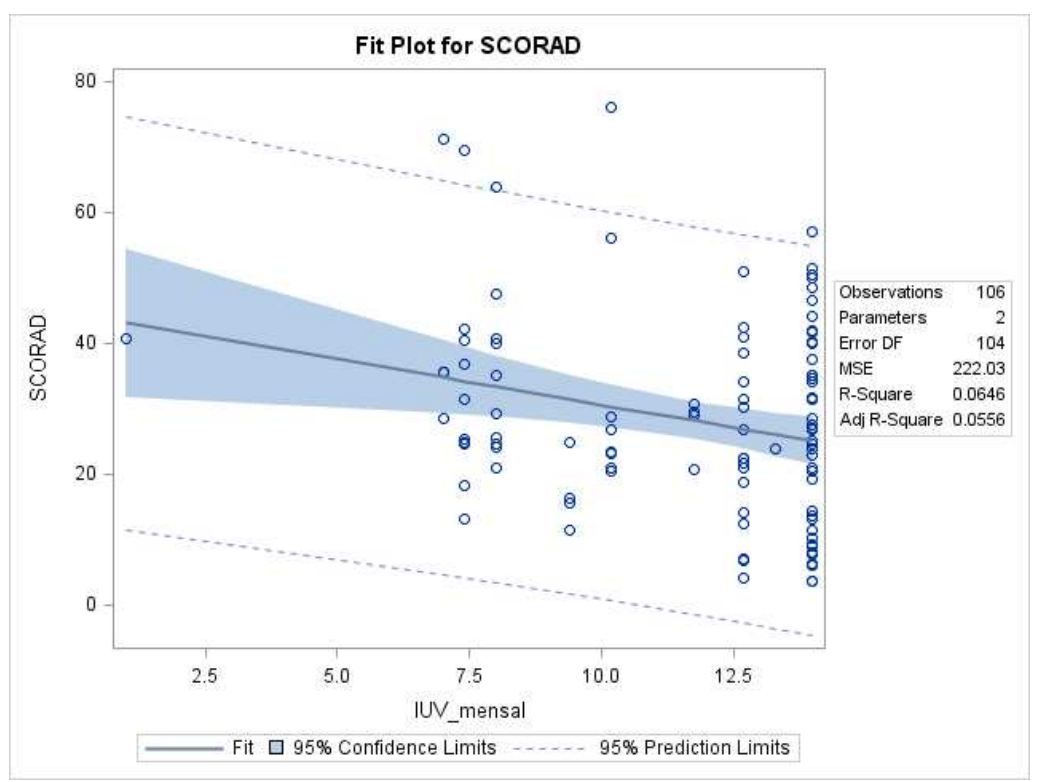

Figura 23 - Correlação entre IUV e SCORAD

Tabela 21 - Correlação entre IUV e SCORAD objetivo

\begin{tabular}{cccccc}
\hline $\begin{array}{c}\text { Variável } \\
\text { dependente }\end{array}$ & $\begin{array}{c}\text { Variável } \\
\text { independente }\end{array}$ & $\mathbf{N}$ & $\begin{array}{c}\text { Correlação } \\
\text { estimada }\end{array}$ & IC 95\% & $\mathbf{p}$ \\
\hline $\begin{array}{c}\text { SCORAD } \\
\text { Objetivo }\end{array}$ & IUV & 106 & $-0,16750$ & $\begin{array}{c}-0,347164 \\
0,024022\end{array}$ & $\mathbf{0 , 0 8 4 7}$ \\
\hline
\end{tabular}

p-valor calculado pelo coeficiente de correlação linear de Pearson 


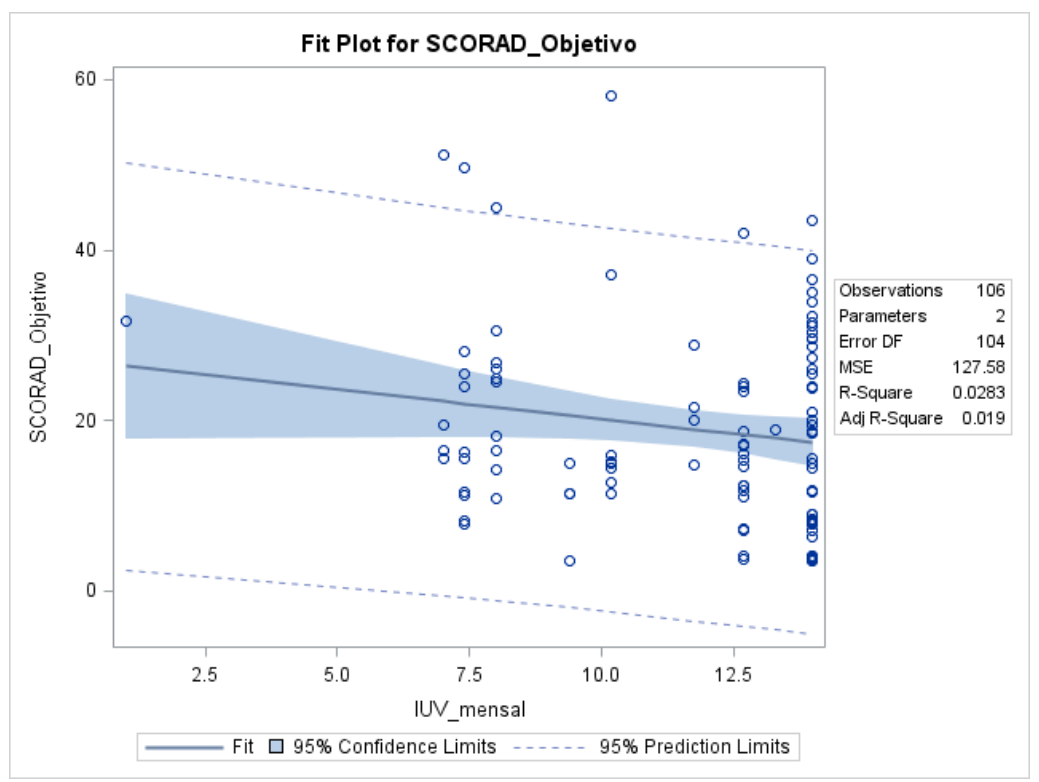

Figura 24 - Correlação entre IUV e SCORAD objetivo

\subsubsection{Associação entre Categorias SCORAD e Variáveis Independentes}

\subsubsection{Metodologia}

Cada uma das variáveis consideradas no presente estudo foi relacionada com a categoria SCORAD a fim de avaliar associação com a gravidade clínica determinada por esse índice. Para as variáveis expressas em média \pm desvio padrão e que apresentavam distribuição gaussiana a comparação entre as categorias de SCORAD se deu pela utilização do teste ANOVA. O teste de Kruskal-Wallis foi utilizado para aquelas que não apresentavam distribuição gaussiana. Empregou-se o teste de comparações múltiplas de Dwass, Steel, Critchlow-Fligner nas situações em que o teste de Kruskal-Wallis apresentou p-valor < 0,05. Para as variáveis expressas em frequência, a comparação entre as categorias do SCORAD se deu pelo uso do teste de qui-quadrado ou pelo teste exato de Fisher quando mais de $20 \%$ das caselas apresentaram frequência esperada inferior a 5. 


\subsubsection{Resultado}

Apenas a variável $\lg \mathrm{E}$ apresentou diferença significativa entre as categorias clínicas de gravidade de DA $(p=0,0148)$. Os valores médios de $\lg E$ não diferiram significativamente entre pacientes com DA leve e moderada ( $p=0,7662)$, porém diferiram significativamente entre pacientes com DA leve e grave $(p=0,0075)$, assim como entre pacientes com DA moderada a grave $(p=0,0474)$. As demais variáveis testadas não apresentaram associação significativa com a categoria SCORAD (Tabela 22, Figuras 25 a 31).

Tabela 22 - Associação das categorias de SCORAD com variáveis independentes

\begin{tabular}{|c|c|c|c|c|}
\hline & & SCORAD & & \\
\hline & $\begin{array}{c}\text { DA leve } \\
(n=49)\end{array}$ & $\begin{array}{c}\text { DA moderada } \\
(n=48)\end{array}$ & $\begin{array}{l}\text { DA grave } \\
\qquad(n=9)\end{array}$ & $\mathbf{p}$ \\
\hline Idade (anos) & $8,34 \pm 4,26$ & $8,19 \pm 3,90 P$ & $7,31 \pm 3,62$ & $0,7822^{\mathrm{a}}$ \\
\hline Gênero & & & & \\
\hline Masculino & $18(36,73 \%)$ & $16(33,33 \%)$ & $4(44,44 \%)$ & $0,8033^{b}$ \\
\hline Feminino & 31 (63,27\%) & $32(66,67 \%)$ & $5(55,56 \%)$ & \\
\hline Fototipo & & & & \\
\hline II & $2(4,08 \%)$ & $5(10,42 \%)$ & 0 & \\
\hline III & $11(22,45 \%)$ & $16(33,33 \%)$ & $3(33,33 \%)$ & $0,4826^{c}$ \\
\hline IV & $33(67,35 \%)$ & $26(54,17 \%)$ & $6(66,67 \%)$ & \\
\hline $\mathbf{V}$ & $3(6,12 \%)$ & $1(2,08 \%)$ & 0 & \\
\hline Renda & $3,69 \pm 2,82$ & $3,26 \pm 2,71$ & $1,67 \pm 0,61$ & $0,0790^{d}$ \\
\hline IMC (kg/m²) & $17,68 \pm 3,47$ & $17,80 \pm 3,00$ & $17,91 \pm 2,60$ & $0,7951^{d}$ \\
\hline IMC & & & & \\
\hline Magreza & $2(4,08 \%)$ & 0 & 0 & \\
\hline Adequado & 34 (69,39\%) & $32(66,67 \%)$ & $4(44,44 \%)$ & 0 n989c \\
\hline Risco sobrep & 7 (14,29\%) & $13(27,08 \%)$ & $4(44,44 \%)$ & 0.0982 \\
\hline Sobrepeso & $5(10,20 \%)$ & $3(6,25 \%)$ & 0 & \\
\hline Obesidade & $1(2,04 \%)$ & 0 & $1(11,11 \%)$ & \\
\hline Asma ou RA & & & & \\
\hline Sim & 27 (55,10\%) & 28 (58,33\%) & $5(55,56 \%)$ & $0,9477^{b}$ \\
\hline Não & $22(44,90 \%)$ & $20(41,67 \%)$ & $4(44,44 \%))$ & \\
\hline Atopia familiar & & & & \\
\hline Sim & 33 (67,35\%) & 34 (70,83\%) & $5(55,56 \%)$ & $0,6617^{b}$ \\
\hline Não & $16(32,65 \%)$ & $14(29,17 \%)$ & $4(44,44 \%)$ & \\
\hline
\end{tabular}


continuação

Tabela 22 - Associação das categorias de SCORAD com variáveis independentes

\begin{tabular}{|c|c|c|c|c|}
\hline & \multicolumn{3}{|c|}{ SCORAD } & \multirow[b]{2}{*}{$\mathbf{p}$} \\
\hline & $\begin{array}{c}\text { DA leve } \\
(n=49)\end{array}$ & $\begin{array}{l}\text { DA moderada } \\
\qquad(n=48)\end{array}$ & $\begin{array}{c}\text { DA grave } \\
(n=9)\end{array}$ & \\
\hline Idade de início & $2,25 \pm 3,25$ & $2,07 \pm 2,51$ & $0,99 \pm 1,92$ & $0.1792^{d}$ \\
\hline IUV & $12,1 \pm 2,36$ & $11,4 \pm 3,17$ & $10,8 \pm 2,93$ & $0,4362^{d}$ \\
\hline IgE total & $718,87 \pm 992,81$ & $\begin{array}{c}1324,80 \pm \\
2297,58\end{array}$ & $\begin{array}{c}3492,78 \pm \\
4841,59\end{array}$ & $0,0148^{\mathrm{d}, \mathrm{e}}$ \\
\hline Eosinofilos (\%) & $6,70 \% \pm 5,47$ & $8,23 \% \pm 4,62$ & $9,83 \% \pm 3,89$ & $0,1376^{a}$ \\
\hline
\end{tabular}

Renda expressa em salários-mínimos

IUV representa a média do IUV máximo nos 30 dias anteriores à avaliação clínica.

Valores expressos em média \pm desvio padrão ou $n(\%)$

a) $p$-valor calculado pelo teste ANOVA

b) $p$-valor calculado pelo teste de qui-quadrado

c) $p$ - valor calculado pelo teste exato de Fisher

d) $p$-valor calculado pelo teste de Kruskal-Wallis

e) comparações múltiplas usando o teste de Dwass, Steel, Critchlow-Fligner. (Leve versus Moderada - $p=0,7662$; Leve versus Grave - $p=0,0075$; Moderada versus Grave - $p=0,0474$ )

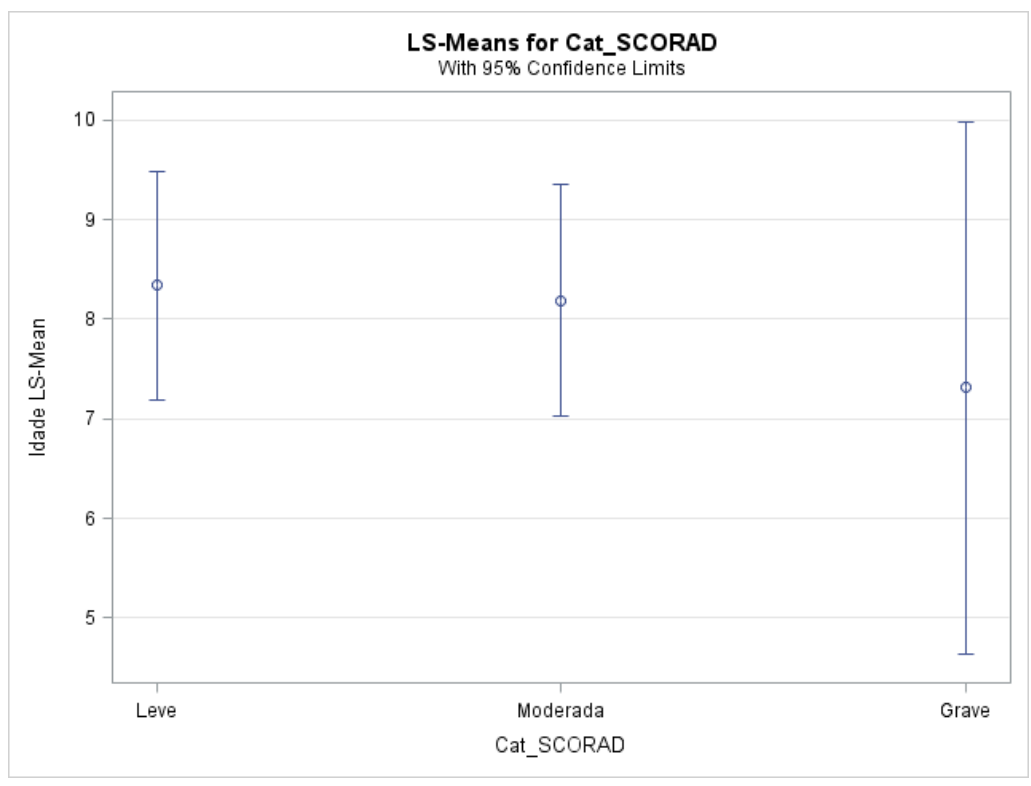

Figura 25 - Distribuição da idade (média \pm desvio padrão) nas diferentes categorias SCORAD 


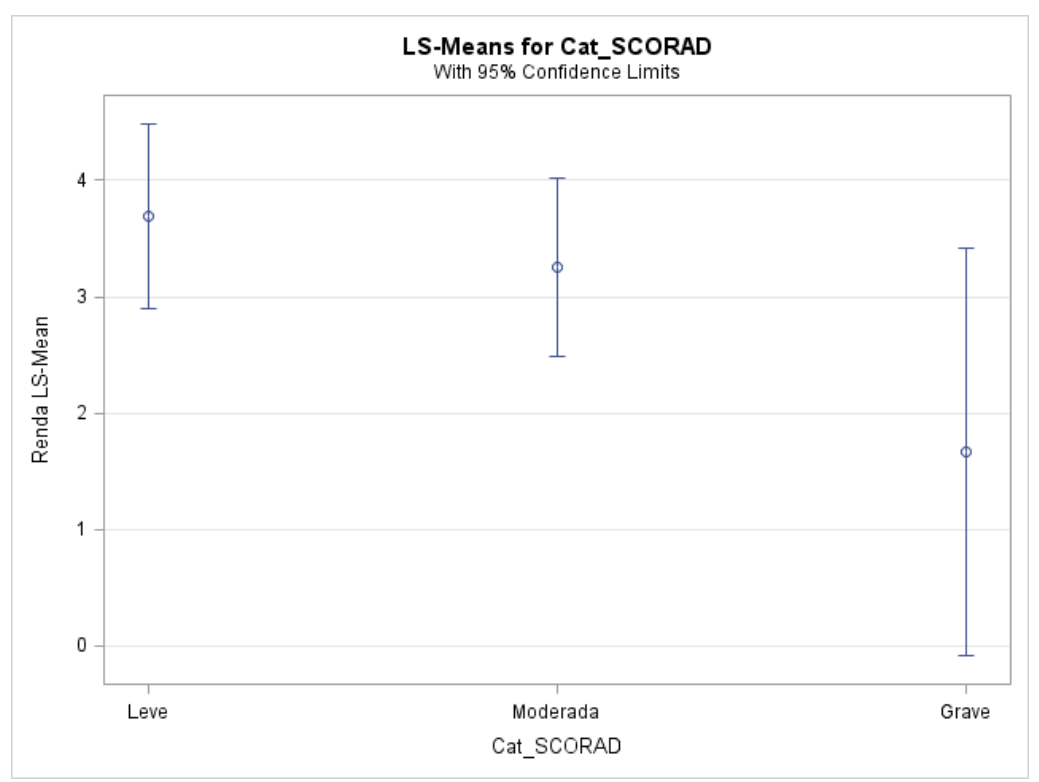

Figura 26 - Distribuição da renda (média \pm desvio padrão) nas diferentes categorias SCORAD

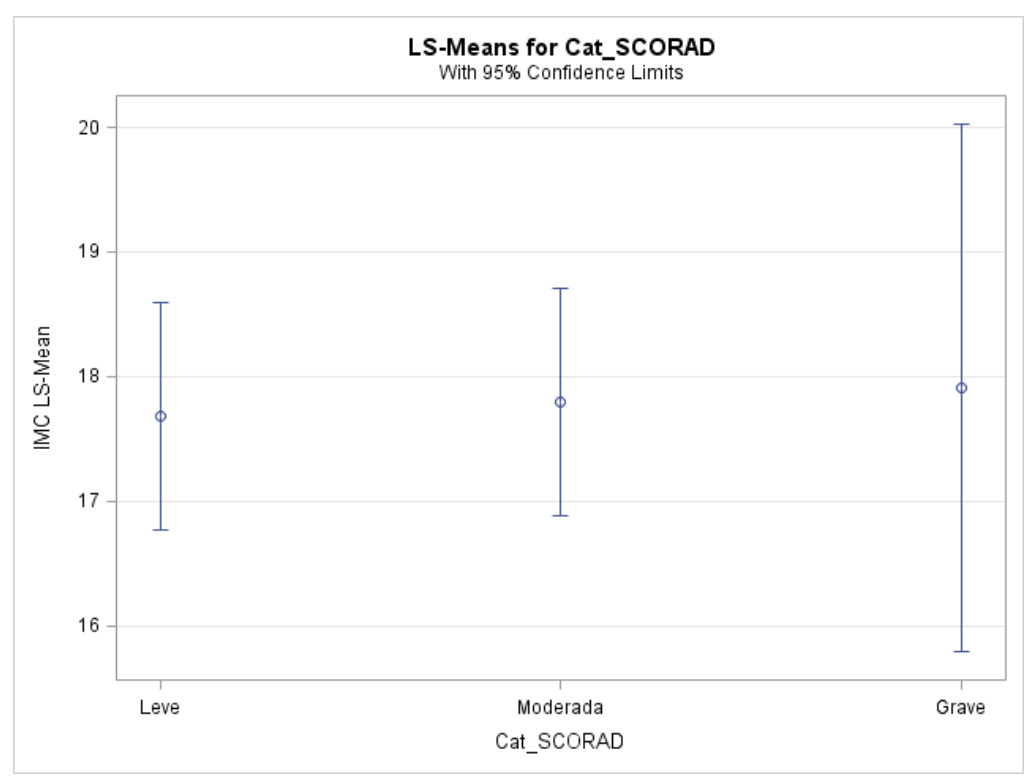

Figura 27 - Distribuição do IMC (média \pm desvio padrão) nas diferentes categorias SCORAD 


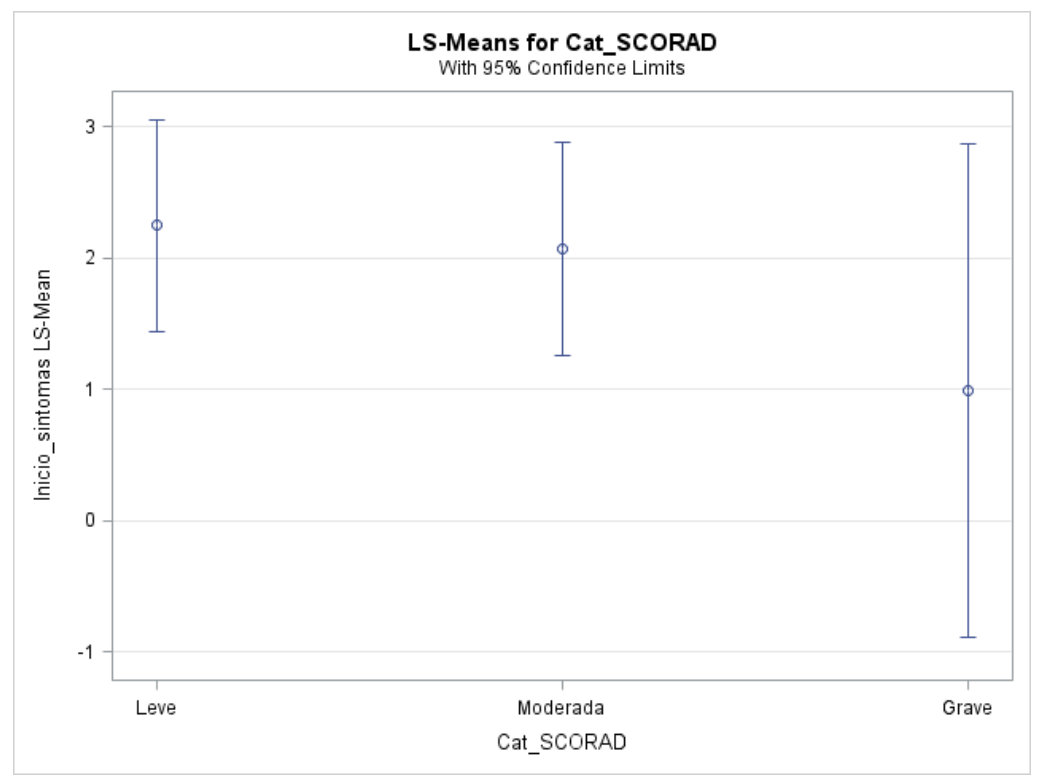

Figura 28 - Distribuição da idade de início dos sintomas (média \pm desvio padrão) nas diferentes categorias SCORAD

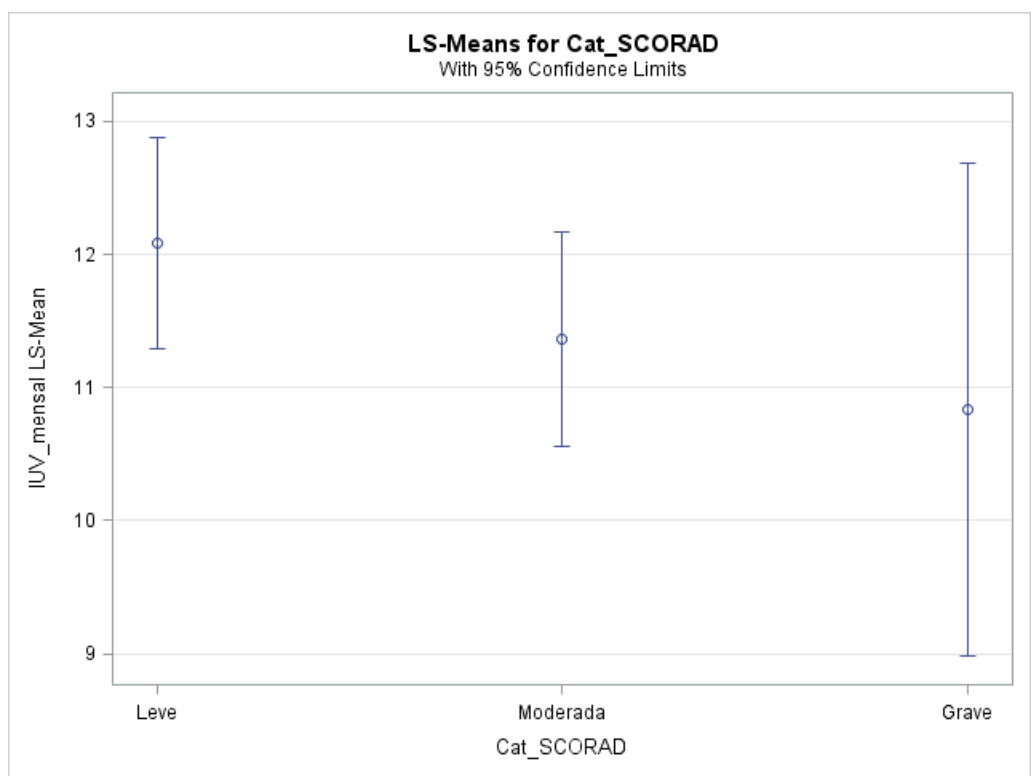

Figura 29 - Distribuição do IUV (média \pm desvio-padrão) nas diferentes categorias SCORAD 


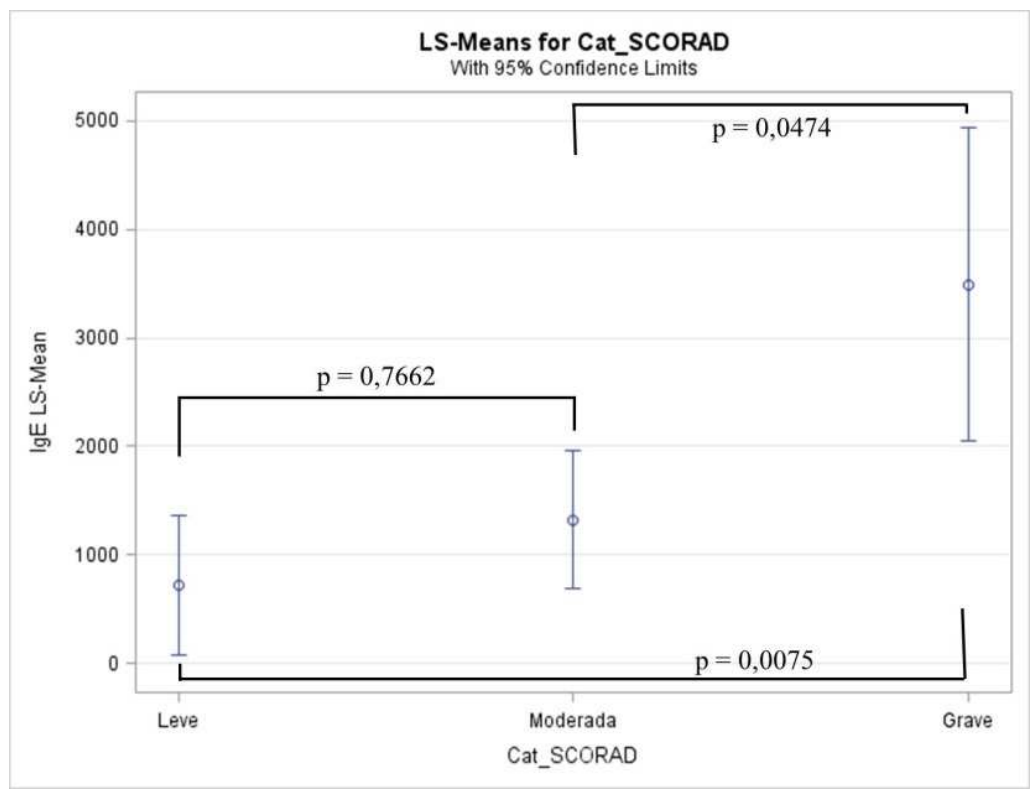

Figura 30 - Distribuição de lgE (média \pm desvio-padrão) nas diferentes categorias SCORAD

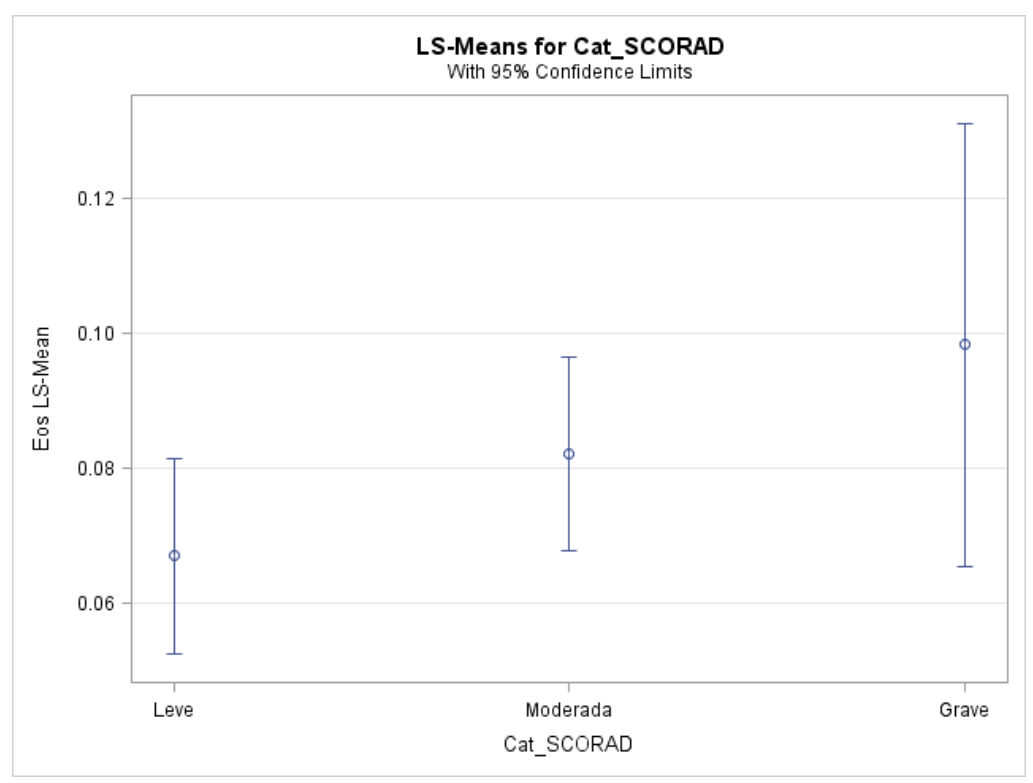

Figura 31 - Distribuição da eosinofilia relativa (média \pm desvio-padrão) nas diferentes categorias SCORAD 


\subsubsection{Análise Multivariada para Identificação de Variáveis Determinantes do SCORAD}

\subsubsection{Metodologia}

Para se analisar a relação entre SCORAD com potenciais confundidores foi realizada análise de regressão linear múltipla. A variável resposta foi SCORAD e como potenciais confundidores idade, gênero (feminino versus masculino), fototipo (II e III versus IV e V), renda, IMC, asma ou RA (sim versus não), atopia familiar (sim versus não), idade de início dos sintomas, IUV, IgE, eosinófilos e concentração sérica de 25(OH)D, que foram introduzidos na equação de regressão através do método stepwise backward. A significância da contribuição das variáveis ao modelo foi estimada e comparada com o critério de remoção $(p=0,1)$. Quando um potencial preditor atingia o critério de remoção, ele era removido do modelo de regressão. $O$ modelo era então reestimado para as variáveis remanescentes, e o processo era então repetido até que nenhum preditor atingia o critério de remoção. Os resíduos padronizados do último modelo foram verificados quanto à normalidade.

\subsubsection{Resultado}

A análise de regressão linear múltipla mostrou que apenas as variáveis $\lg \mathrm{E}$ e IUV foram preditores associados significativamente com SCORAD (Tabela 23). Os resultados indicaram que: quanto maior o valor de $\lg \mathrm{E}$, maiores são os valores de SCORAD e quanto maiores os valores de IUV, menores os valores do SCORAD. 
Tabela 23 - Análise de regressão linear múltipla (modelos para predizer SCORAD)

\begin{tabular}{lcccc}
\hline Modelos e Preditores & $\boldsymbol{\beta}$ & $\mathbf{p}$-valor $\boldsymbol{\beta}$ & $\mathbf{r}^{2}$ & IC 95 \% de $\boldsymbol{\beta}$ \\
\hline Modelo & & & 0,2275 \\
$\quad$ Constante & 44,750 & $<0,0001$ & & 31,852 a 57,648 \\
IUV mensal & $-1,350$ & 0,0085 & & $-2,347$ a $-0,352$ \\
Renda & $-0,916$ & 0,0913 & & $-1,983$ a 0,150 \\
IgE & 0,002 & 0,0003 & & 0,001 a 0,004 \\
\hline
\end{tabular}

Variável dependente: SCORAD; variáveis independentes: idade, gênero, fototipo, renda, IMC, asma ou RA, atopia familiar, idade de início dos sintomas, IUV, IgE, eosinófilos e 25(OH)D.

IC: intervalo de confiança, $\beta$ : coeficiente não padronizado; $p$-valores $<0,05$ foram considerados estatisticamente significativos.

\subsubsection{Correlação entre IMC e Concentrações Séricas de 25(OH)D}

\subsubsection{Metodologia}

As correlações entre as variáveis quantitativas foram feitas empregando-se o coeficiente de correlação linear de Pearson.

\subsubsection{Resultado}

Existiu correlação significativamente diferente de zero entre IMC e 25(OH)D. Observou-se que, quanto o maior o IMC, menor foi o valor encontrado de $25(\mathrm{OH}) \mathrm{D}$ (Tabela 24, Figura 32).

Tabela 24 - Correlação entre IMC e concentrações séricas de 25(OH)D

\begin{tabular}{cccccc}
\hline $\begin{array}{c}\text { Variável } \\
\text { dependente }\end{array}$ & $\begin{array}{c}\text { Variável } \\
\text { independente }\end{array}$ & $\mathbf{N}$ & $\begin{array}{c}\text { Correlação } \\
\text { estimada }\end{array}$ & IC 95\% & $\mathbf{p}$ \\
\hline $25(\mathrm{OH}) \mathrm{D}$ & $\mathrm{IMC}$ & 106 & $-0,19372$ & $\begin{array}{l}-0,370778 \\
-0,003083\end{array}$ & $\mathbf{0 , 0 4 5 4}$ \\
\hline
\end{tabular}

p-valor calculado pelo coeficiente de correlação linear de Pearson 


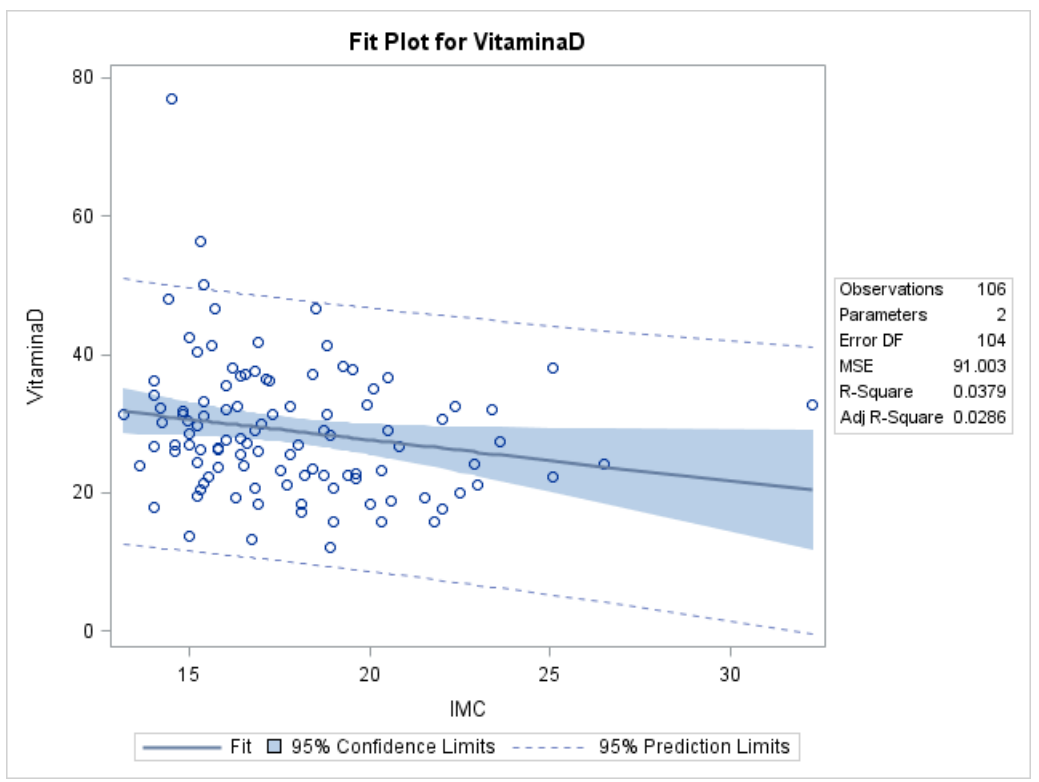

Figura 32 - Correlação entre IMC e 25(OH)D

\subsubsection{Correlação entre Idade e Concentrações Séricas de 25(OH)D}

\subsubsection{Metodologia}

A correlação entre as variáveis foi feita empregando-se o coeficiente de correlação linear de Pearson.

\subsubsection{Resultado}

Existiu correlação significativamente diferente de zero entre idade e $25(O H) D$, no sentido de quanto maior a idade, menor a concentração encontrada de 25(OH)D ( $r$ $=-0,26573 ; p=0,0055)$ (Tabela 25, Figura 33). 
Tabela 25 - Correlação entre idade e concentrações séricas de 25(OH)D

\begin{tabular}{cccccc}
\hline $\begin{array}{c}\text { Variável } \\
\text { dependente }\end{array}$ & $\begin{array}{c}\text { Variável } \\
\text { independente }\end{array}$ & $\mathbf{N}$ & $\begin{array}{c}\text { Correlação } \\
\text { estimada }\end{array}$ & IC 95\% & $\mathbf{p}$ \\
\hline $25(\mathrm{OH}) \mathrm{D}$ & Idade & 106 & $-0,26573$ & $\begin{array}{l}-0,434462 \\
-0,078978\end{array}$ & $\mathbf{0 , 0 0 5 5}$ \\
\hline
\end{tabular}

p-valor calculado pelo coeficiente de correlação linear de Pearson

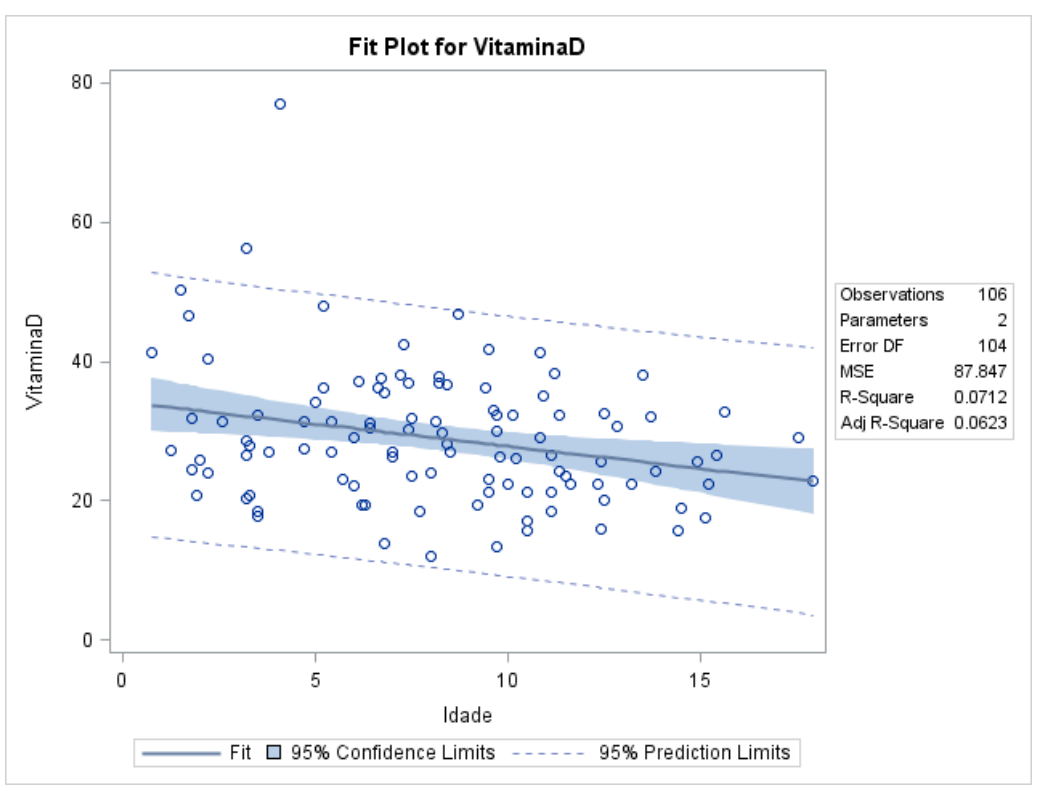

Figura 33 - Correlação entre idade e concentrações séricas de $25(\mathrm{OH}) \mathrm{D}$

\subsubsection{Associação entre Estação do Ano e Concentrações Séricas de 25(OH)D}

\subsubsection{Metodologia}

As variáveis estação do ano e concentrações séricas de 25(OH)D foram analisadas utilizando-se o teste de Kruskal-Wallis. 


\subsubsection{Resultado}

As concentrações médias de $25(\mathrm{OH}) \mathrm{D}$ não diferiram entre as estações climáticas do ano ( $p=0,0675$ ) (Tabela 26, Figura 34).

Tabela 26 - Associação entre estações climáticas e concentrações séricas de 25(OH)D

\begin{tabular}{cccccc}
\hline & $\begin{array}{c}\text { Primavera } \\
(\mathrm{n}=28)\end{array}$ & $\begin{array}{c}\text { Verão } \\
(\mathrm{n}=38)\end{array}$ & $\begin{array}{c}\text { Outono } \\
(\mathrm{n}=22)\end{array}$ & $\begin{array}{c}\text { Inverno } \\
(\mathrm{n}=18)\end{array}$ & $\mathrm{p}$ \\
\hline $\begin{array}{c}25(\mathrm{OH}) \mathrm{D} \\
(\mathrm{ng} / \mathrm{ml})\end{array}$ & $32,89 \pm 12,23$ & $28,74 \pm 9,42$ & $25,53 \pm 6,12$ & $27,39 \pm 7,09$ & $\mathbf{0 , 0 6 7 5}$ \\
\hline${ }^{*} \mathrm{p}$-valor calculado pelo teste de Kruskal-Wallis & & &
\end{tabular}

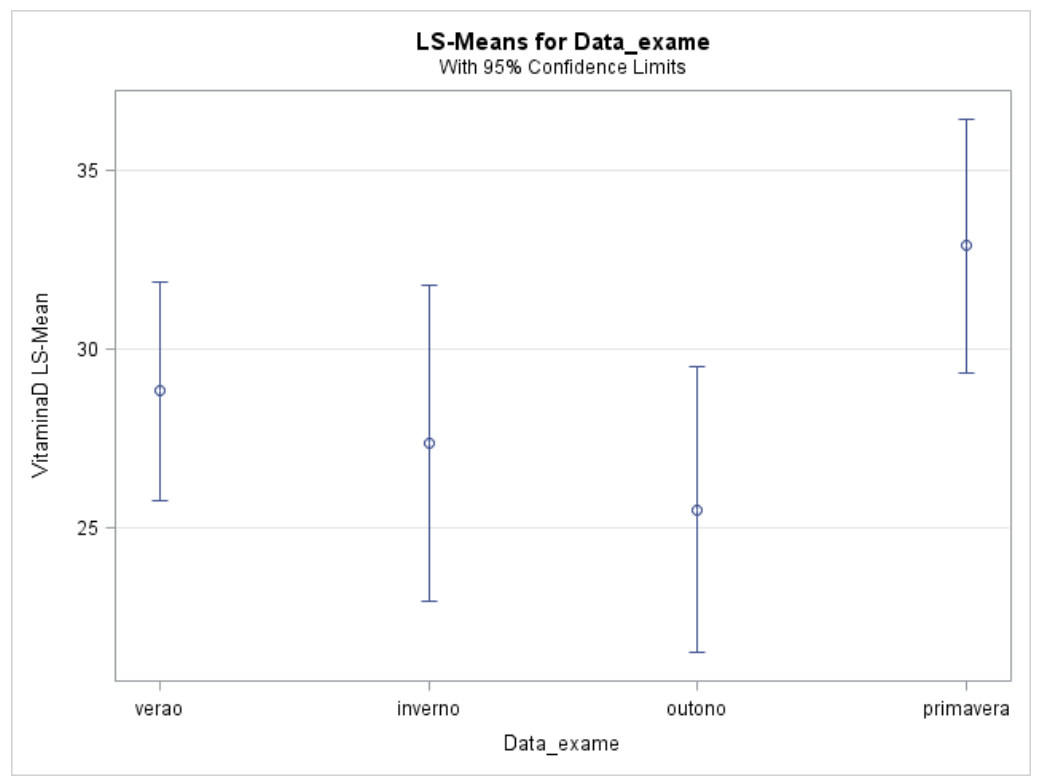

Figura 34 - Distribuição das concentrações séricas de 25(OH)D nas diferentes estações climáticas 


\subsubsection{Associação entre Categorias de 25(OH)D e Variáveis Independentes}

\subsubsection{Metodologia}

Cada variável foi relacionada com a categoria de $25(\mathrm{OH}) \mathrm{D}$ a fim de avaliar a associação daquela com o status de vitamina D. Para as variáveis expressas em média \pm desvio padrão e que apresentavam distribuição gaussiana, a comparação entre os níveis estratificados de $25(\mathrm{OH}) \mathrm{D}$ se deu pela utilização do teste ANOVA, ou pelo teste de Kruskal-Wallis para aquelas que não apresentavam distribuição gaussiana. Para as variáveis expressas em frequência a comparação entre os níveis de $25(\mathrm{OH}) \mathrm{D}$ se deu pelo uso do teste de qui-quadrado, ou pelo teste exato de Fisher quando mais de $20 \%$ das caselas apresentaram frequência esperada inferior a 5.

\subsubsection{Resultado}

Nenhuma variável apresentou associação significativa com as concentrações séricas estratificadas de 25(OH)D (Tabela 27, Figuras 35 a 41).

Tabela 27 - Associação entre categorias de 25(OH)D e variáveis independentes

\begin{tabular}{l|cccc}
\hline & $\begin{array}{c}\text { 25(OH)D } \\
\text { Deficiência } \\
(\mathbf{n = 1 7 )}\end{array}$ & $\begin{array}{c}\text { Insuficiência } \\
(\mathbf{n = 4 4 )}\end{array}$ & $\begin{array}{c}\text { Suficiência } \\
(\mathbf{n}=\mathbf{4 5})\end{array}$ & $\mathbf{p}$ \\
\hline Idade (anos) & $9,52 \pm 3,61$ & $8,44 \pm 4,51$ & $7,43 \pm 3,56$ & $\mathbf{0 , 1 6 4 1 ^ { \text { a } }}$ \\
$\begin{array}{l}\text { Gênero } \\
\text { Masculino }\end{array}$ & $5(29,41 \%)$ & $19(43,18 \%)$ & $14(31,11 \%)$ & $\mathbf{0 , 4 1 1 8 ^ { b }}$ \\
$\quad$ Feminino & $12(70,59 \%)$ & $25(56,82 \%)$ & $31(68,89 \%)$ & \\
Fototipo & & & & \\
II & 0 & $2(4,54 \%)$ & $5(11,11 \%)$ & \\
III & $4(23,53 \%)$ & $9(20,46 \%)$ & $17(37,78 \%)$ & $\mathbf{0 , 1 2 8 5 ^ { c }}$ \\
IV & $12(70,59 \%)$ & $30(68,18 \%)$ & $23(51,11 \%)$ & \\
V & $1(5,88 \%)$ & $3(6,82 \%)$ & 0 & \\
continua & & & &
\end{tabular}


continuação

Tabela 27 - Associação entre categorias de 25(OH)D e variáveis independentes

\begin{tabular}{|c|c|c|c|c|}
\hline & \multicolumn{3}{|c|}{ 25(OH)D } & \multirow[b]{2}{*}{$\mathbf{p}$} \\
\hline & $\begin{array}{c}\text { Deficiência } \\
(n=17)\end{array}$ & $\begin{array}{l}\text { Insuficiência } \\
(n=44)\end{array}$ & $\begin{array}{l}\text { Suficiência } \\
\quad(n=45)\end{array}$ & \\
\hline Renda & $3,86 \pm 3,23$ & $3,04 \pm 2,53$ & $3,35 \pm 2,64$ & $0,5583^{d}$ \\
\hline IMC & $18,64 \pm 2,65$ & $17,79 \pm 2,98$ & $17,39 \pm 3,51$ & $0,1224^{d}$ \\
\hline $\begin{array}{l}\text { IMC } \\
\text { Magreza } \\
\text { Adequado } \\
\text { Risco Sobrep } \\
\text { Sobrepeso } \\
\text { Obesidade }\end{array}$ & $\begin{array}{c}0 \\
12(70,59 \%) \\
4(23,53 \%) \\
0 \\
1(5,88 \%)\end{array}$ & $\begin{array}{c}0 \\
30(68,18 \%) \\
7(15,91 \%) \\
6(13,64 \%) \\
1(2,27 \%)\end{array}$ & $\begin{array}{c}2(4,44 \%) \\
28(62,22 \%) \\
13(28,90 \%) \\
2(4,44 \%) \\
0\end{array}$ & $0,1798^{c}$ \\
\hline $\begin{array}{l}\text { Atopia pessoal } \\
\text { Sim } \\
\text { Não }\end{array}$ & $\begin{array}{c}10(58,82 \%) \\
7(41,18 \%)\end{array}$ & $\begin{array}{l}28(63,64 \%) \\
16(36,36 \%)\end{array}$ & $\begin{array}{l}22(48,89 \%) \\
23(51,11 \%)\end{array}$ & $0,3360^{\mathrm{b}}$ \\
\hline $\begin{array}{l}\text { Atopia familiar } \\
\text { Sim } \\
\text { Não }\end{array}$ & $\begin{array}{l}14(82,35 \%) \\
3(17,65 \%))\end{array}$ & $\begin{array}{l}26(59,09 \%) \\
18(40,91 \%)\end{array}$ & $\begin{array}{l}32(71,11 \%) \\
13(28,89 \%)\end{array}$ & $0,1818^{b}$ \\
\hline SCORAD & $33,16 \pm 16,95$ & $27,14 \pm 14,63$ & $27,58 \pm 15,37$ & $0,3609^{a}$ \\
\hline $\begin{array}{l}\text { SCORAD } \\
\text { Leve } \\
\text { Moderada } \\
\text { Grave }\end{array}$ & $\begin{array}{l}6(35,29 \%) \\
9(52,94 \%) \\
2(11,77 \%)\end{array}$ & $\begin{array}{c}23(52,27 \%) \\
17(38,64 \%) \\
4(9,09 \%)\end{array}$ & $\begin{array}{c}20(44,44 \%) \\
22(48,89 \%) \\
3(6,67 \%)\end{array}$ & $0,7590^{\circ}$ \\
\hline IUV & $11,9 \pm 2,52$ & $11,2 \pm 2,56$ & $12,0 \pm 3,13$ & $0,1228^{d}$ \\
\hline IgE total & $\begin{array}{c}1598,52 \pm \\
1903,07\end{array}$ & $\begin{array}{c}1249,09 \pm \\
2523,54\end{array}$ & $\begin{array}{c}1107,51 \pm \\
2235,86\end{array}$ & $0,3856^{d}$ \\
\hline Eosinófilos (\%) & $7,14 \% \pm 3,66$ & $7,57 \% \pm 5,13$ & $7,98 \% \pm 5,41$ & $0,9729^{d}$ \\
\hline
\end{tabular}

Renda expressa em salários-mínimos

IUV representa a média do IUV máximo nos 30 dias anteriores à avaliação clínica Valores expressos em média \pm desvio padrão ou $n(\%)$
a) $p$-valor calculado pelo teste ANOVA
b) $p$-valor calculado pelo teste de qui-quadrado
c) $p$ - valor calculado pelo teste exato de Fisher
d) p-valor calculado pelo teste de Kruskal-Wallis 


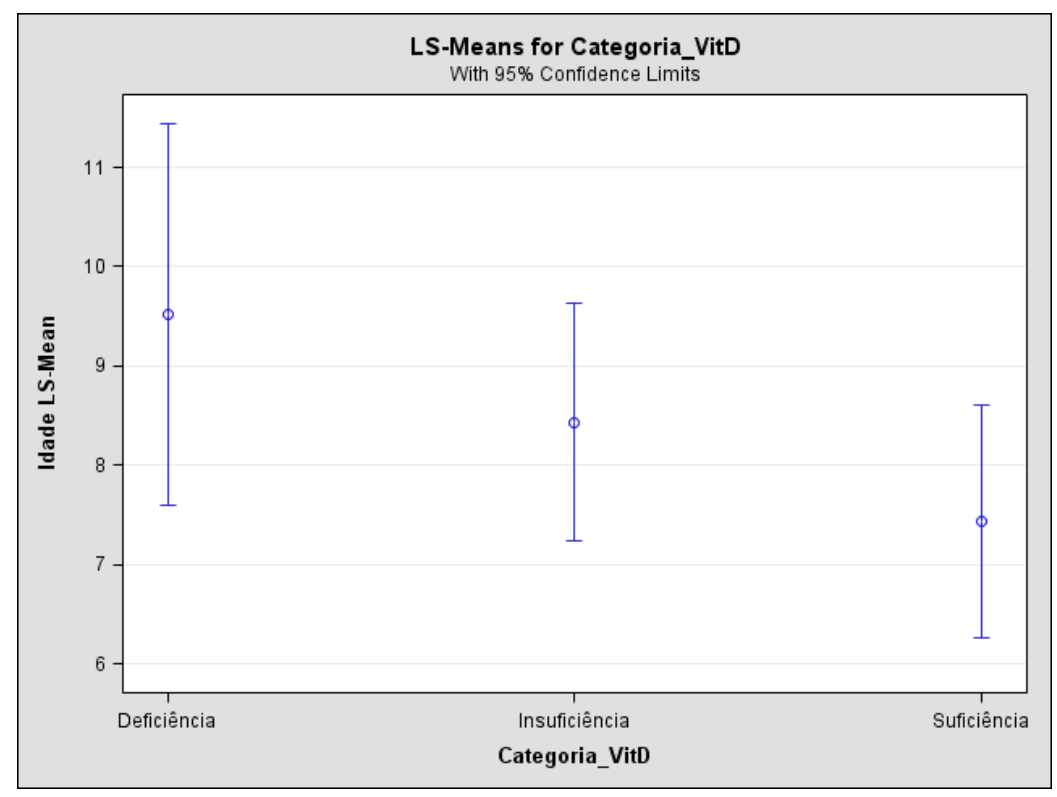

Figura 35 - Distribuição da idade (média \pm desvio padrão) nas diferentes categorias de $25(\mathrm{OH}) \mathrm{D}$

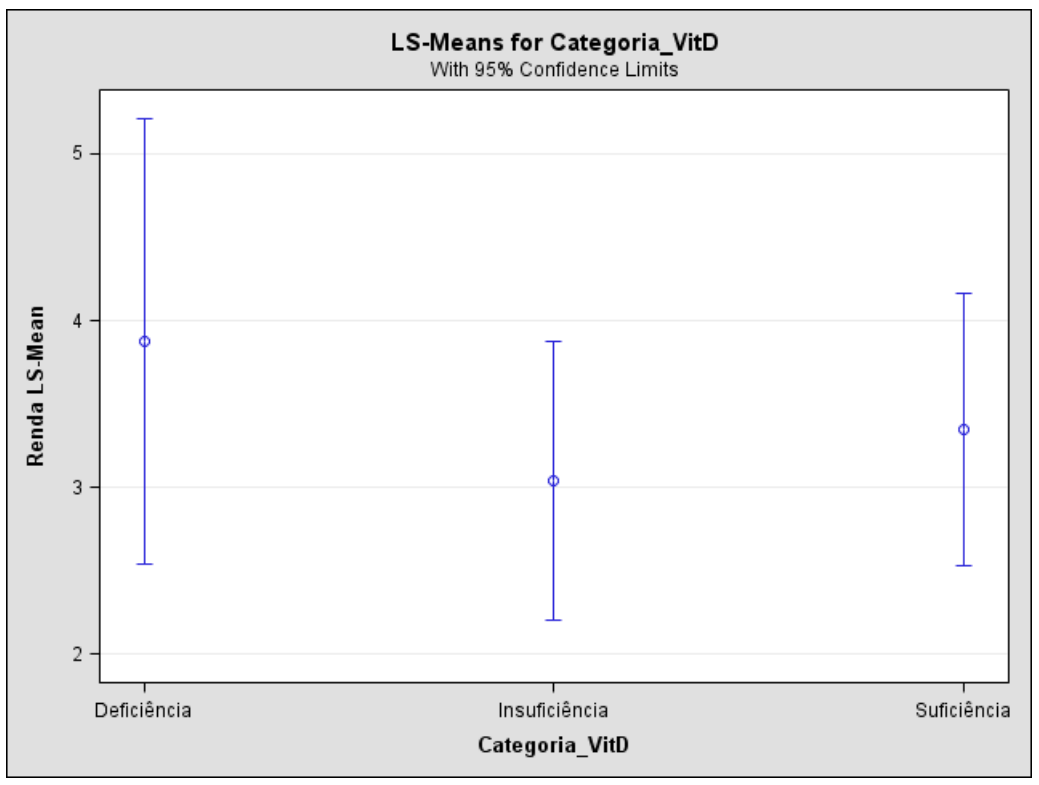

Figura 36 - Distribuição da renda (média \pm desvio padrão) nas diferentes categorias de $25(\mathrm{OH}) \mathrm{D}$ 


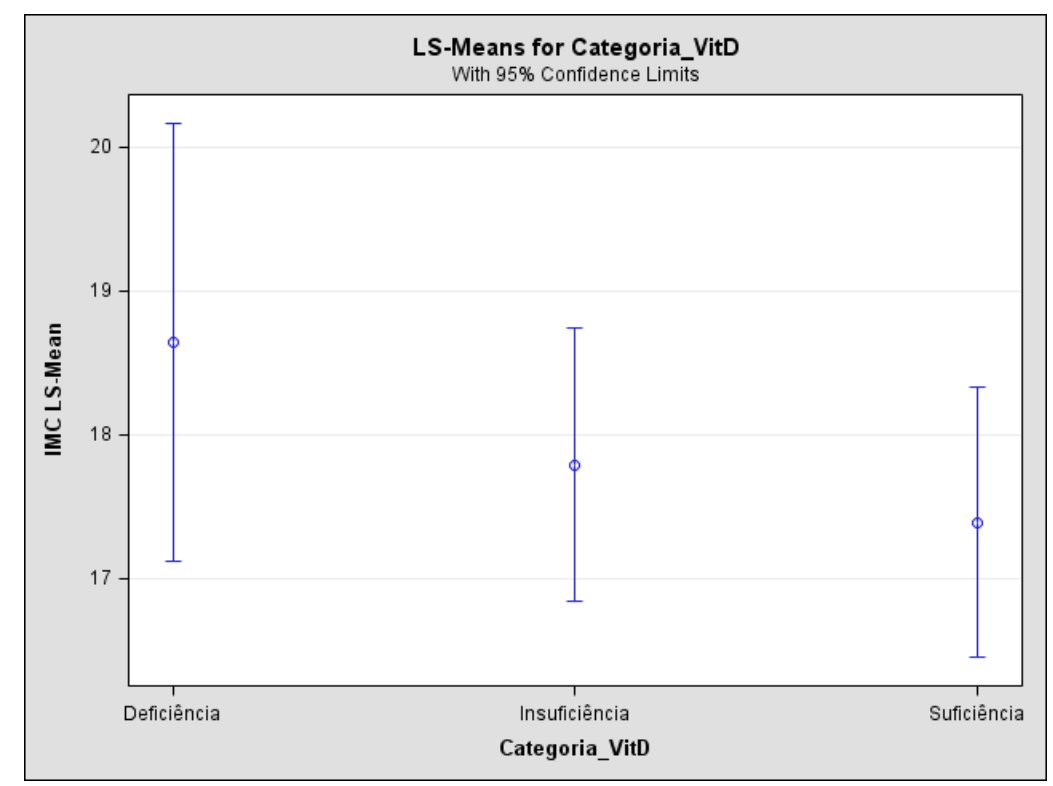

Figura 37 - Distribuição do IMC (média \pm desvio padrão) nas diferentes categorias de $25(\mathrm{OH}) \mathrm{D}$

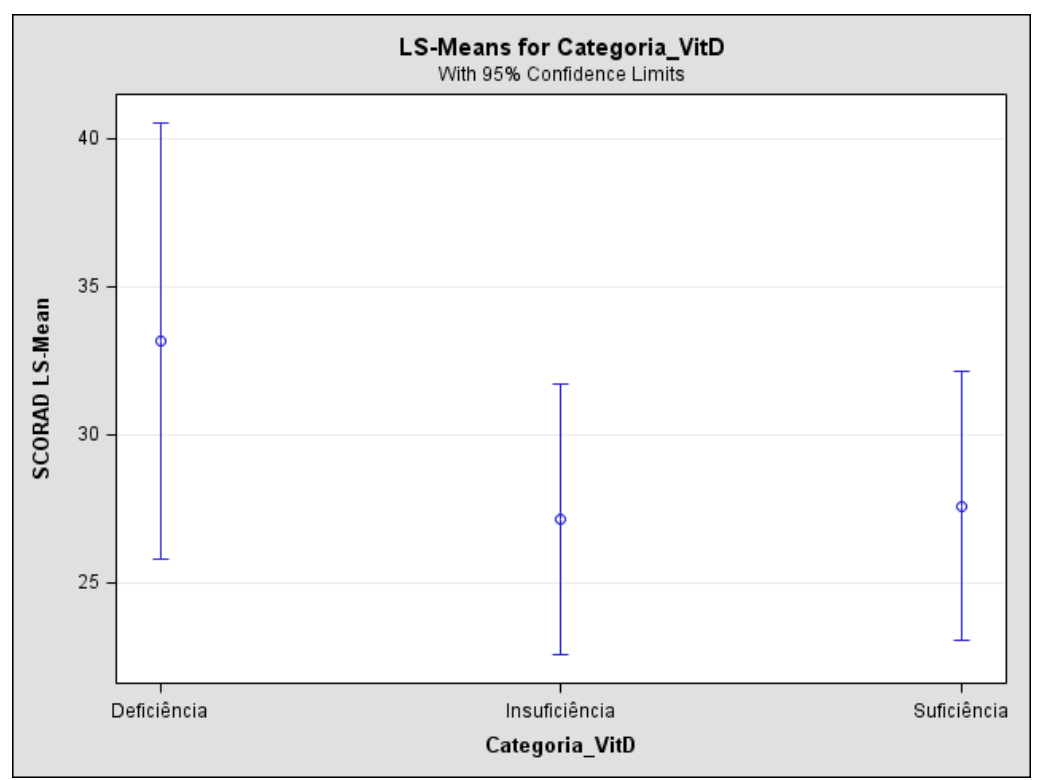

Figura 38 - Distribuição do SCORAD (média \pm desvio padrão) nas diferentes categorias de $25(\mathrm{OH}) \mathrm{D}$ 


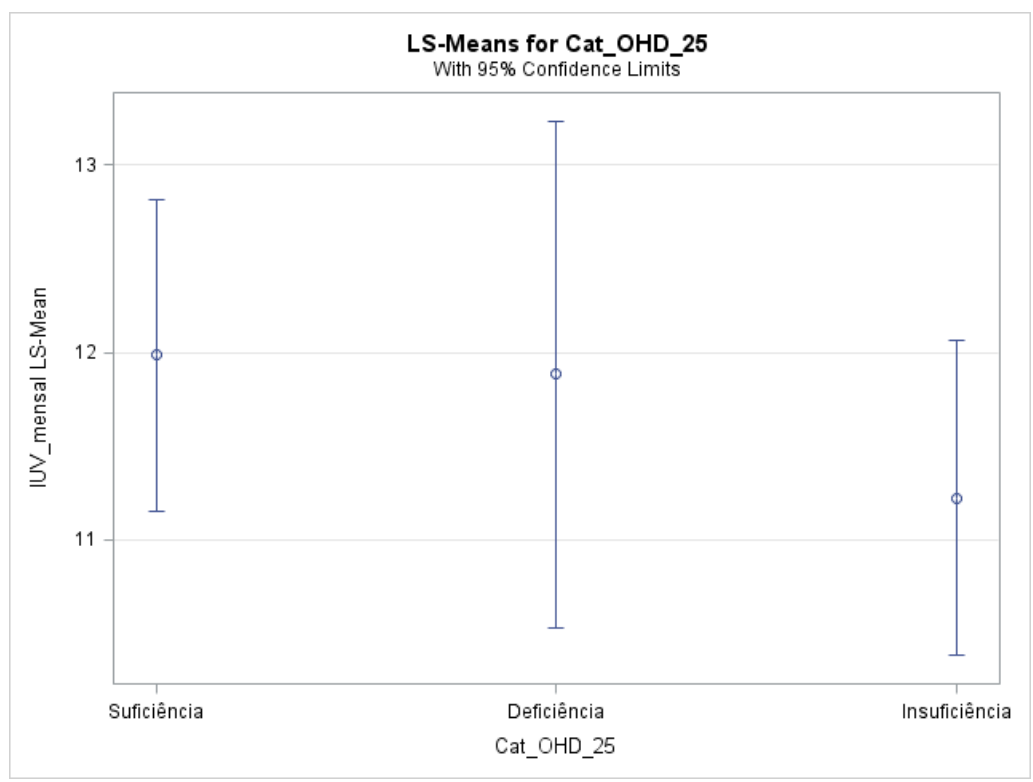

Figura 39 - Distribuição do IUV (média \pm desvio padrão) nas diferentes categorias de $25(\mathrm{OH}) \mathrm{D}$

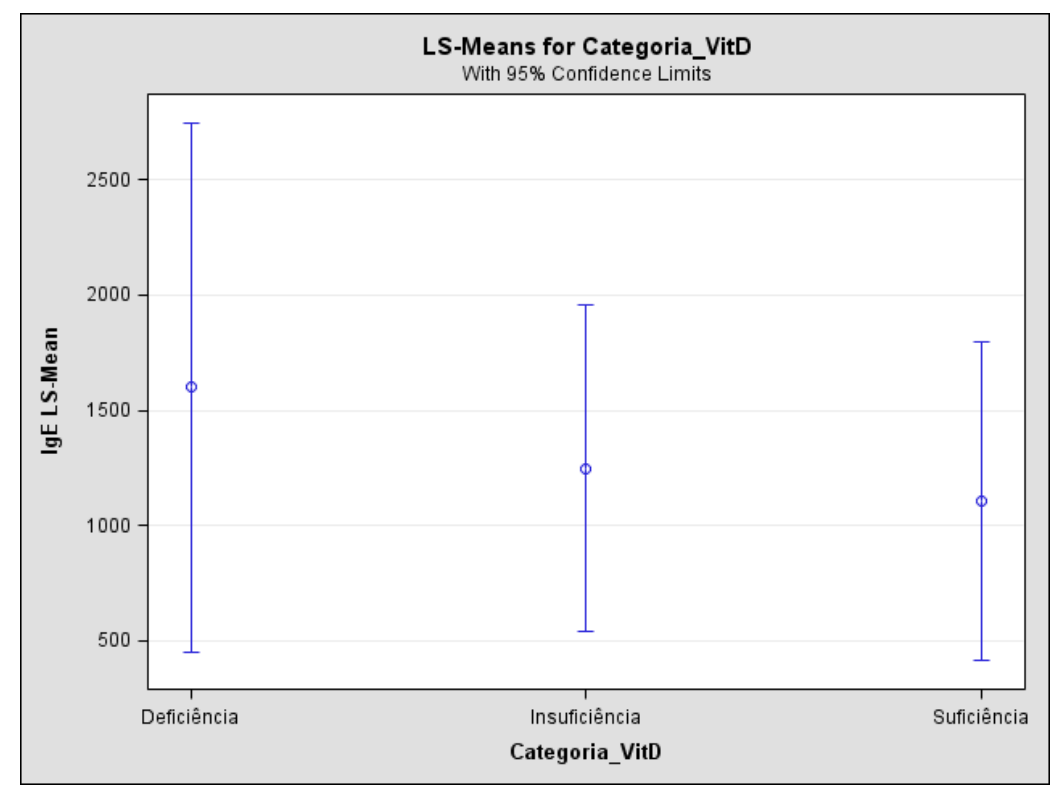

Figura 40 - Distribuição da lgE total (média \pm desvio padrão) nas diferentes categorias de $25(\mathrm{OH}) \mathrm{D}$ 


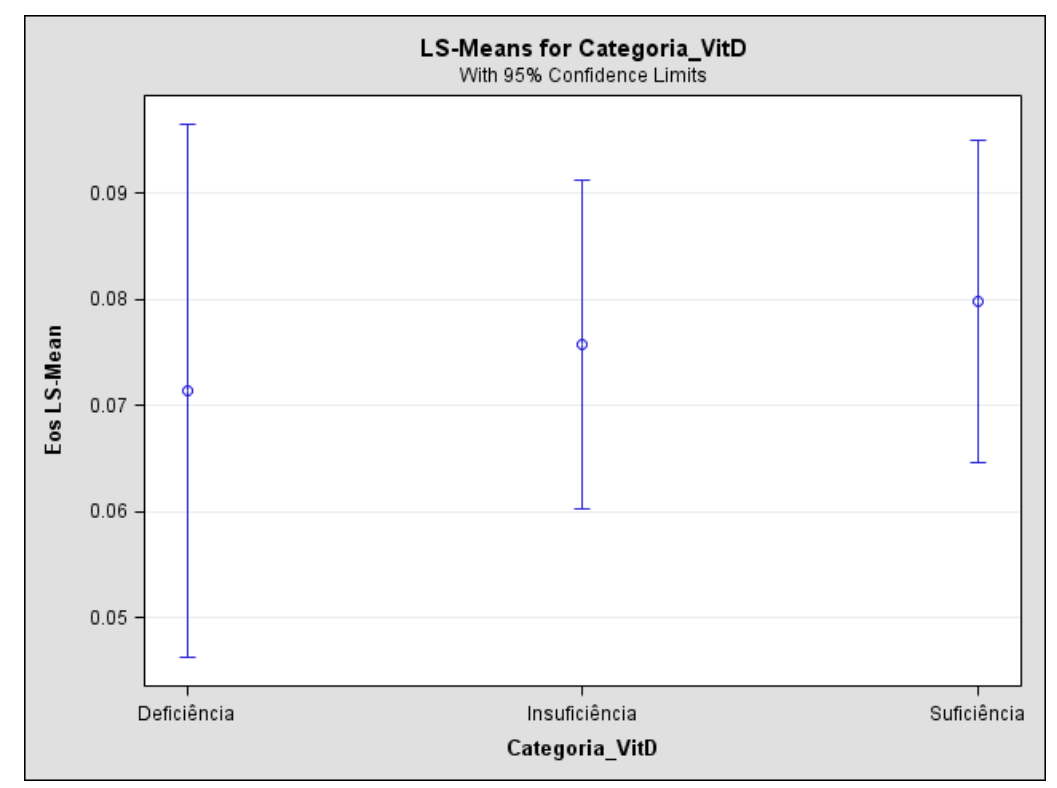

Figura 41 - Distribuição da eosinofilia relativa (média \pm desvio padrão) nas diferentes categorias de $25(\mathrm{OH}) \mathrm{D}$

\subsubsection{Análise Multivariada para Identificação de Variáveis Determinantes da 25(OH)D}

\subsubsection{Metodologia}

Para verificar a relação entre $25(\mathrm{OH}) \mathrm{D}$ com potenciais confundidores, foi realizada análise de regressão linear múltipla. A variável resposta foi 25(OH)D e como potenciais confundidores gênero (feminino versus masculino), idade, fototipo (II e III versus IV e V), renda, IMC, asma ou RA (sim versus não), atopia familiar (sim versus não), SCORAD, IUV, IgE e eosinófilos, que foram introduzidos na equação de regressão através do método stepwise backward. A significância da contribuição das variáveis ao modelo foi estimada e comparada com o critério de remoção $(p=0,1)$. Quando um potencial preditor atingia o critério de remoção ele era removido do modelo de regressão. O modelo era então reestimado para as variáveis remanescentes, e o processo era então repetido até que nenhum preditor atingia o critério de remoção. Os resíduos padronizados do último modelo foram verificados quanto à normalidade. 


\subsubsection{Resultado}

A análise de regressão linear múltipla mostrou que as variáveis fototipo, idade e IUV foram preditores associados significativamente com a concentração sérica de 25(OH)D. Pacientes com fototipo II e III apresentaram valores médios de 25(OH)D $6,012 \mathrm{ng} / \mathrm{ml}$ maiores que os pacientes com fototipo IV e V. Pacientes de maior idade foram associados a menores concentrações de $25(\mathrm{OH}) \mathrm{D}$ do que pacientes mais novos. Sujeitos avaliados em períodos com valor mais elevado de IUV foram associados a maiores concentrações de 25(OH)D (Tabela 28).

Tabela 28 - Análise de regressão linear múltipla [modelos para predizer 25(OH)D]

\begin{tabular}{lcccc}
\hline Modelo e Preditores & $\boldsymbol{\beta}$ & $\mathbf{p}$-valor $\boldsymbol{\beta}$ & $\mathbf{r}^{\mathbf{2}}$ & IC 95 \% de $\boldsymbol{\beta}$ \\
\hline Modelo & & \multicolumn{3}{c}{0,1875} \\
Constante & 22,807 & $<0,0001$ & & 13,814 a 31,800 \\
Fototipo (II e III vs IV e V) & 6,102 & 0,0031 & & 2,116 a 10,088 \\
Idade & $-0,570$ & 0,0189 & & $-1,044$ a $-0,096$ \\
IUV & 0,739 & 0,0270 & & 0,086 a 1,391 \\
\hline
\end{tabular}

Variável dependente: 25(OH)D; variáveis independentes: idade, gênero, fototipo, renda, IMC, asma ou RA, atopia familiar, SCORAD, IUV, IgE e eosinófilos.

IC: intervalo de confiança; $\beta$ : coeficiente não padronizado; $p$ valores $<0,05$ foram considerados estatisticamente significativos.

\subsubsection{Associação entre Concomitância de DA com Asma ou RA e Variáveis Independentes}

\subsubsection{Metodologia}

Para as variáveis expressas em média \pm desvio padrão e que apresentavam distribuição gaussiana, a comparação entre concomitância de atopia pessoal (sim versus não) se deu pela utilização do teste t de Student, ou pelo teste de MannWhitney para aquelas que não apresentavam distribuição gaussiana. Para as 
variáveis expressas em frequência a comparação entre os gêneros se deu pelo uso do teste de qui-quadrado.

\subsubsection{Resultado}

A média de IgE, na população de sujeitos com DA, foi significativamente maior em pacientes com asma ou RA concomitante do que em pacientes sem asma ou RA $(p=0,0066)$. As demais variáveis não apresentaram associação significativa com a presença ou ausência de asma ou RA (Tabela 29).

Tabela 29 - Associação entre concomitância de DA com asma ou RA (sim versus não) e as variáveis genêro, idade de início, SCORAD, 25(OH)D, PTH, IgE e eosinófilos.

\begin{tabular}{|c|c|c|c|}
\hline & \multicolumn{2}{|c|}{ Asma ou RA concomitante com DA } & \multirow{2}{*}{$\mathbf{p}$} \\
\hline & $\operatorname{Sim}(n=60)^{\star}$ & Não $(n=46)^{\star}$ & \\
\hline \multicolumn{4}{|l|}{ Gênero } \\
\hline Masculino & $23(38,33 \%)$ & $15(32,61 \%)$ & \multirow[t]{2}{*}{$0,5424^{a}$} \\
\hline Feminino & $37(61,67 \%)$ & $31(67,39 \%)$ & \\
\hline $\begin{array}{l}\text { Idade de início } \\
\text { (anos) }\end{array}$ & $2,17 \pm 3,12$ & $1,92 \pm 2,45$ & $0,6822^{b}$ \\
\hline SCORAD & $28,86 \pm 14,14$ & $27,56 \pm 16,90$ & $0,6686^{c}$ \\
\hline \multicolumn{4}{|l|}{ SCORAD } \\
\hline Leve & $27(45 \%)$ & $22(47,83 \%)$ & \multirow{3}{*}{$0,9477^{a}$} \\
\hline Moderado & $28(46,67 \%)$ & $20(43,48 \%)$ & \\
\hline Grave & $5(8,33 \%)$ & $4(8,69 \%)$ & \\
\hline 25(OH)D (ng/ml) & $28,63 \pm 10,34$ & $29,42 \pm 8,8$ & $0,6804^{c}$ \\
\hline \multicolumn{4}{|l|}{ 25(OH)D } \\
\hline Suficiência & $22(36,67 \%)$ & $23(50 \%)$ & \multirow{3}{*}{$0,3660^{\mathrm{a}}$} \\
\hline Insuficiência & $28(46,67 \%)$ & $16(34,78 \%)$ & \\
\hline Deficiência & $10(16,66 \%)$ & $7(15,22 \%)$ & \\
\hline PTH (pg/ml) & $34,25 \pm 15,79$ & $33,20 \pm 15,84$ & $0,5987^{c}$ \\
\hline IgE (UI/ml) & $1521 \pm 2254$ & $860,66 \pm 2328,52$ & $0,0066^{b}$ \\
\hline Eosinófilos (\%) & $8,47 \% \pm 4,97$ & $6,60 \% \pm 4,95$ & $0,0633^{c}$ \\
\hline
\end{tabular}

Valores expressos em média \pm desvio padrão ou $n(\%)$
a) $p$-valor calculado pelo teste de qui-quadrado
b) $p$-valor calculado pelo teste de Mann-Whitney
c) $p$-valor calculado pelo teste t de Student 


\section{DISCUSSÃO}

\subsection{DELINEAMENTO E RESULTADOS DESCRITIVOS}

O presente estudo consistiu em pesquisa institucional, em que apenas pacientes com acesso ao ambulatório de dermatologia do HUB tiveram chance de ser selecionados. Cabe destacar que amostras obtidas em estabelecimentos de saúde têm inconvenientes, pois nem todos os indivíduos que necessitam de atendimento o alcançam. Ademais, há variações na maneira como as pessoas percebem anormalidades ou buscam atenção médica. Numerosos fatores intervêm na decisão de procurar ou não atenção especializada, o que depende do tipo de agravo à saúde, da idade, do gênero, da classe social e de outras características individuais, familiares ou comunitárias. Dentre os fatores relevantes, cabe destacar a própria existência do serviço especializado e o nível de acesso que os indivíduos têm a esse serviço. Dessa forma, o grupo que busca cuidados pode ser, e costuma ser, uma amostra nãorepresentativa da população da região onde se localiza o estabelecimento. Não foi realizada, no presente estudo, investigação "comunitária" em busca dos casos de DA e do grupo controle Os pacientes atendidos representam uma proporção desconhecida dos casos que realmente ocorrem na comunidade. A utilização das estatísticas a eles referentes é sempre limitada em termos de representatividade externa (135).

O estudo teve delineamento transversal, com todas as limitações inerentes a esse método. Retrata-se pontualmente o momento da avaliação de cada paciente, não refletindo um contínuo do estado de saúde tanto no aspecto clínico quanto no laboratorial e ambiental. A causalidade não pode ser aqui inferida, uma vez que está ausente a temporalidade necessária a essa associação, um dos critérios fundamentais para estabelecimento de uma relação de causa-efeito postulados por Bradford Hill (1965) (136).

Do mesmo modo, a maioria das pesquisas nesse assunto são estudos do tipo caso-controle ou transversais e, por conseguinte, não estabelecem relação causal entre deficiência de vitamina $\mathrm{D}$ e DA. 
A pesquisa teve controle estrito do pesquisador sobre a coleta de dados e a análise clínica dos participantes, garantindo uniformidade na aferição dos eventos e na expressão dos resultados, minimizando viés de aferição.

A amostra final do estudo foi de 106 pacientes com DA, os quais foram incluídos para análise das variáveis (vide métodos). O tamanho desejado da amostra foi estimado em 105 participantes. Obteve-se, portanto, uma amostra satisfatória para o estudo, o que a torna adequada quanto à validação interna dos dados encontrados. Apesar de se tratar de amostra institucional e não-probabilística, os resultados aqui apresentados são consistentes e as limitações intrínsecas dessa amostra não prejudicam a validade dos principais resultados encontrados.

Podemos inferir que houve uniformidade na mensuração dos exames laboratoriais, uma vez que as dosagens de 25(OH)D foram integralmente realizadas no laboratório Sabin; os exames de hemograma, IgE, PTH e EPF no laboratório de análises clínicas do HUB; e o IUV obtido pelo CPTEC / INPE. Houve, por conseguinte, homogeneidade na obtenção dos resultados, uma vez que os protocolos institucionais e equipamentos utilizados foram semelhantes para todos os participantes.

A dosagem de 25(OH)D foi realizada em laboratório único e utilizando-se sempre o mesmo método (imunoquimioluminescência). Tal estratégica foi fundamental para uma interpretação correta dos resultados, já que há uma importante variabilidade interensaios na dosagem da 25(OH)D (41). A maior acurácia é observada na cromatografia líquida associada à espectrofotometria de massa e na cromatografia líquida de alta pressão. Tal método laboratorial, contudo, é oneroso, pouco utilizado na prática clínica e não se encontrou disponível para o presente estudo. O ensaio de quimioluminescência é um método automatizado e menos dispendioso, porém apresenta menor confiabilidade e acurácia e maior variabilidade (137).

Com a mensuração da concentração sérica de 25(OH)D em laboratório único, minimizou-se viés de aferição decorrente da variabilidade interlaboratorial da dosagem de $25(\mathrm{OH}) \mathrm{D}$. A validade e importância da estratégia pode ser inferida dos resultados de Binkley e colaboradores (2004) (138), os quais demonstraram que os ensaios de 25(OH)D utilizados por diferentes laboratórios resultam em valores divergentes. As análises clínicas do laboratório Sabin têm abrangente permeabilidade na classe médica local, entretanto a empresa não possui o certificado internacional de 
proficiência DEQAS. Nesse laboratório, a comparabilidade entre equipamentos é o método adotado para avaliar a variabilidade da $25(\mathrm{OH}) \mathrm{D}$.

\subsection{HIPOVITAMINOSE D}

Encontramos $41,51 \%$ de pacientes com DA insuficientes em 25(OH)D e $16,04 \%$ deficientes, resultando em um total de 57,55\% não suficientes. Esse resultado aproxima-se da prevalência de 60\% relatada por Peters (2009) (66) em adolescentes brasileiros. Essa alta prevalência é preocupante na faixa etária pesquisada, uma vez que a maximização do pico de massa óssea durante a adolescência e início da fase adulta é considerada a melhor proteção contra a perda óssea relacionada à idade e contra o risco tardio de osteoporose (139). Dessa forma, a adolescência torna-se um período crítico no desenvolvimento esquelético e a hipovitaminose $\mathrm{D}$ pode prejudicar a formação óssea, gerando repercussões futuras (140). Há de se atentar, ainda, para todas as possíveis doenças relacionadas de modo crescente à hipovitaminose $D$, quais sejam neoplásicas, inflamatórias, auto-imunes, degenerativas, metabólicas e alérgicas. Não se sabe até que ponto a grande prevalência de hipovitaminose D encontrada nos dias atuais repercutirá no perfil epidemiológico futuro dessas doenças, porém o subtratamento dessa disseminada condição pode influenciar consideravelmente no atual painel epidemiológico mundial.

Não houve fatores de confundimento referentes a alterações laboratoriais decorrentes do uso de medicamentos sistêmicos que aumentassem o catabolismo da vitamina $D$, tais como anticonvulsivantes, antifúngicos ou glicocorticoides. Pacientes em uso dessas medicações foram excluídos do estudo.

Apesar de este estudo ter sido conduzido em Brasília, uma cidade ensolarada, situada a baixa latitude (15오 S) e com IUV variando de alto a extremo durante o período de realização da pesquisa, isso não foi o bastante para prevenir a alta prevalência de insuficiência de vitamina $D$. Outros autores também encontraram baixas concentrações de 25(OH)D em indivíduos sadios e ativos vivendo em regiões com ampla disponibilidade de luz solar (47).

Frente à alarmante prevalência de hipovitaminose $\mathrm{D}$ ao redor do mundo, os benefícios do uso do protetor solar encontram-se cada vez mais afrontados por 
calorosas discussões que questionam o papel da fotoproteção na deficiência crescente de vitamina $D$ encontrada hodiernamente.

A Sociedade Brasileira de Dermatologia (SBD) lançou em 2013 o Consenso Brasileiro de Fotoproteção, em que não recomenda a exposição ao sol no período entre $10 \mathrm{~h}$ e 15h. A depender da época do ano e da localidade da exposição, recomenda considerar um período ainda maior de restrição ao sol. No Centro-Oeste brasileiro, local de realização deste estudo, orienta-se manter a restrição até às $16 \mathrm{~h}$. As recomendações abrangem todas as faixas etárias, incluindo a população pediátrica. Segundo esse consenso, lactentes menores de 6 meses não devem se expor diretamente ao sol e, quando expostos, devem ser cobertos com roupas e chapéus. O uso de fotoprotetor não é recomendado nessa faixa etária. Crianças acima de 6 meses também devem evitar exposição direta ao sol no período entre 10 e 15 horas e, nessas, o fotoprotetor com fator de proteção solar superior a 30 deve ser utilizado durante a exposição ao sol. A SBD postula que pacientes em risco para hipovitaminose podem utilizar preventivamente fontes dietéticas ou suplementação vitamínica (141).

A SBD considera que a utilização de fotoprotetores da forma que habitualmente é praticada não pode ser considerada fator predisponente à deficiência de vitamina $D$. O protetor solar, na prática diária, não é aplicado na quantidade adequada e com a frequência e regularidade recomendadas, permitindo que suficiente radiação UVB atinja a superfície da pele para a produção de vitamina D (141). Por sua vez, a Sociedade Brasileira de Endocrinologia e Metabologia (SBEM) advoga os benefícios advindos do banho do sol para a produção de vitamina D e considera temerosas recomendações acerca do uso irrestrito de protetores solares (142).

A dose estimada de UVB necessária para a produção de 1.000 UI de vitamina $D$ é de 0,25 dose eritematosa mínima (DEM) em cerca de $25 \%$ da área corporal total (141). Estudo publicado por de Paula Correa e colaboradores (2010) (143) mostra que a exposição não intencional de mãos e face ao ambiente externo, mesmo em dias nublados e chuvosos, por 10 minutos diários na cidade de São Paulo já seria suficiente para a produção adequada de vitamina $\mathrm{D}$ em uma pessoa de fototipo II.

Uma vez que latitude, estação do ano, pigmentação da pele, uso de protetor solar e poluição do ar podem influenciar consideravelmente na síntese cutânea da vitamina $D$, não pode haver uma recomendação simples para a quantidade de exposição solar a fim de satisfazer a necessidade de vitamina D do organismo (144) 
A discussão entre fotoproteção e deficiência de vitamina $D$ permanece acirrada e configura um tema atual com recomendações distintas preconizadas por órgãos oficiais representantes de especialidades médicas.

Há grande variabilidade entre os ensaios de diferentes laboratórios, dificultando a determinação de uma concentração ideal universal de 25(OH)D. Alguns autores sugerem que seria mais prudente a determinação de níveis normais de 25(OH)D para cada população, para cada método e laboratório (47). Essa determinação faz-se importante uma vez que a hipovitaminose $D$ demonstrou ser freqüente em nosso meio, mas ainda pouco reconhecida e, portanto, subtratada.

\subsection{ANÁLISE COMPARATIVA ENTRE SUBGRUPO DA E GRUPO CONTROLE PAREADO}

A análise da concentração sérica de 25(OH)D no subgrupo de pacientes com DA comparado ao grupo controle revelou diferença significativa $(p=0,0176)$. $O$ grupo de pacientes com DA apresentou níveis séricos de $25(\mathrm{OH}) \mathrm{D}$ em média $3,39 \mathrm{ng} / \mathrm{ml}$ (IC $95 \%$ 0,61 - 6,17) maior que o grupo controle. Tal achado surpreende, pois contradiz - de maneira inédita segundo o conhecimento dos pesquisadores - os achados reproduzidos em estudos internacionais que demonstram relação inversa (83$85,145,146)$ ou ausência de associação significativa $(79,82,95)$.

Estudos prévios já demonstraram a associação de maior prevalência de atopias com o aumento da vitamina $D$, porém baseados na ingesta materna de vitamina $D$ (147), em inquéritos alimentares (71), em concentrações séricas maternas (81) ou em concentração de 25(OH)D no cordão umbilical (101). Pudemos demonstrar, de modo primaz, tal associação utilizando a concentração sérica atual de 25(OH)D.

Não se sabe ao certo porque a vitamina $D$ pode correlacionar-se positivamente com a prevalência de atopias. Em 1999 foi sugerido por Wjst \& Dold (75) que a exposição a maiores concentrações de vitamina $D$ durante o desenvolvimento fetal poderia ser um fator para o desenvolvimento de atopias. Corroboraram para tal hipótese o aumento concomitante da prevalência das doenças atópicas e a fortificação do leite com vitamina $D$ (realizada em diversos países com o intuito de erradicar o raquitismo) e a tendência geográfica de maior prevalência da DA em países mais 
desenvolvidos, em que habitualmente há exposição precoce à alimentos fortificados com vitamina $\mathrm{D}$.

Hyppönen e colaboradores (2004) (93) demonstraram que crianças que receberam mais vitamina $D$ na infância tiveram risco aumentado de doenças atópicas quando adultos. Os autores sugeriram que a ingesta de vitamina $D$ na infância tem efeitos a longo prazo na regulação imune, possivelmente induzindo um padrão de resposta imune predominante Th2, característico das doenças alérgicas.

A associação positiva entre vitamina $\mathrm{D}$ e atopias pode ser também, pelo menos em parte e no tocante à DA, explicada pelo aumento da expressão da linfopoetina estromal tímica (LPET). Demonstrou-se experimentalmente que os ligantes ativos do RVD induzem a expressão da LPET em ceratinócitos murinos, promovendo ativação e migração de células de Langerhans, culminando em um fenótipo dermatite atópicasímile (148).

Uma vez que as concentrações séricas de vitamina $D$ são estratificadas em suficientes, insuficientes e deficientes, avaliou-se a variável 25(OH)D não apenas em sua apresentação quantitativa para a associação entre casos e controles, mas também em sua apresentação qualitativa, isto é, categórica. A análise comparativa com as concentrações de $25(\mathrm{OH}) \mathrm{D}$ estratificadas não resultou em diferença significativa entre os grupos.

A associação estatística encontrada quando da análise da variável 25(OH)D contínua, portanto, não refletiu na análise categórica (Tabela 30). Uma vez que pequenas variações nas concentrações séricas de $25(\mathrm{OH}) \mathrm{D}$ podem não refletir no estado de suficiência, insuficiência e deficiência, a associação entre variáveis categóricas parece, num primeiro momento, mais adequada. Variações pequenas em sua concentração podem não gerar repercussão clínica. Entretanto, a estratificação utilizada dos níveis séricos de 25(OH)D ainda é arbitrária e controversa. Destarte, a utilização da variável em sua apresentação contínua pode ser mais oportuna para comparação entre os grupos.

Tabela 30 - Comparação entre análise quantitativa e qualitativa da 25(OH)D entre os grupos

\begin{tabular}{cc}
\hline Tipo de variável analisada & $\mathrm{p}$ \\
\hline 25(OH)D quantitativa & 0,0176 \\
25(OH)D categórica & 0,0885 \\
\hline
\end{tabular}


A maioria dos estudos publicados acerca da associação entre DA e vitamina D não realizou pareamento para composição do grupo controle e, por conseguinte, não se pode afirmar a homogeneidade dos grupos comparados. Encontramos na literatura apenas um trabalho (82) em que foi feita análise semelhante de pacientes com DA e grupo controle pareado. Os autores desse estudo não encontram diferença significativa entre o grupo de pacientes com DA e o grupo controle, o qual foi pareado apenas por gênero e idade. Outros trabalhos realizados não eliminaram o viés de confundimento que pode advir da ausência do pareamento. Dentre esses, Hata e colaboradores (2013) (95) também não encontraram diferença significativa entre 30 pacientes com DA e 30 pacientes não atópicos.

Estudos que advogam associação negativa entre vitamina $\mathrm{D}$ e prevalência de DA baseados na comparação entre grupos são questionáveis. Oren e colaboradores (2008) (83) realizaram estudo tipo caso-controle apenas em pacientes obesos, estreitanto a possibilidade de extrapolação dos resultados; ademais, a doença atópica era auto-declarada. Estudo relacionando menor consumo alimentar de vitamina D pelos pacientes baseou-se apenas em levantamento nutricional, não aferindo as concentrações séricas de 25(OH)D nos grupos (86). Da mesma forma ocorre em outros estudos que associam baixa ingesta de vitamina $D$ pela gestante com maior prevalência de DA em seus filhos (87,88). Gale e colaboradores (2008) (81) forneceram evidência contrária aos estudos acima descritos. Os autores demonstraram maior risco de doenças atópicas em crianças aos 9 meses (eczema) e aos 9 anos (asma) quando suas mães apresentaram 25(OH) maior que $30 \mathrm{ng} / \mathrm{ml}$ no fim da gestação.

O rigoroso pareamento realizado por idade, gênero, IMC e fototipo não encontra precedente nesse tipo de investigação, o que tornou nossa amostra mais uniforme e, portanto, passível de comparação. A ausência de pareamento ou a desconsideração de fatores importantes (como o fototipo) para composição do grupo controle poderia acarretar distribuição irregular das características dos indivíduos, gerando fatores confundidores que obscureceriam a associação almejada. $O$ pareamento anula o efeito de variáveis sem modificar aquela que está sendo investigada, aumenta a comparabilidade entre os casos e os controles e aumenta a possibilidade de que esses provenham de uma população semelhante.

A variável IUV não foi considerada para o pareamento e, dessa forma, diante da fisiologia da vitamina $D$, sua variação pode interferir nas concentrações de 
25(OH)D. O teste t de Student demonstrou que o subgrupo DA foi exposto a um IUV médio 2,54 acima do grupo controle, o que pode justificar as maiores concentrações de 25(OH)D encontradas no subgrupo DA (Tabela 31). Embora os pacientes do grupo controle tenham sido cronologicamente selecionados à medida que preenchiam critérios para inclusão e pareamento, nota-se que houve diferença estatisticamente significante quanto ao IUV. Possivelmente a diferença observada na concentração de 25(OH)D não se manteria caso o IUV fosse considerado dentre os critérios de pareamento. Em locais com maior variação climática e estações bem definidas, a variação desse índice é grande e, portanto, representa uma variável importante a ser considerada em estudos controlados.

Tabela 31 - Diferença entre médias de 25(OH)D e IUV em casos com DA e em controles

\begin{tabular}{ccc}
\hline & $\begin{array}{c}\text { Diferença entre médias } \\
\text { (subgrupo DA - controle) }\end{array}$ & $p$ \\
\hline $25(\mathrm{OH}) \mathrm{D}(\mathrm{ng} / \mathrm{ml})$ & 3,39 & 0,0176 \\
IUV & 2,54 & $<0,0001$ \\
\hline
\end{tabular}

p-valor calculado pelo teste t de Student emparelhado

\subsection{VITAMINA D E GRAVIDADE CLÍNICA DA DA}

$\mathrm{Na}$ busca da associação entre concentrações séricas de 25(OH)D e gravidade clínica da DA determinada pelo SCORAD ou pelo SCORAD objetivo, as análises entre essas variáveis foram realizadas por meio de suas representações quantitativas e qualitativas (categóricas). Em nenhum caso foi encontrada associação estatisticamente significativa entre $25(\mathrm{OH}) \mathrm{D}$ e gravidade clínica.

Dessa forma, na amostra pesquisada, não se encontrou nenhuma associação entre 25(OH)D e gravidade clínica da DA (Tabela 32). Tal achado está em desacordo com Peroni e colaboradores (2011) (12) - estudo italiano com 37 pacientes- e Ronceray e colaboradores (2014) (149) - estudo francês com 60 crianças e adultos -, porém está de acordo com os resultados encontrados por Samochocki e colaboradores (2013) (82) - estudo polonês com 95 pacientes-, Chiu e colaboradores 
(2013) (94) - estudo americano com 94 pacientes -, e Hata e colaboradores (2013) (95) - estudo americano com 30 pacientes.

Tabela 32 - Associação entre 25(OH)D e gravidade clínica da DA

\begin{tabular}{ccc}
\hline 25(OH)D & Gravidade Clínica da DA & $\mathbf{p}$ \\
\hline \multirow{2}{*}{ Quantitativo } & SCORAD quantitativo & $\mathbf{0 , 7 2 6 9}$ \\
& SCORAD objetivo quantitativo & $\mathbf{0 , 9 6 3 3}$ \\
\multirow{2}{*}{ Categórico } & SCORAD categórico & $\mathbf{0 , 7 6 2 9}$ \\
& SCORAD objetivo categórico & $\mathbf{0 , 4 8 1 2}$ \\
\hline
\end{tabular}

As recentes publicações de Lee e e colaboradores (2013) (96) - estudo com 157 pacientes de 4 meses a 56 anos - e de Akan e colaboradores (2013) (74) - estudo com 73 crianças - demonstraram associação significativa entre gravidade clínica da DA e $25(\mathrm{OH}) \mathrm{D}$ apenas em grupo seleto de pacientes: o primeiro em pacientes com sensibilização alimentar (demonstrada por IgE sérica específica para alérgenos alimentares) e o segundo em pacientes com prick test positivo. Uma possível explicação para esses interessantes achados seria que a deficiência de vitamina $D$ promove uma pró-sensibilização imune desbalanceada que compromete a tolerância imunológica. Isso ocorreria porque a hipovitaminose $D$ prejudica a integridade da barreira epitelial, levando a uma exposição aumentada e inapropriada aos antígenos, comprometendo a tolerância aos mesmos (150)

Aprofundando essa linha de pensamento, Baek e colaboradores (2014) (151) demonstraram que a concentração de 25(OH)D está significativamente relacionada com o grau de sensibilização alimentar: quanto menor a concentração de 25(OH)D, maior o número de alérgenos alimentares e maior a concentração de $\operatorname{lgE}$ sérica específica. Os autores concluíram que a deficiência de vitamina $D$ aumenta o risco de sensibilização a alérgenos alimentares, especialmente ao leite e ao trigo.

Pacientes com e sem sensibilização podem ter mecanismos fisiopatológicos diferentes sob uma mesma apresentação clínica. Apresentando um papel na sensibilização alérgica e na inflamação, a vitamina $D$ pode afetar diferentemente a gravidade da doença em indivíduos com e sem sensibilização alérgica. Essas peculiaridades em pacientes sensibilizados e não-sensibilizados podem se relacionar aos achados da ação da vitamina $D$ e seus análogos em células $B$, as quais 
apresentam redução da produção de $\lg E$ após exposição à vitamina D (152). Entretanto, não encontramos, do mesmo modo que Akan e colaboradores (2013) (74), associação entre vitamina $\mathrm{D}$ e lgE.

Não foi observado no presente estudo, mesmo após categorização dos pacientes em DA extrínseca e intrínseca (baseando-se unicamente na IgE total), uma correlação significativa entre 25(OH)D e SCORAD ( $r=0.04977, p=0.6704)$, assim como entre 25(OH)D e SCORAD objetivo $(r=0.02194, p=0.8513)$.

Uma vez que IgE específica ou prick test não foram utilizados para pesquisar sensibilização alérgica, a falta de controle dessas variáveis representa uma limitação do nosso estudo e pode configurar fator de confusão na análise, falseando uma possível associação entre $25(\mathrm{OH}) \mathrm{D}$ e SCORAD no subgrupo de pacientes sensibilizados. Contudo, uma vez que os valores de $\lg E$ total estão significativamente associados com o status de lgE específico a alérgenos, o lgE total é considerado um parâmetro clínico útil para diferenciar entre os tipos intrínseco e extrínseco da DA (153).

\subsection{ASSOCIAÇÕES COM O PTH}

A concentração do PTH possui, tipicamente, relação inversa com a $25(\mathrm{OH}) \mathrm{D}$ (59) e sua elevação é considerada o primeiro sinal laboratorial detectável indicativo de insuficiência de 25(OH)D. Tal associação é a que majoritariamente dita os limites utilizados para predizer o limiar da suficiência em vitamina $D$. A concentração sérica do PTH, portanto, é interpretado como indicador secundário da deficiência de vitamina D. Também podem ser utilizados para predizer o status da vitamina $D$ a absorção de cálcio, a DMO e a concentração de $1,25(\mathrm{OH})_{2} \mathrm{D}$. O estudo conjunto da vitamina $\mathrm{D}$ com - PTH torna-se interessante pela ausência de consenso quanto aos valores de referência da 25(OH)D. Além disso, o PTH e o PTHrP podem agir juntamente com a vitamina $D$ nos ceratinócitos e influenciar a resposta imune contra infecções cutâneas. Já foi demonstrado que o PTH e o PTHrP exercem efeito sobre a produção dos PAM e reduzem a suscetibilidade a infecções em células murinas e humanas. O PTHrP é expresso na pele e em outros tecidos, e seu peptídeo $\mathrm{N}$-terminal pode se ligar a receptores semelhantes ao do PTH. O PTH e sua proteína relacionada foram 
identificados como variáveis que compensam uma vitamina $D$ inadequada durante a produção dos PAM (109) e podem, portanto, estar diretamente relacionadas à DA.

Contudo, as funções exatas do PTH e do PTHrP na pele são pouco compreendidas. O PTHrP pode ter um papel no ciclo de crescimento capilar, na angiogênese, na proliferação e diferenciação de células epidérmicas. O PTHrP modula o cálcio intracelular em vários tipos de células, e o cálcio tem sido implicado na diferenciação de ceratinócitos. Tendo em conta que os ceratinócitos sob condições de alta concentração de cálcio mostram maior expressão de PAM e de suas enzimas de processamento, este pode ser um mecanismo alternativo de ação.

Não foram encontrados, em minuciosa pesquisa bibliográfica realizada pelos pesquisadores e seus consortes, trabalhos publicados na literatura científica que correlacionem, na população com DA, as concentrações séricas de 25(OH)D com as de PTHi, tampouco que correlacionem gravidade clínica da dermatose com as concentrações séricas do PTHi.

Esperava-se, ao associar as variáveis 25(OH)D e PTHi, encontrar uma associação inversa, ou seja, um aumento na concentração sérica de PTHi com a redução da concentração de 25(OH)D. As análises demonstraram haver associação negativa entre ambas, entretanto esta não foi estatisticamente significante ( $r$ = 0,01319; $p=0,9140)$. A distribuição das concentrações séricas de PTHi não diferiu nas categorias de suficiência, insuficiência e deficiência de $25(\mathrm{OH}) \mathrm{D}(\mathrm{p}=0,5429)$. Esse curioso achado levanta questionamentos importantes quanto às concentrações séricas adotados para estratificação da 25(OH)D na amostra estudada. Este estudo demonstrou que $71,01 \%$ dos indivíduos testados para essa associação apresentavam 25(OH)D abaixo das concentrações estabelecidas para suficiência (30 ng/ml). Entretanto, houve elevação do PTHi acima dos valores de referência em apenas 2 indivíduos, sendo que em um deles a 25(OH)D encontrava-se deficiente e em outro, suficiente. O paciente com deficiência de vitamina $D$ recebeu suplementação vitamínica oral, ao passo que o suficiente em vitamina $D$ foi encaminhado à endocrinologia pediátrica para avaliação de hiperparatireoidismo.

A avaliação do perfil hormonal paratireoideano de cada indivíduo paralelamente à dosagem de 25(OH)D permitiu determinar aqueles cuja hipovitaminose $D$ foi substanciosa o suficiente para refletir quebra na homeostase do eixo calcêmico. Haja vista que os valores de referência atuais da 25(OH)D são determinados com base na média populacional - baseado sobretudo em populações estrangeiras -, indivíduos 
com dosagem inferior ao limite de referência estabelecido são considerados deficientes ou insuficientes em vitamina $D$. Entretanto, naqueles em que não ocorreu elevação concomitante de $\mathrm{PTHi}$, indicando real hipovitaminose, a deficiência da vitamina poderia indicar apenas variação interpessoal do limite da normalidade, sem repercussão funcional e sem necessidade de intervenção terapêutica, ao menos no que tange o metabolismo ósseo.

O estudo da associação DA, 25(OH)D e PTHi, portanto, dada à adoção de valores de referência da 25(OH)D obtidos em população distinta da brasileira aliada à variabilidade interpopulacional e interpessoal das concentrações séricas dessa, é de valor singular não só no campo de pesquisa da DA, mas também no campo da vitamina $D$ na população pediátrica brasileira. $A$ avaliação conjunta das variáveis permitiu avaliar a adequabilidade do ponto de corte utilizado. No presente estudo, não conseguimos detectar a ruptura do plateau de equilíbrio entre as variáveis tampouco demonstrar hiperparatireoidismo secundário mesmo com a grande prevalência de hipovitaminose $D$ na amostra testada.

Face a esses achados, surgem algumas questões: As concentrações séricas definidas pela The Endocrine Society são adequadas? A categorização por ela recomendada tem aplicabilidade na população brasileira na faixa etária dos 0 aos 18 anos? Podemos seguir recomendações internacionais ou serão necessários estudos nacionais a fim de definir valores adequados de $25(\mathrm{OH}) \mathrm{D}$ ? Os dados obtidos sugerem que as concentrações séricas adequadas de $25(\mathrm{OH}) \mathrm{D}$ para a saúde óssea na população pediátrica, ao menos em relação à supressão do PTH, são inferiores aos sugeridos pela The Endocrine Society. Sai e colaboradores (2011) (154), com base na revisão de 70 estudos, sugeriram que a insuficiência de vitamina $D$, com referência à saúde óssea, deveria ser redefinida para uma concentração de $25(\mathrm{OH}) \mathrm{D}$ inferior a $20 \mathrm{ng} / \mathrm{ml}$. Esse é o ponto de corte utilizado pelo IOM (65). Outros autores fornecem evidências semelhantes em populações adultas no sentido da redução do ponto de corte para deficiência e insuficiência (155 - 158).

Cabe ressaltar, porém, que a relação entre $25(\mathrm{OH}) \mathrm{D}$ e PTH pode ser errática em crianças e essa metodologia de avaliação pode não ser a mais adequada para avaliar os valores ideais de 25(OH)D nessa população. Devido ao pequeno número de sujeitos pesquisados e em virtude de as variáveis $25(\mathrm{OH}) \mathrm{D}$ e PTHi terem sido avaliadas em um único momento, seria imprudente extrapolar conclusões a esse respeito. Uma vez que não foi detectado o ponto de ruptura do plateau da relação 
entre 25(OH)D e PTHi, não fomos capazes de sugerir um ponto de corte para as concentrações séricas adequadas de $25(\mathrm{OH}) \mathrm{D}$ na população estudada. Para tal fim seria necessário um estudo com maior número de participantes.

Faz-se mister destacar que há um subgrupo de indivíduos com deficiência de vitamina D que não tem hiperparatireoidismo secundário (HPS). Este achado apresenta importância clínica, pois o grupo sem HPS parece comportar-se de maneira diferente do grupo com HPS. O HPS em indivíduos com deficiência de vitamina $D$, por exemplo, associa-se com aumento de mortalidade e aumento do número de internações hospitalares em idosos $(159,160)$. Vários fatores influenciam a relação entre 25(OH)D e PTH e diversas causas têm sido relacionadas à presença ou não de HPS na hipovitaminose D. Indivíduos com menor ingestão de cálcio são mais propensos a apresentar HPS quando deficientes em vitamina D (161). Outra causa é a deficiência de magnésio, que causa hipoparatireoidismo funcional $(45,162)$. Demonstrou-se haver maior elevação do PTH em indivíduos normoalbuminêmicos quando comparado aos hipoalbuminêmicos, sugerindo papel da ligação às proteínas na biodisponibilidade da 25(OH)D (163). Outros fatores também podem estar associados à presença ou não de HPS na hipovitaminose $D$, quais sejam fatores genéticos, IMC e uso de diuréticos tiazídicos. A presença ou a ausência de HPS na hipovitaminose $D$ é, provavelmente, multifatorial e não totalmente compreendida. Estudos adicionais devem ser realizados para melhor esclarecimento das causas e implicações desse fenômeno (162). Dificulta o estudo dessa associação o desconhecimento dos intervalos de referência ótimos para valores de PTH baseados nos níveis coexistentes de 25(OH)D (60).

Em crianças, os potenciais desfechos funcionais das concentrações adequadas de 25(OH)D incluem ausência de raquitismo, supressão máxima do PTH, aumento da DMO, absorção "ótima" de cálcio e redução da taxa de fraturas. Para a determinação dos intervalos ótimos de $25(\mathrm{OH}) \mathrm{D}$, o ideal seria correlacionar sua concentração sérica com eventos hipoteticamente relacionados à sua insuficiência. Um estudo com este desenho, no entanto, é desafiador, uma vez que doenças ligadas à insuficiência de vitamina D são, em sua maioria, crônicas, com longo período de latência e com causas multifatoriais (47).

Os métodos utilizados para definir a suficiência em vitamina D em crianças, em parte devido às peculiaridades metabólicas dessa fase do crescimento, não estão bem estabelecidos $(64,164)$. Em adolescentes, há evidências da relação inversa entre 
25(OH)D e PTH (165). Entretanto, essa relação não é consistentemente observada em infantes e crianças mais novas (59). Parece improvável que a concentração de 25(OH)D que suprime maximamente o PTH em crianças seja a mesma dos adultos (166). Alguns autores defendem que a baixa concentração de $25(\mathrm{OH}) \mathrm{D}$ na população pediátrica pode ser antecipada a partir de um ponto de vista evolutivo, pois a ingestão elevada de cálcio na infância pode permitir a manutenção da homeostase do cálcio, apesar do baixo status da vitamina D (167). Além disso, é possível e provável que existam diferenças genéticas na quantidade de vitamina $D$ necessária para manter a função fisiológica ótima, assim como nas enzimas do citocromo P450, ativando e degradando a vitamina $\mathrm{D}$. Tais diferenças podem contribuir para a ausência de uma relação direta entre $\mathrm{PTH}$ e $25(\mathrm{OH}) \mathrm{D}$, observada neste e em vários estudos $(138,168,169)$.

Em crianças, alterações radiológicas de raquitismo e baixa DMO têm sido relatadas com concentrações de $25(\mathrm{OH}) \mathrm{D}<16$ a $18 \mathrm{ng} / \mathrm{ml}$, e níveis de fosfatase alcalina sobem quando as concentrações de 25(OH)D são inferiores a $20 \mathrm{ng} / \mathrm{ml}$. Alguns defendem que concentrações de 25(OH)D acima de $20 \mathrm{ng} / \mathrm{ml}$ não são necessárias para otimizar a absorção de cálcio ou a DMO (170). A falta de um consenso bem estabelecido sobre pontos de corte a serem utilizados tem implicações clínicas, e alguns limites podem levar a um subtratamento ou a um tratamento excessivo (60).

Não encontramos correlação significativa entre PTHi e gravidade clínica da DA, tanto quando o SCORAD foi considerado como variável contínua ( $r=0,0691$, $p=0,5710$ ) quanto categórica ( $p=0,8039$ ). Não foram encontrados estudos publicados que associem a gravidade clínica da DA com a concentração sérica de PTHi. A plausibilidade dessa pesquisa refere-se sobretudo à interferência do PTH na produção de PAM e na redução da suscetibilidade a infecções (109). Além disso, alguns estudos demonstram que, em condições experimentais, o PTH pode inibir ou promover a proliferação celular e induzir alterações na regulação do ciclo celular (171-173). Não foram encontrados, porém, pesquisas investigando a ação do PTH na barreira cutânea atópica. No tocante à relação entre PTH e pele, estudos em renais crônicos são divergentes quanto à associação do PTH com o prurido $(174,175)$. 


\subsection{DA E INFLUÊNCIAS AMBIENTAIS}

Há milhares de anos a radiação solar já era utilizada nas civilizações egípcia, grega e romana para tratar diversas doenças de pele (176). Àquela época a importância da radição UV não era reconhecida, pois os raios UV apenas foram descobertos em 1801. A luz solar é uma mistura de UV, luz visível (400-800nm) e infravermelho (800-1.700nm). A radiação UV é dividida em UVA (315-400nm), UVB (280-315nm) e UVC (100-280nm) (120,177).

Há diversas moléculas que atuam como cromóforos em diferentes camadas da pele, interagindo com e absorvendo a radiação UV. Essas interações podem ter implicações biológicas positivas ou negativas. Muitos dos efeitos positivos da radiação solar podem ser mediados pela síntese de vitamina D induzida pela UVB. Entretanto, podem coexistir diversas outras vias para esses efeitos.

Estudos demonstraram que a radiação UV modula várias citocinas e enzimas, culminando em efeitos antioxidantes, anti-inflamatórios, antiapoptóticos, antiproliferativos e protegendo células e tecidos contra o estresse oxidativo e dano tecidual. A radição UV induz efeitos fototóxicos diretos nos linfócitos $T$, promovendo redução gradual do infiltrado inflamatório. A pele exposta à radiação UVB e UVA é mais resistente a irritantes primários, o que pode ser decorrente da melhora na função de barreira (121).

Estudos demonstraram a eficácia da helioterapia na DA, melhorando a qualidade de vida, reduzindo o uso de corticoesteroides e reduzindo o SCORAD em cerca $70 \%(118,178)$. Pacientes com DA, sobretudo aqueles que residem em países de clima temperado ou subártico, apresentam significante melhora da doença nos meses de verão (177).

A fototerapia é uma opção valiosa para o tratamento de diversas dermatoses (DA, psoríase, esclerodermia, vitiligo, micose fungoide). Ceratinócitos, linfócitos T cutâneos e circulantes, monócitos, células de Langerhans, mastócitos e fibroblastos são alvos da radiação UV, que promove imunossupressão local e sistêmica (121). A fototerapia com radiação UV artificial - UVB banda estreita ou UVA - constitui um dos pilares do tratamento da DA. Os benefícios são atribuídos sobretudo à sua atividade imunomoduladora e ao seu papel na regulação da expressão de PAM e na 
permeabilidade da barreira. Alguns autores atribuem parte desses efeitos à vitamina D $(113,179,180)$.

Diante do exposto, deduz-se a importância ímpar da inclusão de variáveis ambientais, particularmente o IUV, no campo de pesquisa da vitamina D e DA. Esse índice pode influenciar tanto a concentração sérica de $25(\mathrm{OH}) \mathrm{D}$ quanto a gravidade clínica da DA. A consideração dessa variável no tema em pesquisa não encontra, pelo conhecimento dos pesquisadores, precedente na literatura científica. Tal desconsideração é injustificada, uma vez que nos dias atuais institutos de pesquisas meteorológicas em todo o mundo oferecem gratuitamente e em tempo real ampla gama de informações, incluindo o IUV, temperatura, umidade do ar, insolação e distribuição e conteúdo de ozônio. No Brasil, tais informações podem ser facilmente obtidas pelo sítio eletrônico do CPTEC / INPE (http://satelite.cptec.inpe.br/uv/) e também de modo retrospectivo pelo Sistema de Informações Ambientais - SISAM (http://sisam.cptec.inpe.br/sisam/). As informações são disponibilizadas por data e localidade, abrangendo todo o território nacional. O uso racional e selecionado de variáveis meteorológicas no campo de estudo da DA e da vitamina D deve ser encorajado, porquanto tais dados podem representar fator de confusão e, se desconsiderados, podem distorcer resultados e originar falsas associações.

O IUV é uma estimativa teórica, ou seja, não é uma observação realizada por instrumentos à superfície terrestre. Para esses cálculos o CPTEC / INPE segue as recomendações da OMS. Os dados são estimados por meio de um modelo matemático-físico, o qual descreve a transferência da radiação UV emitida pelo sol na atmosfera terrestre. São considerados no cálculo a concentração de ozônio, posição geográfica, altitude, estação do ano e condições atmosféricas, dentre outros. Tal índice passou a ser calculado e divulgado principalmente com o objetivo de complementar e modernizar programas sociais para a conscientização da população sobre os efeitos danosos que a exposição excessiva à radiação solar exerce sobre a saúde humana (125).

Foi observada no presente estudo uma associação positiva entre 25(OH)D e IUV, porém estatisticamente não significativa $(r=0,1135 ; p=0,2451)$. Embora fosse esperada uma forte e relevante associação, esse achado não causa, à primeira vista, estranheza, pois não foi aferida a exposição solar dos participantes e tal índice isoladamente não reflete a intensidade da exposição individual à radiação solar. Conquanto, o IUV mostrou estar positiva e significativamente associado com as 
concentrações séricas de 25(OH)D após análise de regressão múltipla, a qual será discutida adiante. A discrepância demonstra a importância da análise multivariada, que prevalece sobre as análises brutas, as quais desconsideram as interações entre demais variáveis.

Houve associação negativa entre IUV e gravidade clínica da DA aferida pelo SCORAD e pelo SCORAD objetivo, porém tal relação foi significativa apenas com relação ao primeiro $(r=-0,2531 ; p=0,0083$ e $r=-0,1675 ; p=0,0847$; respectivamente). A radiação UV exerce efeito imunossupressor na pele atópica e seu efeito na melhora da gravidade clínica da DA é amplamente reconhecido. Aplicação prática desse conceito é o tratamento da DA com helioterapia (118) e fototerapia, com excelentes respostas clínicas (178). A associação apenas com o SCORAD demonstra que o IUV atuou predominantemente nas queixas de perda de sono e prurido, e minoritariamente nos sintomas objetivos (extensão e aspecto clínico das lesões cutâneas).

Consideramos o período de 30 dias antes da avaliação clínica para calcular individualmente o IUV médio. Estabelecemos esse período considerando a meia-vida da 25(OH)D (cerca de 2 a 3 semanas),(41) a melhora da gravidade da DA após 4 semanas de climatoterapia (181), e a variação individual de hábitos de exposição solar, tentando englobar períodos de exposição intencional e não intencional. A produção e a degradação de $25(\mathrm{OH}) \mathrm{D}$ é um processo contínuo e não há consenso quanto à quantidade de exposição UV necessária para manter os níveis de vitamina D. Estabelecer o período ideal para mensurar os efeitos do UV tanto na produção de 25(OH)D quanto na imunossupressão em base individual é uma tarefa árdua na pesquisa clínica e precisa ser melhor avaliada em estudos prospectivos. De acordo com a revisão realizada pelos pesquisadores, esse estudo é original em considerar o IUV em pesquisas envolvendo a associação vitamina D e DA. Uma vez que o IUV foi significativamente associado com o 25(OH)D e SCORAD, o período de 30 dias pode ser um ponto de largada para avaliar essa questão em estudos futuros.

Apesar da associação negativa entre IUV e SCORAD, os banhos de sol não são habitualmente encorajados na prática clínica. O espectro da luz solar varia consideravelmente de acordo com as condições climáticas, a hora do dia e a estação do ano. Dessa forma, é muito difícil expor o paciente a uma radiação específica na intensidade desejada. A helioterapia não é isenta de riscos, há possibilidade de queimaduras, aumento do risco do câncer da pele e fotodano. 
Não foi encontrada associação entre estação climática e concentração sérica de 25(OH)D ( $p=0,0675)$. Tal achado era esperado em razão de o clima característico do local de realização do estudo não possuir estações climáticas bem definidas. Dessa forma, percebe-se que o IUV teve maior utilidade que a estação climática para determinar a influência ambiental sobre a variável 25(OH)D em Brasília-DF. Em regiões temperadas e com estações bem definidas, contudo, as estações climáticas podem ser adequadas para predizer o status de vitamina D.

\subsection{PREDITORES DO SCORAD}

Com o intuito de identificar variáveis independentes associadas à gravidade da DA, foi realizada associação entre o SCORAD categórico e idade, gênero, fototipo, renda familiar, IMC, IMC estratificado pelo escore $Z$, asma ou $\mathrm{RA}$, atopia familiar, idade de início dos sintomas de DA, IUV, IgE total e eosinofilia relativa.

Somente a variável $\lg \mathrm{E}$ apresentou diferença significativa entre as categorias do SCORAD ( $p=0,0148)$. A associação positiva entre IgE e SCORAD corresponde aos achados descritos por Hon e colaboradores (2007) (182), Flohr e colaboradores (2004) (183); e Laske \& Niggemann (2004) (184). A associação entre concentrações séricas de lgE e gravidade clínica de doenças atópicas foi primeiramente descrita para a asma. Posteriormente, tal associação foi expandida para a DA.

No presente estudo não foram encontrados geohelmintos. O exame de EPF foi importante para excluir helmintíases que cursam com elevação dos níveis de lgE. Esta busca é importante para exclusão de viés de confundimento no tocante aos níveis séricos de IgE. Os geohelmintos estimulam anticorpos específicos e uma síntese inespecífica exagerada e policlonal de lgE. Dessa forma, Ascaris lumbricoides, Enterobius vermicularis, Trichuris trichiura, Necator americanus, Ancylostoma duodenale e Strongyloides stercoralis encontram-se associados a altos níveis circulantes de $\lg E$ total (185).

Dado o grande número de variáveis envolvidas e a possibilidade da presença de confundidores que prejudiquem as associações, foi realizada análise por meio de modelo de regressão linear múltipla. Observou-se que a lgE continuou apresentando 
associação significativa com o $\operatorname{SCORAD~}(p=0,0003)$, corroborando o achado encontrado na análise bruta.

A análise multivariada demonstrou ainda que o IUV foi significativamente associado com o SCORAD ( $p=0,0085)$, como também fora observado na análise simples das variáveis contínuas IUV e SCORAD. É interessante notar que, quando analisada do ponto de vista categórico do SCORAD, a associação com o IUV não foi significativa, provavelmente porque as pequenas variações do IUV no período de realização do estudo não tenham sido grandes o bastante para repercutir na categoria de gravidade clínica.

\subsection{PREDITORES DA 25(OH)D}

Do mesmo modo, com o intuito de identificar variáveis independentes associadas às concentrações séricas de $25(\mathrm{OH}) \mathrm{D}$, foi realizada associação entre categorias de $25(\mathrm{OH}) \mathrm{D}$ e idade, gênero, fototipo, renda, IMC, IMC escore $Z$, asma ou RA, atopia familiar, IUV, IgE total, eosinofilia relativa. Nenhuma das variáveis demonstrou associação estatisticamente significativa com as categorias de 25(OH)D.

Não encontramos, do mesmo modo que Akan e colaboradores (2013) (74), associação entre 25(OH)D e lgE ou eosinofilia relativa, apesar de estudos demonstrarem que a vitamina $D$ afeta as funções dos linfócitos $B$ e modula a resposta imune humoral, incluindo a secreção de lgE (150). Alguns autores encontraram associação significativa não-linear entre 25(OH)D sérica e $\operatorname{lgE}(186)$.

Apesar de não associado significativamente com a variável categórica 25(OH)D, o IMC apresentou significância estatística com as concentrações séricas absolutas de 25(OH)D ( $r=-0,1937 ; p=0,0454)$, no sentido de haver redução na 25(OH)D com o aumento do IMC. Tal achado é esperado e corresponde ao descrito por Hata e colaboradores (2013) (95). Sugere-se que essa relação negativa seja devida à natureza lipofílica da vitamina $\mathrm{D}$. O aumento do tecido adiposo reduz a biodisponibilidade pelo sequestro da vitamina $D$ na gordura corporal (187-189). Além disso, os sujeitos com IMC elevado costumam ter uma exposição solar reduzida (82).

$\mathrm{Na}$ análise de variáveis contínuas, assim como o IMC, a idade teve associação estatística significativa com as concentrações séricas de 25(OH)D $(r=-0,2657 ; p=$ 
0,0055). Quanto maior a idade, menor foi a concentração sérica de 25(OH)D encontrada. Essa associação seria esperada em uma população adulta, porquanto ocorre redução do 7-DHC na pele e da capacidade de sintetizar vitamina D com o envelhecimento (45). A amostra do estudo, entretanto, é composta por uma população jovem de até 18 anos. Esse curioso achado foi previamente descrito: Weng e colaboradores (2007) (190) também encontraram associação significativa negativa entre 25(OH)D e idade numa população de 382 indivíduos de 6 a 21 anos no Nordeste dos EUA; Chiu e colaboradores (2013) (94) relataram achado semelhante em 97 sujeitos de 0 a 18 anos com DA em Wisconsin (EUA).

$A$ associação inversa entre a concentração de vitamina $\mathrm{D}$ e a idade durante a infância e a adolescência ainda não é bem compreendida. Redução das atividades físicas relacionadas à idade provavelmente tem efeito sobre atividades ao ar livre e repercute na exposição ao sol, o que representa uma explicação plausível para o status inferior de vitamina D nas crianças mais velhas (190). Adicionalmente, crianças mais velhas podem ter uma suplementação oral diminuída de vitamina D. Estudos futuros prospectivos devem medir a exposição ao sol e atividades ao ar livre, assim como a ingesta de vitamina $D$ nessa faixa etária a fim de esclarecer essa associação.

Repetiu-se análise de regressão linear múltipla para excluir potenciais confundidores e encontrar variáveis independentes verdadeiramente associadas às concentrações séricas de $25(\mathrm{OH}) \mathrm{D}$. A análise multivariada demonstrou que as variáveis fototipo, idade e IUV foram preditores associados a 25(OH)D. Pacientes com fototipo mais baixo (II e III) apresentaram valores médios de 25(OH)D 6,012 ng/ml maiores que pacientes com fototipo mais alto (IV e V) $(p=0,0031)$. Esse resultado é esperado e biologicamente plausível, pois a melanina compete pelo fóton da radiação UVB nos comprimentos de onda entre 280 e $315 \mathrm{~nm}$, diminuindo a disponibilidade de fótons para a fotólise do 7-DHC (41). Hata e colaboradores (2013) (95) também demonstraram associação da concentração sérica de $25(\mathrm{OH}) \mathrm{D}$ com o fototipo de Fitzpatrick: indivíduos com fototipo V/VI tiveram uma média de 25(OH)D de 18,8 ng/ml, significativamente menor quando comparada com a média de $28,7 \mathrm{ng} / \mathrm{ml}$ dos indivíduos com fototipos III/IV ( $p=0,04)$.

A análise de regressão linear múltipla confirmou o achado de que pacientes mais velhos estão associados a menores concentrações de $25(\mathrm{OH}) \mathrm{D}$ do que pacientes mais novos ( $p=0,0189$ ). A análise de regressão linear múltipla também demonstrou que o IUV foi significativamente associado com a concentração sérica de 
25(OH)D ( $p=0,0270)$. A associação positiva entre as variáveis era esperada. Embora não tenham sido considerados os hábitos de exposição solar dos sujeitos, constatamos que quanto maior o IUV nos 30 dias anteriores à avaliação clínica, maior foi a concentração encontrada de $25(\mathrm{OH}) \mathrm{D}$. A ausência dessa associação na análise simples das variáveis IUV e $25(\mathrm{OH}) \mathrm{D}(\mathrm{r}=0,1135 ; \mathrm{p}=0,2451)$ demonstra a presença de fatores de confundimento, possivelmente idade e fototipo, que obscureceram, naquele primeiro momento, uma relação significativa.

Faz-se mister notar que, em análises multivariadas, o IUV teve associação negativa com o SCORAD e positiva com a 25(OH)D. Porém, a 25(OH)D não mostrou associação significativa com o SCORAD. Partindo-se dessa observação, somos levados a crer que o IUV exerce efeitos sobre o SCORAD diverso da influência que exerce na $25(\mathrm{OH}) \mathrm{D}$, tal como uma imunomodulação direta independente da 25(OH)D. Os trabalhos que associam 25(OH)D e gravidade da DA não incluíram o IUV como variável, o que pode representar a desconsideração de um importante fator de confundimento e a obtenção de resultados distorcidos. Entretanto, resultados divergentes dos aqui relatados não podem ser desconsiderados ou tomados como equivocados baseados em tal presunção sem os dados de IUV da localidade em que foram realizados.

Não foi obtida, após análise de regressão linear múltipla, associação significativa entre IMC e 25(OH)D. Isso pode ter ocorrido porque a amostra de obesos foi pequena (apenas $1,86 \%$ da amostra total) ou porque o IMC na faixa etária pediátrica per se não fornece o status nutricional como nos adultos, em que a relação é linear. Em crianças e adolescentes, há curvas específicas para cada gênero e faixa etária para caracterizar o estado nutricional do sujeito $(129,130)$.

Observa-se que o resultado da análise das variáveis IMC, fototipo e IUV versus 25(OH)D diferiu entre a análise bruta e a análise multivariada, o que demonstra a importância da realização dessa. A análise bruta não é capaz de excluir confundidores, o que pode levar a conclusões equivocadas sobre a amostra pesquisada. O IMC, inicialmente encontrado como significativo, mostrou não estar associado após a regressão linear múltipla, que prevalece sobre a associação bruta.

Por outro lado, após isolamento de confundidores, comprovou-se a associação entre fototipo e 25(OH)D. Fototipos elevados são conhecidamente considerados fator de risco para insuficiência / deficiência de 25(OH)D. Ademais, demonstrou-se a associação positiva entre IUV e concentrações de $25(\mathrm{OH}) \mathrm{D}$. A fisiologia da vitamina 
D presume essa associação, uma vez que a radiação UVB é condição necessária para a síntese cutânea de 25(OH)D.

\subsection{DA INTRÍNSECA E EXTRÍNSECA}

A DA intrínseca é caracterizada por ausência de anticorpos lgE alérgenoespecíficos e concentrações séricas normais de lgE total (191). Alguns estudiosos denominam essa entidade de dermatite atopiforme, uma vez que os pacientes podem não ser atópicos (192). Cabe ressaltar que 'sensibilização' difere de 'atopia' e 'alergia'. Atopia refere-se à predisposição genética de produzir lgE alérgeno-específica após exposição a alérgenos. Sensibilização refere-se à presença de lgE alérgenoespecífica; ser sensibilizado não é sinônimo de ser alérgico: um indivíduo pode produzir IgE ao alérgeno, mas não ter sintomas quando exposto. Os indivíduos são considerados alérgicos quando apresentam lgE alérgeno-específica e desenvolvem sintomas quando expostos a ele (193). As diferenças genéticas, humorais e celulares entre pacientes com formas alérgicas e não-alérgicas de doenças atópicas espelham uma complexa rede de distintas propriedades, que, em conjunto, determinam o desfecho das variantes extrínseca e intrínseca (25).

$\mathrm{Na}$ busca da prevalência da DA extrínseca e intrínseca, utilizamos apenas a $\lg \mathrm{E}$ total para a categorização. Não foram dosadas $\lg \mathrm{E}$ específicas, tampouco foi realizado o prick test. Dos 102 sujeitos que realizaram dosagem de lgE, 75 (73,53\%) apresentaram concentrações séricas elevadas de $\lg E$ total e foram alocados na categoria DA extrínseca. Os demais participantes (26,47\%) apresentaram concentração sérica normal de lgE total e foram considerados portadores de DA intrínseca. Esse valor aproxima-se da prevalência de $27 \%$ relatado por Ott e colaboradores (2010) (194). A frequência de DA intrínseca nos estudos varia entre 10 a $45 \%$ dos pacientes com DA $(23,195)$.

Diversas pesquisas encontraram predomínio feminino no grupo DA intrínseca $(25,26,195)$, o que foi reproduzido neste estudo $(66,67 \%$ de mulheres). A maioria das publicações não relata diferença entre gêneros na prevalência da DA extrínseca, porém encontramos o predomínio feminino também neste grupo $(62,67 \%$ de 
mulheres). Não houve diferença significativa ( $p=0,7109)$ no tocante ao gênero entre os subtipos de DA.

Alguns estudos apontam que a DA intrínseca tem início mais tardio $(26,195)$. Encontramos que a idade de início foi menor no grupo DA intrínseca (média de 1,72 anos) quando comparado ao grupo DA extrínseca (2,12 anos), porém sem diferença significativa $(p=0,3854)$. A informação dada pelos responsáveis quanto à idade de instalação da doença, porém, pode sofrer viés de aferição. A idade média dos participantes foi de 8,18 anos, ao passo que a média da idade de início da DA em toda a amostra foi de 2,06 anos. Devido ao grande intervalo entre a idade de início e o momento da requisição do dado ao responsável pelo paciente, a informação tem sua confiabilidade reduzida. Ademais, a percepção do início da doença é variável, assim como a busca e o acesso ao suporte médico que assevera o diagnóstico.

A DA intrínseca é considerada uma doença com quadro clínico mais brando $(23,26)$. Observamos que o SCORAD objetivo mostrou-se significativamente menor no grupo DA intrínseca ( $p=0,0233$ ), o que é consoante com dados da literatura. $O$ SCORAD total entre os grupos, entretanto, não mostrou diferença significativa ( $p=$ $0,1361)$, embora a média \pm desvio-padrão tenha sido menor no grupo com DA intrínseca $(30,14 \pm 16,63$ vs 23,96 $\pm 10,69)$. Brenninkmeijer e colaboradores (2008) (26), assim como Fölster-Holst e colaboradores (2006) (196), demonstraram menor gravidade clínica na DA intrínseca com base no SCORAD, porém não significativa quando usado o índice EASI. Essa divergência observada nos resultados quando considerados índices distintos ecoa a ausência de consenso quanto à melhor ferramenta para aferir a atividade da doença.

Não observamos diferença na concentração sérica de $25(\mathrm{OH}) \mathrm{D}$ entre o grupo DA intrínseca e extrínseca ( $p=0,6086)$. De acordo com o conhecimento dos autores, essa associação foi feita previamente apenas por Akan e colaboradores (2013) (74), os quais também não encontraram diferença na concentração de $25(\mathrm{OH}) \mathrm{D}$ entre os grupos de DA.

Encontramos uma prevalência de asma ou RA concomitante à DA em 62,67\% dos pacientes portadores da variante extrínseca e em 44,44\% da variante intrínseca da dermatose. A menor prevalência de doenças atópicas em pacientes com DA intrínseca foi descrito por Brenninkmeijer e colaboradores (2008) (26). Contudo, no presente estudo a prevalência de outra atopia pessoal associada à DA não diferiu significativamente entre os grupos $(p=0,1001)$. Com relação à atopia familiar, a 
prevalência foi de $68 \%$ no grupo DA extrínseca e 70,37\% no grupo DA intrínseca, novamente sem diferença significativa entre os grupos ( $p=0,8199)$. SchmidGrendelmeier e colaboradores (2001) (195) descreveram achado semelhante no tocante à atopia familiar.

O achado da ausência de diferença significativa quanto à outra atopia pessoal (presença de asma ou RA) entre os dois grupos de DA suscita a indagação acerca da adequabilidade do $\lg \mathrm{E}$ total como parâmetro confiável para distinguir as duas categorias de DA. Entretanto, relata-se que o nível sérico de lgE total está associado com o status de $\lg E$ alérgeno-específica e que a $\lg E$ total tem sido considerada um parâmetro adequado para diferenciação entre DA extrínseca e DA intrínseca (153). Cabe recordar que os parâmetros classicamente utilizados para distinguir as entidades são a $\lg E$ específica a antígenos aéreos e alimentares e a $\lg E$ total. Salienta-se que a $\operatorname{lgE}$ total per se não é o melhor método para distinguir a DA extrínseca da intrínseca. Na contramão do acima exposto, alguns estudiosos defendem que níveis séricos de $\lg E$ total raramente fornecem informações sobre $\lg E$ específica para alérgenos, uma vez que aquela pode elevar-se em uma grande variedade de condições (Quadro 8). Ademais, não há uniformização nos níveis superiores de $\lg$ E considerados normais nas diferentes faixas etárias que discriminem pacientes com ou sem doença alérgica, além de haver uma considerável sobreposição, o que dificulta a distinção entre as formas alérgicas e não alérgicas das doenças baseada apenas nesse exame $(193,197)$.

Quadro 8 - Causas de aumento de lgE

\begin{tabular}{|l|}
\hline Doenças Infecciosas \\
\hline Ascaridíase \\
Esquistossomose \\
Estrongiloidíase \\
Infecção pelo vírus da imunodeficiência humana \\
Mycobaterium tuberculosis \\
Citomegalovirus \\
Vírus Epstein Barr \\
Candidíase \\
\hline Doenças atópicas \\
Aspergilose broncopulmonar alérgica \\
Sinusite fúngica alérgica \\
continua
\end{tabular}


continuação

Quadro 8 - Causas de aumento de lgE

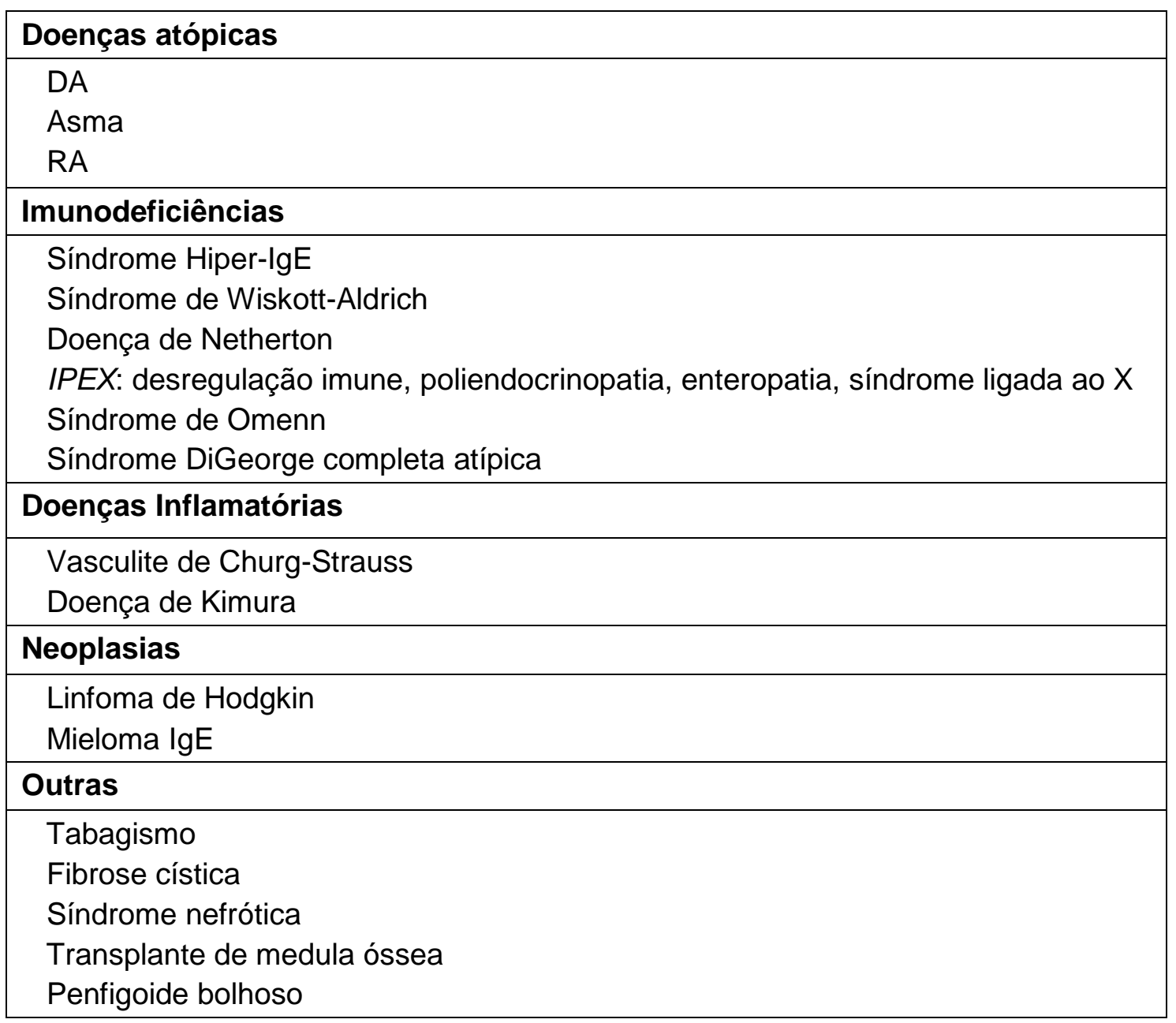

Adaptado de Stokes \& Casale, 2014 (193)

A concentração sérica de $\lg E$ e a regulação da produção de $\lg E$ sérica são fortemente influenciadas por fatores genéticos, além de raciais, imunitários e ambientais. Adicionalmente, a IgE pode flutuar em pacientes atópicos a depender da exposição aos alérgenos $(193,198)$. Por se tratar de estudo transversal, a dosagem de IgE foi realizada apenas em um momento. A utilidade de medir a lgE sérica total ou específica para alérgenos para fins de diagnóstico e tratamento da DA é variável. 


\subsection{ATOPIA PESSOAL CONCOMITANTE}

A presença ou ausência de outra atopia pessoal (asma ou RA), utilizada como variável independente, mostrou associação apenas com as concentrações séricas de lgE total. Observou-se que pacientes com outra atopia pessoal além da DA, ou seja, pacientes com DA que também sofrem de asma ou RA, têm maiores níveis de lgE do que pacientes exclusivamente com DA (diferença entre médias de 660,34 UI/ml, p = 0,0066). Tal achado vai de encontro aos demonstrados por Wittig e colaboradores (1980) (197), em que crianças com DA e asma tiveram maior nível de lgE $(985 \mathrm{Ul} / \mathrm{ml})$, seguidos por crianças apenas com asma (305 Ul/ml), com eczema (273 Ul/ml) e com rinite alérgica (171 Ul/ml). Hetman e colaboradores (1988) (199), de modo condizente, demonstraram que os maiores valores de $\mathrm{IgE}$ foram encontrados em pacientes com doenças atópicas associadas.

A presença de outra atopia pessoal não mostrou associação com concentrações séricas de 25(OH)D ( $p=0,6804)$. A concentração sérica de $25(\mathrm{OH}) \mathrm{D}$ em pacientes com asma ou RA, da mesma forma que na DA, é tema controverso. Alguns estudos demonstram menor concentração sérica de $25(\mathrm{OH}) \mathrm{D}$ em pacientes asmáticos ou com RA $(76,200)$, porém outros estudos não demonstraram tal associação (146). Não foi realizada, entretanto, análise exclusiva dos pacientes com asma ou RA; apenas análise comparativa de pacientes com DA exclusiva versus pacientes com DA e outra atopia. Conclusões a respeito da associação entre asma ou RA e concentrações séricas de $25(\mathrm{OH}) \mathrm{D}$ não podem, portanto, ser aqui inferidas.

\subsection{FORÇAS E LIMITAÇÕES}

De acordo com o conhecimento dos pesquisadores, relatamos a maior amostra de pacientes pediátricos em que a associação $25(\mathrm{OH}) \mathrm{D}$ e gravidade clínica da DA foi testada $(n=106)$ de modo não retrospectivo. Não foram encontrados estudos científicos publicados nesse campo de estudo que tenham considerado as concentrações séricas de PTHi e o IUV no local de realização do projeto. Os dados foram colhidos por entrevistador único e os exames laboratoriais de todos os sujeitos 
realizados nos mesmos laboratórios, o que reduz viés de aferição. Foram feitas análises simples e multivariadas, por vezes com resultados discrepantes, o que demonstra a importância da interação entre as variáveis estudadas.

Limitações do estudo incluem a incapacidade de controlar a exposição solar, a ingesta de cálcio e vitamina $\mathrm{D}$ e o tratamento individualizado da DA, o qual gera repercussão direta no SCORAD. Ademais, não foram avaliados percentual de gordura corporal, vestuário, uso de protetor solar, sensibilização alérgica e atividades físicas (que se correlacionam com tempo fora de casa e exposição solar), albumina, fatores genéticos, magnésio, fósforo - o fósforo diminui a produção de calcitriol renal -, marcadores de remodelação óssea, DMO e função renal. Além disso, há variabilidade no método utilizado para a medição da $25(\mathrm{OH}) \mathrm{D}$, a quimioluminescência. Apenas um único ponto do tempo foi capturado, momento este que pode não refletir verdadeiramente um estado contínuo do quadro clínico ou da homeostase do organismo. A concentração sérica de 25(OH)D em um indivíduo reflete uma ingesta recente de vitamina $D$ e/ou exposição solar, e pode variar grandemente em curtos intervalos de tempo (140).

Faz-se mister ressaltar que o IUV máximo diário não representa a exposição solar diária dos participantes. Não aferimos horário e duração de exposição solar nos voluntários. A variável IUV não pode, portanto, ser considerada como preditor único da exposição solar. O método ideal para uma medida fidedigna seria utilizando dosímetros individuais de UV. Dosímetros individuais são capazes de fornecer uma medida dinâmica e objetiva da exposição UV acumulada, uma vez que seu resultado é determinado pelas variações diárias de exposição ao UV e pelas condições ambientais. Os dosímetros químicos mais utilizados são feitos com polissulfona ou óxido de polifenileno (201), mas atualmente também há modelos eletrônicos disponíveis (202).

Amostras institucionais podem ser vistas como limitadas em termos de representatividade externa. No entanto, os resultados aqui apresentados são consistentes e essa limitação não é suscetível de prejudicar a validade dos nossos principais resultados.

Variações individuais nas concentrações de vitamina D não são totalmente explicadas por fatores externos (203). Os diferentes fenótipos que os indivíduos podem apresentar em relação à homeostase da vitamina $D$ podem resultar também de particularidades genéticas, como polimorfismos nos genes que regulam a 
expressão dos vários componentes do eixo hormonal da vitamina D (VDR, proteína carreadora da vitamina $D$ e enzimas do complexo do citocromo P450, dentre outros). Estudos de análise genômica poderão futuramente fornecer dados sobre a influência da determinação genética nos componentes desse complexo sistema endocrinológico (41). 


\section{CONCLUSÃO}

Pacientes com DA apresentaram concentrações séricas de 25(OH)D significativamente maiores que grupo controle - em média $3,39 \mathrm{ng} / \mathrm{ml}$-, porém tal diferença não gerou repercussão na distribuição das categorias de $25(\mathrm{OH}) \mathrm{D}$ entre os grupos. A abrangência do pareamento realizado não encontra precedente nos estudos em que a associação foi testada. De acordo com o conhecimento dos pesquisadores, o estudo relata de modo inédito maior concentração de 25(OH)D em grupo DA que em grupo controle utilizando a concentração atual da 25(OH)D. Tal achado, contudo, pode estar relacionado ao maior IUV médio encontrado nos pacientes com DA.

A ausência de correlação significativa entre concentrações séricas de 25(OH)D e PTHi na amostra examinada sugere inadequabilidade dos valores de referência de $25(\mathrm{OH}) \mathrm{D}$ atualmente adotados no tocante ao metabolismo ósseo e necessidade da revisão de tais valores na população pediátrica, assim como da padronização dos métodos para avaliar seus pontos de corte. Não encontramos correlação significativa entre PTHi e gravidade clínica da DA.

Demonstrando a adequabilidade da aferição das variáveis e dos métodos utilizados no estudo, encontramos associações antecipadamente previstas e biologicamente plausíveis no campo da DA e da vitamina $\mathrm{D}$, tais como a correlação significativa entre IgE e gravidade clínica da DA, fototipo e vitamina D, IUV e vitamina D, IUV e SCORAD.

Uma vez que foi observada associação significativa entre 25(OH)D e IUV, assim como entre SCORAD e IUV, porém não entre 25(OH)D e SCORAD, os efeitos benéficos da exposição solar nas doenças alérgicas parece operar independente da vitamina $\mathrm{D}$.

O IUV, variável fácil e gratuitamente obtida por meio da internet, correlacionase tanto com a gravidade clínica da DA quanto com a vitamina D. Não foram encontrados estudos prévios que tenham considerado o IUV como fator de confusão na associação DA e vitamina D. O uso dessa variável em estudos envolvendo doenças atópicas e vitamina $\mathrm{D}$ deve ser encorajado.

Enquanto existem evidências crescentes mostrando que a vitamina $D$ desempenha um papel importante no sistema imune e especificamente em doenças alérgicas, a extensão do impacto não foi totalmente esclarecido. São necessários 
estudos complexos e a longo prazo, envolvendo desfechos calcêmicos e não calcêmicos, para elucidação dos reais efeitos da vitamina $D$ na saúde humana. Esforços devem ser dirigidos à identificação de variáveis confundidoras em tais associações para que se evitem falsas conclusões decorrentes de desenhos epidemiológicos inadequados. 


\section{REFERÊNCIAS}

1. Spergel JM. Epidemiology of atopic dermatitis and atopic march in children. Immunol Allergy Clin North Am. 2010;30(3):269-80.

2. Zeppa L, Bellini V, Lisi P. Atopic dermatitis in adults. Dermatitis. 2011;22(1):40-6.

3. Palmer CN, Irvine AD, Terron-Kwiatkowski A, Zhao Y, Liao H, Lee SP, Goudie DR, Sandilands A, Campbell LE, Smith FJ, et al. Common loss-of-function variants of the epidermal barrier protein filaggrin are a major predisposing factor for atopic dermatitis. Nat Genet. 2006;38(4):441-6.

4. Eichenfield LF, Ellis CN, Mancini AJ, Paller AS, Simpson EL. Atopic dermatitis: epidemiology and pathogenesis update. Semin Cutan Med Surg. 2012;31(3 Suppl):S35.

5. Boguniewicz M, Leung DY. Atopic dermatitis: a disease of altered skin barrier and immune dysregulation. Immunol Rev. 2011;242(1):233-46.

6. Kapoor R, Menon C, Hoffstad O, Bilker W, Leclerc P, Margolis DJ. The prevalence of atopic triad in children with physician-confirmed atopic dermatitis. J Am Acad Dermatol. 2008;58(1):68-73.

7. Boguniewicz M, Schmid-Grendelmeier P, Leung DY. Atopic dermatitis. J Allergy Clin Immunol. 2006;118(1):40-3.

8. Amestejani M, Salehi BS, Vasigh M, Sobhkhiz A, Karami M, Alinia H, Kamrava SK, Shamspour N, Ghalehbaghi B, Behzadi AH. Vitamin D supplementation in the treatment of atopic dermatitis: a clinical trial study. J Drugs Dermatol. 2012;11(3):32730.

9. Amaral CS, March Mde F, Sant'Anna CC. Quality of life in children and teenagers with atopic dermatitis. An Bras Dermatol. 2012;87(5):717-23. 
10. Weber MB, Lorenzini D, Reinehr CP, Lovato B. Assessment of the quality of life of pediatric patients at a center of excellence in dermatology in southern Brazil. An Bras Dermatol. 2012;87(5):697-702.

11. Kiebert G, Sorensen SV, Revicki D, Fagan SC, Doyle JJ, Cohen J, Fivenson D. Atopic dermatitis is associated with a decrement in health-related quality of life. Int $\mathrm{J}$ Dermatol. 2002;41(3):151-8.

12. Peroni DG, Piacentini GL, Cametti E, Chinellato I, Boner AL. Correlation between serum 25-hydroxyvitamin $\mathrm{D}$ levels and severity of atopic dermatitis in children. $\mathrm{Br} \mathrm{J}$ Dermatol. 2011;164(5):1078-82.

13. Wuthrich B, Schmid-Grendelmeier P. The atopic eczema/dermatitis syndrome. Epidemiology, natural course, and immunology of the lgE-associated ("extrinsic") and the nonallergic ("intrinsic") AEDS. J Investig Allergol Clin Immunol. 2003;13(1):1-5.

14. Wuthrich B. Clinical aspects, epidemiology, and prognosis of atopic dermatitis. Ann Allergy Asthma Immunol. 1999;83(5):464-470

15. Silverberg JI, Hanifin J, Simpson EL. Climatic factors are associated with childhood eczema prevalence in the United States. J Invest Dermatol. 2013;133(7):1752-9.

16. Borges WG, Burns DAR, Guimarães FATM, Felizola MLMB, Borges VM. Dermatite atópica em adolescentes do Distrito Federal: comparação entre as fases I e III do ISAAC, de acordo com a situação socioeconômica. Rev bras alergia imunopatol. $2004 ; 31(4): 146-150$.

17. Shaw TE, Currie GP, Koudelka CW, Simpson EL. Eczema prevalence in the United States: data from the 2003 National Survey of Children's Health. J Invest Dermatol. $2011 ; 131(1): 67-73$.

18. Nichols KM, Cook-Bolden FE. Allergic skin disease: major highlights and recent advances. Med Clin North Am. 2009;93(6):1211-24. 
19. Hanifin JM, Rajka G. Diagnostic features of atopic dermatitis. Acta Derm Venereol (Stockh). 1980;Suppl 92:44-7.

20. European Task Force on Atopic Dermatitis. Severity scoring of atopic dermatitis: the SCORAD index. Consensus Report of the European Task Force on Atopic Dermatitis. Dermatology. 1993;186(1):23-31.

21. Hanifin JM, Thurston M, Omoto M, Cherill R, Tofte SJ, Graeber M. The eczema area and severity index (EASI): assessment of reliability in atopic dermatitis. EASI Evaluator Group. Exp Dermatol. 2001;10(1):11-8.

22. Hon KL, Ma KC, Wong E, Leung TF, Wong Y, Fok TF. Validation of a selfadministered questionnaire in Chinese in the assessment of eczema severity. Pediatr Dermatol. 2003;20(6):465-9.

23. Tokura Y. Extrinsic and intrinsic types of atopic dermatitis. J Dermatol Sci. $2010 ; 58(1): 1-7$.

24. Mori T, Ishida K, Mukumoto S, Yamada Y, Imokawa G, Kabashima K, Kobayashi M, Bito T, Nakamura M, Ogasawara K, Tokura Y. Comparison of skin barrier function and sensory nerve electric current perception threshold between IgE-high extrinsic and IgE-normal intrinsic types of atopic dermatitis. Br J Dermatol. 2010;162(1):83-90.

25. Novak N, Bieber T. Allergic and nonallergic forms of atopic diseases. J Allergy Clin Immunol. 2003;112(2):252-62.

26. Brenninkmeijer EE, Spuls PI, Legierse CM, Lindeboom R, Smitt JH, Bos JD. Clinical differences between atopic and atopiform dermatitis. J Am Acad Dermatol. 2008;58(3):407-14.

27. Schneider L, Tilles S, Lio P, Boguniewicz M, Beck L, LeBovidge J, Novak N, Bernstein D, Blessing-Moore J, Khan D, et al. Atopic dermatitis: a practice parameter update 2012. J Allergy Clin Immunol. 2013;131(2):295-9.e1-27. 
28. Leung DYM, Eichenfield LF, Boguniewicz M. Atopic Dermatitis (Atopic Eczema). Em: Wolff K, Goldsmith LA, Katz SI, Gilchrest BA, Paller AS, Leffell DJ, editores. Fitzpatrick's Dermatology in General Medicine. McGraw-Hill; 2008. p. 146-158.

29. Petry V, Bessa GR, Poziomczyck CS, Oliveira CF, Weber MB, Bonamigo RR, d'Azevedo PA. Bacterial skin colonization and infections in patients with atopic dermatitis. An Bras Dermatol. 2012;87(5):729-34.

30. Dold S, Wjst M, von Mutius E, Reitmeir P, Stiepel E. Genetic risk for asthma, allergic rhinitis, and atopic dermatitis. Arch Dis Child. 1992;67(8):1018-22.

31. Tromp SW. Influence of weather and climate on asthma and bronchitis. Rev Allergy. 1968;22(11):1027-44.

32. Weiland SK, Husing A, Strachan DP, Rzehak P, Pearce N, ISAAC Phase One Study Group. Climate and the prevalence of symptoms of asthma, allergic rhinitis, and atopic eczema in children. Occup Environ Med. 2004;61(7):609-15.

33. Byremo G, Rød G, Carlsen KH. Effect of climatic change in children with atopic eczema. Allergy. 2006;61(12):1403-10.

34. De Benedetto A, Rafaels NM, McGirt LY, Ivanov AI, Georas SN, Cheadle C, Berger $A E$, Zhang $K$, Vidyasagar $S$, Yoshida $T$, et al. Tight junction defects in patients with atopic dermatitis. J Allergy Clin Immunol. 2011;127(3):773-86.e1-7.

35. Mesquita Kde C, Igreja AC, Costa IM. Atopic dermatitis and vitamin D: facts and controversies. An Bras Dermatol. 2013;88(6):945-53.

36. Miller J, Gallo RL. Vitamin D and innate immunity. Dermatol Ther. 2010;23(1):1322.

37. Van Etten E, Mathieu C. Immunoregulation by 1,25-dihydroxyvitamin D3: basic concepts. J Steroid Biochem Mol Biol. 2005;97(1-2):93-101. 
38. Mutgi K, Koo J. Update on the Role of Systemic Vitamin D in Atopic Dermatitis. Pediatr Dermatol. 2013;30(3):303-307.

39. Norman AW. Minireview: vitamin D receptor: new assignments for an already busy receptor. Endocrinology. 2006;147(12):5542-8.

40. Bouillon R, Carmeliet G, Verlinden L, van Etten E, Verstuyf A, Luderer HF, Lieben L, Mathieu C, Demay M. Vitamin D and human health: lessons from vitamin $D$ receptor null mice. Endocr Rev. 2008;29(6):726-76.

41. Castro LC. The vitamin D endocrine system. Arq Bras Endocrinol Metabol. 2011;55(8):566-75.

42. Glade MJ. Vitamin D: Health Panacea or false Prophet? Nutrition. 2013;29(1):3741.

43. Russell M. Assessing the relationship between vitamin D3 and stratum corneum hydration for the treatment of xerotic skin. Nutrients. 2012;4(9):1213-8.

44. Holick MF, Binkley NC, Bischoff-Ferrari HA, Gordon CM, Hanley DA, Heaney RP, Murad $\mathrm{MH}$, Weaver $\mathrm{CM}$; Endocrine Society. Evaluation, treatment, and prevention of vitamin D deficiency: an Endocrine Society clinical practice guideline. J Clin Endocrinol Metab. 2011;96(7):1911-30.

45. Holick MF. Vitamin D deficiency. N Engl J Med. 2007;357(3):266-81.

46. Bringhurst $F R$, Demay MB, Kronenberg HM. Hormônios e distúrbios do metabolismo mineral. Em: Kronenberg HM, Melmed S, Polonsky KS, Larsen PR, editores. Williams Tratado de Endocrinologia. Rio de Janeiro: Elsevier, 2010, p. 9561009.

47. Silva BCC, Camargos BM, Fujii JB, Dias EP, Soares MMS. Prevalence of vitamin D deficiency and its correlation with PTH, biochemical bone turnover markers and bone 
mineral density, among patients from ambulatories. Arq Bras Endrocrinol Metab. 2008;52(3):482-488.

48. Carter GD. Accuracy of 25-hydroxyvitamin D assays: confronting the issues. Curr Drug Targets. 2011;12(1):19-28.

49. Arabi A, El Rassi R, El-Hajj Fuleihan G. Hypovitaminosis D in developing countriesprevalence, risk factors and outcomes. Nat Rev Endocrinol. 2010;6(10):550-61.

50. Benson AA, Toh JA, Vernon N, Jariwala SP. The role of vitamin $D$ in the immunopathogenesis of allergic skin diseases. Allergy. 2012;67(3):296-301.

51. Tang JY, Fu T, Lau C, Oh DH, Bikle DD, Asgari MM. Vitamin D in cutaneous carcinogenesis: part I. J Am Acad Dermatol. 2012;67(5):803.e1-12.

52. Reinholz M, Schauber J. Vitamin D and innate immunity of the skin. Dtsch Med Wochenschr. 2012;137(46):2385-9.

53. Bikle DD. Vitamin D metabolism and function in the skin. Mol Cell Endocrinol. 2011;347(1-2):80-9.

54. Li YC, Pirro AE, Amling M, Delling G, Baron R, Bronson R, Demay MB. Targeted ablation of vitamin $D$ receptor: an animal model of vitamin D-dependent rickets type II with alopecia. Proc Natl Acad Sci USA. 1997;94(18):9831-5.

55. Bikle DD, Oda Y, Xie Z. Calcium and 1,25(OH)2D: interacting drivers of epidermal differentiation. J Steroid Biochem Mol Biol. 2004;89-90(1-5):355-60.

56. Xie Z, Komuves L, Yu QC, Elalieh H, Ng DC, Leary C, Chang S, Crumrine D, Yoshizawa $T$, Kato $S$, Bikle DD. Lack of the vitamin $D$ receptor is associated with reduced epidermal differentiation and hair follicle growth. J Invest Dermatol. 2002;118(1):11-6. 
57. Bikle DD, Pillai S, Gee E, Hincenbergs M. Regulation of 1,25-dihydroxyvitamin D production in human keratinocytes by interferon-gamma. Endocrinology. $1989 ; 124(2): 655-60$.

58. Ross AC, Manson JE, Abrams SA, Aloia JF, Brannon PM, Clinton SK, DurazoArvizu RA, Gallagher JC, Gallo RL, Jones G, Kovacs CS, Mayne ST, Rosen CJ, Shapses SA. The 2011 report on dietary reference intakes for calcium and vitamin D from the Institute of Medicine: what clinicians need to know. J Clin Endocrinol Metab. $2011 ; 96(1): 53-8$.

59. Pazirandeh S, Burns DL. Overview of vitamin D. Em: UpToDate, Mulder JE, editor. UpToDate, 2013 [acesso 10 mar 2013]. Disponível em: http://www.uptodate.com.

60. Saliba W, Barnett O, Rennert HS, Lavi I, Rennert G. The relationship between serum 25(OH)D and parathyroid hormone levels. Am J Med. 2011;124(12):1165-70.

61. Lips P. Which circulating level of 25-hydroxyvitamin $D$ is appropriate? J Steroid Biochem Mol Biol. 2004;89-90(1-5):611-4.

62. Dawson-Hughes $B$. What is the optimal dietary intake of vitamin $D$ for reducing fracture risk? Calcif Tissue Int. 2013;92(2):184-90.

63. Need, AG, Horowitz, M, Morris, HA, Nordin, BEC. Vitamin D status: effects on parathyroid hormone and 1,25-dihydroxyvitamin $D$ in postmenopausal women. Am $J$ Clin Nutr. 2000;71(6):1577-1581.

64. Pela I. How much vitamin D for children? Clin Cases Miner Bone Metab. 2012;9(2):112-7.

65. Institute of Medicine. Dietary reference intakes for calcium and vitamin $D$. Washington, DC: The National Academies Press, 2011. Disponível em: http://www.nap.edu/catalog.php?record_id=13050. 
66. Peters BS, dos Santos LC, Fisberg M, Wood RJ, Martini LA. Prevalence of vitamin D insufficiency in Brazilian adolescents. Ann Nutr Metab. 2009;54(1):15-21.

67. Premaor MO, Paludo P, Manica D, Paludo AP, Rossatto ER, Scalco R, Furlanetto TW. Hypovitaminosis $D$ and secondary hyperparathyroidism in resident physicians of a general hospital in southern Brazil. J Endocrinol Invest. 2008;31(11):991-5.

68. Scalco R, Premaor MO, Fröehlich PE, Furlanetto TW. High prevalence of hypovitaminosis $D$ and secondary hyperparathyroidism in elders living in nonprofit homes in South Brazil. Endocrine. 2008;33(1):95-100

69. Zittermann A, Prokop S, Gummert JF, Börgermann J. Safety Issues of Vitamin D Supplementation. Anticancer Agents Med Chem. 2013;13(1):4-10.

70. Gupta A, Bush A, Hawrylowicz C, Saglani S. Vitamin D and asthma in children. Paediatr Respir Rev. 2012;13(4):236-43.

71. Bäck $O$, Blomquist HK, Hernell O, Stenberg B. Does vitamin D intake during infancy promote the development of atopic allergy? Acta Derm Venereol. 2009;89(1):28-32.

72. Tavera-Mendoza LE, White JH. Cell defenses and the sunshine vitamin. Sci Am. 2007;297(5):62-5, 68-70,72.

73. Mithal A, Wahl DA, Bonjour JP, Burckhardt P, Dawson-Hughes B, Eisman JA, ElHajj Fuleihan G, Josse RG, Lips P, Morales-Torres J; IOF Committee of Scientific Advisors (CSA) Nutrition Working Group. Global vitamin D status and determinants of hypovitaminosis D. Osteoporos Int. 2009;20(11):1807-20.

74. Akan A, Azkur D, Ginis T, Toyran M, Kaya A, Vezir E, Ozcan C, Ginis Z, Kocabas $\mathrm{CN}$. Vitamin $\mathrm{d}$ level in children is correlated with severity of atopic dermatitis but only in patients with allergic sensitizations. Pediatr Dermatol. 2013;30(3):359-63.

75. Wjst M, Dold S. Genes, factor X, and allergens: what causes allergic diseases? Allergy. 1999;54(7):757-9. 
76. Brehm JM, Celedón JC, Soto-Quiros ME, Avila L, Hunninghake GM, Forno E, Laskey D, Sylvia JS, Hollis BW, Weiss ST, Litonjua AA. Serum vitamin D levels and markers of severity of childhood asthma in Costa Rica. Am J Respir Crit Care Med. $2009 ; 179(9): 765-71$.

77. Bener A, Ehlayel MS, Tulic MK, Hamid Q. Vitamin D deficiency as a strong predictor of asthma in children. Int Arch Allergy Immunol. 2012;157(2):168-175.

78. Hollams EM, Hart PH, Holt BJ, Serralha M, Parsons F, de Klerk NH, Zhang G, Sly $P D$, Holt PG. Vitamin $D$ and atopy and asthma phenotypes in children: a longitudinal cohort study. Eur Respir J. 2011;38(6):1320-7.

79. Ito $\mathrm{Y}$, Adachi $\mathrm{Y}$, Yoshida $\mathrm{K}$, Akasawa A. No association between serum vitamin D status and the prevalence of allergic diseases in Japanese children. Int Arch Allergy Immunol. 2013;160(2):218-20.

80. Devereux G, Wilson A, Avenell A, McNeill G, Fraser WD. A case-control study of vitamin $D$ status and asthma in adults. Allergy. 2010;65(5):666-667.

81. Gale CR, Robinson SM, Harvey NC, Javaid MK, Jiang B, Martyn CN, Godfrey KM, Cooper C; Princess Anne Hospital Study Group. Maternal vitamin D status during pregnancy and child outcomes. Eur J Clin Nutr. 2008;62(1):68-77.

82. Samochocki Z, Bogaczewicz J, Jeziorkowska R, Sysa-Jędrzejowska A, Glińska O, Karczmarewicz E, McCauliffe DP, Woźniacka A. Vitamin D effects in atopic dermatitis. J Am Acad Dermatol. 2013;69(2):238-44.

83. Oren E, Banerji A, Camargo CA Jr. Vitamin D and atopic disorders in an obese population screened for vitamin D deficiency. J Allergy Clin Immunol. 2008;121(2):5334. 
84. El Taieb MA, Fayed HM, Aly SS, Ibrahim AK.Assessment of serum 25hydroxyvitamin d levels in children with atopic dermatitis: correlation with SCORAD index. Dermatitis. 2013;24(6):296-301.

85. Wang SS, Hon KL, Kong AP, Pong HN, Wong GW, Leung TF. Vitamin D deficiency is associated with diagnosis and severity of childhood atopic dermatitis. Pediatr Allergy Immunol. 2014;25(1):30-5.

86. Solvoll K, Soyland E, Sandstad B, Drevon CA. Dietary habits among patients with atopic dermatitis. Eur J Clin Nutr. 2000;54(2):93-7.

87. Willers SM, Devereux G, Craig LC, McNeill G, Wijga AH, Abou El-Magd W, Turner SW, Helms PJ, Seaton A. Maternal food consumption during pregnancy and asthma, respiratory and atopic symptoms in 5-year-old children. Thorax. 2007;62(9):773-9.

88. Miyake $Y$, Sasaki S, Tanaka K, Hirota Y. Dairy food, calcium and vitamin D intake in pregnancy, and wheeze and eczema in infants. Eur Respir J. 2010;35(6):1228-34.

89. Kuzume K, Kusu M. Before-birth climatologic data may play a role in the development of allergies in infants. Pediatr Allergy Immunol. 2007;18(4):281-7.

90. Asher MI, Keil U, Anderson HR, Beasley R, Crane J, Martinez F, Mitchell EA, Pearce N, Sibbald B, Stewart AW, et al. International study of asthma and allergies in childhood (ISAAC): rationale and methods. Eur Respir J. 1995;8(3):483-91.

91. Kull I, Böhme M, Wahlgren CF, Nordvall L, Pershagen G, Wickman M. Breastfeeding reduces the risk for childhood eczema. J Allergy Clin Immunol. 2005;116(3):657-61.

92. Milner JD, Stein DM, McCarter R, Moon RY. Early infant multivitamin supplementation is associated with increased risk for food allergy and asthma. Pediatrics. 2004;114(1):27-32. 
93. Hyppönen E, Sovio U, Wjst M, Patel S, Pekkanen J, Hartikainen AL, Järvelinb MR. Infant vitamin d supplementation and allergic conditions in adulthood: northern Finland birth cohort 1966. Ann N Y Acad Sci. 2004;1037:84-95.

94. Chiu YE, Havens PL, Siegel DH, Ali O, Wang T, Holland KE, Galbraith SS, Lyon VB, Drolet BA. Serum 25-hydroxyvitamin D concentration does not correlate with atopic dermatitis severity. J Am Acad Dermatol. 2013;69(1):40-6.

95. Hata TR, Audish D, Kotol P, Coda A, Kabigting F, Miller J, Alexandrescu D, Boguniewicz M, Taylor P, Aertker L, Kesler K, Hanifin JM, Leung DY, Gallo RL. A randomized controlled double-blind investigation of the effects of vitamin $D$ dietary supplementation in subjects with atopic dermatitis. J Eur Acad Dermatol Venereol. 2013 May 3. doi: 10.1111/jdv.12176.

96. Lee SA, Hong S, Kim HJ, Lee SH, Yum HY. Correlation between serum vitamin d level and the severity of atopic dermatitis associated with food sensitization. Allergy Asthma Immunol Res. 2013;5(4):207-10.

97. Mullins RJ, Clark S, Katelaris C, Smith V, Solley G, Camargo CA Jr. Season of birth and childhood food allergy in Australia. Pediatr Allergy Immunol. 2011;22:583-9.

98. Stumpf WE, Sar M, Reid FA, Tanaka Y, DeLuca HF. Target cells for 1,25dihydroxyvitamin D3 in intestinal tract, stomach, kidney, skin, pituitary, and parathyroid. Science. 1979;206(4423):1188-90.

99. Gurlek A, Pittelkow MR, Kumar R. Modulation of growth factor/cytokine synthesis and signaling by 1 alpha,25-dihydroxy vitamin $\mathrm{D}(3)$ : implications in cell growth and differentiation. Endocr Rev. 2002;23(6):763-86.

100. Heine G, Hoefer N, Franke A, Nöthling U, Schumann RR, Hamann L, Worm M. Association of vitamin $\mathrm{D}$ receptor gene polymorphisms with severe atopic dermatitis in adults. Br J Dermatol. 2013;168(4):855-8. 
101. Baïz N, Dargent-Molina P, Wark JD, Souberbielle JC, Annesi-Maesano I; EDEN Mother-Child Cohort Study Group. Cord serum 25-hydroxyvitamin D and risk of early childhood transient wheezing and atopic dermatitis. J Allergy Clin Immunol. 2014;133(1):147-53.

102. Youssef DA, Miller CW, El-Abbassi AM, Cutchins DC, Cutchins C, Grant WB, Peiris AN. Antimicrobial implications of vitamin D. Dermatoendocrinol. 2011;3(4):2209.

103. Hewison M. Vitamin D and immune function: an overview. Proc Nutr Soc. 2012;71(1):50-61.

104. Norval M. The challenges of UV-induced immunomodulation for children's health. Prog Biophys Mol Biol. 2011;107(3):323-32.

105. Chi A, Wildfire J, McLoughlin R, Wood RA, Bloomberg GR, Kattan M, Gergen P, Gold DR, Witter F, Chen T, Holick M, Visness C, Gern J, O'Connor GT. Umbilical cord plasma 25-hydroxyvitamin $D$ concentration and immune function at birth: the urban environment and childhood asthma study. Clin Exp Allergy. 2011;41(6):842-50

106. Bals R. Epithelial antimicrobial peptides in host defense against infection. Respir Res. 2000;1(3):141-150.

107. Schauber J, Dorschner RA, Yamasaki K, Brouha B, Gallo RL. Control of the innate epithelial antimicrobial response is cell-type specific and dependent on relevant microenvironmental stimuli. Immunology. 2006;118(4):509-19.

108. Matheson EM, Mainous AG 3rd, Hueston WJ, Diaz VA, Everett CJ. Vitamin D and methicillin-resistant Staphylococcus aureus nasal carriage. Scand J Infect Dis. 2010;42(6-7):455-60.

109. Muehleisen B, Bikle DD, Aguilera C, Burton DW, Sen GL, Deftos LJ, Gallo RL. PTH/PTHrP and Vitamin D Control Antimicrobial Peptide Expression and Susceptibility to Bacterial Skin Infection. Sci Transl Med. 2012;4(135):135ra66. 
110. Büchau AS, MacLeod DT, Morizane S, Kotol PF, Hata T, Gallo RL. Bcl-3 acts as an innate immune modulator by controlling antimicrobial responses in keratinocytes. $J$ Invest Dermatol. 2009;129(9):2148-55.

111. Vähävihu K, Ala-Houhala $M$, Peric $M$, Karisola $P$, Kautiainen $H$, Hasan $T$, Snellman E, Alenius H, Schauber J, Reunala T. Narrowband ultraviolet B treatment improves vitamin $\mathrm{D}$ balance and alters antimicrobial peptide expression in skin lesions of psoriasis and atopic dermatitis. Br J Dermatol. 2010;163(2):321-8.

112. Reichrath J, Müller SM, Kerber A, Baum HP, Bahmer FA. Biologic effects of topical calcipotriol (MC 903) treatment in psoriatic skin. J Am Acad Dermatol. 1997;36(1):19-28.

113. Hong SP, Kim MJ, Jung MY, Jeon H, Goo J, Ahn SK, Lee SH, Elias PM, Choi EH. Biopositive effects of low-dose UVB on epidermis: coordinate upregulation of antimicrobial peptides and permeability barrier reinforcement. $J$ Invest Dermatol. 2008;128(12):2880-7.

114. Bikle DD, Chang S, Crumrine D, Elalieh H, Man MQ, Dardenne O, Xie Z, Arnaud RS, Feingold K, Elias PM. Mice lacking 25OHD 1alpha-hydroxylase demonstrate decreased epidermal differentiation and barrier function. J Steroid Biochem Mol Biol. $2004 ; 89-90(1-5): 347-53$.

115. Jung T, Stingl G. Atopic dermatitis: therapeutic concepts evolving from new pathophysiologic insights. J Allergy Clin Immunol. 2008;122(6):1074-81.

116. Sidbury R, Sullivan AF, Thadhani RI, Camargo CA Jr. Randomized controlled trial of vitamin $D$ supplementation for winter-related atopic dermatitis in Boston: a pilot study. Br J Dermatol. 2008;159(1):245-7.

117. Javanbakht MH, Keshavarz SA, Djalali M, Siassi F, Eshraghian MR, Firooz A, Seirafi $\mathrm{H}$, Ehsani $\mathrm{AH}$, Chamari $\mathrm{M}$, Mirshafiey A. Randomized controlled trial using 
vitamins $\mathrm{E}$ and $\mathrm{D}$ supplementation in atopic dermatitis. J Dermatolog Treat. $2011 ; 22(3): 144-50$.

118. Vähävihu K, Ylianttila L, Salmelin R, Lamberg-Allardt C, Viljakainen H, Tuohimaa P, Reunala T, Snellman E. Heliotherapy improves vitamin D balance and atopic dermatitis. Br J Dermatol. 2008;158(6):1323-8.

119. Hata TR, Kotol P, Jackson M, Nguyen M, Paik A, Udall D, Kanada K, Yamasaki K, Alexandrescu D, Gallo RL. Administration of oral vitamin D induces cathelicidin production in atopic individuals. J Allergy Clin Immunol. 2008;122(4):829-31.

120. World Health Organization, World Meteorological Organization, United Nations Environment Programme and International Commission on Non-Ionizing Radiation Protection [Internet]. Global Solar UV Index: A Practical Guide (2002) [acesso 02 jan 2014]. Disponível em: http://www.who.int/uv/publications/globalindex/en/.

121. Juzeniene A, Moan J. Beneficial effects of UV radiation other than via vitamin D production. Dermatoendocrinol. 2012;4(2):109-17.

122. Dupont E, Craciun L. UV-induced immunosuppressive and anti-inflammatory actions: mechanisms and clinical applications. Immunotherapy. 2009;1(2):205-10

123. Norval M, Halliday GM.The consequences of UV-induced immunosuppression for human health. Photochem Photobiol. 2011;87(5):965-77.

124. Diffey BL. Solar ultraviolet radiation effects on biological systems. Phys Med Biol. $1991 ; 36(3): 299-328$.

125. Corrêa MP. A divulgação do índice ultravioleta como prevenção ao excesso de exposição ao sol: uma contribuição da meteorologia para o desenvolvimento de políticas públicas para a saúde no País. Anais do XIII Congresso Brasileiro de Meteorologia. Fortaleza - CE; 2004. 
126. Kemp AS, Ponsonby AL, Pezic A, Cochrane JA, Dwyer T, Jones G. The influence of sun exposure in childhood and adolescence on atopic disease at adolescence. Pediatr Allergy Immunol. 2013;24(5):493-500.

127. Rucević I, Barisić-Drusko V, Glavas-Obrovac L, Stefanić M. Vitamin D endocrine system and psoriasis vulgaris--review of the literature. Acta Dermatovenerol Croat. 2009;17(3):187-92.

128. Ekiz O, Balta I, Sen BB, Dikilitaş MC, Ozuğuz P, Rifaioğlu EN. Vitamin D status in patients with rosacea. Cutan Ocul Toxicol. 2014;33(1):60-2.

129. Ministério da Saúde. Caderneta de Saúde da Criança. $7^{\text {ạ }}$ edição. Brasília: Editora MS; 2011. Disponível em: http://www.saude.gov.br/bvs.

130. World Health Organization [Internet]. WHO Child Growth Standards (2007) [acesso 02 jan 2014]. Disponível em: http://www.who.int/childgrowth/standards/.

131. Dati F, Ringel KP. Reference values for serum IgE in healthy non-atopic children and adult. Clin Chem. 1982; 28:1556.

132. Schmitt J, Langan S, Williams HC; European Dermato-Epidemiology Network. What are the best outcome measurements for atopic eczema? A systematic review. J Allergy Clin Immunol. 2007;120(6):1389-98.

133. Gelmetti C, Colonna C. The value of SCORAD and beyond. Towards a standardized evaluation of severity? Allergy. 2004;59(S78):61-5.

134. Oranje AP, Glazenburg EJ, Wolkerstorfer A, de Waard-van der Spek FB. Practical issues on interpretation of scoring atopic dermatitis: the SCORAD index, objective SCORAD and the three-item severity score. Br J Dermatol. 2007;157(4):645-8.

135. Pereira MG. Usos da Epidemiologia; Conceitos básicos de Epidemiologia; Indicadores de Saúde; Morbidade; Métodos empregados em Epidemiologia; 
Estrutura, Vantagens e Limitações dos Principais Métodos. Em: Pereira, MG, editor. Epidemiologia Teoria e Prática. Guanabara Koogan; 2012. p. 1-29, 49-104, 269-306.

136. Hill AB. The environment and disease: association or causation? Proc R Soc Med. 1965;58(5):295-300.

137. Roth HJ, Schmidt-Gayk H, Weber H, Niederau C. Accuracy and clinical implications of seven 25-hydroxyvitamin D methods compared with liquid chromatography-tandem mass spectrometry as a reference. Ann Clin Biochem. 2008;45(Pt 2):153-9.

138. Binkley N, Krueger D, Cowgill CS, Plum L, Lake E, Hansen KE, DeLuca HF, Drezner MK. Assay variation confounds the diagnosis of hypovitaminosis D: a call for standardization. J Clin Endocrinol Metab. 2004;89(7):3152-7.

139. Heaney RP, Abrams S, Dawson-Hughes B, Looker A, Marcus R, Matkovic V, Weaver C. Peak bone mass. Osteoporos Int. 2000;11(12): 985-1009.

140. Ovesen L, Andersen R, Jakobsen J. Geographical differences in vitamin D status, with particular reference to European countries. Proc Nutr Soc. 2003;62(4):813-21.

141. Schalka S, Steiner D, Ravelli FN, Steiner T, Terena AC, Marçon CR, Ayres EL, Addor FA, Miot HA, Ponzio H, Duarte I, Neffá J, Cunha JA, Boza JC, Samorano Lde P, Maia M, Nasser N, Leite OM. Brazilian consensus on photoprotection. An Bras Dermatol. 2014;89(6 Suppl 1):1-74.

142. Sociedade Brasileira de Endocrinologia e Metabologia [Internet]. Comunicados Oficiais - Vitamina D e Posicionamento Oficial (2013) [acesso 27 jan 2014] Disponível em: http://www.endocrino.org.br/vitamina-d-e-posicionamento-oficial/.

143. de Paula Corrêa M, Ceballos JC. Solar ultravioleta radiation measurements in one of the most populous cities of the world: aspects related to skin câncer and vitamin D availability. Photochem Photobiol. 2010;86(2):438-44. 
144. Holick MF. Sunlight "D"ilemma: risk of skin cancer or bone disease and muscle weakness. Lancet. 2001;357(9249):4-6.

145. Ehlayel MS, Bener A, Sabbah A. Is high prevalence of vitamin D deficiency evidence for asthma and allergy risks? Eur Ann Allergy Clin Immunol. 2011;43(3):818.

146. Cheng HM, Kim S, Park GH, Chang SE, Bang S, Won CH, Lee MW, Choi JH, Moon KC. Low vitamin D levels are associated with atopic dermatitis, but not allergic rhinitis, asthma, or IgE sensitization, in the adult Korean population. J Allergy Clin Immunol. 2013. doi:10.1016/j.jaci.2013.10.055.

147. Miyake Y, Tanaka K, Okubo H, Sasaki S, Arakawa M. Maternal consumption of dairy products, calcium, and vitamin $\mathrm{D}$ during pregnancy and infantile allergic disorders. Ann Allergy Asthma Immunol. 2014;113(1):82-7.

148. Li M, Hener P, Zhang Z, Kato S, Metzger D, Chambon P. Topical vitamin D3 and low-calcemic analogs induce thymic stromal lymphopoietin in mouse keratinocytes and trigger an atopic dermatitis. Proc Natl Acad Sci U S A. 2006;103(31):11736-41.

149. Ronceray S, Benkalfate L, Saillard C, Ezzedine K, Adamski H, Dupuy A, Droitcourt C. Atopic dermatitis severity and vitamin D concentration: A cross-sectional study. Ann Dermatol Venereol. 2014;141(4):265-71.

150. Oh JW. The clinical impact of vitamin d in children with atopic dermatitis. Allergy Asthma Immunol Res. 2013;5(4):179-80.

151. Baek JH, Shin YH, Chung IH, Kim HJ, Yoo EG, Yoon JW, Jee HM, Chang YE, Han MY. The Link between Serum Vitamin D Level, Sensitization to Food Allergens, and the Severity of Atopic Dermatitis in Infancy. J Pediatr. 2014;165(4):849-54.

152. Hartmann B, Heine G, Babina M, Steinmeyer A, Zugel U, Radbruch A, Worm M. Targeting the vitamin $D$ receptor inhibits the $B$ cell-dependent allergic immune response. Allergy. 2011;66(4):540-8. 
153. Ott H, Stanzel S, Ocklenburg C, Merk HF, Baron JM, Lehmann S. Total serum IgE as a parameter to differentiate between intrinsic and extrinsic atopic dermatitis in children. Acta Derm Venereol. 2009;89(3):257-61.

154. Sai AJ, Walters RW, Fang X, Gallagher JC. Relationship between vitamin D, parathyroid hormone, and bone health. J Clin Endocrinol Metab. 2011;96(3):E436-46.

155. Hwang YC, Ahn HY, Jeong IK, Ahn KJ, Chung HY. Optimal serum concentration of 25-hydroxyvitamin $D$ for bone health in older Korean adults. Calcif Tissue Int. 2013;92(1):68-74.

156. Ensrud KE, Taylor BC, Paudel ML, Cauley JA, Cawthon PM, Cummings SR, Fink HA, Barrett-Connor E, Zmuda JM, Shikany JM, et al. Serum 25-hydroxyvitamin D levels and rate of hip bone loss in older men. J Clin Endocrinol Metab. 2009;94(8):2773-2780.

157. Nakamura K, Nashimoto M, Tsuchiya Y, Saito T, Nishiwaki T, Ueno K, Okuda Y, Oshiki R, Yamamoto M. Threshold value of serum 25-hydroxyvitamin D concentration in relation to elevated serum parathyroid hormone concentrations in elderly Japanese women. J Bone Miner Metab. 2006;24(5):395-400

158. Priemel M, von Domarus C, Klatte TO, Kessler S, Schlie J, Meier S, Proksch N, Pastor F, Netter $C$, Streichert $T$, et al. Bone mineralization defects and vitamin D deficiency: histomorphometric analysis of iliac crest bone biopsies and circulating 25hydroxyvitamin D in 675 patients. J Bone Miner Res. 2010;25(2):305-12.

159. Chen JS, Sambrook PN, March L, Cameron ID, Cumming RG, Simpson JM, Seibel MJ. Hypovitaminosis $D$ and parathyroid hormone response in the elderly: effects on bone turnover and mortality. Clin Endocrinol (Oxf). 2008;68(2):290-8.

160. Premaor MO, Scalco R, da Silva MJS, Furlanetto TW. Secondary hyperparathyroidism is associated with increased risk of hospitalization or death in elderly adults living in a geriatric institution. Gerontology. 2009;55(4):405-10. 
161. Steingrimsdottir L, Gunnarsson O, Indridason OS, Franzson L, Sigurdsson G. Relationship between serum parathyroid hormone levels, vitamin D sufficiency, and calcium intake. JAMA. 2005;294(18):2336-41.

162. Vanacor R, Premaor MO, Furlanetto TW. Patients with hypovitaminosis D may not have secondary hyperparathyroidism. Arq Bras Endocrinol Metabol. 2008;52(7):1202-3.

163. Premaor MO, Alves GV, Crossetti LB, Furlanetto TW. Hyperparathyroidism secondary to hypovitaminosis $D$ in hypoalbuminemic is less intense than in normoalbuminemic patients: a prevalence study in medical inpatients in southern Brazil. Endocrine. 2004;24(1):47-53.

164. Thacher TD, Clarke BL. Vitamin D insufficiency. Mayo Clin Proc. 2011;86(1):5060.

165. Gordon CM, DePeter KC, Feldman HA, Grace E, Emans SJ. Prevalence of vitamin $D$ deficiency among healthy adolescents. Arch Pediatr Adolesc Med. 2004;158(6):531-7.

166. Greer FR. Defining vitamin D deficiency in children: beyond $25-\mathrm{OH}$ vitamin D serum concentrations. Pediatrics. 2009;124(5):1471-3.

167. Eaton SB, Nelson DA. Calcium in evolutionary perspective. Am J Clin Nutr. $1991 ; 54(1$ Suppl):281S-287S.

168. Dawson-Hughes B, Harris SS, Dallal GE. Plasma calcidiol, season, and serum parathyroid hormone concentrations in healthy elderly men and women. Am J Clin Nutr. 1997;65(1):67-71

169. Lips P. Vitamin D deficiency and secondary hyperparathyroidism in the elderly: consequences for bone loss and fractures and therapeutic implications. Endocr Rev. $2001 ; 22(4): 477-501$ 
170. Misra $M$. Vitamin $D$ insufficiency and deficiency in children and adolescents $E m$ : UpToDate, Hoppin AG, editor. UpToDate, 2013 [acesso 10 mar 2013]. Disponível em: http://www.uptodate.com.

171. Calvo N, Gentili C, de Boland AR. Parathyroid hormone and the regulation of cell cycle in colon adenocarcinoma cells. Biochim Biophys Acta. 2011;1813(10):1749-57

172. Datta NS, Pettway GJ, Chen C, Koh AJ, McCauley LK. Cyclin D1 as a target for the proliferative effects of PTH and PTHrP in early osteoblastic cells. J Bone Miner Res. 2007;22(7):951-64.

173. Qin L, Li X, Ko JK, Partridge NC. Parathyroid hormone uses multiple mechanisms to arrest the cell cycle progression of osteoblastic cells from $\mathrm{G} 1$ to $S$ phase. J Biol Chem. 2005;280(4):3104-11.

174. Tajbakhsh R, Joshaghani HR, Bayzayi F, Haddad M, Qorbani M. Association between pruritus and serum concentrations of parathormone, calcium and phosphorus in hemodialysis patients. Saudi J Kidney Dis Transpl. 2013;24(4):702-6.

175. Makhlough A, Emadi N, Sedighi O, Khademloo M, Bicmohamadi AR. Relationship between serum intact parathyroid hormone and pruritus in hemodialysis patients. Iran J Kidney Dis. 2013;7(1):42-6.

176. Roelandts R. The history of phototherapy: something new under the sun? J Am Acad Dermatol. 2002;46(6):926-30.

177. Horio T. Skin disorders that improve by exposure to sunlight. Clin Dermatol. 1998;16(1):59-65.

178. Autio $P$, Komulainen $P$, Larni HM. Heliotherapy in atopic dermatitis: a prospective study on climatotherapy using the SCORAD index. Acta Derm Venereol. 2002; 82(6):436-40. 
179. Jekler J, Larkö O. UVB phototherapy of atopic dermatitis. $\mathrm{Br} \mathrm{J}$ Dermatol. 1988;119(6):697-705.

180. Wulf HC, Bech-Thomsen N. A UVB phototherapy protocol with very low dose increments as a treatment of atopic dermatitis. Photodermatol Photoimmunol Photomed. 1998;14(1):1-6.

181. Harari M, Shani J, Seidl V, Hristakieva E. Climatotherapy of atopic dermatitis at the Dead Sea: demographic evaluation and cost-effectiveness. Int J Dermatol. 2000;39(1):59-69.

182. Hon KL, Lam MC, Leung TF, Wong KY, Chow CM, Fok TF, Ng PC. Are agespecific high serum IgE levels associated with worse symptomatology in children with atopic dermatitis?

183. Flohr C, Johansson SG, Wahlgren CF, Williams H. How atopic is atopic dermatitis? J Allergy Clin Immunol. 2004;114(1):150-8.

184. Laske N, Niggemann B. Does the severity of atopic dermatitis correlate with serum IgE levels? Pediatr Allergy Immunol. 2004;15(1):86-8.

185. Copper PJ, Chico ME, Rodrigues LC, Ordonez M, Stracham D, Griffin GE, Nutman TB. Reduced risk of atopy among school-age children infected with geohelminth parasites in a rural area of the tropics. J Allergy Clin Immunol. 2003;111(5):995-1000.

186. Hyppönen E, Berry DJ, Wjst M, Power C. Serum 25-hydroxyvitamin D and IgE a significant but nonlinear relationship. Allergy. 2009;64(4):613-620.

187. Lee P, Greenfield JR, Seibel MJ, Eisman JA, Center JR. Adequacy of vitamin D replacement in severe deficiency is dependent on body mass index. Am J Med 2009. 122(11):1056-1060. 
188. Çizmecioğlu FM, Etiler N, Görmüş U, Hamzaoğlu O, Hatun Ş. Hypovitaminosis D in obese and overweight schoolchildren. J Clin Res Pediatr Endocrinol. 2008;1(2):8996.

189. Muscogiuri G, Sorice GP, Prioletta A, Policola C, Della Casa S, Pontecorvi A, Giaccari A. 25-Hydroxyvitamin D concentration correlates with insulin-sensitivity and BMI in obesity. Obesity (Silver Spring). 2010;18(10):1906-10.

190. Weng FL, Shults J, Leonard MB, Stallings VA, Zemel BS. Risk factors for low serum 25-hydroxyvitamin $D$ concentrations in otherwise healthy children and adolescents. Am J Clin Nutr. 2007;86(1):150-8.

191. Roguedas-Contios AM, Misery L. What is Intrinsic Atopic Dermatitis? Clin Rev Allergy Immunol. 2011;41(3):233-6.

192. Bos JD. Atopiform dermatitis. Br J Dermatol. 2002;147(3):426-9.

193. Stokes J, Casale TB. The biology of $\lg \mathrm{E}$. The relationship between $\lg \mathrm{E}$ and allergic disease. Em: UpToDate, Feldweg AM, editors. UpToDate, 2014 [acesso 02 fev 2014]. Disponível em: http://www.uptodate.com.

194. Ott H, Wilke J, Baron JM, Höger PH, Fölster-Holst R. Soluble immune receptor serum levels are associated with age, but not with clinical phenotype or disease severity in childhood atopic dermatitis. J Eur Acad Dermatol Venereol. 2010;24(4):395402.

195. Schmid-Grendelmeier P, Simon D, Simon HU, Akdis CA,Wüthrich B. Epidemiology, clinical features, and immunology of the "Intrinsic" (non-IgE-mediated) type of atopic dermatitis (constitutional dermatitis). Allergy. 2001;56(9):841-9.

196. Fölster-Holst R, Pape M, Buss YL, Christophers E, Weichenthal M. Low prevalence of the intrinsic form of atopic dermatitis among adult patients. Allergy. 2006;61(5):629-32. 
197. Wittig HJ, Belloit J, De Fillippi I, Royal G. Age-related serum immunoglobulin E levels in healthy subjects and in patients with allergic disease. J Allergy Clin Immunol. $1980 ; 66(4): 305-13$.

198. Stone KD, Prussin C, Metcalfe DD. IgE, mast cells, basophils, and eosinophils. J Allergy Clin Immunol. 2010;125(2 Suppl 2):S73-80.

199. Hetman S, Kivity S, Greif J, Fireman EM, Topilsky M. IgE values in the allergic and healthy Israeli population. Ann Allergy. 1988;61(2):123-8.

200. Jung JW, Kim JY, Cho SH, Choi BW, Min KU, Kang HR. Allergic rhinitis and serum 25-hydroxyvitamin D level in Korean adults. Ann Allergy Asthma Immunol. 2013;111(5):352-7.

201. Amar A, Parisi AV. Optical properties of a long dynamic range chemical UV dosimeter based on solvent cast polyvinyl chloride (PVC). J Photochem Photobiol B. 2013;128:92-9.

202. Heydenreich J, Wulf HC. Miniature Personal Electronic UVR Dosimeter with Erythema Response and Time-stamped Readings in a Wristwatch. Photochem Photobiol. 2005;81(5):1138-44.

203. Christensen MH, Apalset EM, Nordbø Y, Varhaug JE, Mellgren G, Lien EA. 1,25dihydroxyvitamin $d$ and the vitamin $d$ receptor gene polymorphism apa1 influence bone mineral density in primary hyperparathyroidism. PLoS One. 2013;8(2):e56019. 


\section{APÊNDICE A - TCLE \\ TERMO DE CONSENTIMENTO LIVRE E ESCLARECIDO}

\section{Dados de identificação}

Título do Projeto: "DERMATITE ATÓPICA: ASSOCIAÇÃO ENTRE GRAVIDADE CLÍNICA E NÍVEIS SÉRICOS DE VITAMINA D".

Pesquisador Responsável: Kleyton de Carvalho Mesquita.

Instituição: Universidade de Brasília /Hospital Universitário de Brasília.

Telefone para contato: $3448-5415$

Nome do voluntário:

Idade: anos

Responsável legal:

R.G. Responsável legal:

A criança ou o adolescente sob sua responsabilidade está sendo convidada(o) a participar do projeto de pesquisa "DERMATITE ATÓPICA: ASSOCIAÇÃO ENTRE GRAVIDADE CLÍNICA E NÍVEIS SÉRICOS DE VITAMINA D", de responsabilidade do pesquisador Kleyton de Carvalho Mesquita.

O presente estudo tem como objetivos: 1) Avaliar a prevalência de deficiência de vitamina $\mathrm{D}$ em pacientes de 0 a 18 anos com Dermatite Atópica e sem Dermatite Atópica (grupo controle); 2) Correlacionar a gravidade do quadro clínico dessa doença de pele aos níveis sanguíneos de vitamina $\mathrm{D}$; 3) Correlacionar os níveis sanguíneos de vitamina $\mathrm{D}$ aos níveis de imunoglobulina $\mathrm{E}$ (um anticorpo frequentemente aumentado em indivíduos alérgicos) e à contagem de eosinófilos (um tipo específico de célula do sangue aumentado em pacientes alérgicos).

Os dados serão colhidos a partir de entrevistas com os pacientes e de exames laboratoriais (sangue e fezes). No grupo controle (pacientes sem Dermatite Atópica), será realizado apenas exame de sangue para dosagem de vitamina D. Após a coleta de dados, será feita análise estatística e posterior publicação. Tal estudo trará benefícios para a comunidade médica e para os pacientes ao suprir com informações científicas sobre a presença da associação entre a Dermatite Atópica e os níveis sanguíneos de vitamina D.

Esse é um estudo observacional, não acarretando alterações de conduta médica. Os pacientes não são submetidos a exames desnecessários nesse estudo, uma vez que há recomendações atuais direcionadas à realização desses exames nos portadores de Dermatite Atópica. Nos pacientes diagnosticados com deficiência da vitamina D, será recomendada suplementação de acordo com os conhecimentos clínicos vigentes.

Em caso de dúvidas acerca de assuntos relacionados com a pesquisa, o voluntário deve procurar o pesquisador responsável pelo número de telefone acima, a fím de saná-las.

A participação neste estudo é voluntária e, a qualquer momento, este consentimento poderá ser retirado pelo voluntário ou seu responsável, sem prejuízos à continuidade do tratamento. Os dados colhidos nessa pesquisa são confidenciais e as informações geradas serão publicadas anonimamente sem prejuízo a privacidade dos participantes.

$\mathrm{Eu}$, $\mathrm{RG} \mathrm{n}^{\circ}$ , responsável legal pela criança ou pelo adolescente acima identificada(o) fui informado e concordo com sua participação no projeto de pesquisa acima descrito.

Brasília, de de 2013 


\section{APÊNDICE B - FICHA DE COLETA DE DADOS CLÍNICOS E LABORATORIAIS}

\section{FICHA DE COLETA DE DADOS CLÍNICOS}

Nome:

Reg:

Data de Nascimento:

Data da consulta:

Telefone:

Fototipo:

Peso:

IMC:

Altura:

IMC escore Z:

Renda familiar (salários-mímimos):

História pessoal de atopia:

( ) Não ( ). Sim. Especificar:

História familiar de atopia:

( ) Não ( ). Sim. Quem?

Especificar:

Idade de início dos Sintomas:

Escore clínico e exames laboratoriais

Índice SCORAD:

SCORAD objetivo:

25-OH-Vitamina D:

PTH:

$\lg \mathrm{E}$ :

Eosinófilos:

EPF:
Categoria SCORAD:

Categoria SCORAD objetivo: 
ANEXO A - APROVAÇÃO DO COMITÊ DE ÉTICA (página 1/2)

\section{FACULDADE DE MEDICINA DA UNIVERSIDADE DE BRASÍLIA - UNB}

\section{PARECER CONSUBSTANCIADO DO CEP}

\section{DADOS DO PROJETO DE PESQUISA}

Título da Pesquisa: DERMATITE ATÓPICA: ASSOCIAÇÃO ENTRE GRAVIDADE CLÍNICA E NÍVEIS SÉRICOS DE VITAMINA D

Pesquisador: Kleyton de Carvalho Mesquita

Área Temática:

Versão: 2

CAAE: 12362913.6 .0000 .5558

Instituição Proponente: Faculdade de Medicina da Universidade de Brasília - UNB

Patrocinador Principal: Financiamento Próprio

\section{DADOS DO PARECER}

Número do Parecer: 293.564

Data da Relatoria: 24/04/2013

Apresentação do Projeto:

Adequada

Objetivo da Pesquisa:

Já avaliados anteriormente e considerados adequados

Avaliação dos Riscos e Benefícios:

Já avaliados anteriormente e considerados adequados

Comentários e Considerações sobre a Pesquisa:

Já avaliados anteriormente e considerados adequados

Considerações sobre os Termos de apresentação obrigatória:

Havia sido solicitada a formalização do apoio do laboratório Sabin à pesquisa. Este item foi devidamente contemplado na versão atual do projeto, uma vez que um contrato formal foi anexado à doucmentação obrigatória.

Recomendações:

Conclusões ou Pendências e Lista de Inadequações:

Pela aprovação

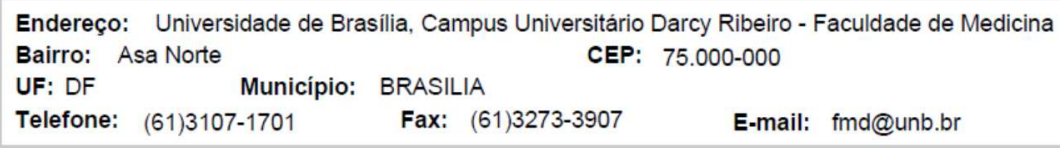


ANEXO A - APROVAÇÃO DO COMITÊ DE ÉTICA (página 2/2)

\section{FACULDADE DE MEDICINA DA UNIVERSIDADE DE BRASÍLIA - UNB}

Continuaçăo do Parecer: 293.564

Situação do Parecer:

Aprovado

Necessita Apreciação da CONEP:

Não

Considerações Finais a critério do CEP:

O CEP-FM/UnB concorda com o parecer do(a) relator(a) e aprova o projeto de pesquisa em questão.

Assinador por:

Elaine Maria de Oliveira Alves

(Coordenador)

Endereço: Universidade de Brasilia, Campus Universitario Darcy Ribeiro - Faculdade de Medicina

Bairro: Asa Norte CEP: $75.000-000$

UF: DF Municipio: BRASILIA

Telefone: (61)3107-1701 Fax: (61)3273-3907 E.mail: fmd@unb.br 


\title{
ANEXO B - BULA DO EXAME 25(OH)D (página 1/10)
}

\author{
DiaSorin Inc \\ 1951 Northwestern Ave - Stillwater, MN 55082 - EUA \\ Tel: 1.651.439.9710 - Fax: 1.651.351.5669
}

$c \epsilon$

Preste atenção às mudanças!

\author{
Ensaio LIAISON ${ }^{\circledast} 25$ OH Vitamin D TOTAL (310600)
}

1. USO INDICADO

O Ensaio LIAISON 25 OH Vitamin D TOTAL utiliza tecnologia de imunoensaio quimioluminescente (CLIA) para a determinação quantitativa da 25 -hidroxivitamina $D$ e outros metabolitos hidroxilados da vitamina $D$ no soro humano, plasma-EDTA ou plasma com heparina de litio, a usar na avaliação da quantidade de vitamina $D$ utilizando a familia de Analisadores LIAISON $^{\circledR}$. Os resultados dos ensaios devem ser usados em conjunto com outros dados clinicos e laboratoriais para ajudar o médico a tomar decisões individuais de tratamento dos doentes numa população adulta.

\section{RESUMO E EXPLICAÇÃO DO TESTE}

O papel da vitamina $D$ no osso e no metabolismo mineral foi reconhecido primeiramente através da sua identificação como factor possivel para a cura do raquitismo. Contudo, actualmente a vitamina $\mathrm{D}$ é aceite como uma pró-hormona com múltiplas funções na manutenção de um estado de saúde ideal. [1]

A vitamina $D_{3}$ (colecalciferol) e a vitamina $D_{2}$ (ergocalciferol) são as formas mais abundantes de vitamina $D$ existentes no organismo. A vitamina $D_{3}$ é sintetizada na pele a partir do 7-desidrocolesterol em resposta à luz solar. As melhores fontes de nutrição da $D_{3}$ são os peixes gordos como o salmão e a cavala. As fontes de nutrição de vitamina $D_{2}$ provêm

A vitamina $D\left(D_{3}, D_{2}\right.$ e metabolitos) é convertida em 25-hidroxivitamina $D$ no figado. A medição da concentração de $25 \mathrm{OH}$ vitamina $\mathrm{D}$ no soro ou plasma é o melhor indicador do estado nutricional da vitamina $\mathrm{D}$. [2] O nivel ideal de $25 \mathrm{OH}$ vitamina $\mathrm{D}$ é objecto de alguma discussão, mas um valor de $>32 \mathrm{ng} / \mathrm{mL}$ ( $>80 \mathrm{nmol} / \mathrm{L})$ é
geralmente aceite como suficiente para a saúde óssea.[3-13] A toxicidade da vitamina $D$ é um problema conhecido, mas é uma ocorrência rara. Ao contrário, um recente problema de saúde pública crescente é a insuficiência de vitamina $D$. todo o mundo. [3-13] $O$ défice de Vitamina $D$ é habitualmente tratado com fármacos de vitamina $D_{2}$ ou $D_{3}$ em doses que variam de
$50.000 \mathrm{Ul} / \mathrm{mês}$ a 50.000 Ul/semana. [14] Os alimentos reforçados e os suplementos nutricionais podem conter
qualquer uma das formas. Para garantir a avalionazon qualquer uma das formas. Para garantir a avaliação exacta do total de vitamina $D$, todas as formas, incluindo $D_{3}, D_{2}$
e metabolitos, devem ser medidas.

Estudos recentes identificaram um 3-epímero inactivo da $25 \mathrm{OH}$ vitamina $\mathrm{D}$, que pode estar presente no soro de crianças com menos de 1 ano de idade. [15] Por conseguinte, é importante que um ensaio evite a medição da forma 3-epi inactiva e que meça apenas e igualmente, as formas $D_{3} \in D_{2}$ activas. Mais recentemente, vários estudos sugeriram que a insuficiência de Vitamina $D$ se associa a um aumento do risco para o desenvolvimento de muitas doenças crónicas, incluindo doença cardiovascular, cancro, doenças infecciosas e doenças autoimunes.

\section{PRINCÍPIO DO PROCEDIMENTO}

O ensaio LIAISON ${ }^{\circledast} 25 \mathrm{OH}$ Vitamin D é um imunoensaio quimioluminescente competitivo (CLIA) directo para a determinação quantitativa da $25 \mathrm{OH}$ vitamina $\mathrm{D}$ total no soro. Durante a primeira incubação, a 25 OH vitamina D é dissociada da sua proteina de ligação e liga-se ao anticorpo especifico na fase sólida. Ao fim de 10 minutos, é adicionado o marcador vitamina $D$ ligado a um derivado de isoluminol. Após uma segunda incubação de 10 minutos, o material não ligado é removido com um ciclo de lavagem. Subsequentemente, os reagentes iniciadores são então adicionados e inicia-se uma reacção quimioluminescente rápida. O sinal de luz é medido por um fotomultiplicador como unidades de luz relativas (RLU), sendo inversamente proporcional à concentração de $25 \mathrm{OH}$ vitamina $\mathrm{D}$ presente nos calibradores, nos controlos ou nas amostras. 


\section{ANEXO B - BULA DO EXAME 25(OH)D (página 2/10)}

\section{MATERIAIS FORNECIDOS}

Integral de Reagente:

\begin{tabular}{|c|c|c|}
\hline $\begin{array}{l}\text { Particulas magnéticas } \\
(2,4 \mathrm{~mL})\end{array}$ & SORB & $\begin{array}{l}\text { Particulas magnéticas revestidas com anticorpo de cabra contra a } 25 \mathrm{OH} \\
\text { vitamina } \mathrm{D} \text {, proteina, tampão fosfato, }<0,1 \% \text { de azida de sódio. }\end{array}$ \\
\hline $\begin{array}{l}\text { Tampão de ensaio } \\
(28,0 \mathrm{~mL})\end{array}$ & BUF $A S$ & Tampão com $10 \%$ de etanol, surfactantes e $0,2 \%$ de ProClin 300 \\
\hline $\begin{array}{l}\text { Conjugado } \\
(4,5 \mathrm{~mL})\end{array}$ & CONJ & $\begin{array}{l}25-\mathrm{OH} \text { vitamina D conjugada com um derivado de isoluminol, em tampão } \\
\text { fosfato com } 10 \% \text { de etanol, EDTA, surfactante e } 0,1 \% \text { de ácido benzóico } \\
\text { como conservante. }\end{array}$ \\
\hline $\begin{array}{l}\text { Calibrador } 1 \\
(1,0 \mathrm{~mL})\end{array}$ & \begin{tabular}{|l|l|}
$\mathrm{CAL}$ & 1 \\
\end{tabular} & $\begin{array}{l}\text { Soro humano, albumina sérica bobina (BSA), }<0,1 \% \text { de azida de sódio e } \\
25 \mathrm{OH} \text { vitamina D. As concentrações do calibrador ( } \mathrm{ng} / \mathrm{mL} \text { ) estão } \\
\text { referenciadas para preparações padrão contendo } 25 \mathrm{OH} \text { vitamina D } \\
\text { altamente purificada. }\end{array}$ \\
\hline $\begin{array}{l}\text { Calibrador } 2 \\
(1,0 \mathrm{~mL})\end{array}$ & CAL2 2 & $\begin{array}{l}\text { Soro humano, } \mathrm{BSA},<0,1 \% \text { de azida de sódio e } 25 \mathrm{OH} \text { vitamina D. As } \\
\text { concentrações do calibrador }(\mathrm{ng} / \mathrm{mL} \text { ) estão referenciadas para preparações } \\
\text { padrão contendo } 25 \mathrm{OH} \text { vitamina } \mathrm{D} \text { altamente purificada. }\end{array}$ \\
\hline Número de testes & & 100 \\
\hline
\end{tabular}

ProClin 300 é uma marca registada da Rohm and Haas Co.

Todos os reagentes são fornecidos prontos para serem utilizados.

Materiais necessários, mas não fornecidos (relacionados com o sistema)

\begin{tabular}{|c|c|}
\hline Analisador $\mathrm{LIAISON}^{6} \mathrm{XL}$ & Analisador LIAISON ${ }^{\circledR}$ \\
\hline LIAISON ${ }^{3}$ Wash/System Liquid (REF. 319100) & LIAISON $^{\otimes}$ Wash/System Liquid (REF. 319100) \\
\hline LIAISON $^{\circledR}$ XL Waste Bags (REF. X0025) & LIAISON ${ }^{\circledR}$ Waste Bags (REF. 9450003) \\
\hline LIAISON ${ }^{\otimes}$ XL Cuvettes (REF. X0016) & LIAISON $^{\ominus}$ Module (REF. 319130) \\
\hline LIAISON ${ }^{\otimes}$ XL Starter Kit (REF. 319200) & LIAISON ${ }^{\circledast}$ Starter Kit (REF. 319102), \\
\hline LIAISON $^{\circledast}$ XL Disposable Tips (REF. X0015) & LIAISON ${ }^{\circledast}$ XL Starter Kit (REF. 319200) \\
\hline & LIAISON ${ }^{2}$ Cleaning Kit (REF, 310990) \\
\hline & LIAISON $^{\circledR}$ Light Check (REF. 319101) \\
\hline
\end{tabular}

Material adicional necessário:

LIAISON $^{\otimes} 25 \mathrm{OH}$ Vitamin D TOTAL

Control Set (ref. 310601)

LIAISON $^{\circledR} 25 \mathrm{OH}$ Vitamin D TOTAL

Specimen Diluent (ref. 310602)

\section{AVISOS E PRECAUÇÕES}

PARA UTILIZAÇÃO EM DIAGNÓSTICO IN VITRO - Não se destina a utilização externa nem interna em seres humanos ou animais.

\section{REAGENTES COM MATERIAL DE ORIGEM HUMANA}

Atenção - Trate como se fossem potencialmente infecciosos.

Cada unidade de doador de soro/plasma utilizada na preparação deste produto foi testada por um método aprovado pela FDA (EUA) e determinada como sendo não reactiva para a presença de anticorpos contra 0 virus da imunodeficiência humana (HIV 1/2), de antigénio de superficie da hepatite $B(H B V)$ e de anticorpos contra a hepatite $\mathrm{C}(\mathrm{HCV})$. Embora estes métodos apresentem uma precisão elevada, não garantem que todas as unidades infectadas sejam detectadas. Este produto também poderá conter outras doenças de origem humana para as quais não existem testes aprovados. Como nenhum método de teste conhecido pode oferecer garantia total em relação à ausência de HIV, HBV e HCV ou outros agentes infecciosos, todos os produtos que contenham material de origem humana devem ser manuseados seguindo as precauções universais e, conforme aplicável, de acordo com as boas práticas laboratoriais como descrito no manual actual dos Centros de Controlo de Doenças e Institutos Nacionais de Saúde, Biosafety in Microbiological e Biomédica Laboratories (BMBL); ou a edição actual do Manual de segurança biológica em laboratório da Organização Mundial de Saúde.

REAGENTES COM AZIDA DE SÓDIO:

Alguns reagentes presentes neste kit contêm azida de sódio. A azida de sódio pode reagir com o chumbo ou cobre das canalizações para formar azidas de metal altamente explosivas. Ao eliminar, lave com grande quantidade de água para impedir a acumulação de azida. Para mais informações, consulte "Descontaminação de tubos de pias de laboratórios para remover sais de azidas," no Manual Guia-Gestão de Segurança N CDC-22 emitido pelos Centros
de Controlo e Prevenção de Doenças, Atlanta, GA, 1976. 


\section{ANEXO B - BULA DO EXAME 25(OH)D (página 3/10)}

Reagentes que contêm Proclin ${ }^{\circledR} 300$ :

Os reagentes que contêm ProClin 300 são classificados como irritantes de acordo com as directivas europeias

R 43 - Pode causar sensibilização em contacto com a pele.

$\mathrm{S} 24$ - Evite o contacto com a pele.

$\mathrm{S} 37$ - Utilize luvas adequadas.

$\mathrm{S} 60$ - Este material e o respectivo recipiente devem ser eliminados como residuos perigosos.

6. SEGURANÇA GERAL:

- Deve considerar todas as amostras, reagentes biológicos e materiais utilizados nos ensaios como potencialmente capazes de transmitir agentes infecciosos. Evitar o contacto com a pele, olhos ou membranas mucosas. Seguir as boas práticas de higiene industrial durante o teste.

- Não comer, beber, fumar ou aplicar cosméticos no laboratório de ensaio.

- Não pipetar as soluçōes com a boca.

- Evitar o contacto directo com todos os materiais pote ncialmente infecciosos usando bata de laboratório. equipamento de protecção dos olhos/face e luvas descartáveis

- Lavar bem as mãos no final de cada ensaio.

- Evitar salpicos ou a formação de aerossóis durante a manipulação, diluição ou transferência de amostras ou $0.5 \%$ de hipoclorito de sódio) e eliminar como potencialmente infeccioso.

- Os materiais de desperdicio devem ser eliminados de acordo com os regulamentos e directivas dos órgãos responsáveis pelo laboratório e os regulamentos de cada pais.

- Năo utilizar kits ou componentes para além do prazo de validade que consta do rótulo.

\section{PREPARAÇÃo do INTEGRAL dE REAGENTE}

Tenha em atenção as seguintes precauções importantes referentes ao manuseamento de reagentes:

1. Ressuspensão de particulas magnéticas As particulas magnéticas devem ser totalmente ressuspensas antes do integral de reagente ser colocado no aparelho. Siga os passos a seguir para assegurar a suspensão completa:

- Antes de retirar o selo, rode a pequena roda situada no compartimento da partícula magnética até a suspensão adquirir uma cor castanha. Agitar delicadamente e no sentido horizontal, pode ajudar a suspensão das partículas magnéticas (evite a formaçăo de espuma). Verifique visualmente o fundo do frasco de particulas magnéticas para confirmar a ressuspensão de todas as particulas
magnéticas depositadas no fundo. - Repita tantas vezes quantas as necessárias até as partículas magnéticas estarem completamente
ressuspensas. - Depois da remoçăo do selo, limpe cuidadosamente a superficie de cada septo para remover
liquido residual, se for necessário.

Em alternativa, pode utilizar-se o LIAISON ${ }^{\otimes}$ Xcelerator (Ref. A0O9O) para ajudar na ressuspensăo.

2. Espuma nos reagentes

De modo a garantir um desempenho óptimo do integral, deve-se evitar a formaçăo de espuma nos reagentes. Cumpra a recomendaçăo abaixo para prevenir esta ocorrência:

- Inspeccione visualmente os reagentes, especialmente os calibradores (posição dois e três a seguir ao frasco de particulas magnéticas), para garantir a ausência de espuma antes de utilizar 0 integral. Se estiver presente espuma após a ressuspensão das particulas magnéticas, coloque 0 integral no aparelho e deixe a espuma dissipar-se. $O$ integral está pronto a usar assim que a período mínimo de 30 minutos.
pestiver permanecido dentro do aparelho, sob agitação, durante um

3. Carregar o integral para a área de reagentes

Analisador LIAISON ${ }^{\circ}$

- Coloque o integral na área de reagentes do analisador com o rótulo com código de barras virado para a esquerda e deixe repousar durante 30 minutos antes de usar. $\mathrm{O}$ analisador mistura automaticamente e ressuspende completamente as particulas magnéticas.

- Siga o manual do utilizador do analisador para carregar as amostras e iniciar o ensaio.

Analisador LIAISON ${ }^{8} \mathrm{XL}$

- O analisador $\mathrm{LIAISON}^{\ominus} \mathrm{XL}$ está equipado com um dispositivo magnético de estado sólido integrado que auxilia a dispersão das microparticulas antes da colocação de um integral de reagente na área de reagentes do analisador. Para mais informaçōes, consulte o manual do operador do analisador.

a. Insira o integral de reagente na ranhura dedicada.

b. Deixe ficar 0 integral de reagente no dispositivo magnético de estado sólido durante pelo menos 30 segundos (até vários minutos). Repita as vezes que forem necessárias. 


\section{ANEXO B - BULA DO EXAME 25(OH)D (página 4/10)}

- Coloque o integral na área de reagentes do analisador com a etiqueta virada para a esquerda $e$ deixe-o repousar durante 15 minutos antes de 0 utilizar. O analisador mexe e ressuspende completamente as particulas magnéticas de forma automática.

- Siga o manual do operador do analisador para introduzir as amostras e inicie o ensaio

8. CONSERVAÇÃO E ESTABILIDADE DO INTEGRAL DE REAGENTE

ressus a recepção, o integral de reagente deve ser armazenado num local escuro, na posição vertical, para facilitar a mantido na vertical, os alas magnéticas. Quando o integral de reagente é armazenado fechado, protegido da luz e O Integral de Reagente não deve ser usado apóstáveis a $2-8^{\circ} \mathrm{C}$ até ao final do prazo de validade. Náo congele. Reagente. Após ser utilizado, o integral após o prazo de validade indicado nos rótulos do kit e do Integral de armazenado de novo a $2-8^{\circ} \mathrm{C}$ no escuro. Após a a deve ser selado com a fita adesiva fornecida com o kit e armazenado adequadamente. Deve evitar-se uma exposiçăo indevida à luz produto durante 4 semanas se este for

\section{COLHEITA E PREPARAÇĀO DE AMOSTRAS}

Pode usar-se soro humano, plasma EDTA, plasma com heparina de lítio ou tubos SST. Recomenda-se a utilizaçăo de deixá-lo coagular em jejum, mas năo è obrigatório. Deve colher o sangue assepticamente através de venipunctura, frascos de vidro ou de plarstico. As particulas podem interferir com o ensaio. Nãorios aditivos ou conservantes para manter a integridade da amostra. amostras que contenas hemolisadas ou com lipémia macroscópica, bem como no prazo de 120 horas após a recolha que apresentem contaminação microbiana evidente. Se 0 ensaio for efectuado ser armazenadas congeladas (a - 20 ${ }^{\circ} \mathrm{Ca}$ amostra, as amostras devem ser mantidas a $2-8{ }^{\circ} \mathrm{C}$; caso contrário, devem amostras descongeladas antes de testar. Evite ciclos repetidostras forem conservadas congeladas, misture bem as bolhas de ar e remova-as antes de proceder ao ciclos repetidos de congelação-descongelação. Verifique se existem primeiro teste, e $25 \mathrm{\mu L}$ mais para cada tester ao ensaio. O volume minimo necessário é de $250 \mu \mathrm{L}$ de amostra para o Plasma humano colhido em tipos de tubos

$22 \%$ versus soro.

\section{CALIBRAÇĀO}

à teste de calibradores específicos do ensaio permite que os valores de unidades de luz relativas (RLU) se ajustem proceder a uma recalibraçã̃o em triplução de calibraçăo permite a realização de seis (6) calibraçōes. E obrigatório

- Com cada novo lote de reagentes (integra de Relo menos uma das condiçōes seguintes:

- De sete em 7 dias.

- Após cada manutençăo efectuada ao analisador LIAISON ${ }^{\ominus}$

- Se os resultados do controlo de qualidade estiverem fora do seu intervalo aceitável.

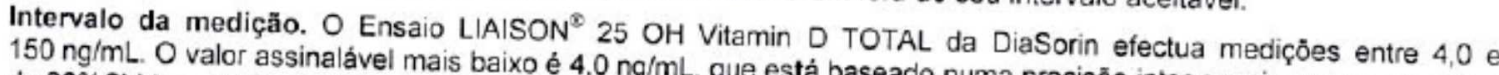
de $20 \% \mathrm{CV}$ (sensibilidade funcional) baixo é $4,0 \mathrm{ng} / \mathrm{mL}$, que está baseado numa precisão inter-ensaio que se aproxima assinalável mais alto sem diluição é de $150 \mathrm{ng} / \mathrm{mL}$.

\section{PROCEDIMENTO DO ENSAIO}

Para garantir um bom desempenho do teste, siga rigorosamente as instruções de utilização do analisador LIAISON ${ }^{\circ}$. Analisador LIAISON ${ }^{\circ}$ : Cada parảmetro de teste é identificado por meio de códigos de barras no rótulo do Integral
do Reagente. Em caso de avaria do leitor de códigos de eliminado. Para obter mais informaçōes, leitor de códigos de barras, o cartucho năo pode ser usado e deve ser Analisador

Analisador LIAISON ${ }^{\Im}$ XL: Cada parâmetro de teste é identificado por meio de informaçōes codificadas no transceptor cartucho não pode ser usado e deve do Integral do Reagente (Etiqueta RFID). Em caso de avaria da Etiqueta RFID. o analisador.

As operações do analisador são as seguintes:

Analisador LIAISON ${ }^{3}$ :

1. Deite a amostra, o calibrador ou o controlo no módulo de reacçāo.

2. Deite particulas magnéticas e o tampăo do ensaio no módulo de reaco

3. Incube

4. Deite o marcador no módulo de reacção.

5. Incube

6. Lave com liquido de lavagem/sistema

7. Adicione os Reagentes Iniciadores e efectue a medição da luz emitida

LIAISON ${ }^{2} \mathrm{XL}$ :

1. Deite particulas magnéticas e o tampão do ensaio no módulo de reaç̧ão.

2. Deite a amostra, o calibrador ou o controlo no módulo de reacçắo.
3. Incube. 


\section{ANEXO B - BULA DO EXAME 25(OH)D (página 5/10)}

4. Deite o marcador no módulo de reacçäo.

5. Incube.

6. Lave com liquido de lavagem/sistema.

7. Adicione os Reagentes Iniciadores e efectue a mediçấo da luz emitida

Os resultados do imunoensaio podem ser influenciados por flutuaçōes de temperatura. Os utilizadores devem estar cientes das variaçóes do seu ambiente de laboratório; pode ser necessaria uma utilizaçăo mais frequente dos
controlos e recalibração subsequente.

\section{CONTROLO DE QUALIDADE}

O controlo de qualidade está recomendado uma vez por dia de utilização, ou de acordo com os regulamentos ou requisitos de acreditação locais, estatais e/ou federais e com os procedimentos de controlo de qualidade do seu laboratório. Recomenda-se que o utilizador consulte o documento do CLSI C24-A2 e 42 CFR 493.1256 para obter instruçōes sobre as práticas de controlo de qualidade adequadas. O Conjunto de Controlo LIAISON $25 \mathrm{OH}^{3}$ Vitamin D TOTAL (Ref. 310601) é adequado para a determinaçäo das exigências do controlo de qualidade para este ensaio Os controlos LIAISON ${ }^{\odot}$ devem ser executados com apenas um processamento para monitorizar o desempenho do
ensaio. Se os valores de controlo estiverem fora dos intervalos esperados, o teste é inválido e os resultados do doente não
podem ser participados.

Se um controlo estiver fora do intervalo, tal deve ser investigado e terá que ocorrer recalibração. Os resultados da amostra do doente associados são inválidos e as amostras devem ser testadas novamente.

o desempenho de outros controlos deve ser avaliado para verificar a compatibilidade com este ensaio antes de qualidade utilizados.

$O$ intervalo de concentraçōes de cada controlo é descrito no certificado de análise e indica os limites estabelecidos os seus pró para niveis de controlo que podem ser obtidos em ensaios fiáveis. Os laboratórios devem estabelecer os seus próprios intervalos alvo com base nos seus critérios de aceitaçáo para o desempenho do ensaio.

\section{INTERPRETAÇĀO DOS RESULTADOS}

O Analisador LIAISON ${ }^{3}$ calcula automaticamente a concentração de $25-\mathrm{OH}$ vitamina $D$ na amostra. Essa concentração é apresentada em ng/mL. Para converter os resultados para unidades SI: $\mathrm{ng} / \mathrm{mL} \times 2,5=n \mathrm{~mol} / \mathrm{L}$. Intervalo do ensaio: 4,0 a $150 \mathrm{ng} / \mathrm{mL}$. Calibradores e controlos podem produzir RLU ou resultados de dose diferentes no LIAISON
mas os resultados dos doentes são equivalentes.

\section{LIMITAÇÖES DO PROCEDIMENTO}

- É necessário cumprir as instruções de utilização e possuir uma formação técnica adequada para obter
resultados fiáveis. afectar os resultados do teste. do reagente, interferindo com os imunoensaios in vitro com imunoglobulinas do reagente ou outro material

- Doentes expostos por rotina a animais, produtos derivados de soro animal ou outros produtos imunogénicos que podem estimular a produçấo de anticorpos heterofilicos contra os reagentes do ensaio podem ser propensos a esta interferência e podem observar-se valores anómalos.

- Os resultados dos ensaios devem ser usados em conjunto com outros dados clinicos e laboratoriais para ajudar o médico a tomar decisões individuais de tratamento dos doentes numa população adulta.

- Os integrais não podem ser trocados entre tipos de analisador (LIAISON ${ }^{3}$ e LIAISON $^{\circ} \mathrm{XL}$ ). - Depois de um integral ter sido introduzido num tipo de analisador particular, este deve sempre ser utilizado
nesse analisador até que se tenha gasto.

- Em virtude de aspectos relacionados com rastreabilidade decorrente da frase acima, os acompanhamentos de doentes não poderão ser concluidos entre tipos de analisador. Estes devem ser efectuados num tipo de 


\section{ANEXO B - BULA DO EXAME 25(OH)D (página 6/10)}

\section{VALORES PREVISTOS}

Intervalo de referência

E importante para cada laboratório estabelecer a sua própria faixa de referẽncia representativa da sua população tipica. Sabe-se que factores como exposiçăo UV [16,17], estação do ano [18, 19], raça [20] e dieta [21] afectam os de $25-\mathrm{OH}$ vitamina $\mathrm{D}$ em muitos paises $[3-8]$. U [3-8], particularmente nos meses de Inverno.

Uma análise da literatura sugere os seguintes limites para a classificaçăo do estado da $25 \mathrm{OH}$ vitamina D.

\begin{tabular}{lrr} 
Estado da vitamina D & \multicolumn{2}{c}{$25-\mathrm{OH}$ vitamina D } \\
Deficiência & $<10 \mathrm{ng} / \mathrm{mL}$ & $<25 \mathrm{nmol} / \mathrm{L}$ \\
Insuficiência & $10-30 \mathrm{ng} / \mathrm{mL}$ & $25-75 \mathrm{nmol} / \mathrm{L}$ \\
Suficiência & $30-100 \mathrm{ng} / \mathrm{mL}$ & $75-250 \mathrm{nmol} / \mathrm{L}$ \\
Toxicidade & $>100 \mathrm{ng} / \mathrm{mL}$ & $>250 \mathrm{nmol} / \mathrm{L}$
\end{tabular}

A DiaSorin avaliou 396 amostras de soro colhidas em individuos adultos. As amostras foram colhidas em várias estaç̋̃es e em várias regiões geográficas dos Estados Unidos. Deste estudo, foram excluídas amostras com valores valores, de acordo cam e TSH. Com base no intervalo de confiança de $95 \%$, foram estabelecidos os seguintes ( $28-A 2$ do CLSI. Foram obtidos os seguintes valores:

\begin{tabular}{lcc}
\hline \multicolumn{3}{c}{ Intervalos de referência observados } \\
\hline Populaçăo (396) & Média de $25 \cdot \mathrm{OH}$ vitamina D & Intervalo observado Percentil $2,5^{\circ}$ ao $97,5^{\circ}$ \\
\hline Estados Unidos & $24,9 \mathrm{ng} / \mathrm{mL}$ & $9,3 \mathrm{ng} / \mathrm{mL}-47,9 \mathrm{ng} / \mathrm{mL}$
\end{tabular}

\section{CARACTERISTICAS DE DESEMPENHO ESPECIFICAS}

16.1 Sensibilidade funcional: A sensibilidade funcional é definida como a concentraçăo da dose na qual a \% de CV excede os $20 \%$, tendo sido avaliada de acordo com o documento EP17-A do CLSI. As amostras foram preparadas a \% de CV. Açes nominais de $2-14 \mathrm{ng} / \mathrm{mL}$ e ensaiadas em séries múltiplas para determinar a concentração média e a \% de CV. A concentraçăo da amostra foi traçada em relação à \% de CV e foi preparada uma regressão para . A sensibilidade funcional derivada de uma análise de regressão é $\leq 4,0 \mathrm{ng} / \mathrm{mL}$.

LAISON ${ }^{\Phi} 25$ Ção de métodos: Um total de 587 amostras, variando entre 3,6 e $153,2 \mathrm{ng} / \mathrm{mL}$, foram testadas com o CLSI $25 \mathrm{OH}$ Vitamin D TOTAL e com o DiaSorin $25 \mathrm{OH}$ Vitamin D RIA, de acordo com o documento EP9-A2 do

\begin{tabular}{|c|c|c|c|c|c|c|c|}
\hline Ensaio & $\mathrm{N}$ & Declive (IC 95\%) & $\begin{array}{c}\text { Intercepçăo } \\
\text { (IC 95\%) }\end{array}$ & $\begin{array}{c}\text { Coeficiente de } \\
\text { Correlação }\end{array}$ & $\begin{array}{c}\text { Erro } \\
\text { Padrão Est }\end{array}$ & $\begin{array}{c}\text { Tendéncia } \\
\text { média }\end{array}$ & $\begin{array}{c}\text { DP das } \\
\text { diferenças }\end{array}$ \\
\hline RIA & 587 & $1,047(1,02-1,07)$ & $2,41(1,43-3,40)$ & 0,936 & 7,116 & 4,083 & 7,212 \\
\hline
\end{tabular}

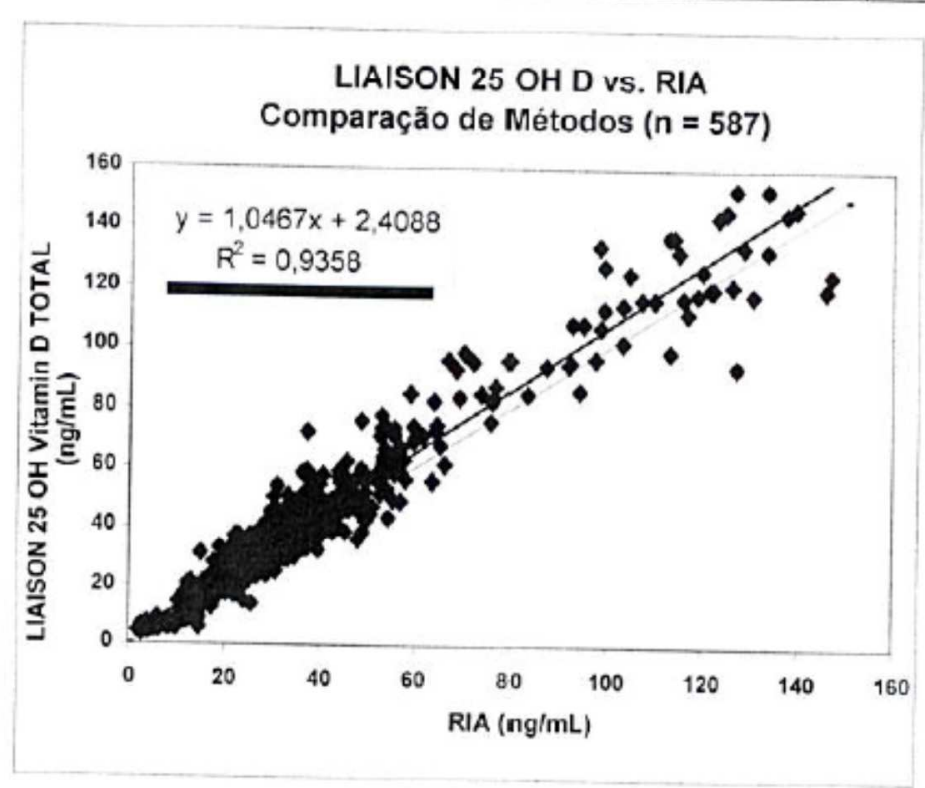




\section{ANEXO B - BULA DO EXAME 25(OH)D (página 7/10)}

16.3 Precisão com o Analisador LIAISON ${ }^{\otimes}$ :

A precisão do ensaio foi avaliada de acordo com o documento EP5-A2 do CLSI. Ensaiaram-se seis amostras de 20 dias de trabalho em dois lotes. As amostras foram controlos do kit em duplicado em dois ensaios por dia ao longo de 20 dias de trabalho em dois lotes. As amostras foram testadas internamente na DiaSorin Inc e em 2 locais externos.

\begin{tabular}{|c|c|c|c|c|c|}
\hline \multirow{2}{*}{$\begin{array}{c}\text { ID da } \\
\text { Amostra }\end{array}$} & \multirow{2}{*}{$\begin{array}{c}\text { Média } \\
(\mathbf{n g} / \mathrm{mL})\end{array}$} & \multicolumn{2}{|c|}{ Intra-Série Por Lotes e Locais } & \multicolumn{2}{c|}{ Total Por Lotes e Locais } \\
\cline { 3 - 6 } & Desvio padrão & \%CV & Desvio padrão & $\% \mathrm{CV}$ \\
\hline Amostra \#1 & 7,9 & 0,6 & $7,7 \%$ & 1,0 & $12,6 \%$ \\
\hline Amostra \#2 & 12,0 & 0,7 & $5,8 \%$ & 1,3 & $11,1 \%$ \\
\hline Amostra \#3 & 18,0 & 0,9 & $5,0 \%$ & 1,7 & $9,7 \%$ \\
\hline Amostra \#4 & 20,4 & 1,0 & $5,0 \%$ & 2,1 & $10,4 \%$ \\
\hline Amostra \#5 & 24,3 & 1,2 & $5,0 \%$ & 2,6 & $10,6 \%$ \\
\hline Amostra \#6 & 56,8 & 2,9 & $5,0 \%$ & 5,8 & $10,3 \%$ \\
\hline Amostra \#7 & 61,8 & 3,0 & $4,9 \%$ & 5,8 & $9,5 \%$ \\
\hline Amostra \#8 & 112,1 & 5,4 & $4,8 \%$ & 12,2 & $10,8 \%$ \\
\hline
\end{tabular}

Obtiveram-se os seguintes resultados com as mesmas oito amostras num local e com um lote de kit ensaiado em duplicado em dois ensaios por dia ao longo de 20 dias de trabalho.

\begin{tabular}{|c|c|c|c|c|c|}
\hline \multirow{2}{*}{$\begin{array}{c}\text { ID da } \\
\text { Amostra }\end{array}$} & \multirow{2}{*}{$\begin{array}{c}\text { Média } \\
\text { (ng/mL) }\end{array}$} & \multicolumn{2}{|c|}{$\begin{array}{c}\text { Intra-Série Dentro de um } \\
\text { Lote e Local }\end{array}$} & \multicolumn{2}{c|}{$\begin{array}{c}\text { Total Dentro de um } \\
\text { Lote e Local }\end{array}$} \\
\cline { 3 - 6 } & Desvio padrão & $\% \mathrm{CV}$ & Desvio padrão & $\% \mathrm{CV}$ \\
\hline Amostra \#1 & 7,9 & 0,6 & $7,7 \%$ & 0,9 & $10,9 \%$ \\
\hline Amostra \#2 & 12,2 & 0,6 & $5,2 \%$ & 1,1 & $9,3 \%$ \\
\hline Amostra \#3 & 17,6 & 0,8 & $4,8 \%$ & 1,0 & $5,8 \%$ \\
\hline Amostra \#4 & 20,7 & 1,1 & $5,1 \%$ & 1,9 & $9,1 \%$ \\
\hline Amostra \#5 & 24,0 & 1,0 & $4,1 \%$ & 1,8 & $7,7 \%$ \\
\hline Amostra \#6 & 56,8 & 2,3 & $4,0 \%$ & 3,6 & $6,3 \%$ \\
\hline Amostra \#7 & 60,8 & 2,2 & $3,7 \%$ & 3,7 & $6,0 \%$ \\
\hline Amostra \#8 & 109,6 & 4,6 & $4,2 \%$ & 7,8 & $7,2 \%$ \\
\hline
\end{tabular}

16.4 Precisão com o Analisador LIAISON ${ }^{\circledast} \mathrm{XL}$ :

A precisāo do ensaio no Analisador LIAISON ${ }^{\ominus}$ XL foi avaliada de acordo com o documento EP5-A2 do CLSI. Ensaiaram-se seis amostras de soro contendo várias concentraçōes de analitos e controlos do kit em duplicado em dois ensaios por dia ao longo de 20 dias de trabalho e um lote de reagente. As amostras foram testadas em dois Analisadores LIAISON ${ }^{*} \mathrm{XL}$. Foram obtidos os seguintes resultados:

\begin{tabular}{|c|c|c|c|c|c|}
\hline \multirow{2}{*}{$\begin{array}{c}\text { ID da } \\
\text { Amostra }\end{array}$} & \multirow{2}{*}{$\begin{array}{c}\text { Média } \\
\text { (ng/mL) }\end{array}$} & $\begin{array}{c}|c| \\
\text { Desvio } \\
\text { padräo }\end{array}$ & $\% \mathrm{CV}$ & $\begin{array}{c}\text { Desvio } \\
\text { padrão }\end{array}$ & $\% \mathrm{CV}$ \\
\hline Amostra \#1 & 7,85 & 0,3 & $3,8 \%$ & 0,8 & $9,8 \%$ \\
\hline Amostra \#2 & 17,2 & 0,6 & $3,2 \%$ & 1,5 & $8,9 \%$ \\
\hline Amostra \#3 & 19,6 & 0,4 & $2,3 \%$ & 1,4 & $7,3 \%$ \\
\hline Amostra \#4 & 22,8 & 0,4 & $1,8 \%$ & 2,0 & $8,9 \%$ \\
\hline Amostra \#5 & 51,9 & 1,0 & $2,0 \%$ & 3,1 & $6,0 \%$ \\
\hline Amostra \#6 & 55,2 & 1,7 & $3,1 \%$ & 3,6 & $6,4 \%$ \\
\hline Amostra \#7 & 109,3 & 2,1 & $1,9 \%$ & 6,9 & $6,3 \%$ \\
\hline Amostra \#8 & 120,5 & 0,2 & $0,1 \%$ & 11,0 & $9,1 \%$ \\
\hline
\end{tabular}




\section{ANEXO B - BULA DO EXAME 25(OH)D (página 8/10)}

\subsection{Veracidade}

A veracidade do ensaio foi verificada através do teste de diluição e do teste de recuperação.

análise de dois (2) aglomerade foi avaliada de acordo com o documento EP6-A do CLSI. Procedeu-se à diluição e TOTAL (ref. 310602). Os resultas (pools) de amostras com o Diluente de Amostras LIAISON $25 \mathrm{OH}^{*}$ Vitamin D Observados. A equação da regressão resultante édos como uma regressão linear dos valores Esperados vs. valores variaram, em dose, de 3,8 a $151 \mathrm{ng} / \mathrm{mL}$.

Soro de Linearidade e SST do LLAISON 25 OH Vitamin D TOTAL.

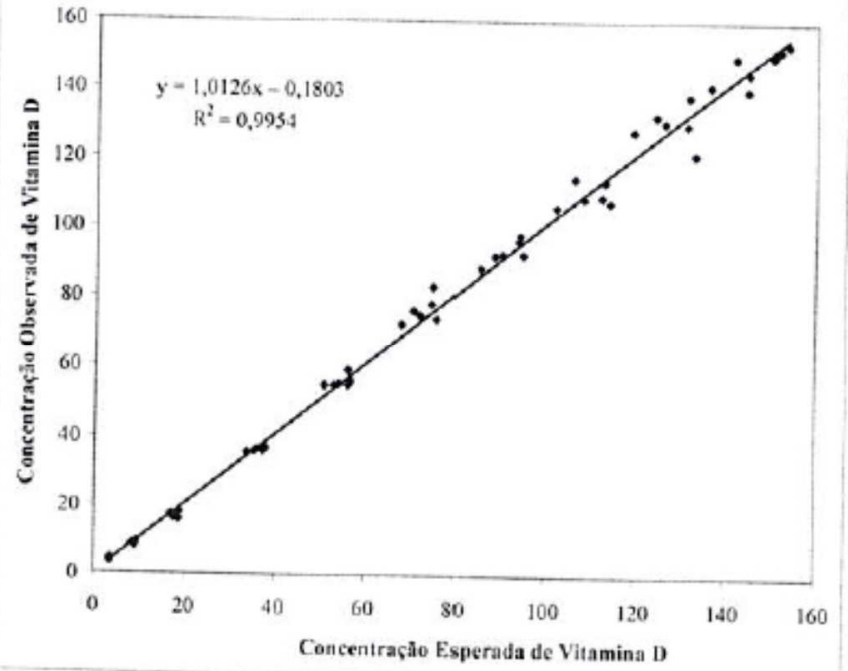




\section{ANEXO B - BULA DO EXAME 25(OH)D (página 9/10)}

Teste de recuperação. Procedeu-se à mistura de amostras com concentração elevada e amostras com concentraçăo baixa em razőes de 1:2, 1:1 e 2:1. Os valores observados foram depois comparados com os valores esperados para determinar a \% de recuperação. A recuperação média é de $93 \%$.

\begin{tabular}{|c|c|c|c|}
\hline & $\begin{array}{l}\text { Concentraçào Esperada } \\
\text { (ng } / \mathrm{mL})\end{array}$ & $\begin{array}{l}\text { Concentração Observada } \\
\text { (ng/mL) }\end{array}$ & $\begin{array}{c}\% \text { de } \\
\text { recuperação }\end{array}$ \\
\hline $\begin{array}{c}\text { Amostra } 1 \\
\text { Pura elevada } \\
2 \mathrm{H}: 1 \mathrm{~L} \\
1 \mathrm{H}: 1 \mathrm{~L} \\
1 \mathrm{H}: 2 \mathrm{~L} \\
\text { Pura baixa }\end{array}$ & $\begin{array}{c}86,4 \\
68,8 \\
51,1 \\
- \\
\end{array}$ & $\begin{array}{l}121 \\
77,8 \\
58,4 \\
46,4 \\
16,9 \\
\end{array}$ & $\begin{array}{c}- \\
90 \% \\
85 \% \\
91 \% \\
-\end{array}$ \\
\hline $\begin{array}{c}\text { Amostra } 2 \\
\text { Pura elevada } \\
2 \mathrm{H}: 1 \mathrm{~L} \\
1 \mathrm{H}: 1 \mathrm{~L} \\
1 \mathrm{H}: 2 \mathrm{~L} \\
\text { Pura baixa }\end{array}$ & $\begin{array}{c}- \\
81,0 \\
64,9 \\
48,9 \\
- \\
\end{array}$ & $\begin{array}{r}112 \\
77,4 \\
60,3 \\
48,7 \\
17,7 \\
\end{array}$ & $\begin{array}{c}- \\
96 \% \\
93 \% \\
100 \% \\
- \\
\end{array}$ \\
\hline $\begin{array}{c}\text { Amostra } 3 \\
\text { Pura elevada } \\
2 \mathrm{H}: 1 \mathrm{~L} \\
1 \mathrm{H}: 1 \mathrm{~L} \\
1 \mathrm{H}: 2 \mathrm{~L} \\
\text { Pura baixa }\end{array}$ & $\begin{array}{c}- \\
84,7 \\
65,9 \\
47,1 \\
- \\
\end{array}$ & $\begin{array}{r}121 \\
80,3 \\
59,9 \\
42,5 \\
10,6 \\
\end{array}$ & $\begin{array}{r}- \\
95 \% \\
91 \% \\
90 \% \\
- \\
\end{array}$ \\
\hline $\begin{array}{c}\text { Amostra } 4 \\
\text { Pura elevada } \\
2 \mathrm{H}: 1 \mathrm{~L} \\
1 \mathrm{H}: 1 \mathrm{~L} \\
1 \mathrm{H}: 2 \mathrm{~L} \\
\text { Pura baixa } \\
\text { Amostra } 5\end{array}$ & $\begin{array}{c}- \\
44,7 \\
37,0 \\
29,3 \\
- \\
\end{array}$ & $\begin{array}{l}59,6 \\
42,8 \\
35,5 \\
27,4 \\
14,3 \\
\end{array}$ & $\begin{array}{c}- \\
96 \% \\
96 \% \\
94 \% \\
- \\
\end{array}$ \\
\hline $\begin{array}{c}\text { Amostra } 5 \\
\text { Pura elevada } \\
2 \mathrm{H}: 1 \mathrm{~L} \\
1 \mathrm{H}: 1 \mathrm{~L} \\
1 \mathrm{H}: 2 \mathrm{~L} \\
\text { Pura baixa } \\
\end{array}$ & $\begin{array}{c}- \\
47,6 \\
38,5 \\
29,5 \\
-\end{array}$ & $\begin{array}{l}65,2 \\
45,3 \\
36,6 \\
28,2 \\
11,9 \\
\end{array}$ & $\begin{array}{c}- \\
95 \% \\
95 \% \\
96 \% \\
-\end{array}$ \\
\hline & & Recuperação média & $93 \%(85 \%-100 \%)$ \\
\hline
\end{tabular}

16.6 Especificidade

A reactividade cruzada foi testada conforme descrito no documento EP7-A2 do CLSI. Foram obtidos dados sobre a reactividade cruzada do anti-soro usado neste ensaio adicionando até $100 \mathrm{ng} / \mathrm{mL}$ do potencial reagente cruzado e ensaiando. A reactividade cruzada de cada composto, normalizado a $25-\mathrm{OH}$ vitamina $\mathrm{D}_{3}$, é indicada a seguir. $O$ anticorpo utilizado neste ensaio irá demonstrar reactividade cruzada com muitos metabolitos dihidroxilados da
Vitamina $D$.

$\begin{array}{lc}\text { Esteróide } & \text { \% de Reactividade cruzada } \\ 25 \mathrm{OH} \text { Vitamina } \mathrm{D}_{2} & 100,0 \% \\ 25 \mathrm{OH} \text { Vitamina } \mathrm{D}_{3} & 100,0 \% \\ \text { Vitamina } \mathrm{D}_{2} & 1,9 \% \\ \text { Vitamina } \mathrm{D}_{3} & 1,9 \% \\ 1,25-(\mathrm{OH})_{2} \text { Vitamina } \mathrm{D}_{2} & 6,7 \% \\ 1,25-(\mathrm{OH})_{2} \text { Vitamina } \mathrm{D}_{3} & 9,3 \% \\ \text { 3-epi-25 OH Vitamina } \mathrm{D}_{3} & 1,3 \%\end{array}$




\section{ANEXO B - BULA DO EXAME 25(OH)D (página 10/10)}

16.7 Substãncias interferentes

As substāncias interferentes foram testadas conforme descrito no documento EP7-A2 do CLSI utilizando o Ensaio LIAISON $25 \mathrm{OH}$ Vitamin D TOTAL. Os resultados são apresentados em baixo.

Amostras que são

Hemolisadas

Lipémicas

Ictéricas

Ictéricas

\section{Amostras que contèm}

Colesterol

Ácido úrico

Proteinas Totais
Demonstram uma alteração $\leq 10 \%$ nos resultados até $200 \mathrm{mg} / \mathrm{dL}$ de hemoglobina $589 \mathrm{mg} / \mathrm{dL}$ de triglicéridos

$40 \mathrm{mg} / \mathrm{dL}$ de bilirrubina conjugada

$40 \mathrm{mg} / \mathrm{dL}$ de bilirrubina não conjugada

Demonstram uma alteração $\leq 10 \%$ nos resultados até $301 \mathrm{mg} / \mathrm{dL}$

$20 \mathrm{mg} / \mathrm{dL}$

$12 \mathrm{~g} / \mathrm{dL}$

Distribuido no Brasil por:

DiaSorin Lida - CNPJ 01.896.764/0001-70 - Av.

Ermano Marchetti, 1435 B - Lapa

Săo Paulo SP S.A.C 08007716216

e-mail: diasorin@diasorin.com.br 
ANEXO C - BULA DO EXAME PTHi (página 1/3)

$12130091001 \mathrm{v} 20$

Hormona paratiróidea (parathormona, paratirina) - PTH, intacta

REF 11972103122

100 testes

- Indica os analisadores onde o dispositivo pode ser utilizado

\begin{tabular}{c|c|c|c|c}
\hline Elecsys 2010 & $\begin{array}{c}\text { MODULAR } \\
\text { ANALYTICS } \\
\text { E170 }\end{array}$ & cobas e 411 & cobas e 601 & cobas e 602 \\
\hline$\bullet$ & $\bullet$ & $\bullet$ & $\bullet$ & $\bullet$ \\
\hline
\end{tabular}

\section{Português}

Utilização prevista

Imunoensaio para a determinaçăo quantitativa in vitro da hormona paratiróidea intacta em soro e plasma humanos para o diagnóstico diferencial da hiper e hipocalcemia. O teste Elecsys PTH pode ser utilizado intraoperativamente.

O ensaio de electroquimioluminescência (electrochemiluminescence immunoassay ou "ECLIA") foi concebido para ser utilizado nos analisadores de imunoensaios Elecsys e cobas e.

\section{Resumo}

A hormona paratiróidea (PTH) é formada na glândula paratiróidea e segregada na circulação sanquínea. A PTH intacta é composta por uma única cadeia polipeptídica com 84 aminoácidos e tem um peso molecular de aprox. 9500 daltons.

$\mathrm{O}$ fragmento $\mathrm{N}$-terminal biologicamente activo tem uma semi-vida de poucos minutos. Uma medição selectiva da hormona paratiróidea (substancialmente) intacta permite uma determinação directa da actividade secretora da glândula paratiróidea. ${ }^{1,2}$

A PTH provoca, juntamente com a vitamina $D \in$ a calcitonina, a mobilização de cálcio e de fosfato no sistema esquelético e aumenta a absorção de cálcio no intestino, assim como a eliminaçăo de fosfatos através dos rins. A constância do nivel de cálcio no sangue é garantida pela acção conjunta

da PTH e da calcitonina. A secreçăo de PTH é inibida pelas elevadas concentraçōes de cálcio e promovida pelas baixas concentraçōes. Deficiências da função da glândula paratiróidea provocam o aumento (hipercalcemia) ou a diminuição (hipocalcemia) do nivel de cálcio no sangue, que é condicionado por uma alteração da secreção de PTH.

A determinação do hipofuncionamento da glândula paratiróidea (hipoparatiroidismo) exige um teste de sensibilidade elevada para poder detectar um nivel de PTH que se encontre substancialmente abaixo do normal..$^{3,4}$

Uma hiperfunção da glândula paratiróidea resulta num aumento da secreção de PTH (hiperparatiroidismo). A causa primária são adenomas da glândula paratiróidea. No hiperparatiroidismo secundário, o nivel de cálcio no sangue é baixo dévido a a outros estados patológicos (por ex., falta de vitamina D). Hoje em dia, a determinação das concentraçōes de PTH e de cálcio é da maior importância para a análise do hiperparatiroidismo.

A determinaçăo da PTH intraoperativamente durante a ressecção de um adenoma na glândula paratiróide foi também reportada no caso do hiperparatiroidismo primário, $, 6,7$ do hiperparatiroidismo secundário relacionado com insuficiência renal, 8.9 e do hiperparatiroidismo terciário após cirurgia de transplante renal. ${ }^{10}$ Como a PTH tem uma semi-vida de $3-5$ minutos, ${ }^{11}$ uma queda significativa dos niveis de PTH após ressecçăo de uma glândula ou glândulas anómalas permite ao cirurgião avaliar se a ressecção foi completa $\theta$ se todo o tecido hiperfuncional da paratiróide foi removido do doente. ${ }^{12}$ As directrizes da NACB recomendam que sejam obtidas amostras iniciais antes da intervenção cinúrgica e pré-excisăo da glândula hiperfuncional suspeita. ${ }^{13}$ As amostras para a realização do teste de PTH devem ser colhidas 5 e 10 minutos após a ressecção, devendo uma redução $>50 \%$ nos niveis de PTH em relação ao valor inicial mais elevado ser utilizada como critério de êxito clínico. Podem ser necessárias amostras adicionais, uma vez que ficou demonstrado que a sensibilidade pode aumentar com o tempo. ${ }^{14}$ 0 facto de o valor de PTH não descer abaixo dos níveis recomendados indica que: 1) continua presente tecido hiperfuncional residual, podendo ser necessária uma exploração mais rigorosa, como aconteceu no caso de dois doentes, ambos com uma quinta glândula paratiróide ectópica, que exigiu nova cirurgia, ${ }^{7}$ ou 2) ocorreu pico nos niveis de PTH durante a mobilização do adenoma. ${ }^{15}$ As determinações intraoperatórias da PTH permitem avaliar de forma rápida e fiável se todo o tecido da paratióide hiperfuncional foi removido durante a intervenção cirúrgica.

\section{cobas $^{\circ}$}

O teste Elecsys para determinação da PTH intacta utiliza a técnica sandwich em que 0 anticorpo monoclonal biotinilado reage com o fragmento $\mathrm{N}$-terminal (1-37) e 0 anticorpo monoclonal marcado com 0 complexo de ruténioa reage com o fragmento C-terminal (38-84). Os anticorpos utilizados neste ensaio são reactivos com os epitopos localizados nas regióes de aminoácidos 26-32 e 37-42.

a) Tris(2,2'bipiridil) ruténio(II) $(\text { Ru(boy })_{3}^{2+}$ )

\section{Principio do teste}

Técnica de sandwich. Duraçäo total do ensaio: 18 minutos.

- $1 .{ }^{3}$ incubaçăo: $50 \mu \mathrm{L}$ de amostra, um anticorpo monoclonal biotinilado específico anti-PTH e um anticorpo monoclonal especifico anti-PTH marcado com complexo de ruténio reagem entre si e formam um complexo sandwich.

- 2." incubação: Após a adição das micropartículas revestidas de estreptavidina, o complexo formado liga-se à fase sólida pela interacção da biotina $\Theta$ da estreptavidina.

- A mistura de reacção é aspirada para a célula de leitura, onde as micropartículas săo fixadas magneticamente à superfície do eléctrodo. Os elementos não ligados são então removidos com ProCell. A aplicação de uma corrente eléctrica ao eléctrodo induz uma emissão quimioluminescente que è medida por um fotomultiplicador.

- Os resultados são determinados com base numa curva de calibração gerada especificamente pelo analisador, através de uma calibração de 2 pontos, e numa curva principal inciuida no código de barras dos reagentes.

Reagentes - soluçōes de trabalho

M Micropartículas revestidas de estreptavidina (tampa transparente), 1 frasco, $6,5 \mathrm{~mL}$ :

Microparticulas revestidas de estreptavidina, $0,72 \mathrm{mg} / \mathrm{mL}$; conservante.

R1 Anticorpo anti-PTH biotina (tampa cinzenta), 1 frasco, $7 \mathrm{~mL}$ : Anticorpo monoclonal biotinilado anti-PTH (ratinho) $2,3 \mathrm{mg} / \mathrm{L}$; tampäo fosfato $100 \mathrm{mmol} / \mathrm{L}, \mathrm{pH} 7,0$; conservante.

R2 Anticorpo anti-PTH Ru(bpy) ${ }_{3}^{2+}$ (tampa preta), 1 frasco, $7 \mathrm{~mL}$ : Anticorpo monocional anti-PTH (ratinho) marcado com complexo de ruténio 2,0 mg/L; tampão fosfaio $100 \mathrm{mmol} / \mathrm{pH}$, 7,0; conservante.

\section{Avisos e precauções}

Para utilização em diagnóstico in vitro.

Respeite as precauçōes normais de manuseamento de reagentes laboratoriais. Elimine todos os residuos de acordo com os regulamentos locais. Ficha de segurança fornecida a pedido, para uso profissional. Evite a formação de espuma com todos os reagentes e com todo 0 tipo de amostras (amostras de pacientes, calibradores e controlos).

\section{Preparação dos reagentes}

Os reagentes do kit foram incluidos numa unidade pronta a ser utilizada que não pode ser separada.

Toda a informação necessária ao correcto funcionamento é introduzida no analisador através dos respectivos códigos de barras do reagente.

\section{Armazenamento e estabilidade}

Armazenar a $2-8^{\circ} \mathrm{C}$.

Coloque o dispositivo de reagentes Elecsys PTH na vertical para

assegurar a total disponibilidade das micropartículas durante a mistura automática, antes da utilizaçäo.

Estabilidade:

\begin{tabular}{l|l}
\hline fechado a $2-8^{\circ} \mathrm{C}$ & até ao fim do prazo de validade indicado \\
\hline após abertura a $2-8^{\circ} \mathrm{C}$ & 12 semanas \\
\hline nos analisadores & 8 semanas \\
\hline
\end{tabular}

\section{Colheita e preparaçäo das amostras}

Apenas as amostras indicadas em seguida foram testadas

e consideradas aceitáveis.

O soro é colhido utilizando tubos de amostra padrẫo.

Plasma com EDTA-Kও.

Devido à breve semi-vida da PTH, para obtençăo do soro, recomenda-se

a centrifugação imediata do sangue. 


\section{ANEXO C - BULA DO EXAME PTHi (página 2/3)}

\section{PTH}

Hormona paratiróidea (parathormona, paratirina) - PTH, intacta

Use preferencialmente plasma com EDTA-K $K_{3}$ uma vez que é mais estável do que o soro.

Critério: Comparaç̃es dos métodos de soro versus plasma, declive

0,9-1,1 + interceoção dentro de $< \pm 2 \times$ sensibilidade analítica

$(\mathrm{LDL})+$ coeficiente de correlação $>0,95$.

Soro: Estabilidade: 8 horas a $15-25^{\circ} \mathrm{C}, 2$ dias a $2-8^{\circ} \mathrm{C}, 6$ meses a $-20^{\circ} \mathrm{C}$.

Plasma: Estabilidade: 2 dias a $15-25^{\circ} \mathrm{C}, 3$ dias a $2.8^{\circ} \mathrm{C}$ e 6 meses a $-20^{\circ} \mathrm{C}$.

Os tipos de amostras indicados foram testados usando tubos de colheita

de amostras seleccionados e comercialmente disponiveis à data do

teste, i.e. nem todos os tubos dos diferentes fabricantes disponíveis no mercado foram testados. Os sistemas de colheita de amostras de diferentes fabricantes podem, por sua vez, conter materiais diferentes que, em alguns casos, podem afectar os resultados dos testes. Se processar amostras em tubos primários (sistemas de colheita de amostras) consulte as instruçôes do fabricante dos tubos.

As amosiras que contêm precipitado têm de ser centrifugadas antes da realização do ensaio. Não utilize amostras $\theta$ controlos estabilizados com azida. Antes da determinação, certifique-se de que as amostras dos pacientes, os calibradores $e$ os controlos estäo à temperatura ambiente $\left(20-25^{\circ} \mathrm{C}\right)$.

Devido a possiveis efeitos de evaporação, as amostras, os calibradores e os controlos colocados no analisador deverăo ser analisados no prazo de 2 horas.

\section{Materiais fornecidos}

Consulte a secção "Reagentes - soluçōes de trabalho".

Materiais necessários (mas não fornecidos)

- REF 11972219122, PTH CalSet, para $4 \times 1 \mathrm{~mL}$

- REF 11972227122, PreciControl Anemia, para $2 \times 2 \mathrm{~mL}$ cada de PreciControl Bone 1, 2 e 3 ou REF 05618860190, PreciControl Varia, para $2 \times 3 \mathrm{~mL}$ cada de PreciControl Varia 1 e 2

- Equipamento normal de laboratório

- Analisadores Elecsys 2010, MODULAR ANALYTICS E170 ou cobas e

Acessórios para os analisadores Elecsys 2010 e cobas e 411:

- REF 11662988122, tampão de sistema ProCell, $6 \times 380 \mathrm{~mL}$

- REF 11662970122, CleanCell, 6 × $380 \mathrm{~mL}$ de solução de limpeza para a célula de leitura

- AEF 11930346122, Elecsys SysWash, $1 \times 500 \mathrm{~mL}$ de aditivo para água de lavagem

- REF 11933159001, Adaptador para SysClean

- REF 11706802001. Elecsys 2010 AssayCup, 60 × 60 cuvetes de reacção

- REF 11706799001, Elecsys 2010 AssayTip, $30 \times 120$ pontas de pipeta Acessórios para analisadores MODULAR ANALYTICS E170, cobas e 601 e cobas e 602 :

- REF 04880340190, ProCell M, 2 × 2 L de tampão de sistema

- REF 04880293190, CleanCell M, $2 \times 2$ L de soluçăo de limpeza para a célula de leitura

- REF 03023141001, PC/CC-Cups, 12 cuvetes para ProCell M e CleanCell M pré-aquecidos antes da utilizaçẵo

- REF 03005712190, ProbeWash M, $12 \times 70$ mL de soluçăo de limpeza para finalização da análise e lavagem durante a mudança de reagentes

- REF 03004899190, PreClean M, 5 × $600 \mathrm{~mL}$ de soluçăo de limpeza de detecção

- REF 12102137001, AssayTip/AssayCup Combimagazine M, 48 tabuleiros $\times 84$ cuvetes de reacção ou pontas de pipeta, sacos de lixo

- REF 03023150001, WasteLiner, sacos de lixo

- REF 03027651001, SysClean Adapter M

Acessórios para todos os analisadores:

- REF 11298500316, Elecsys SysClean, $5 \times 100 \mathrm{~mL}$ de solução de limpeza do sistema

\section{Ensaio}

Para assegurar a correcta execuçāo do ensaio é importante cumprir as instruçōes fornecidas neste documento para 0 analisador utilizado. Consulte o manual do operador apropriado para obter informaçōes mais especificas sobre o ensaio feito no analisador.

\section{coobas}

A ressuspensão das micropartículas é efectuada automaticamente antes de usar. Introduza os parâmetros especificos do teste através dos códigos de barras dos reagentes. Se, em algum caso excepcional, não for possivel ler o código de barras, o código numérico de 15 dígitos deverá ser introduzido manualmente.

Analisadores MODULAR ANALYTICS E170, cobas e 601 e cobas e 602 É necessária a soluçāo PreClean M.

Analisadores MODULAR ANALYTICS E170, Elecsys 2010 e cobas e: Eleve a temperatura dos reagentes refrigerados até aprox. $20^{\circ} \mathrm{C} \theta$ coloque-os no disco dos reagentes $\left(20^{\circ} \mathrm{C}\right)$ do analisador. Evite a formação de espuma. $\mathrm{O}$ sistema regula automaticamente a temperatura dos reagentes e a abertura/fecho dos frascos.

\section{Calibração}

Rastreabilidade: Este método foi padronizado contra um teste PTH (RIA) à venda no mercado.

Cada dispositivo de reagentes do teste Elecsys PTH contém um código de barras com informações específicas para a calibracăo do lote de reagentes em questão. A curva principal previamente definida é adaptada ao analisador através do dispositivo Elecsys PTH CalSet.

Frequência das callibraçôes: Uma calibração por lote de reagentes utilizando reagente recém-colocado (i.e., dentro de um máximo de 24 horas após ter sido registado no analisador).

Devem ser feitas as seguintes recalibraçōes:

- após 1 mês (28 dias) quando se utiliza o mesmo lote de reagentes

- após 7 dias (quando se utiliza o mesmo kit de reagentes no analisador)

- conforme necessário: p. ex., em resultados de ensaios de controlo da qualidade fora dos limites especificados.

\section{Controlo da qualidade}

Para o controlo de qualidade, utilize Elecsys PreciControl Bone 1, 2 e 3 ou Elecsys PreciControl Varia 1 e 2 .

Adicionalmente, pode ser utilizado outro material de controlo adequado. Efectue os controlos dos diversos intervalos de concentração como determinacōes simples, pelo menos uma vez em cada 24 horas quando o teste estiver a ser utilizado, uma vez por kit de reagentes $e$ após cada calibração. Os intervalos e limites de controlo devem ser adaptados às exigências específicas de cada laboratório. Os valores obtidos devern situar-se dentro dos limites definidos.

Cada laboratório deve estabelecer as medidas correctivas a tornar no caso de os valores se situarem fora dos limites.

Cumpra os regulamentos governamentais aplicáveis e as directrizes locais de controlo da qualidade.

\section{Cálculo dos resultados}

$\mathrm{O}$ analisador calcula automaticamente a concentração de analito de cada amosira (em pg/mL ou pmol/L)

Factores de conversão: $\quad \mathrm{pg} / \mathrm{mL} \times 0,106=\mathrm{pmo} / \mathrm{L}$ $\mathrm{pmol} / \mathrm{L} \times 9,43=\mathrm{pg} / \mathrm{mL}$

Limitações - interferências

O ensaio não é áfectado pela icterícia (bilirrubina < $1112 \mu \mathrm{mol} / \mathrm{L}$ ou $<65 \mathrm{mg} / \mathrm{dL}$ ), lipemia (Intralipid $<1500 \mathrm{mg} / \mathrm{dL}$ ) e biotina $(<205 \mathrm{nmol} / \mathrm{L}$ ou $<50 \mathrm{ng} / \mathrm{mL}$ ). O ensaio é afectado por uma hemólise $\geq 0,15 \mathrm{~g} / \mathrm{dL}$. Não analise amostras que apresentem sinais visiveis de hemólise. Critério: Recuperação dentro de $\pm 10 \%$ do valor inicial. Nos pacientes em tratamento com doses elevadas de biotina (i.e. $>5 \mathrm{mg} / \mathrm{dia}$ ), as amostras só deverăo ser colhidas no mínimo 8 horas após a última administração de biotina.

Não foi observada interferência dos factores reumaióides até a uma concentraçăo de $1500 \mathrm{UV} / \mathrm{mL}$.

Não foi observado qualquer efeito "high-dose hook" em concentrações de PTH até $17000 \mathrm{pg} / \mathrm{mL}$ (1.802 pmol/L).

Foram efectuados testes in vitro com 16 fármacos frequentemente utilizados. Não se encontrou qualquer interferência com o ensaio.

En casos isolados, podem ocorrer interferências devido a titulos extremamente elevados de anticorpos contra anticorpos especificos do analito, contra a estreptavidina $\theta$ contra o ruténio. Estes efeitos săo minimizados por um desenho de teste adequado. 


\section{ANEXO C - BULA DO EXAME PTHi (página 3/3)}

\section{V20 PTH \\ Hormona paratiróidea (parathormona, paratirina) - PTH, intacta}

Quando o objectivo é o diagnóstico, os resultados devem ser sempre interpretados em conjunto com a história clínica do paciente, 0 exame clínico e outros resultados.

\section{Limites e intervalos}

Intervalo de medição

1,20-5000 pg/mL ou 0,127-530 pmoll (definido pelo limite de detecçāo inferior e pelo máximo da curva principal). Os valores inferiores ao limite de detecção são indicados como $<1,20 \mathrm{pg} / \mathrm{mL}(<0,127 \mathrm{pmol} / \mathrm{L})$ e os valores acima do intervalo de medição como $>5000 \mathrm{pg} / \mathrm{mL}$ (>530 pmol/L). Limites inferiores de medição

Limite de detecção inferior

Limite de detecção inferior: $1,20 \mathrm{pg} / \mathrm{mL}(0,127 \mathrm{pmo} / \mathrm{L})$

O limite de deteccăo representa o nivel de analito mais baixo mensurável passivel de ser distinguido de zero. É calculado como o valor situado dois desvios padrăo (DP) acima do padrã̃o mais baixo (calibrador principal, padrăo $1+2 \mathrm{DP}$, estudo de repetibilidade, $n=21$ ).

Diluiçăo

Não necessária devido à grande amplitude do intervalo de medição.

Valores teóricos 16,17

$15-65 \mathrm{pg} / \mathrm{mL}(1,6-6,9 \mathrm{pmoll})$

Cada laboratório deve verificar a transferibilidade dos valores teóricos para a sua própria populaçăo de pacientes e, se necessário, determinar os seus próprios intervalos de referẻncia.

Dados específicos sobre o desempenho

Säo apresentados a seguir dados representativos do desempenho nos analisadores. Os resultados podem diferir de laboratório para laboratório.

\section{Precisão}

A precisäo foi determinada com reagentes Elecsys, um pool de soros humanos e controlos, de acordo com um protocolo modificado (EP5-A) do CLSI (Clinical and Laboratory Standards Institute): 6 vezes por dia durante 10 dias $(n=60)$; repetibilidade no analisador MODULAR ANALYTICS E170, $n=21$. Obtiveram-se os seguintes resultados:

\begin{tabular}{|c|c|c|c|c|c|c|c|c|c|c|}
\hline \multicolumn{11}{|c|}{ Analisadores Elecsys 2010 e cobas e 411} \\
\hline & & & & Repei & tibilida & ade $^{b}$ & \multicolumn{4}{|c|}{ Precisão interméclia } \\
\hline \multirow[t]{2}{*}{ Amostra } & & \multicolumn{2}{|c|}{ Média } & \multicolumn{2}{|c|}{ DP } & \multirow{2}{*}{$\begin{array}{c}\text { CV } \\
\%\end{array}$} & \multirow{2}{*}{$\mathrm{pg} / \mathrm{mL}$} & \multicolumn{2}{|c|}{\begin{tabular}{l|l} 
DP &
\end{tabular}} & \multirow{2}{*}{$\begin{array}{l}\mathrm{CV} \\
\%\end{array}$} \\
\hline & \multicolumn{2}{|c|}{$\mathrm{pg} / \mathrm{mL}$} & pmol/L & & & & pmo & & \\
\hline $\mathrm{SH}^{\mathrm{C}} 1$ & & 26,7 & 2,83 & 0,711 & 0,075 & 2,7 & 1,73 & 0,18 & & 6,5 \\
\hline $\mathrm{SH} 2$ & & 52,5 & 5,56 & 0,853 & 0,091 & 1,6 & 2,07 & 0,2 & & 3,9 \\
\hline$\overline{\mathrm{SH}} 3$ & & 261 & 27,7 & 4,0 & 0,424 & 1,5 & 7,81 & 0,8 & & 3,0 \\
\hline $\mathrm{PC}^{\mathrm{d}}$ Bone1 & & 20,2 & 2,14 & 0,840 & 0,089 & 4,1 & 1,25 & 0,13 & & 6,2 \\
\hline PC Bone2 & & 58,0 & 6,15 & 1,28 & 0,136 & 2,2 & 2,38 & 0,2 & 53 & 4,1 \\
\hline PC Bone3 & & 676 & 71,7 & 12,5 & 1,32 & 1,9 & 17,3 & 1,8 & & 2,6 \\
\hline \multicolumn{11}{|c|}{$\begin{array}{l}\text { b) Repetibilidade = precisẫo intra-ensaio } \\
\text { c) } \mathrm{SH}=\text { Soro humano } \\
\text { d) } P C=\text { PreciControl }\end{array}$} \\
\hline \multicolumn{11}{|c|}{ Analisadores MODULAR ANALYTICS E170, cobas e 601 e cobas e 602} \\
\hline & \multicolumn{5}{|c|}{\begin{tabular}{l|} 
Repetibilidade \\
\end{tabular}} & \multicolumn{5}{|c|}{ Precisão intermédia } \\
\hline Amostra & M & Aédia & & DP & $\begin{array}{l}\mathrm{CV} \\
\% \\
\end{array}$ & $\begin{array}{c}M e ́ c \\
\mathrm{~g} g / \mathrm{mL}\end{array}$ & dia & & $\begin{array}{l}\mathrm{P} \\
\mathrm{pmol} / \mathrm{L}\end{array}$ & $\begin{array}{r}\mathrm{CV} \\
\% \\
\end{array}$ \\
\hline $\mathrm{SH} 1$ & 21,9 & 2,32 & 0,44 & 0,05 & 2,0 & 23,2 & 2,46 & 0,79 & 0,08 & 3,4 \\
\hline $\mathrm{SH} 2$ & 35,0 & 3,71 & 0,43 & 0,05 & 1,2 & 80,9 & 8,58 & 2,01 & 0,21 & 2,5 \\
\hline $\mathrm{SH} 3$ & 123 & 13,04 & 1,31 & 0,14 & 1,1 & 240 & 25,4 & 6,72 & 0,71 & 2,8 \\
\hline PC Bone1 & 72,7 & 7,71 & 1,63 & 0,17 & 2,2 & 73,0 & 7,74 & 1,21 & 0,13 & 1,7 \\
\hline PC Bone2 & 236 & 25,0 & 6,58 & 0,70 & 2,8 & 238 & 25,2 & 3,86 & 0,41 & 1,6 \\
\hline PC Bone3 & 1092 & 116 & 6,97 & 0,74 & 0,6 & 1098 & 116 & 17,9 & 1,90 & 1,6 \\
\hline
\end{tabular}

Comparação dos métodos

Uma comparação do teste Elecsys PTH (y) com um teste de PTH

à venda no mercado $(x)$, utilizando amostras clínicas, teve como

resultado as seguintes correlaçōes $(\mathrm{pg} / \mathrm{mL})$ :

Número de amostras medidas: 152

Passing/Baioioik

$y=1,01 x+4,86$

$T=0,886$

Regressāo lineai

$y=0,83 x+19,4$

$r=0,991$

\section{cobas}

As concentraç̄es das amostras variaram entre aprox.

1,4-1880 pg/mL (0,15-199 pmoll).

\section{Especificidade analítica}

Não se registaram reacçōes cruzadas para: a osteocalcina, o fragmento

1-37 da PTH, a proteína associada à PTH (1-86), a fosfatase alcalina específica dos ossos $\theta$ os $\beta$-CrossLaps.

\section{Sensibilidade funcional}

$6,0 \mathrm{pg} / \mathrm{mL}(0,64 \mathrm{pmol} /)$

A sensibilidade funcional é a concentração de analito mais baixa que pode ser medida de modo reprodutivel com um coeficiente de variação de precisão intermédia $<20 \%$.

\section{Investigaçōes clínicas na utilização intraoperatória}

Em 2006, a National Academy of Clinical Biochemistry publicou as Laboratory Medicine Practice Guidelines para análises realizadas junto do paciente (Point of Care Testing - POCT), denominadas Evidence Based Practice for Point of Care Testing..$^{13}$ Estas directrizes recomendam a utilizaçăo de análises da hormona paratiróide intraoperalivamente 1) em doentes submetidos a cirurgia devido a hiperparatiroidismo, especialmente em procedimentos minimamente invasivos ou direccionados, 2) em doentes submetidos a nova intervenção cinúrgica e 3) como substituição de determinações laboratoriais tradicionais da PTH durante a localização venosa, para ajudar a equipa de angiografia na colheita de amostras. As directrizes recomendam ainda, para os doentes submetidos a paratiroidectomia devido a hiperparatiroidismo, que as amostras iniciais sejam obtidas na exploração pré-operatória e pré-excisão da glândula, e que a colheita de amostras pós-excisão seja feita 5 e 10 minutos após a ressecção, com uma redução de $50 \%$ das concentrações de PTH relativamente ao nivel inicial mais elevado. As directrizes alertam também para o facto de poderem ser necessárias mais amostras. ${ }^{13}$ A determinação da PTH durante a cirurgia da paratiróide.foi conduzida por vários grupos de investigadores, mediante utilizacãa do imunoensaio Elecsys PTH. 6,7,8,10 A sensibilidade global e a especificidade do ensaio para demonstrar que a cirurgia é bem sucedida, conforme a definicãa, através de uma redução pós-operatória dos niveis de cálcio, foi de $99,6 \%$ e 93,7\%, respectivamente.

\section{Bibliografia}

1. Silverman R, Yalow RS. Heterogeneity of parathyroid hormone: Clinical and physiologic implications. J Clin Invest 1973:52:1958-1971.

2. Flentje D, Schmidt-Gayk H, Fischer S, Stern J, Blind E, Buhr $\mathrm{H}$, Herfarth $\mathrm{Ch}$. Intact parathyroid hormone in primary hyperparathyroidism. Br J Surg 1990;77:168-172.

3. Nussbaum S, Potts JT. Advances in Immunoassays for Parathyroid Hormone. Clinical Applications to Skeletal Disorders of Bone and Mineral Metabolism. In Bilezikian JP, Levine MA, Marcus R (eds). The Parathyroids: Basic an Clinical Concepis. Raven Press, New York 1994:157-169.

4. Berson SA, Yalow RS, Aurbach GD, Potts JT. Immunoassay of bovine and human parathyroid hormone. Proc Natl Acad Sci USA 1963:49:613-617.

5. Bergenfelz A, Nordén NE, Ahrén B. Intraoperative fall in plasma levels of intact parathyroid hormone after removal of one enlarged parathyroid gland in hyperthyroid patients. Eur J Surg 1991;157:109-112.

6. Ohe MN, Santos RO, Kunii IS, Carvalho AB, Abrahao M, Cervantes O, Lazaretti-Castro M, Vieira JG. Usefulness of a rapid immunometric assay for intfa-operative parathyroid hormone measurements. Braz J Med Biol Res 2003;36(6):715-721.

7. Ohe, Monique Nakayama, Santos, Rodrigo Oliveira, Kunii, Ilda Shizue et al. Usefulness of intra-operative PTH measurement in primary and secondary hyperparathyroidism: experience with 109 patients. Arq Bras Endocrinol Metab 2006;50(5):869-875.

8. Seehofer D, Rayes N, Ulrich F, Muller C, Lang M, Neuhaus P, Steinmuller T. intra-operative measurement of intact parathyroid hormone in renal hyperparathyroidism by an inexpensive routine assay. Langenbecks Arch Surg 2001;386(6):440-443.

9. Sechofer D, Rayes N, Klupp J, Steinmuller T, Ulich F, Muller C Schindler R, Frei U, Neuhaus P. Predictive value of intact parathyroid hormone measurement during surgery for renal hyperparathyroidism. Langenbecks Arch Surg 2005;390(3):222-229. 
ANEXO D - BULA DO EXAME IgE (página 1/2)

\section{Mono IgE Látex $\mathrm{N}$ N IGE}

Sistemas BN II / BN ProSpec*

Campo de aplicaçăo

Reagentes de diagnóstico in-vitro para a determinaçăo quantitativa de $\mathrm{gE}$ em soro huma-
no, plasma EDTA e heparinizado por meio de imunonefelometria potenciada por particulas utilizando os Sistemas BN II e BN ProSpec ${ }^{\oplus}$.

Sumário e Explicação

IgE é responsável pelo quadro clínico observado em alergias do tipo imediatas. Em doenças alergicas como a dermatite atopica ou asma, as concentraçós serricas de lgE correla.

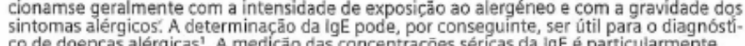
co de doenças alérgicas'. A mediçāo das concentraçoes séricas da IgE é particularmente mas alérgicos ${ }^{2}$.
Limites: Valores

Limites: Valores elevados de lgE podem ser úteis na diferenciaçăo de doenças de génese devem ser sempre considerados associados a resultados cles dénicos e outros laboratoriais, que valores IgE baixos năo indicam necessariamente a ausência de alergias e valores IgE cificos para provar a existência de uma alergia.

Nos casos muitositarias, os niveis séricos de lgE são também distintamente elevados ${ }^{1}$. Muitas imunodeficiências herdadas, especialmente do sistema celular, bem como infecçőes avançadas por VIH, acompanham concentraç̄es de lgE elevadas, enquanto que ou Assim, a determinaçåo de lgE é importante no diagnóstico diferencial de imunodeficiênci-

Princípo do método

As particulas de polistireno revestidas com anticorpos específicos para lgE humana agregamse quando misturadas com amostras contendo 1 E humana. Estes acregados dispersam um raio de luz que passa através da amostra. A intensidade da luz dispersa é proporci. onal à concentraça da prespectiva proterina na amoste. Orasulado é avaliado por compaReagentes

Material fornecido

$3 \times 3$ mL MAIGE REAGENT, mono lge Látex $N$

Composição 0 mono lgE Látex $\mathrm{N}$ consiste numa suspensão de partículas de polistireno revestidas com anticorpos monoclonais (rato) $(0,030 \mathrm{~g} / \mathrm{L})$ para lge humana.

Gentamicina $6,25 \mathrm{mg} / \mathrm{h}$

Advertências e medidas de precauçăo

1. Para utilizar no diagnóstico in-vitro.

Cada doador ou unidade de doaçáo foi testado para detectar a presença de vírus da VHC) de acordo com as técnicas a provadas pelas directivas de diagnóstico in-vitro na UE ou FDA. Como năo existe nenhum teste que ofereça a garantia completa de ausência de agentes infecciosos, todos os materiais obtidos a partir de material de origem
Preparação dos reagentes

mono lgE Látex N é fornecido pronto a usar. A suspensāo deve ser agitada cuidadosa Estabilidade e condiçóes de armazenagem Estabilidade entre 2 a $8^{\circ} \mathrm{C}:$ :

Stabilidade depois de aberto: seguir a cada utilizaçẫo e se se estiver exclúído a hipótese de contaminaçăo (ex., por mi crorganismos)

Năo congelar.

Ustabilidade:

Nota: A estabilidade pode variar, dependendo do Sistema BN utilizado e das condiçōes la-

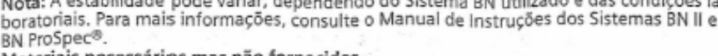

Materiais necessários mas năo fornecidos

Sistema BN II ou BN ProSpec

Controlo $S 4 L$ de Proteina NT, REP OQIN

Controlo SLIM de Prateína NT, , REF OQIO

Controlo SLH de Proteina NIT, REF OQIP
Reagente L Suplementar N, REF OQTD

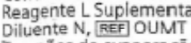

Diluente N, LEF

Materiais e suprimentos adicionais conforme descrito no Manual de Instruçōes do Sistema BN.

Amostras

Amostras adequadas de soro humano o mais frescas possiveis (conservadas durante nāo mais de 7 dias a 2 a $8^{\circ} \mathrm{C}$ ) ou conservadas congeladas, bern como plasma EDTA e heparinizado. As armostras podem ser conservadas a temperaturas inferiores a $-20^{\circ} \mathrm{C}$ durante um ciclos repetidos de congelamento-descongelamento. năo podem conter quaisquer particulas nem vestígios de fibrina.

As amostras lipémicas ou as amostras congeladas que apresentem turvaçăo depois de des. congeladas, tém que ser clarificadas por centrifugaçăo (10 minutos a cerca de $15.000 \times 9$ ) antes das análises.

Procedimento

Notas

1. Consulte o Manual de Instruçōes do Sistema BN para mais informaçōes sobre o funcio2. Com um sistema BN II ou BN ProSpec ${ }^{\circ}$, os reagentes e amostras conservados entre

Protocols de ensaio nos sistemas BN BNre no software do instrumento. fodos os passos săo executados automaticamente pelo sistema. Definiçăo da curva de rợerência

As curvas de referência şáo construf́das por calibraçăo de pontos múltiplos. As diluiç̄es em Diluente N. As diluiçóses de padrăo tếm que ser utilizadas no espaco te 4 horas. A curva de referência é válida durante 4 semanas e pode ser utilizada depois deste período desde que os controlos com os correspondentes valores-alvo dependentes do métocio, por exemplo. os Controlos SL/L, M e H da Proteína N/T, sejam reproduzidos dentro dos respectivos intervalos de confiança. Se for utilizado um lote de reagente diferente, terá que se gerar uma Mediçăo de amostras de pacientes

As amostras sáo autromaticamente diluídas a 1:20 com Diluente $\mathrm{N}$. As amostras diluidas
tém que ser utilizadas no espaco de 4 horas. Se o5 resultados obtidos estiverem fora do temm que ser utilizadas no espaço de 4 horas. Se os resultados obtidos estiverem fora do
intervalo de mediçáo, o ensaio pode ser repetido utilizando uma diluiçăo maior da amos-

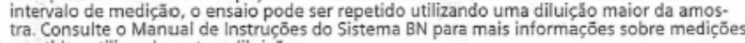
repetidas utilizando outras diluiç̄es.

Controlo interno de qualidade

Ensaie os Controlos SLLL, M e H da Proteina N/T, depois de definir uma curva de referencia depois da primeira utilizaçăo de um frasco de reagente, bem como com cada processamento de amostras. Os controlos devem ser ensalados e avaliados tal como para amostras valores atribuidos do respectivo controlo. Seguir as normas governamentais ou os requisitos de validaçấo quanto a frequência do controlo de qualidade.
Para o Sistema BN Prospeco, pode utilizar um CD de Dados do Lote (RREF OVLP) para introPara o Sistema BN ProSpec," pode utilizar um CD de Dados do Lote [Rer OVLP) pára intro-
duzir o valor atriburdo.

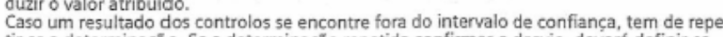
tir-se a determinaç̧ăo. Se a determinaçăo repetida confirmar o desvio, deverá definir-se desvio tenha sido id entificada e corrigida.

Cálculo dos resultados

A avaliaçăo é realizada automaticamente em IU/mL ou numa unidade seleccionada pelo Limitaçãoes do procedimento

A interferência por factores reumatóides (até $2.400 \mathrm{IU} / \mathrm{mL}$ ) é suprimida pela utilização do Reagente L Suplementar N. Contudo, em aiguns casos, niveis elevados de factores reuma tro método.

Turvaçăo e particulas nas amostras podem interferir com a determinaçäo. Por conseguinte, as amostras contendo partículas têm que ser centrifugadas antes das análises. As amostras lipémicas ou turvas que nảo se consigam
de $15.000 \times \mathrm{g}$ ) não podem ser utilizadas.

Em amostras contendo níveis muito elevados de lgE, como os que se encontram ocasionalmente em, por exemplo, doenças parasitárias ou com mielomas IgE, náo se observou qualquer fenómeno de excesso de antigénio até à concentraçäo máxima testada de cerca de $40.00 \mathrm{ma}$ estrutura de opitopica têm uma estrutura de epitopo que difere das imunoglobulinas policlonais, é apesar de tude doentes com mieloma IgE como resultado de um efeito viciante de dose elevada. Estas amostras têm que ser medidas numa diluiçăo de 1:100.

Depois de medir amostras com uma concentraçăo de IgE de cerca de $>40.000 \mathrm{IU} / \mathrm{mL}$ num Sistemas alos fama des. Se suspertar noensaios de modo a produzir resultados falsamente elevados ou reduzidos ${ }^{3}$. Este ensaio foi concebido para minimizar a a interferência de anticorpos heterofílicos. Contudo, não é possivel garantir total eliminaçao desta interferência de todas as amostras de doentes. dores, com o intuito de optimizar o desempenho do produto e satisfazer as especificacōes do produto. As modificaçōes definidas pelo utilizador năo săo suportadas pela Siemens, na medida em que podem afectar o desempenho do sistema e os resultados do ensaio. Cons-

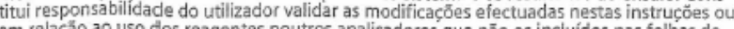
em relaças de aplicas reagentes noutros analisadores que năo os incluidos nas follhas de Os resultados deste teste devem sempre ser interpretados em conjunto com o histórico médico do doente, estado clinico e outros dados de interesse.

Devido a efeitos de matriz, as amostras de controlo e as amostras de estudos inter-labora- 


\section{ANEXO D - BULA DO EXAME IgE (página 2/2)}

Por conseguinte, poderá ser necessário avaliar estes resultados em relaçăo a valores-alvo especificos do método.

Intervalos de Referência

Em individuos clinicamente saudáveis, os niveis séricos de lgE exibem uma ampla gama de distribuição e não seguem uma distribuiçăo normal. As concentraçōes séricas de lgE nas criancas estao altamente dependentes ca idade. Os valores adultos obtem-se perto dos 7. 10 anos de idade. Valores mals al dos iccorrem a cerca de a

encia para soro em IgE IU/mL:

Recém-nascidos $<1,5$

Crianças no primeiro ano de vida $<15$

Crianças (1 a 5 anos) $\quad<60$

Criancas ( 6 a 9 anos) $<90$

Crianças ( 10 a 15 anos) $\quad<200$

Adultos $<100$

Estes vaiores de referência foram estabelecidos num estudo abrangente (448 crianças, 200 adultos) realizado na Europa ${ }^{24}$

os seus próprios intervalos de referência, visto os da populaçăo estudada.

Características do teste

A sensibilidade analítica do ensaio é determinada pelo limite inferior da curva de referência chende portanto da concentraçăo da proteína no Padrăo SL da Proteína N Os intervalos de mediçāo tipicos sāo fornecidos nos Manuais de Instruçōes do Sistema BN.

Especifidade

Precisăo recarm realizados estudos de precisâo num Sistema BN mediante a avaliaçăo de três niveis com o documento CLSI EPS-A?

\begin{tabular}{|c|c|c|c|c|}
\hline \\
\hline Amostra & $\begin{array}{l}\text { Méclia } \\
\text { (IU/mL) }\end{array}$ & $\begin{array}{l}\text { Intra- } \\
\text { processamento } \\
\text { CV (5) }\end{array}$ & $\begin{array}{l}\text { Processamento } \\
\text { a Processamento } \\
\mathrm{CV}(\%)\end{array}$ & $\begin{array}{l}\text { Total } \\
\text { cV(\%) }\end{array}$ \\
\hline Controlo SLLL de Proteína N/T & 79,36 & 2,2 & 1,5 & 2,4 \\
\hline Controlo 5LMM de Proteina NT & 193,25 & 1.7 & 1,8 & 2,3 \\
\hline Controlo SLIH de Proteína N/T & 520,0 & 1,7 & 2,0 & 2,5 \\
\hline Pool de soro 1 & 31,05 & 3,0 & 4,1 & 4,9 \\
\hline Pcol de soro 2 & 630,65 & 2,0 & 1,9 & 2,5 \\
\hline
\end{tabular}

Pool de sor 2 2

Os resultados foram avaliados por análise de variância.

ensalo mono lgE Látex $N$ fol comparado com um método lgE nefelométrico disponivel 14 e $855 \mathrm{IU} / \mathrm{mL}$. Obteve-se um coeficiente de correlaçăo de 1,0 com um valor de intercepcắ y de $6.1 \mathrm{IU} / \mathrm{mL}$ e um declive de 1,0 .

Nota

Os valores citados para caracteristicas do teste representam valores típicos e năo devem ser considerados como especificaçōes para o mono lgE Látex N.

Bibliografia

Ver Instruçö̌es em inglês.

BN ProSpec ${ }^{\circledR}$ é uma marca comercial da Siemens Healthcare Diagnostics.

Siemens Healthcare Diagnosfics Products Gmb-

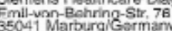

ivww.siemens.com'diagnostic

Symbois Key / Symbolschlüssel / Explication des Symboles / Interpretazione simboll / Clave de los Simbolos / Chave dies Símbolos

(2) Do not reuse f Kicht zur Wiederverwendung / No pas réutiliser / Non riutilizare

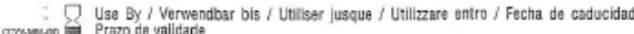

LOT Baich Code / Chargenbeasichnung / Code fu lot / Codce del lotto / Godigo de lote /

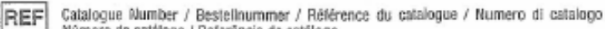
centar

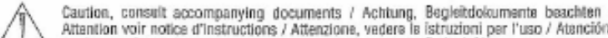

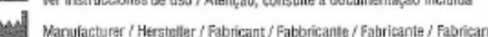

EC AEP Authorized Raprasentative in the Europsan Communily / Bevollmächtigter in der

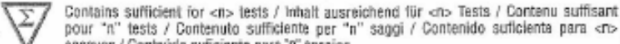

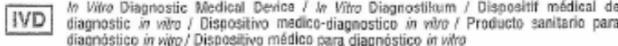

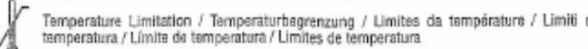

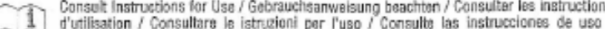

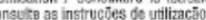

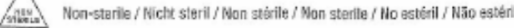

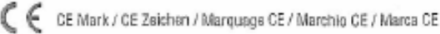

CONTENTS Contentis / Inhalt/ / Contenu / Conisanuto / Conterios / Conteòid

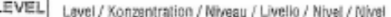
2311.11_tonisp

2008 Siemens Healthcare Diagnostics Products GmbH. 
ANEXO E - SCORAD

Nome:

Reg:

Data de Nascimento:

Data da consulta:

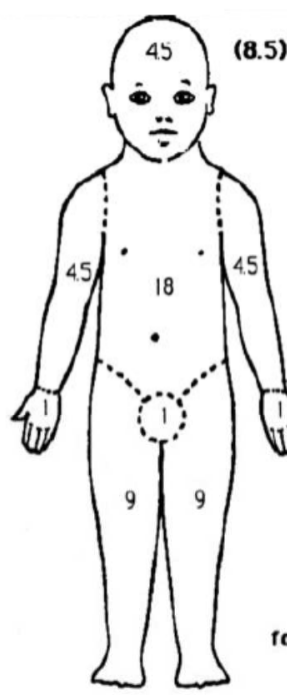

(8.5)
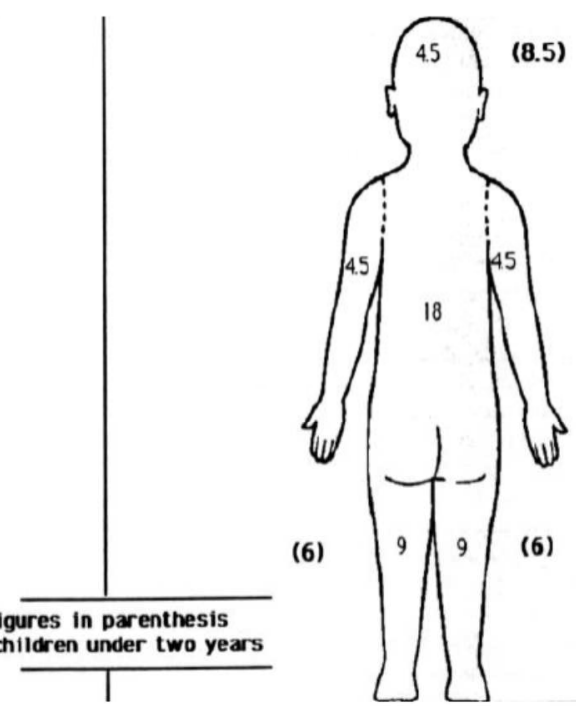

A: Extensão - Área envolvida:

\section{B: Intensidade}

\begin{tabular}{|l|l|}
\hline Critério & Intensidade \\
\hline Eritema & \\
\hline Edema / pápulas & \\
\hline Exsudato/ crostas & \\
\hline Escoriação & \\
\hline Liquenificação & \\
\hline Ressecamento* & \\
\hline
\end{tabular}

Intensidade

(área representativa média)

0 . Ausente

1. Leve

2. Moderada

3. Grave

* Ressecamento em áreas não envolvidas
C. Sintomas Subjetivos

Prurido

Perda de sono

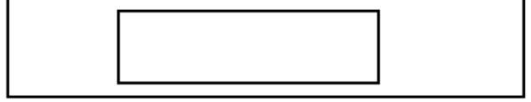

SCORAD $\quad A / 5+7 B / 2+C$

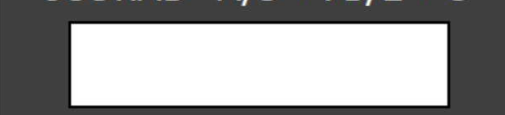

Escala Visual Analógica - Média para 3 últimos dias/noites:

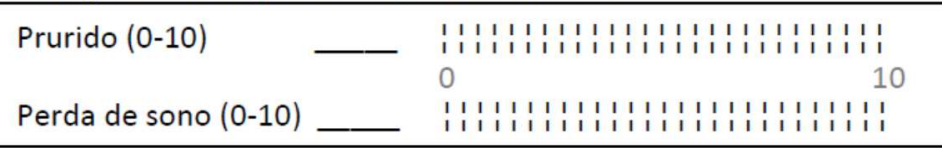

Tratamento:

Observações: 


\section{ANEXO F - CONTRATO DE PRESTAÇÃO DE SERVIÇOS DO LABORATÓRIO SABIN (página 1/3)}

\section{CONTRATO DE PRESTAÇÃO DE SERVIÇOS LABORATORIAIS}

Contrato de prestação de serviços laboratoriais (análises e pesquisas clínicas em geral) que entre si fazem, de um lado como CONTRATANTE Professora Dra Izelda Maria Carvalho Costa, CPF: 113.382.291-68, do outro lado como CONTRATADO o Laboratório Sabin de Análises Clínicas Ltda, com sede SCN Quadra 05, Bloco A, Centro Empresarial Brasília Shopping, Torre Sul, $1^{\circ}$ andar, Brasília-DF, CEP: $70715-$ 900; CNPJ: 00.718.528/0001-09. Inscrição Estadual: 07305368/001-00, fone: (61) 3329-8000, mediante as seguintes cláusulas e condições:

Cláusula Primeira - O presente contrato tem por objeto a prestação de serviços laboratoriais (Análises e Pesquisas Clínicas em Geral) ao pesquisador Dr. Kleyton de Carvalho Mesquita, referente ao Projeto "Prevalência e gravidade de dermatite atópica em crianças e adolescentes: associação com níveis séricos de vitamina $D^{\prime \prime}$.

Cláusula Segunda - O contratado fornecerá orientações técnicas, insumos, metodologias, equipamentos e tecnologia disponivel, para a realização de ensaios e pesquisas clínicas (procedimento laboratorial).

Cláusula Terceira - $O$ valor da contraprestação pelos serviços executados e materiais utilizados, terá por referência a tabela de preços dos produtos utilizados, em vigor, previamente negociada entre as partes.

Cláusula Quarta - As faturas, comprovantes de prestação de serviços com os respectivos valores deverão ser encaminhados ao setor financeiro do contratante, até $\circ 10^{\circ}$ (décimo) dia útil de cada mês, obrigando-se o contratante a efetuar 0 pagamento até 20 dias após a entrega da mesma.

Parágrafo Primeiro - O orçamento especificado para esse projeto de pesquisa encontra-se detalhado na tabela em anexo, cabendo ao Instituto Sabin arcar com as despesas, sem ônus para os pesquisadores. 


\title{
ANEXO F - CONTRATO DE PRESTAÇÃO DE SERVIÇOS DO LABORATÓRIO SABIN (página 2/3)
}

\author{
Parágrafo Segundo - Em contrapartida, deverá constar da publicação \\ científica, um agradecimento ao Instituto Sabin através do Núcleo de Apoio à \\ Pesquisa, pela realização de dosagens sanguíneas.
}

Cláusula Quinta - O presente contrato terá inicio na data de sua assinatura e sua vigência será por prazo de um ano renovável por igual período, podendo qualquer das partes rescindirem-lo, mediante comunicação por escrito, com antecedência mínima de 30 dias.

Cláusula Sexta - Fica eleito o foro da comarca de Brasília-DF, para dirimir quaisquer dúvidas decorrentes do cumprimento das obrigações assumidas pelas partes, no presente contrato.

Assim, justas e contratadas, as partes firmam o presente instrumento, juntamente com duas testemunhas e em duas vias de igual forma e teor.

Brasília-DF, 20 de novembro de 2012.

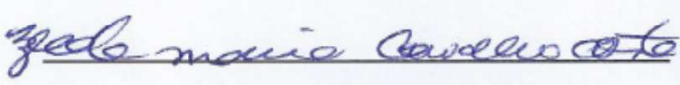

Prof. Dra Izelda Maria Carvalho Costa

CPF: 113382291-68

Testemunhas:

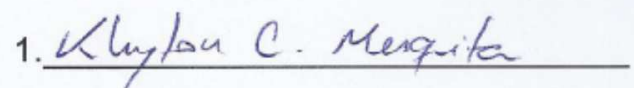

Dr Kleyton de Carvalho Mesquita

CPF: 905372111-87
Núcleo de Appoio a Pesquisa

LABORATÓRIO SABIN

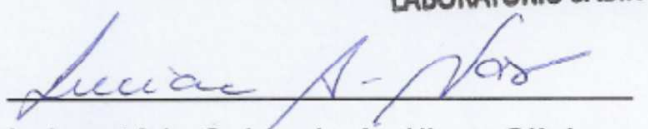

Laboratório Sabin de Análises Clínicas

CNPJ: 00.718.528/0001-09

Observações:

1. Preencher devidamente todos os campos com os dados do contratante.

2. Listar testemunhas, com nome por extenso. 


\section{ANEXO F - CONTRATO DE PRESTAÇÃO DE SERVIÇOS DO LABORATÓRIO SABIN (página 3/3)}

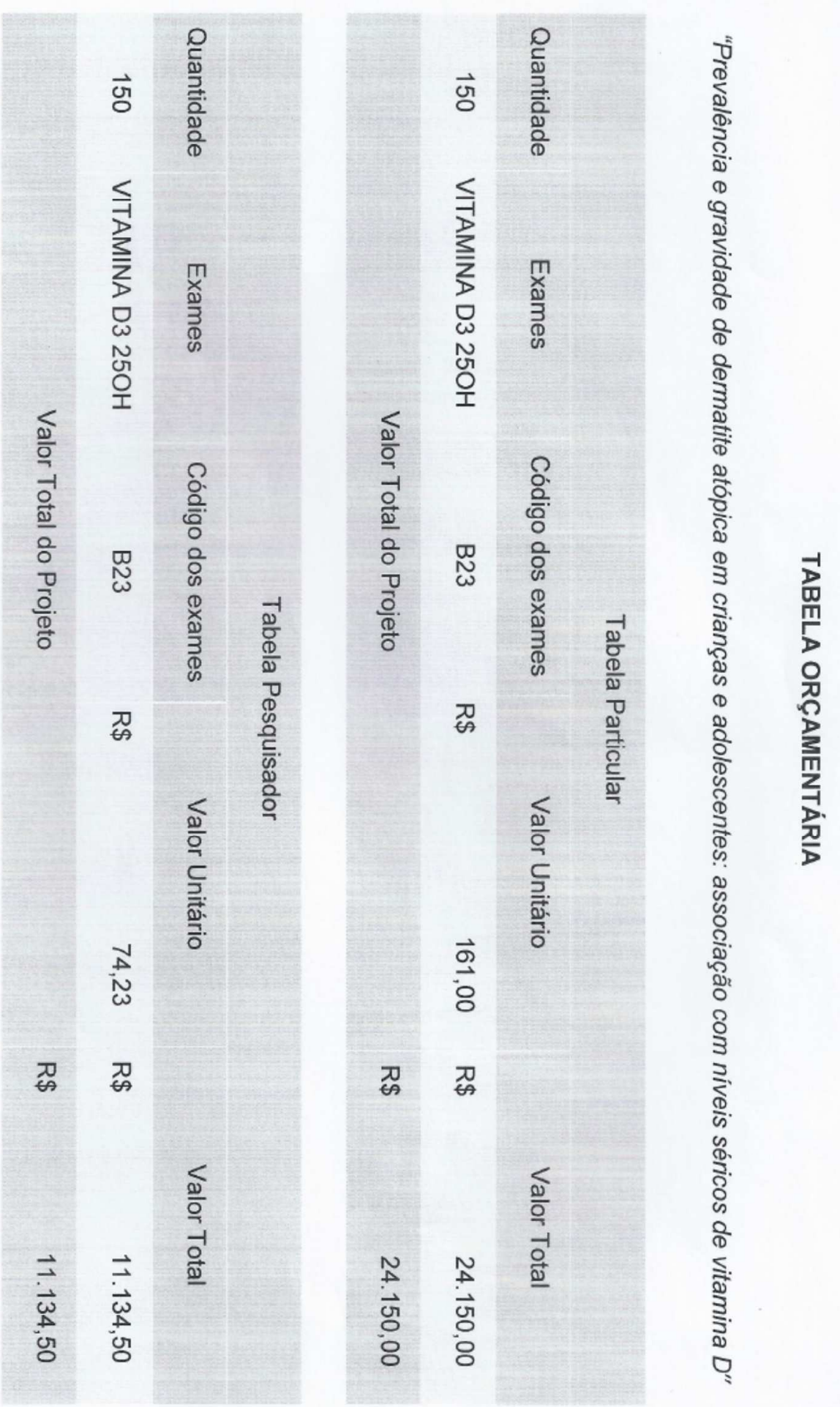

